\title{
Discovery, Characterization, and Linkage Mapping of Simple Sequence Repeat Markers In Hazelnut
}

\author{
Gehendra Bhattarai ${ }^{1,2}$ and Shawn A. Mehlenbacher ${ }^{3}$ \\ Department of Horticulture, Oregon State University, Corvallis, OR 97331
}

\begin{abstract}
Additional Index words. Corylus avellana, dendrogram, filbert, genetic diversity, microsatellite
Abstract. From the genome sequence of hazelnut (Corylus avellana), 192 new polymorphic simple sequence repeat (SSR) markers were developed, characterized, and used to investigate genetic diversity in 50 accessions. Nextgeneration sequencing allows inexpensive sequencing of plant genomes and transcriptomes, and efficient development of polymorphic SSR markers, also known as microsatellite markers, at low cost. A search of the genome sequence of 'Jefferson' hazelnut identified 9094 fragments with long repeat motifs of 4, 5, or 6 base pairs (bp), from which polymorphic SSR markers were developed. The repeat regions in the 'Jefferson' genome were used as references to which genomic sequence reads of seven additional cultivars were aligned in silico. Visual inspection for variation in repeat number among the aligned reads identified 246 as polymorphic, for which primer pairs were designed. Polymerase chain reaction (PCR) amplification followed by agarose gel separation indicated polymorphism at 195 loci, for which fluorescent forward primers were used to amplify the DNA of 50 hazelnut accessions. Amplicons were post-PCR multiplexed for capillary electrophoresis, and allele sizes were determined for 50 accessions. After eliminating three, 192 were confirmed as polymorphic, and 169 showed only one or two alleles in each of the 50 cultivars, as expected in a diploid. At these 169 SSRs, a total of 843 alleles were found, for an average of 4.99 and a range of 2 to 17 alleles per locus. The mean observed heterozygosity, expected heterozygosity, polymorphism information content, and the frequency of null alleles were $0.51,0.53,0.47$, and 0.03 , respectively. An additional 25 primer pairs produced more than two bands in some accessions with an average of 6.8 alleles. The UPGMA dendrogram revealed a wide genetic diversity and clustered the 50 accessions according to their geographic origin. Of the new SSRs, 132 loci were placed on the linkage map. These new markers will be useful for diversity and parentage studies, cultivar fingerprinting, marker-assisted selection, and aligning the linkage map with scaffolds of the genome sequence.
\end{abstract}

Hazelnut, one of the world's major nut crops, is an important crop in the Willamette Valley of Oregon where $99 \%$ of the U.S. hazelnut crop is produced. Over a 10-year period (2005-14), Turkey produced $67.2 \%$ of the world crop, followed by Italy $(12.6 \%)$, the United States (4.0\%), Azerbaijan (3.4\%), and Republic of Georgia (3.1\%) (Food and Agriculture Organization of the United Nations, 2017). In Oregon, hazelnuts are planted on 27,000 ha and plantings are expanding at 1200 ha per year (Oregon Hazelnuts, 2018). There are also many new plantings and production is increasing in China, Chile, Republic of Georgia, and other countries.

Hazelnut is diploid $(2 n=2 x=22)$ and belongs to the family Betulaceae. Of the 13 commonly recognized species of Cor$y l u s$, only the European species (C. avellana) is widely planted for commercial production. Hazelnuts are monoecious, dichogamous, and self-incompatible, and thus cross-pollinated in nature. Cultivars are highly heterozygous and clonally propagated. Most of the world's cultivars are selections from local wild vegetation. Based on simple sequence repeat markers, most cultivars have been assigned to one of four

Received for publication 21 May 2018. Accepted for publication 18 July 2018. This research was supported by the Oregon Hazelnut Commission, USDANIFA Specialty Crops Research Initiative Competitive Grants (2009-5118106028 and 2016-51181-25412), and a USDA Specific Cooperative Agreement for Eastern Filbert Blight Research.

This research partially fulfilled the requirement for G. Bhattarai's Master of Science degree. The authors thank Erik Rowley and Todd Mockler for providing the hazelnut genome sequences used in this study.

${ }^{1}$ Former graduate research assistant.

${ }^{2}$ Current address: Department of Horticulture, University of Arkansas, Fayetteville, AR 72701

${ }^{3}$ Corresponding author. E-mail: shawn.mehlenbacher@oregonstate.edu. major geographical groups: Central European, Black Sea, English or Spanish-Italian (Boccacci et al., 2006; Gökirmak et al., 2009).

Simple sequence repeat markers are DNA segments comprised of tandem repeat motifs that are 1 to 8 nucleotides in length. SSRs are polymerase chain reaction (PCR)-based markers for which primers are designed from conserved sequences that flank the repeat region. At polymorphic loci, PCR amplification results in different product sizes. SSR markers are preferred over several other marker types because of their high level of polymorphism, multiple alleles, codominant inheritance, good genome coverage, interspecific and intergeneric transferability, high reproducibility, amenability to automated high-throughput genotyping, and ease of sharing among laboratories (Parida et al., 2009). SSR markers are widely used in plant genetics and breeding, including studies of genetic diversity and evolution, association, gene flow, genetic mapping, gene tagging, gene cloning, cultivar identification, parentage analysis, identification of duplicates, marker-assisted selection (MAS), and quantitative trait locus (QTL) analysis (Ellegren, 2004; Hearne et al., 1992; Parida et al., 2009). In hazelnut, SSR markers were initially developed from DNA libraries enriched for specific repeats (Bassil et al., 2005a, 2005b; Boccacci et al., 2005; Gürcan et al., 2010). Later, Gürcan and Mehlenbacher (2010a) developed SSRs from the sequences of inter simple sequence repeat (ISSR) markers and flanking regions. Sathuvalli and Mehlenbacher (2013) developed SSR markers from bacterial artificial chromosome (BAC) sequences. SSRs have also been developed from sequences of the hazelnut transcriptome (Colburn et al., 2017) and genome 
Table 1. Hazelnut accessions used to identify and characterize tetra-, penta-, and hexa- repeat microsatellite markers mined from genome sequences. Accessions 1 to 24 were used to screen for polymorphism on agarose gels, while all 50 accessions were used for characterization of polymorphic simple sequence repeat loci. Some were imported as scions, and others as seed lots from which individuals were selected.

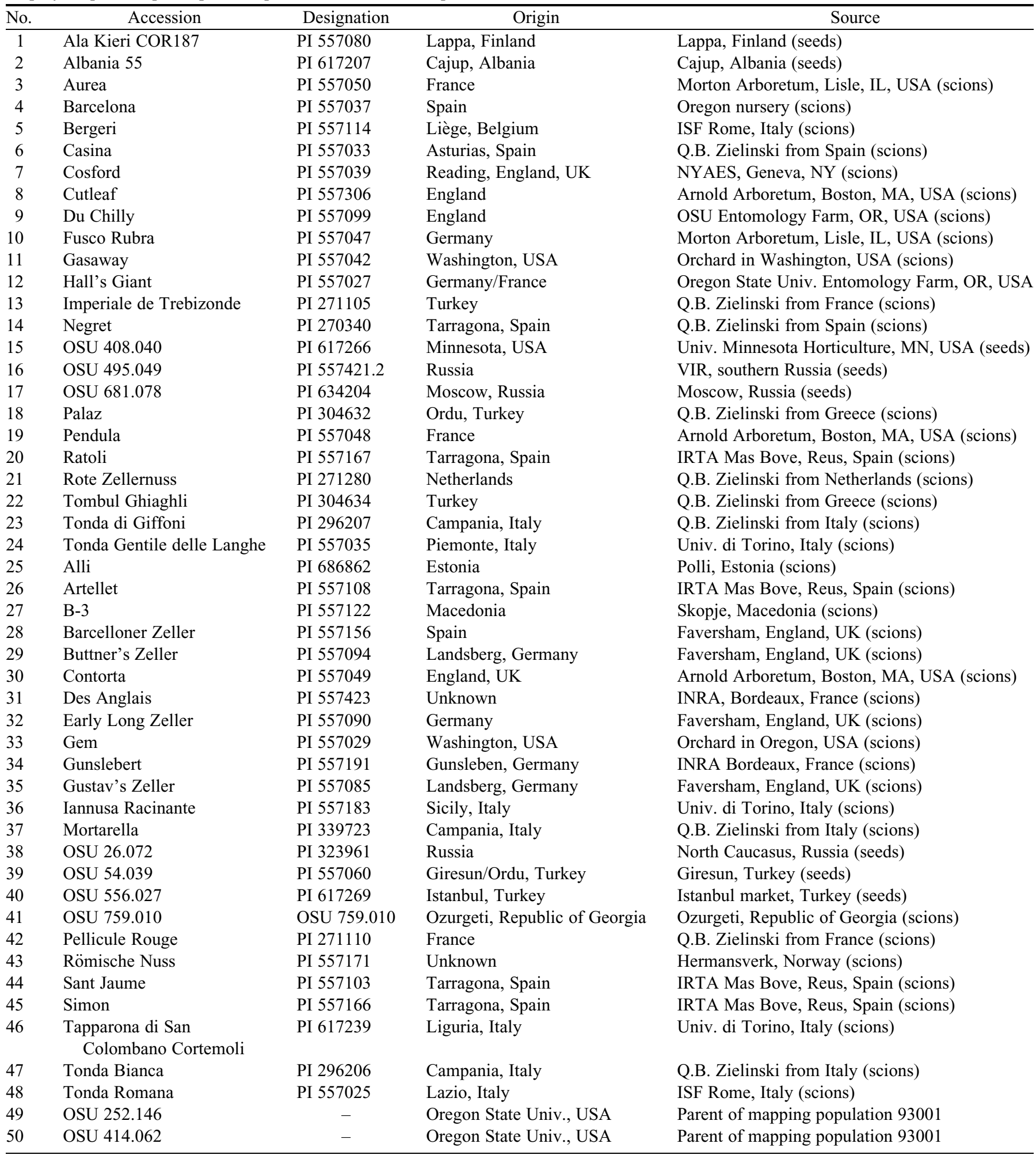

(Bhattarai and Mehlenbacher, 2017), and sequences in public databases (Boccacci et al., 2015; Gürcan and Mehlenbacher, 2010b). Although about 525 SSR markers are publicly available in hazelnut, the majority contain di-nucleotide motifs which suffer from PCR artifacts that prevent automated scoring (Testolin and Cipriani, 2010). In this study, we mined the 'Jefferson' genome sequence to develop new polymorphic SSR markers with repeat motifs of 4,5 , or $6 \mathrm{bp}$ and further saturated the reference hazelnut genetic linkage map. 


\section{Materials and Methods}

Plant material. A set of 48 diverse hazelnut accessions plus the two parents of a mapping population (Table 1) were used to characterize the new SSR markers. These accessions were a subset of the 198 unique types investigated by Gökirmak et al. (2009), and are phenotypically, genetically, and geographically diverse. The same 50 accessions were used in previous characterization studies (Bhattarai and Mehlenbacher, 2017; Colburn et al., 2017; Gürcan and Mehlenbacher, 2010a; Gürcan et al., 2010). Of these accessions, 24 were used to screen all primer pairs for polymorphism on agarose gels. For SSRs that appeared to be polymorphic on agarose gels, all 50 accessions and capillary electrophoresis were used to characterize them.

DNA EXTRACTION. DNA was extracted from two to four young leaves collected during early spring from trees growing in fields at the USDA-ARS National Clonal Germplasm Repository (NCGR) and Smith Horticultural Research Farm of Oregon State University (OSU) in Corvallis. DNA extraction followed the method of Lunde et al. (2000) without RNAase treatment. The extracted DNA was quantified using ultraviolet spectrophotometry with a Synergy 2 Multi-Mode Reader with a Take 3 microplate reader and the data were analyzed with Gen5 software (all Biotek Instruments, Winooski, VT). The DNA was diluted with TE buffer to a concentration of $20 \mathrm{ng} \cdot \mu \mathrm{L}^{-1}$.

SSR IDENTIFICATION. The hazelnut genome sequences of Rowley (2016) generated by Illumina (San Diego, CA) technology were used in this study. The 'Jefferson' genome sequence $(93 \times$ coverage with 333,492 sequences comprising $224.58 \mathrm{Mb}$ ) was used as the reference. Seven other cultivars (Barcelona, Ratoli, Tonda Gentile delle Langhe, Tonda di Giffoni, Daviana, Hall's Giant, and Tombul) were resequenced at lower coverage $(\approx 20 \times)$. The 'Jefferson' genome sequences were searched for SSRs using the MISA tool (Thiel et al., 2003) with the search criteria for minimum number of repeats set at six for dinucleotide repeats, five for trinucleotide repeats, and four each for tetra-, penta-, hexa-, hepta- and octanucleotide motifs. This study pursued only the tetra-, penta-, and hexanucleotide repeat SSRs. Repeats that contained only As and Ts were removed, as they tend to be very difficult to score. Short fragments $(<400$ bases) and fragments with repeats near the ends of the contigs were also removed, the latter because they lacked a flanking sequence sufficient for primer design. Paired-end Illumina reads from the seven other cultivars were concatenated into a single file, and aligned with SSRcontaining sequences in the 'Jefferson' reference using the
MAQ program (Li et al., 2008). The aligned reads were imported into Tablet software (Milne et al., 2013) for visualization and identification of SSRs with variation in the number of repeat units but conserved flanking sequences. Tablet software displayed the reference sequence at the top of the screen, with the aligned reads from the seven cultivars shown in subsequent rows without identification of the originating cultivar. The four nucleotides were displayed with unique colors for ease of visualization. After alignment and visualization, each sequence was classified as "clearly polymorphic," "slightly polymorphic," "not polymorphic," "poor alignment," or "no reads." Of these categories, only the "clearly polymorphic" sequences were pursued, and forward and reverse primers were designed using the Websat (Martins et al., 2009) and Primer 3 (Untergasser et al., 2012) programs with lengths of 18 to $27 \mathrm{bp}$, annealing temperature of $60{ }^{\circ} \mathrm{C}$, and a range of expected product sizes of 90-400 bp to facilitate post-PCR multiplexing. Non-fluorescent forward and reverse primers were ordered from Integrated DNA Technologies (Coralville, IA). The "slightly polymorphic" sequences, for which $<2 \%$ of the aligned reads showed variation in the number of repeats, were not pursued.

PCR AMPLIFICATION FOR POLYMORPHISM SCREENING. PCR was performed with each primer pair using DNA of 24 accessions in the diversity panel (Table 1). PCRs were in $10-\mu \mathrm{L}$ volumes containing $0.3 \mu \mathrm{M}$ each of forward and reverse primers, $1 \times$ Biolase $\mathrm{NH}_{4}$ reaction buffer, $2 \mathrm{mM} \mathrm{MgCl}_{2}, 200 \mu \mathrm{M}$ each of dATP, dCTP, dGTP, and dTTP, $20 \mathrm{ng}$ template DNA, and 0.25 units of DNA polymerase (Biolase; Bioline USA, Taunton, MA). PCR amplification was performed in thermal cyclers (GeneAmp PCR system 9700; Applied Biosystems, Foster City, $\mathrm{CA}$ ) in 96-well plates using the following program: denaturation at $95{ }^{\circ} \mathrm{C}$ for $5 \mathrm{~min}$ followed by 40 cycles of at $94{ }^{\circ} \mathrm{C}$ for $40 \mathrm{~s}$, $60{ }^{\circ} \mathrm{C}$ for $40 \mathrm{~s}, 72^{\circ} \mathrm{C}$ for $40 \mathrm{~s}$, a final extension at $72^{\circ} \mathrm{C}$ for $7 \mathrm{~min}$, and an infinite hold at $4{ }^{\circ} \mathrm{C}$. The PCR products were separated by electrophoresis on $3 \%$ agarose gels in TBE buffer at $90 \mathrm{~V}$ for $3.5 \mathrm{~h}$, stained for $30 \mathrm{~min}$ in ethidium bromide and then destained in distilled water for $25 \mathrm{~min}$. The gels were then photographed under ultraviolet light using an imaging system (BioDoc-It ${ }^{\circledR}$; UVP, Upland, CA), and the images were inspected for size polymorphism among the 24 genotypes.

Genotyping AT POLYMORPhic SSRs. For SSR loci that were polymorphic on the agarose gels, fluorescent forward primers labeled with 6-FAM or 5-HEX were ordered from Integrated DNA Technologies and fluorescent forward primers labeled with NED were ordered from Applied Biosystems. The fluorescent forward and non-fluorescent reverse primers (Supplemental Table 1) were used to amplify DNA from the 48

Table 2. Counts of SSR in the 'Jefferson' hazelnut genome by type and number of repeats.

\begin{tabular}{|c|c|c|c|c|c|c|c|c|c|c|c|c|c|}
\hline \multirow[b]{2}{*}{ Repeat type } & \multicolumn{12}{|c|}{ Repeats (no.) } & \multirow[b]{2}{*}{ Repeat type (\%) } \\
\hline & 4 & 5 & 6 & 7 & 8 & 9 & 10 & 11 & 12 & 13 & 14 & Total & \\
\hline Dinucleotide & - & - & 11,131 & 7,079 & 4,962 & 3,453 & 2,340 & 2,109 & 1,832 & 348 & 19 & 33,273 & 64.90 \\
\hline Trinucleotide & - & 4,625 & 2,181 & 1,079 & 616 & 191 & 14 & 2 & 0 & 0 & 0 & 8,708 & 16.99 \\
\hline Pentanucleotide & 1,481 & 266 & 13 & 0 & 0 & 0 & 0 & 0 & 0 & 0 & 0 & 1,760 & 3.43 \\
\hline Hexanucleotide & 825 & 98 & 8 & 0 & 0 & 0 & 0 & 0 & 0 & 0 & 0 & 931 & 1.82 \\
\hline Heptanucleotide & 176 & 12 & 3 & 0 & 0 & 0 & 0 & 0 & 0 & 0 & 0 & 191 & 0.37 \\
\hline Sum & & & & & & & & & & & & 51,268 & 100.00 \\
\hline
\end{tabular}


Table 3. Characteristics and linkage group assignments of new simple sequence repeat markers developed from the 'Jefferson' hazelnut genome sequence.

\begin{tabular}{|c|c|c|c|c|c|c|c|}
\hline Marker & GenBank no. & $\mathrm{n}^{\mathrm{z}}$ & $\mathrm{H}_{\mathrm{e}}^{\mathrm{y}}$ & $\mathrm{H}_{\mathrm{o}}{ }^{\mathrm{x}}$ & $\mathrm{PIC}^{\mathrm{w}}$ & $\mathrm{F}\left(\right.$ null $^{\mathrm{v}}$ & $\mathrm{LG}^{\mathrm{u}}$ \\
\hline \multicolumn{8}{|c|}{ Loci with one or two bands in all accessions } \\
\hline GB401 & KU131606 & 4 & 0.63 & 0.82 & 0.56 & -0.15 & $5 \mathrm{~S}, 5 \mathrm{R}$ \\
\hline GB402 & KU131607 & 3 & 0.34 & 0.42 & 0.29 & -0.11 & 9S, 9R \\
\hline GB403 & KU131608 & 2 & 0.40 & 0.44 & 0.32 & -0.04 & NA \\
\hline GB404 & KU131609 & 2 & 0.08 & 0.08 & 0.07 & -0.01 & $7 \mathrm{~S}$ \\
\hline GB405 & KU131610 & 3 & 0.04 & 0.04 & 0.04 & 0.00 & NA \\
\hline GB407 & KU131611 & 7 & 0.51 & 0.40 & 0.49 & 0.13 & NA \\
\hline GB408 & KU131612 & 4 & 0.40 & 0.28 & 0.38 & 0.19 & $5 \mathrm{R}$ \\
\hline GB409 & KU131613 & 4 & 0.17 & 0.14 & 0.16 & 0.08 & NA \\
\hline GB410 & KU131614 & 6 & 0.67 & 0.70 & 0.61 & -0.03 & $4 \mathrm{R}$ \\
\hline GB413 & KU131615 & 8 & 0.65 & 0.74 & 0.59 & -0.07 & $1 \mathrm{~S}, 1 \mathrm{R}$ \\
\hline GB414 & KU131616 & 4 & 0.73 & 0.64 & 0.68 & 0.06 & $8 \mathrm{~S}$ \\
\hline GB416 & KU131617 & 5 & 0.49 & 0.42 & 0.45 & 0.09 & NA \\
\hline GB417 & KU131618 & 2 & 0.42 & 0.40 & 0.33 & 0.02 & 9S, 9R \\
\hline GB418 & KU131619 & 7 & 0.43 & 0.40 & 0.40 & 0.03 & $1 \mathrm{~S}$ \\
\hline GB420 & KU131620 & 6 & 0.75 & 0.74 & 0.70 & 0.00 & $9 \mathrm{~S}, 9 \mathrm{R}$ \\
\hline GB421 & KU131621 & 3 & 0.17 & 0.10 & 0.16 & 0.25 & NA \\
\hline GB422 & KU131622 & 11 & 0.85 & 0.78 & 0.83 & 0.04 & $7 \mathrm{~S}$ \\
\hline GB423 & KU131623 & 7 & 0.60 & 0.70 & 0.57 & -0.09 & $6 \mathrm{~S}, 6 \mathrm{R}$ \\
\hline GB424 & KU131624 & 2 & 0.49 & 0.46 & 0.37 & 0.03 & $9 \mathrm{~S}, 9 \mathrm{R}$ \\
\hline GB425 & KU131625 & 4 & 0.27 & 0.26 & 0.26 & 0.00 & NA \\
\hline GB426 & KU131626 & 5 & 0.27 & 0.30 & 0.26 & -0.07 & NA \\
\hline GB427 & KU131627 & 3 & 0.23 & 0.18 & 0.21 & 0.12 & NA \\
\hline GB428 & KU131628 & 3 & 0.53 & 0.50 & 0.42 & 0.03 & $8 \mathrm{~S}$ \\
\hline GB429 & KU131629 & 9 & 0.83 & 0.68 & 0.81 & 0.11 & NA \\
\hline GB430 & KU131630 & 5 & 0.72 & 0.68 & 0.68 & 0.04 & $9 \mathrm{~S}, 9 \mathrm{R}$ \\
\hline GB431 & KU131621 & 5 & 0.69 & 0.78 & 0.64 & -0.07 & NA \\
\hline GB432 & KU131622 & 9 & 0.78 & 0.80 & 0.75 & -0.02 & $4 \mathrm{~S}, 4 \mathrm{R}$ \\
\hline GB433 & KU131623 & 3 & 0.27 & 0.26 & 0.25 & 0.00 & $10 \mathrm{~S}, 10 \mathrm{R}$ \\
\hline GB434 & KU131624 & 5 & 0.63 & 0.56 & 0.57 & 0.05 & $4 \mathrm{~S}$ \\
\hline GB435 & KU131625 & 6 & 0.65 & 0.62 & 0.59 & 0.03 & 9S, 9R \\
\hline GB436 & KU131626 & 2 & 0.13 & 0.14 & 0.12 & -0.03 & $4 \mathrm{~S}$ \\
\hline GB437 & KU131627 & 5 & 0.52 & 0.48 & 0.47 & 0.04 & $4 S, 4 R$ \\
\hline GB438 & KU131628 & 4 & 0.39 & 0.36 & 0.36 & 0.06 & $4 \mathrm{~S}, 4 \mathrm{R}$ \\
\hline GB441 & KU131629 & 2 & 0.26 & 0.26 & 0.22 & -0.01 & $4 \mathrm{~S}$ \\
\hline GB444 & KU131630 & 5 & 0.73 & 0.80 & 0.68 & -0.05 & $1 \mathrm{~S}$ \\
\hline GB445 & KU131641 & 2 & 0.26 & 0.22 & 0.22 & 0.07 & NA \\
\hline GB446 & KU131642 & 2 & 0.06 & 0.06 & 0.06 & -0.01 & NA \\
\hline GB447 & KU159355 & 5 & 0.53 & 0.54 & 0.49 & -0.02 & $1 \mathrm{~S}, 1 \mathrm{R}$ \\
\hline GB448 & KU159356 & 3 & 0.56 & 0.60 & 0.47 & -0.04 & NA \\
\hline GB450 & KU131643 & 4 & 0.34 & 0.36 & 0.30 & -0.05 & $11 \mathrm{~S}, 11 \mathrm{R}$ \\
\hline GB452 & KU131644 & 4 & 0.57 & 0.58 & 0.48 & -0.01 & NA \\
\hline GB454 & KU131645 & 7 & 0.72 & 0.42 & 0.67 & 0.26 & NA \\
\hline GB456 & KU131646 & 2 & 0.44 & 0.44 & 0.34 & -0.01 & $6 \mathrm{~S}$ \\
\hline GB457 & KU131647 & 2 & 0.24 & 0.24 & 0.21 & 0.00 & $6 \mathrm{~S}, 6 \mathrm{R}$ \\
\hline GB458 & KU131648 & 5 & 0.74 & 0.74 & 0.70 & 0.00 & $2 \mathrm{~S}, 2 \mathrm{R}$ \\
\hline GB461 & KU131649 & 5 & 0.56 & 0.34 & 0.49 & 0.23 & $4 \mathrm{~S}$ \\
\hline GB463 & KU131651 & 8 & 0.54 & 0.46 & 0.50 & 0.08 & NA \\
\hline GB465 & KU131652 & 8 & 0.53 & 0.26 & 0.47 & 0.37 & NA \\
\hline GB466 & KU131653 & 2 & 0.47 & 0.32 & 0.36 & 0.19 & $8 \mathrm{R}$ \\
\hline GB467 & KU131654 & 3 & 0.51 & 0.60 & 0.41 & -0.09 & $7 \mathrm{~S}, 7 \mathrm{R}$ \\
\hline GB468 & KU131655 & 6 & 0.58 & 0.44 & 0.49 & 0.15 & $4 \mathrm{~S}, 4 \mathrm{R}$ \\
\hline GB469 & KU131656 & 8 & 0.70 & 0.78 & 0.65 & -0.05 & $1 \mathrm{~S}, 1 \mathrm{R}$ \\
\hline GB470 & KU131657 & 11 & 0.69 & 0.48 & 0.64 & 0.17 & $1 \mathrm{R}$ \\
\hline GB473 & KU131658 & 3 & 0.35 & 0.40 & 0.33 & -0.07 & $1 \mathrm{~S}, 1 \mathrm{R}$ \\
\hline GB475 & KU131659 & 2 & 0.48 & 0.42 & 0.37 & 0.07 & 4R (gap) \\
\hline GB476 & KU131660 & 6 & 0.51 & 0.46 & 0.48 & 0.06 & NA \\
\hline
\end{tabular}


Table 3. Continued.

\begin{tabular}{|c|c|c|c|c|c|c|c|}
\hline Marker & GenBank no. & $\mathrm{n}^{\mathrm{z}}$ & $\mathrm{H}_{\mathrm{e}}^{\mathrm{y}}$ & $\mathrm{H}_{\mathrm{o}}{ }^{\mathrm{x}}$ & $\mathrm{PIC}^{\mathrm{w}}$ & $\mathrm{F}(\text { null })^{\mathrm{v}}$ & $\mathrm{LG}^{\mathrm{u}}$ \\
\hline$\overline{\text { GB477 }}$ & KU131661 & 3 & 0.37 & 0.48 & 0.31 & -0.13 & $3 \mathrm{R}$ \\
\hline GB478 & KU131662 & 3 & 0.63 & 0.48 & 0.56 & 0.14 & $6 \mathrm{R}$ \\
\hline GB480 & KU131663 & 5 & 0.40 & 0.34 & 0.34 & 0.09 & NA \\
\hline GB482 & KU131664 & 4 & 0.68 & 0.66 & 0.63 & 0.01 & $7 \mathrm{~S}, 7 \mathrm{R}$ \\
\hline GB483 & KU131665 & 5 & 0.52 & 0.44 & 0.47 & 0.10 & $2 \mathrm{R}$ \\
\hline GB504 & KU159292 & 4 & 0.60 & 0.52 & 0.53 & 0.07 & NA \\
\hline GB505 & KU159293 & 8 & 0.72 & 0.40 & 0.68 & 0.31 & $8 \mathrm{~S}, 8 \mathrm{R}$ \\
\hline GB526 & KU159294 & 9 & 0.77 & 0.78 & 0.75 & -0.01 & NA \\
\hline GB527 & KU159295 & 4 & 0.49 & 0.42 & 0.40 & 0.08 & NA \\
\hline GB532 & KU159296 & 6 & 0.71 & 0.30 & 0.66 & 0.42 & $3 R$ \\
\hline GB533 & KU159297 & 3 & 0.54 & 0.56 & 0.44 & -0.02 & $1 \mathrm{~S}$ \\
\hline GB537 & KU159299 & 2 & 0.32 & 0.32 & 0.27 & 0.00 & NA \\
\hline GB544 & KU159300 & 6 & 0.61 & 0.66 & 0.56 & -0.05 & $5 \mathrm{~S}, 5 \mathrm{R}$ \\
\hline GB545 & KU159301 & 3 & 0.32 & 0.34 & 0.30 & -0.04 & NA \\
\hline GB548 & KU159302 & 3 & 0.34 & 0.38 & 0.31 & -0.06 & $1 \mathrm{~S}, 1 \mathrm{R}$ \\
\hline GB551 & KU159303 & 3 & 0.52 & 0.56 & 0.40 & -0.04 & NA \\
\hline GB560 & KU159304 & 6 & 0.69 & 0.72 & 0.63 & -0.04 & NA \\
\hline GB563 & KU159305 & 4 & 0.57 & 0.58 & 0.50 & -0.02 & $1 \mathrm{~S}$ \\
\hline GB565 & KU159306 & 2 & 0.50 & 0.54 & 0.37 & -0.04 & $2 \mathrm{R}$ \\
\hline GB577 & KU159308 & 9 & 0.75 & 0.78 & 0.71 & -0.02 & NA \\
\hline GB580 & KU159309 & 2 & 0.11 & 0.12 & 0.11 & -0.02 & NA \\
\hline GB581 & KU159310 & 5 & 0.67 & 0.80 & 0.60 & -0.10 & $1 \mathrm{R}$ \\
\hline GB587 & KU159311 & 6 & 0.54 & 0.60 & 0.44 & -0.06 & $4 S, 4 R$ \\
\hline GB601 & KU306263 & 4 & 0.12 & 0.12 & 0.11 & -0.02 & NA \\
\hline GB602 & KU306264 & 3 & 0.50 & 0.48 & 0.41 & 0.02 & $6 \mathrm{R}$ \\
\hline GB603 & KU306265 & 4 & 0.36 & 0.40 & 0.32 & -0.07 & NA \\
\hline GB604 & KU306266 & 2 & 0.31 & 0.34 & 0.26 & -0.05 & 9S, 9R \\
\hline GB605 & KU306267 & 5 & 0.48 & 0.56 & 0.43 & -0.08 & $6 \mathrm{~S}$ \\
\hline GB606 & KU306268 & 11 & 0.79 & 0.66 & 0.76 & 0.09 & $11 \mathrm{~S}$ \\
\hline GB614 & KU306272 & 6 & 0.54 & 0.54 & 0.50 & 0.00 & $1 \mathrm{R}$ \\
\hline GB616 & KU306274 & 2 & 0.10 & 0.10 & 0.09 & -0.02 & $1 \mathrm{R}$ \\
\hline GB617 & KU306275 & 3 & 0.64 & 0.48 & 0.57 & 0.15 & NA \\
\hline GB618 & KU306276 & 17 & 0.84 & 0.70 & 0.82 & 0.10 & $2 \mathrm{R}$ \\
\hline GB619 & KU306277 & 5 & 0.70 & 0.86 & 0.65 & -0.13 & $1 \mathrm{R}$ \\
\hline GB620 & KU306278 & 2 & 0.46 & 0.56 & 0.35 & -0.10 & 9S, 9R \\
\hline GB621 & KU306279 & 6 & 0.64 & 0.64 & 0.57 & 0.00 & $4 \mathrm{~S}$ \\
\hline GB622 & KU306280 & 5 & 0.68 & 0.66 & 0.63 & 0.02 & $9 \mathrm{R}$ \\
\hline GB623 & KU306281 & 3 & 0.46 & 0.54 & 0.36 & -0.08 & $2 \mathrm{R}$ \\
\hline GB624 & KU306282 & 5 & 0.24 & 0.10 & 0.23 & 0.40 & NA \\
\hline GB625 & KU306283 & 11 & 0.84 & 0.80 & 0.82 & 0.03 & $11 \mathrm{R}$ \\
\hline GB626 & KU306284 & 4 & 0.41 & 0.46 & 0.36 & -0.06 & $4 \mathrm{R}$ \\
\hline GB627 & KU306285 & 4 & 0.69 & 0.70 & 0.63 & -0.01 & $1 \mathrm{~S}, 1 \mathrm{R}$ \\
\hline GB628 & KU306286 & 10 & 0.74 & 0.68 & 0.70 & 0.05 & $4 \mathrm{~S}$ \\
\hline GB631 & KU306288 & 2 & 0.50 & 0.66 & 0.37 & -0.14 & $9 \mathrm{~S}$ \\
\hline GB633 & KU306289 & 3 & 0.50 & 0.62 & 0.39 & -0.11 & 9S, 9R \\
\hline GB635 & KU306291 & 5 & 0.42 & 0.46 & 0.39 & -0.06 & $6 \mathrm{R}$ \\
\hline GB636 & KU306292 & 4 & 0.55 & 0.58 & 0.44 & -0.04 & $11 \mathrm{~S}, 11 \mathrm{R}$ (poor fit) \\
\hline GB638 & KU306293 & 4 & 0.55 & 0.42 & 0.46 & 0.14 & $9 \mathrm{R}$ \\
\hline GB639 & KU306294 & 7 & 0.68 & 0.76 & 0.63 & -0.05 & NA \\
\hline GB640 & KU306295 & 5 & 0.52 & 0.14 & 0.49 & 0.61 & $4 \mathrm{R}$ \\
\hline GB641 & KU306296 & 3 & 0.31 & 0.38 & 0.27 & -0.10 & $2 \mathrm{R}$ \\
\hline GB642 & KU306297 & 2 & 0.33 & 0.34 & 0.28 & -0.01 & $7 \mathrm{~S}$ \\
\hline GB643 & KU306298 & 6 & 0.61 & 0.68 & 0.54 & -0.06 & $10 \mathrm{R}$ \\
\hline GB645 & KU306300 & 5 & 0.65 & 0.76 & 0.60 & -0.08 & $10 \mathrm{~S}, 10 \mathrm{R}$ \\
\hline GB646 & KU306301 & 7 & 0.71 & 0.42 & 0.67 & 0.28 & $5 \mathrm{~S}$ \\
\hline GB647 & KU306302 & 7 & 0.65 & 0.66 & 0.60 & 0.00 & $9 \mathrm{~S}, 9 \mathrm{R}$ \\
\hline GB649 & KU306304 & 5 & 0.67 & 0.42 & 0.61 & 0.25 & $2 \mathrm{~S}, 2 \mathrm{R}$ \\
\hline
\end{tabular}


Table 3. Continued.

\begin{tabular}{|c|c|c|c|c|c|c|c|}
\hline Marker & GenBank no. & $\mathrm{n}^{\mathrm{z}}$ & $\mathrm{H}_{\mathrm{e}}{ }^{\mathrm{y}}$ & $\mathrm{H}_{\mathrm{o}}{ }^{\mathrm{x}}$ & $\mathrm{PIC}^{\mathrm{w}}$ & $\mathrm{F}(\text { null })^{\mathrm{v}}$ & $\mathrm{LG}^{\mathrm{u}}$ \\
\hline$\overline{\text { GB652 }}$ & KU306306 & 9 & 0.53 & 0.56 & 0.49 & -0.05 & NA \\
\hline GB653 & KU306307 & 5 & 0.57 & 0.80 & 0.51 & -0.20 & NA \\
\hline GB654 & KU306308 & 6 & 0.57 & 0.50 & 0.50 & 0.08 & $10 \mathrm{R}$ \\
\hline GB655 & KU306309 & 5 & 0.63 & 0.70 & 0.56 & -0.07 & $11 \mathrm{~S}, 11 \mathrm{R}$ \\
\hline GB657 & KU306310 & 8 & 0.76 & 0.74 & 0.73 & 0.02 & $4 \mathrm{R}$ \\
\hline GB658 & KU306311 & 7 & 0.68 & 0.78 & 0.63 & -0.08 & 1R (poor fit) \\
\hline GB659 & KU306312 & 4 & 0.65 & 0.70 & 0.60 & -0.04 & $5 \mathrm{~S}, 5 \mathrm{R}$ \\
\hline GB660 & KU306313 & 8 & 0.83 & 0.86 & 0.81 & -0.02 & $5 \mathrm{~S}, 5 \mathrm{R}$ \\
\hline GB661 & KU306314 & 3 & 0.54 & 0.48 & 0.48 & 0.08 & 1S \\
\hline GB663 & KU306316 & 3 & 0.37 & 0.46 & 0.34 & -0.12 & $4 \mathrm{R}$ \\
\hline GB664 & KU306317 & 2 & 0.44 & 0.42 & 0.34 & 0.03 & $8 \mathrm{~S}$ \\
\hline GB665 & KU306318 & 5 & 0.54 & 0.60 & 0.49 & -0.06 & $4 S$ \\
\hline GB668 & KU306320 & 4 & 0.45 & 0.50 & 0.36 & -0.05 & NA \\
\hline GB669 & KU306321 & 3 & 0.55 & 0.74 & 0.47 & -0.17 & $2 \mathrm{~S}$ \\
\hline GB670 & KU306322 & 9 & 0.76 & 0.56 & 0.73 & 0.17 & $4 S, 4 R$ \\
\hline GB671 & KU306323 & 12 & 0.69 & 0.40 & 0.67 & 0.25 & $6 \mathrm{~S}, 6 \mathrm{R}$ \\
\hline GB672 & KU306324 & 4 & 0.53 & 0.48 & 0.49 & 0.04 & NA \\
\hline GB673 & KU306325 & 7 & 0.67 & 0.80 & 0.63 & -0.10 & $5 \mathrm{~S}, 5 \mathrm{R}$ \\
\hline GB674 & KU306326 & 7 & 0.66 & 0.60 & 0.62 & 0.06 & NA \\
\hline GB675 & KU306327 & 5 & 0.67 & 0.62 & 0.61 & 0.02 & $4 \mathrm{~S}, 4 \mathrm{R}$ \\
\hline GB676 & KU306328 & 4 & 0.55 & 0.36 & 0.51 & 0.19 & $2 \mathrm{~S}, 2 \mathrm{R}$ \\
\hline GB678 & KU306329 & 11 & 0.70 & 0.70 & 0.67 & 0.00 & $5 \mathrm{~S}, 5 \mathrm{R}$ \\
\hline GB702 & KU159313 & 3 & 0.47 & 0.50 & 0.42 & -0.05 & $2 \mathrm{R}$ \\
\hline GB705 & KU159315 & 2 & 0.15 & 0.12 & 0.14 & 0.10 & NA \\
\hline GB706 & KU159316 & 6 & 0.54 & 0.42 & 0.49 & 0.10 & $1 \mathrm{R}$ \\
\hline GB709 & KU159319 & 14 & 0.85 & 0.82 & 0.84 & 0.02 & $6 \mathrm{R}$ \\
\hline GB710 & KU159320 & 3 & 0.29 & 0.22 & 0.26 & 0.13 & NA \\
\hline GB712 & KU159321 & 7 & 0.77 & 0.86 & 0.74 & -0.06 & $1 \mathrm{R}$ \\
\hline GB716 & KU159322 & 4 & 0.58 & 0.58 & 0.50 & 0.00 & $2 \mathrm{R}, 2 \mathrm{~S}$ (poor fit) \\
\hline GB717 & KU159323 & 3 & 0.38 & 0.30 & 0.32 & 0.12 & $4 \mathrm{R}$ \\
\hline GB718 & KU159324 & 4 & 0.65 & 0.42 & 0.60 & 0.21 & $1 \mathrm{R}$ \\
\hline GB719 & KU159325 & 3 & 0.44 & 0.40 & 0.40 & 0.05 & $1 \mathrm{~S}, 1 \mathrm{R}$ \\
\hline GB720 & KU159326 & 3 & 0.63 & 0.55 & 0.56 & 0.07 & NA \\
\hline GB721 & KU159327 & 5 & 0.54 & 0.26 & 0.48 & 0.35 & $2 \mathrm{R}$ \\
\hline GB722 & KU159328 & 12 & 0.82 & 0.72 & 0.80 & 0.06 & $2 \mathrm{~S}, 2 \mathrm{R}$ \\
\hline GB723 & KU159329 & 2 & 0.13 & 0.10 & 0.12 & 0.13 & NA \\
\hline GB724 & KU159330 & 5 & 0.61 & 0.60 & 0.56 & 0.00 & $10 \mathrm{~S}, 10 \mathrm{R}$ \\
\hline GB725 & KU159331 & 2 & 0.33 & 0.34 & 0.28 & -0.01 & $9 \mathrm{~S}, 9 \mathrm{R}$ \\
\hline GB726 & KU159332 & 9 & 0.81 & 0.90 & 0.78 & -0.06 & $11 \mathrm{~S}$ \\
\hline GB727 & KU159333 & 3 & 0.66 & 0.68 & 0.59 & -0.01 & $1 \mathrm{~S}, 1 \mathrm{R}$ \\
\hline GB729 & KU159335 & 4 & 0.49 & 0.56 & 0.41 & -0.06 & $4 \mathrm{R}$ \\
\hline GB732 & KU159336 & 6 & 0.53 & 0.52 & 0.44 & 0.01 & $1 \mathrm{~S}$ \\
\hline GB733 & KU159337 & 4 & 0.34 & 0.36 & 0.32 & -0.05 & unlinked \\
\hline GB734 & KU159338 & 2 & 0.11 & 0.12 & 0.11 & -0.02 & $5 \mathrm{~S}, 5 \mathrm{R}$ \\
\hline GB735 & KU159339 & 3 & 0.23 & 0.22 & 0.21 & 0.02 & NA \\
\hline GB737 & KU159340 & 2 & 0.48 & 0.42 & 0.36 & 0.06 & unlinked \\
\hline GB739 & KU159341 & 5 & 0.53 & 0.62 & 0.47 & -0.09 & 9S, 9R \\
\hline GB740 & KU159342 & 9 & 0.77 & 0.66 & 0.74 & 0.08 & $2 \mathrm{~S}$ \\
\hline GB743 & KU159345 & 5 & 0.52 & 0.58 & 0.48 & -0.07 & NA \\
\hline GB744 & KU159346 & 6 & 0.70 & 0.78 & 0.64 & -0.06 & $8 \mathrm{~S}, 8 \mathrm{R}$ \\
\hline GB745 & KU159347 & 5 & 0.62 & 0.50 & 0.56 & 0.10 & NA \\
\hline GB747 & KU159349 & 5 & 0.62 & 0.76 & 0.55 & -0.11 & NA \\
\hline GB748 & KU159350 & 9 & 0.78 & 0.78 & 0.76 & 0.01 & 9S, 9R \\
\hline GB749 & KU159351 & 5 & 0.58 & 0.68 & 0.50 & -0.08 & NA \\
\hline GB750 & KU159352 & 5 & 0.57 & 0.52 & 0.51 & 0.06 & $2 \mathrm{R}$ \\
\hline GB751 & KU159353 & 2 & 0.38 & 0.40 & 0.31 & -0.02 & $9 \mathrm{~S}, 9 \mathrm{R}$ \\
\hline Mean & & 4.988 & 0.526 & 0.507 & 0.474 & 0.025 & \\
\hline
\end{tabular}

Continued next page 
Table 3. Continued.

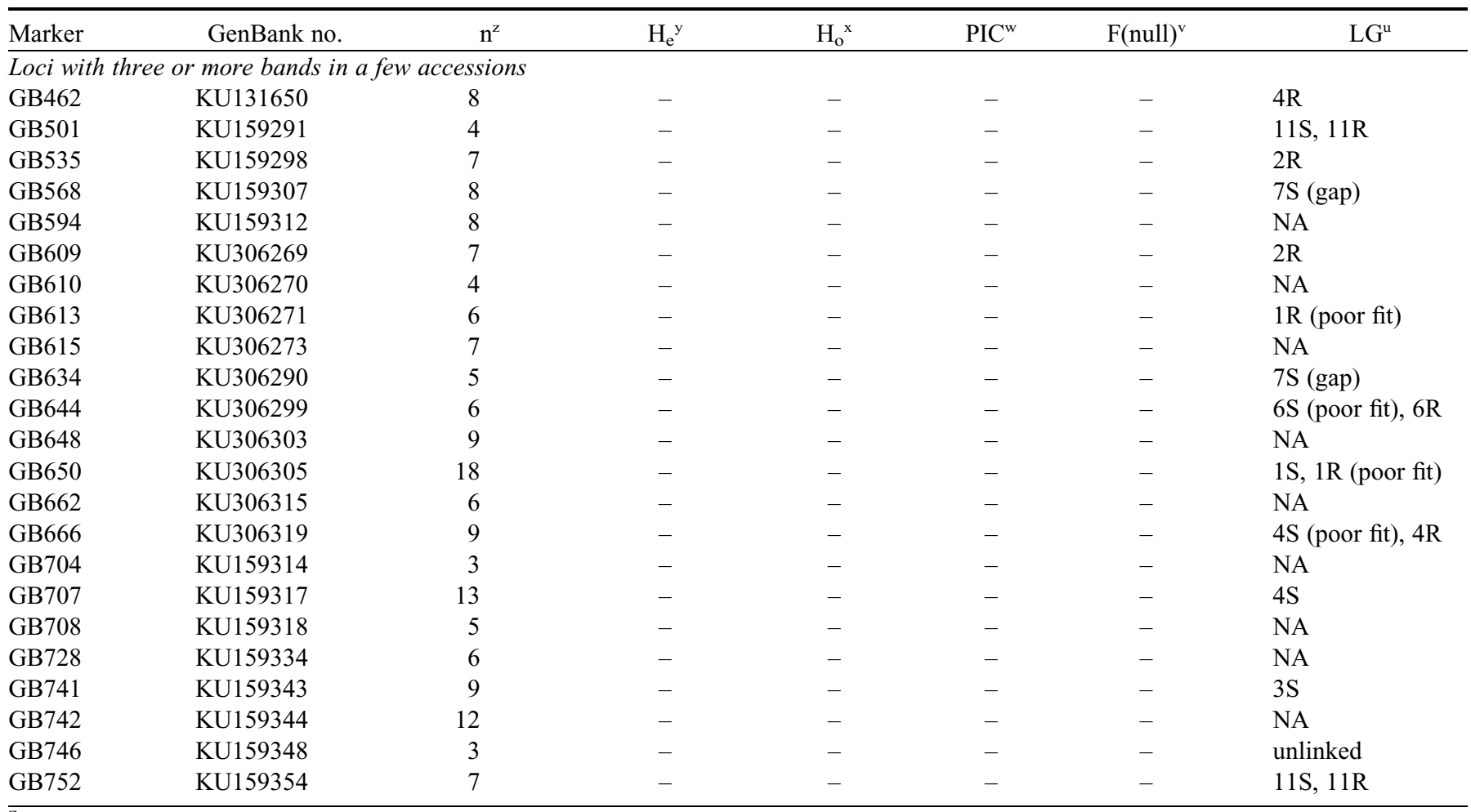

${ }_{\mathrm{z}}$ Number of alleles.

${ }^{\mathrm{y}}$ Expected heterozygosity.

${ }^{\mathrm{x}}$ Observed heterozygosity.

${ }^{\mathrm{w}}$ Polymorphism information content.

${ }^{v}$ Frequency of null alleles.

uLinkage group.

accessions and the two parents of the mapping population (Table 1). The use of fluorescent primers and PCR products of different sizes allowed efficient post-PCR multiplexing of 5 to 7 primer pairs in a single well. For multiplexing, $2 \mu \mathrm{L}$ of the PCR products from each primer pair were mixed and diluted with water to make a final volume of $150 \mu \mathrm{L}$. An aliquot of 1 to $1.5 \mu \mathrm{L}$ of multiplexed PCR products was submitted to the Core Laboratories of OSU's Center for Genome Research and Biocomputing (CGRB) for fragment sizing by a capillary electrophoresis instrument (ABI 3730; Life Technologies, Carlsbad, CA) using ROX-500 as the size standard. GeneMapper $^{\circledR}$ software (Life Technologies) was used for allele sizing and sizes were recorded in a spreadsheet. PCR amplification and capillary electrophoresis were repeated if the initial PCR failed or the result was ambiguous, and to verify unique allele sizes.

Characterization of polymorphic SSRs. For polymorphic primer pairs that showed the expected one or two PCR products in all cultivars, PowerMarker software (Liu and Muse, 2005) was used to calculate number of alleles $(n)$, observed heterozygosity $\left(\mathrm{H}_{\mathrm{o}}\right)$, expected heterozygosity $\left(\mathrm{H}_{\mathrm{e}}\right)$, and polymorphism information content (PIC). Observed heterozygosity is the number of heterozygous genotypes divided by the total number of genotypes. Expected heterozygosity estimates the probability that a randomly chosen individual is heterozygous at a locus and is calculated as $H e=1-\sum_{i=1}^{n} p_{i}^{2}$, where $p_{i}$ is the frequency of the $i^{\text {th }}$ allele and $n$ is the number of alleles (Nei, 1973). The PIC value is a measure of marker informativeness and is calculated as PIC $=1-\left(\sum_{i=1}^{n} p_{i}^{2}\right)-$ $\sum_{i=1}^{n-1} \sum_{j=i+1}^{n} 2 p_{i}^{2} p_{j}^{2}$, where $p_{i}$ is the frequency of the $i^{\text {th }}$ allele, $p_{j}$ is the frequency of the $j^{\text {th }}$ allele, and $n$ is the number of alleles (Botstein et al., 1980). The frequency of null alleles (r) was calculated using Cervus software (Field Genetics, London, UK), which uses the formula of Kalinowski and Taper (2006). Genetic similarities between pairs of accessions were calculated as the proportion of shared alleles $\left(\mathrm{P}_{\mathrm{s}}\right)$ and genetic distance was calculated as $\left(1-\mathrm{P}_{\mathrm{s}}\right)$, resulting in a frequencybased distance matrix. For SSRs with one or two bands per accession, dendrograms were constructed using PowerMarker (Liu and Muse, 2005) and the unweighted pair-group method using arithmetic averages (UPGMA) algorithms. To include SSRs with more than two PCR products in some accessions, the genotype data for the 50 accessions at all new SSR loci were converted to binary format (i.e., dominant scoring) using an Excel macro (Rinehart, 2004). The dendrograms were visualized using Mega7 software (Kumar et al., 2016).

Segregation AND Linkage mapping. For the newly developed SSR marker loci at which the parent genotypes of the mapping population [OSU 252.146 x OSU 414.062 (Mehlenbacher et al., 2006)] predicted segregation, all 138 available seedlings were genotyped as described above. The expected allele sizes were known, and genotyping was in multiplex sets of 10 to 14 primer pairs. Each allele was scored as present or absent in each 


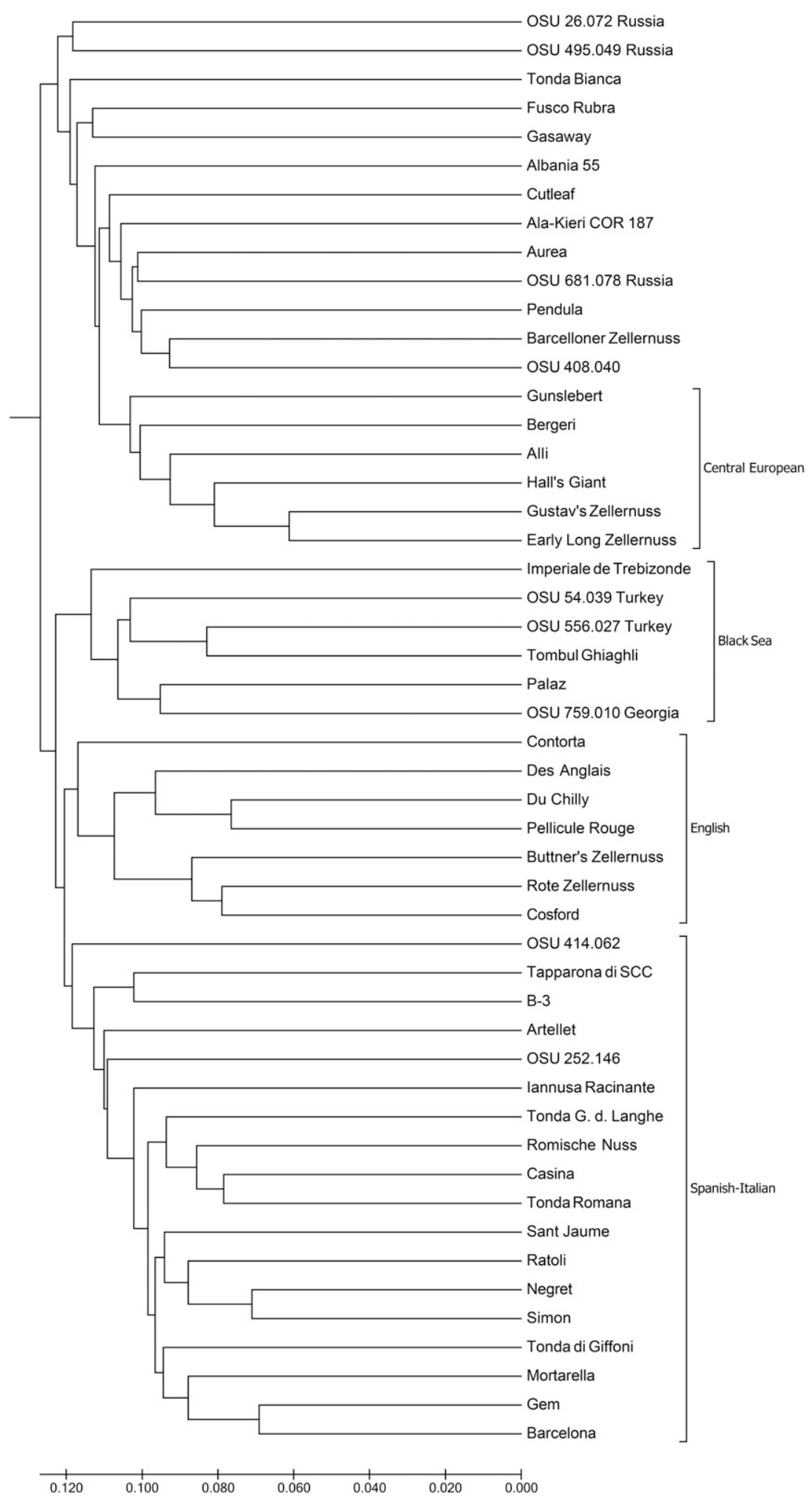

Fig. 1. UPGMA dendrogram of 50 hazelnut accessions constructed from binary data for 192 simple sequence repeat markers.

seedling, scores were tallied, and the expected ratio $(1: 1$ or 1:1:1:1 or $1: 2: 1)$ was noted. Scores for the new SSR markers were added to those for previously mapped random amplified polymorphic DNA (RAPD) and SSR markers (Bhattarai and Mehlenbacher, 2017). Linkage maps were constructed using the two-way pseudo-testcross method and the BC1 function in JoinMap 4.1 (Kyazma; Wageningen, Netherlands). Markers segregating in a ratio of $1: 1$ or 1:1:1:1 were scored as $\mathrm{h}$, a or $\mathrm{u}$ for presence, absence, or unknown status, respectively, for each allele in each seedling. Similarly, markers segregating in a ratio of 1:2:1 were scored as $h$ if present in homozygous state, a if absent (homozygous), and $\mathrm{u}$ if heterozygous or unknown status. Heterozygotes at loci segregating in a 1:2:1 ratio provide no information useful for mapping. Markers were assigned to linkage groups (LGs) using a median logarithm of odds (LOD) score of 12 (range 9 to 15). Maps were constructed separately for each linkage group using the maximum likelihood (ML) algorithm and distances shown in Haldane units (centimorgans). Markers that clustered loosely with the others and fell out at LOD scores $<9$ were removed. Markers present in repulsion phase were included in the map by creating "dummy variables," the use of which allowed the merger of the repulsion phase and coupling phase markers, and generation of a single map for each linkage group in each parent. The JoinMap output was inspected for "Fit and Stress" and markers were removed in stepwise manner until the "Nearest Neighbor Stress" value for all markers was less than an arbitrarily set value of 7.60. The "Nearest Neighbor Fit (cM)" values were also inspected, as high values indicate blocks of markers that fit poorly with adjacent markers. In addition, the length of the gaps between markers was inspected, with gaps of $>20 \mathrm{cM}$ considered suspicious.

\section{Results}

SSR DISCOVERY AND CHARACTERIZATION. A search of the 'Jefferson' genome sequence identified 51,268 SSRs with repeat motifs of 2 to $8 \mathrm{bp}$ (Table 2). Dinucleotide repeats (64.90\%) were most abundant, followed by trinucleotide (16.99\%), tetranucleotide (12.49\%), pentanucleotide (3.43\%), hexanucleotide $(1.82 \%)$, heptanucleotide $(0.37 \%)$, and octanucleotide $(0.001 \%)$ repeats. The number of repeats in these SSRs ranged from 6 to 14 in the dinucleotide repeats, and decreased as the motif length increased. Among the dinucleotide repeats, AG and AT repeats were most common, representing $49.4 \%$ and $40.2 \%$ of the total, respectively (Supplemental Table 2). Among the trinucleotide repeats, AAT and AAG were most common, representing $43.1 \%$ and $28.4 \%$ of the total, respectively. The most common motifs were AAAT $(55.0 \%)$ among the tetranucleotide repeats, AAAAT $(36.3 \%)$ and AAAAG $(25.7 \%)$ among the pentanucleotide repeats, and AAAAAG (18.3\%) and AAAAAT (12.6\%) among the hexanucleotide repeats. The focus of this study was the tetra-, penta- and 
1S

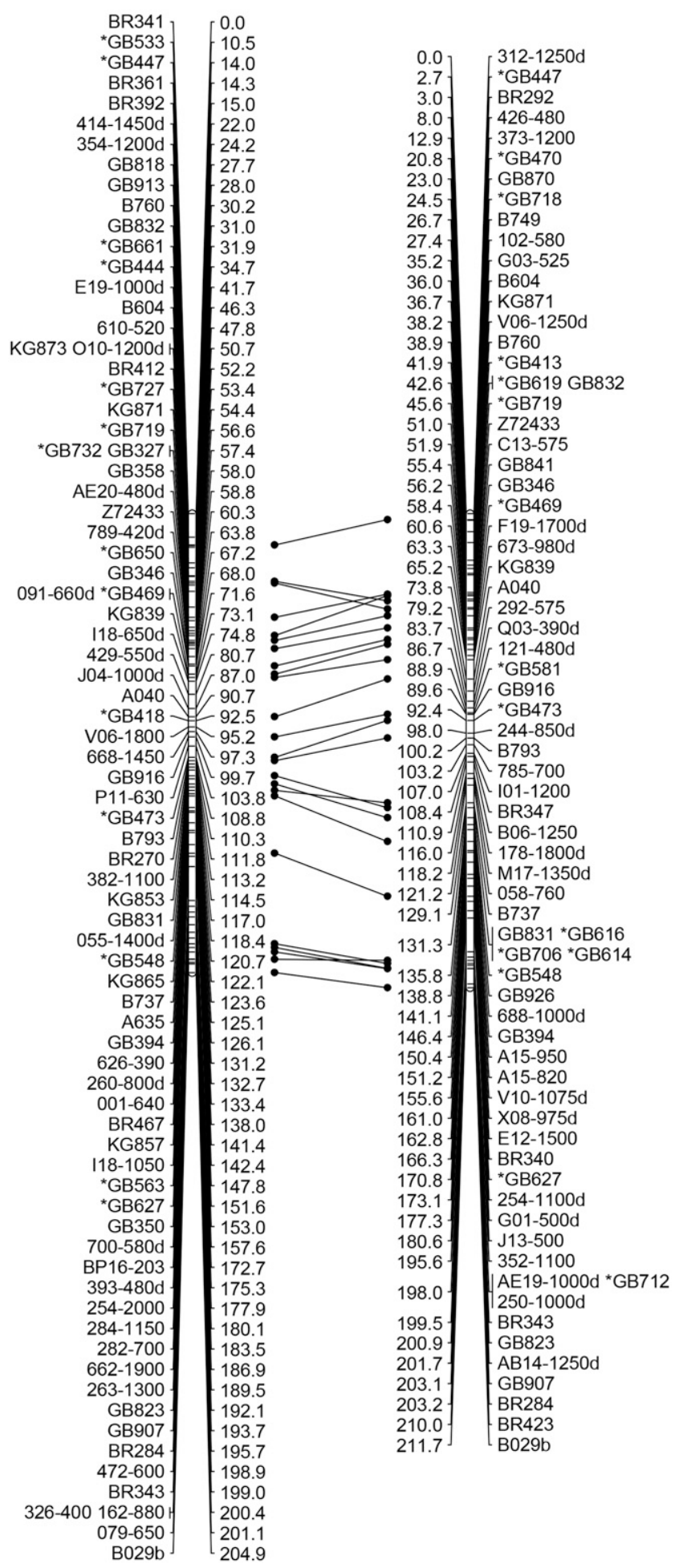

Fig. 2. Linkage maps of the hazelnut reference mapping population (OSU $252.146 \mathrm{x}$ OSU 414.062). The new simple sequence repeat markers are indicated by * and bold font.

hexanucleotide repeats, for which the maximum number of repeats was 8, 6, and 6, respectively. Among the 192 polymorphic SSRs markers developed in this study, the most common motifs were ACGT/TGCA, AAAGG/TTTCC, and AGTTGG/TCAACC for the tetra-, penta-, and hexanucleotide repeats, respectively.

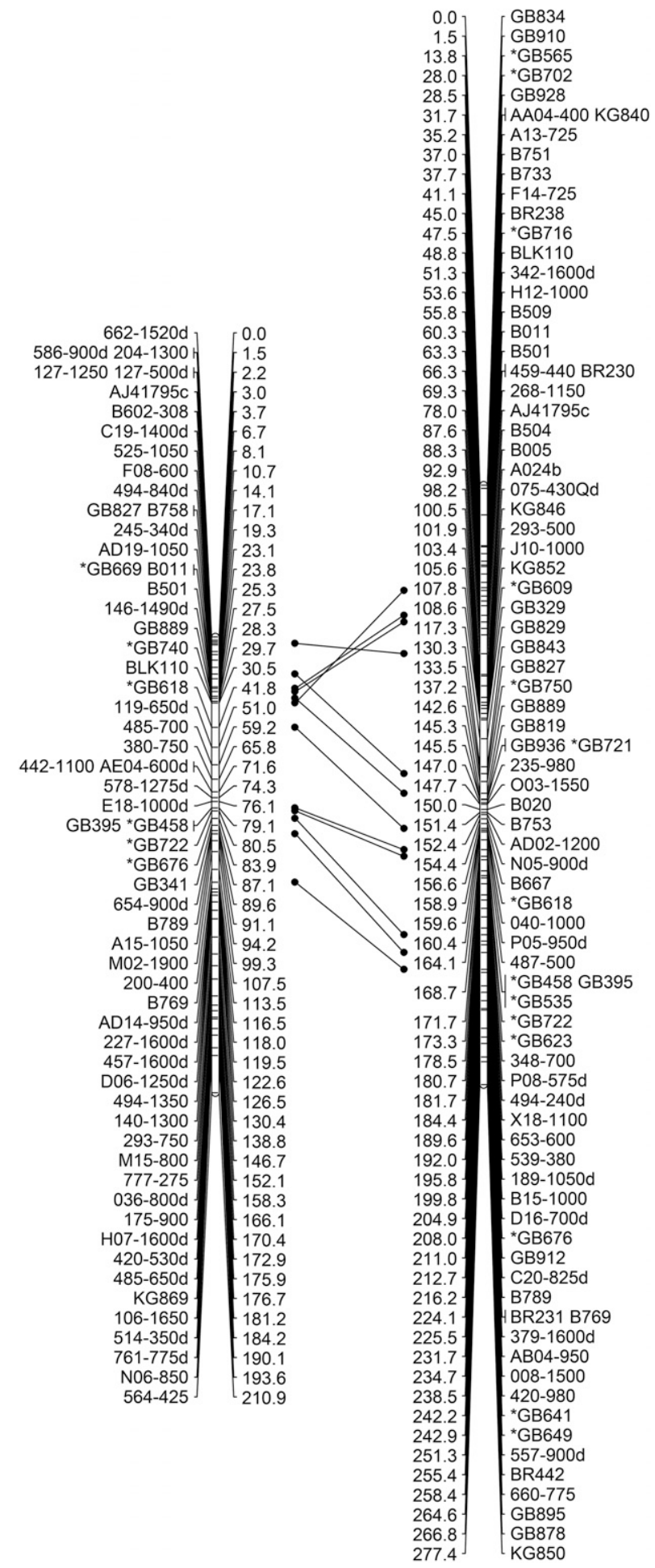

Fig. 2. (Continued)

Initially, the number of sequences containing tetra-, penta-, and hexanucleotide repeats was 9094 . The number of sequences was reduced in stepwise manner, resulting in the final set of 192 polymorphic SSR markers (Table 3). Of the 9094 repeats, 4774 were removed because the repeat motifs contained only As and Ts. The removal of short fragments $(<400 \mathrm{bp})$ and those with 


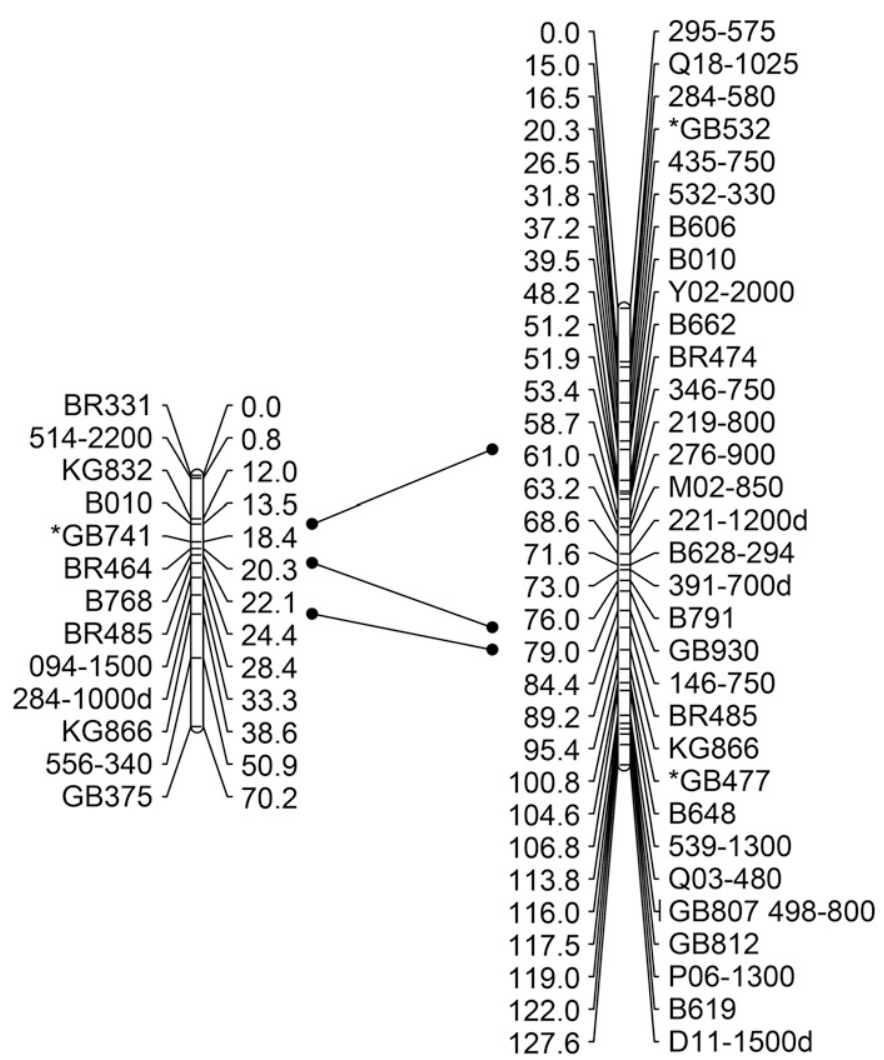

Fig. 2. (Continued)

the repeats at the fragment ends further reduced the number to 1013. After alignment with the reference genome, 246 were scored as "polymorphic" as they showed variation in number of repeat units but conserved flanking sequences. An additional 17 were scored as "slightly polymorphic," and 616 showed no polymorphism in number of repeat motifs. For 114 sequences, the reads of the seven cultivars aligned poorly with the reference, and for 20 sequences none of the reads from the seven cultivars aligned with the reference. Primers were designed for the 246 scored as polymorphic based on visual inspection of aligned sequences. After amplification of 24 diverse accessions followed by separation on agarose gels, 195 were scored as polymorphic. Fluorescent forward primers were ordered for these 195, which were then used to amplify and score allele sizes in 50 accessions after separation by capillary electrophoresis. Two primer pairs gave poor amplification in many cultivars, and one was monomorphic, while 192 new polymorphic SSR markers were pursued, of which 89 were labeled with 6-FAM, 70 with 5-HEX, and 33 with NED (Supplemental Table 1). Of the newly developed SSRs, 60, 66 , and 66 consist of tetra-, penta-, and hexanucleotide repeats, respectively. Allele sizes at the 192 new marker loci in the 50 accessions are presented (Supplemental Tables 3 and 4). At 169 SSR loci $(88.0 \%)$, all 50 accessions showed the one or two alleles expected in a diploid, and diversity parameters were estimated for them (Table 3; Supplemental Table 3). However, at 23 SSRs (12.0\%), more than one accession generated more than two PCR products; for these the presence of each allele

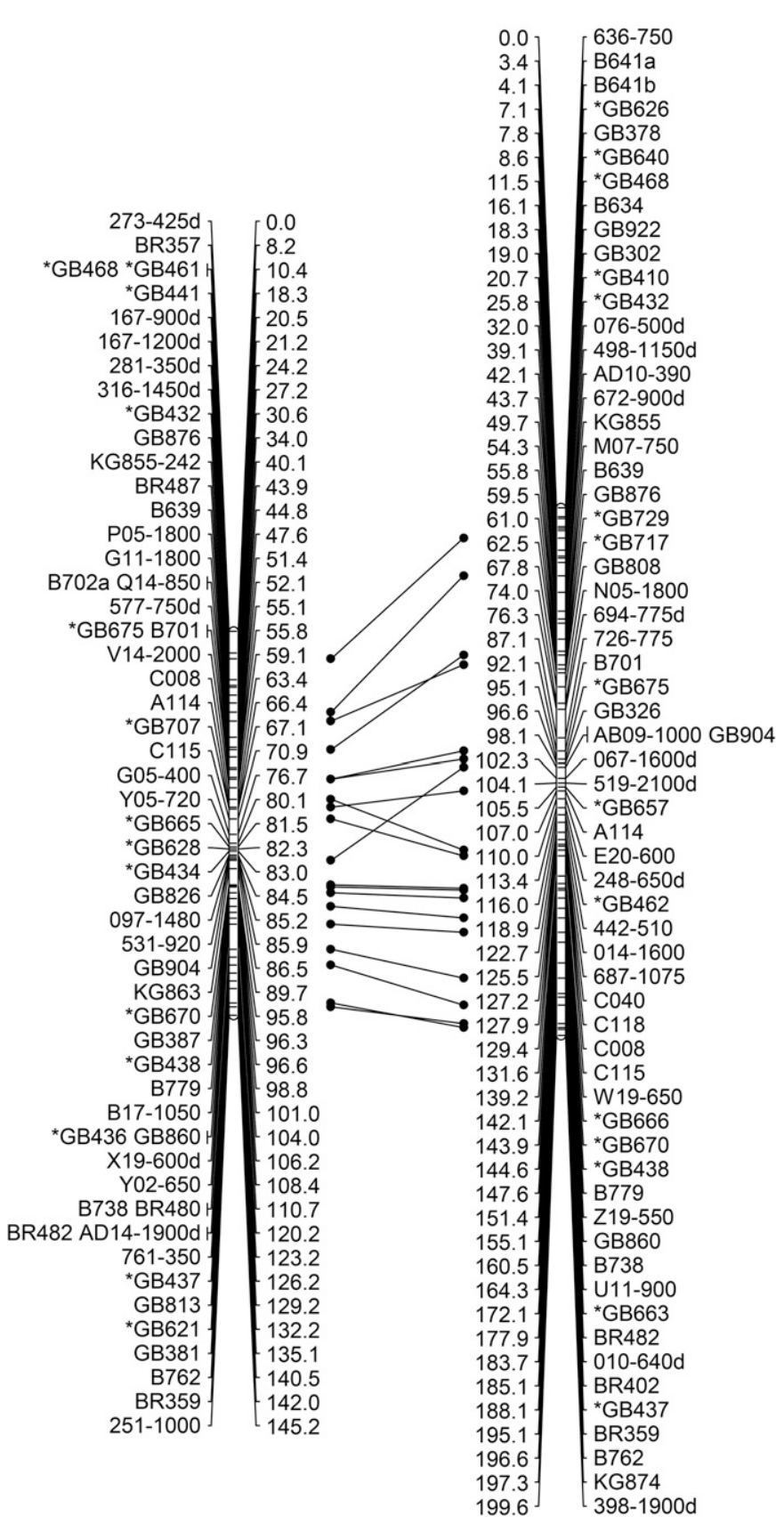

Fig. 2. (Continued)

was scored in each accession (Table 3; Supplemental Table 4). In the 169 characterized markers (Table 3), 846 alleles were detected. The number of alleles per locus ranged from 2 to 17 with an average of 4.99. Expected heterozygosity had a mean of 0.53 and a range of 0.04 to 0.85 , while observed heterozygosity had a mean of 0.51 and a range of 0.04 to 0.90 . The PIC value averaged 0.47 and ranged from 0.04 to 0.84 . GB726 was the most polymorphic marker $\left(\mathrm{H}_{\mathrm{o}}=0.81\right)$, while the four least informative markers (GB404, GB405, GB446, and GB616) had PIC values less than 0.10 . Of these, GB405 had four alleles while the other three had only two alleles each. The average frequency of null alleles was 0.03 , with values for individual 
$5 S$

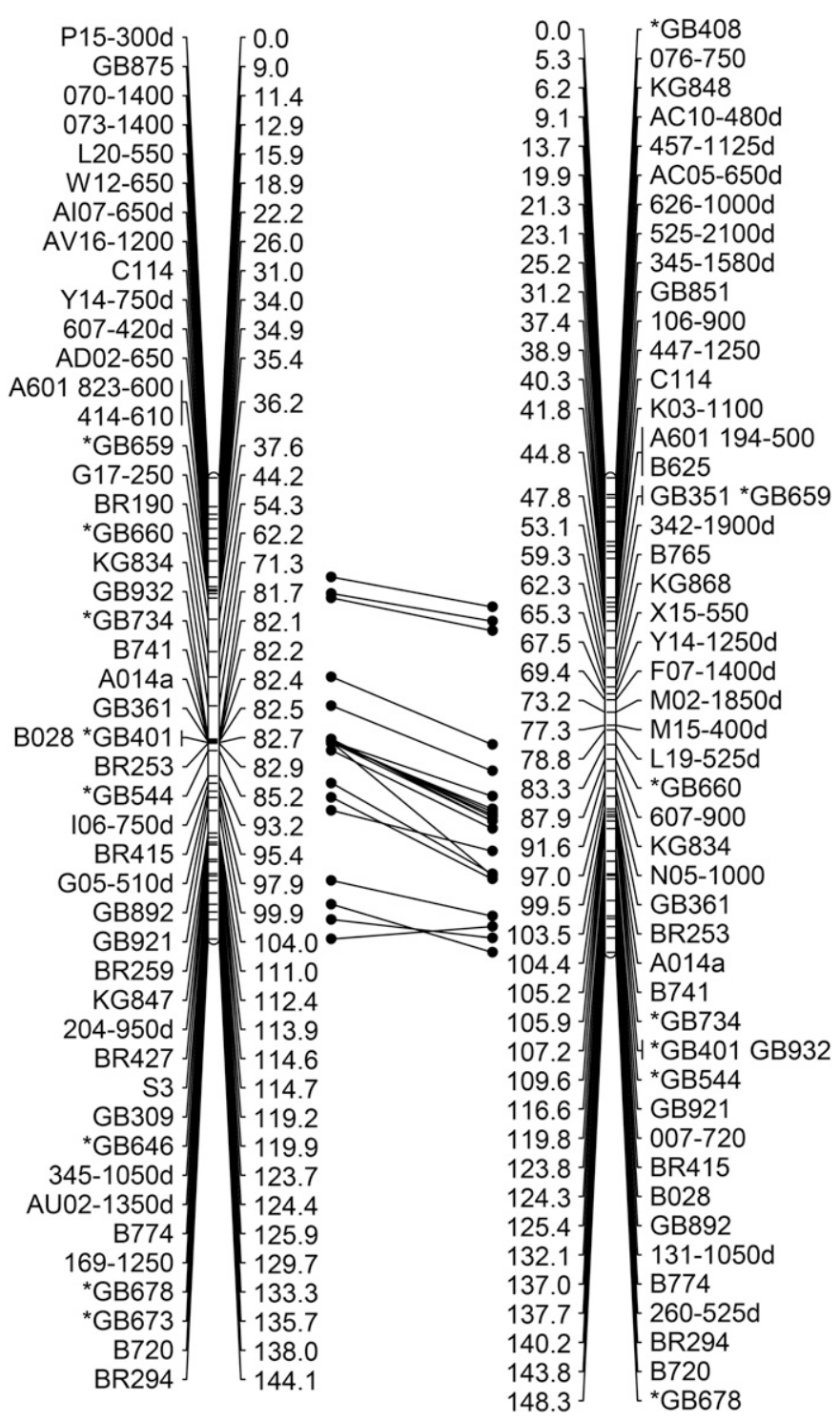

Fig. 2. (Continued)

loci ranging from -0.20 to 0.59 . At the 23 primer pairs that gave more than two PCR products in one or more accessions, 170 alleles were present with an average of 7.39 alleles per primer pair (Table 3). Allele size distributions at the 192 polymorphic SSR markers are shown as histograms (Supplemental Fig. 1).

SEgRegation AND Linkage Mapping. A total of 135 loci segregated in the mapping population, of which $70(51.9 \%)$ segregated in a $1: 1$ ratio, $35(25.9 \%)$ in a $1: 1: 1: 1$ ratio, and 30 $(22.2 \%)$ in a 1:2:1 ratio (Supplemental Table 5). New markers were placed in each of the 11 linkage groups, and the resulting genetic map included 132 new and 297 previously mapped SSR loci (Fig. 2). Three loci (GB733, GB737, and GB746) showed severe segregation distortion and could not be assigned to a $\mathrm{LG}$ (Supplemental Table 4). The lengths of the linkage groups ranged from 63.5 to $277 \mathrm{cM}$.

GENETIC DIVERSITY IN HAZELNUT ACCESSIONS. A dendrogram was constructed for the 50 accessions using the UPGMA
$6 S$

$6 \mathbf{R}$

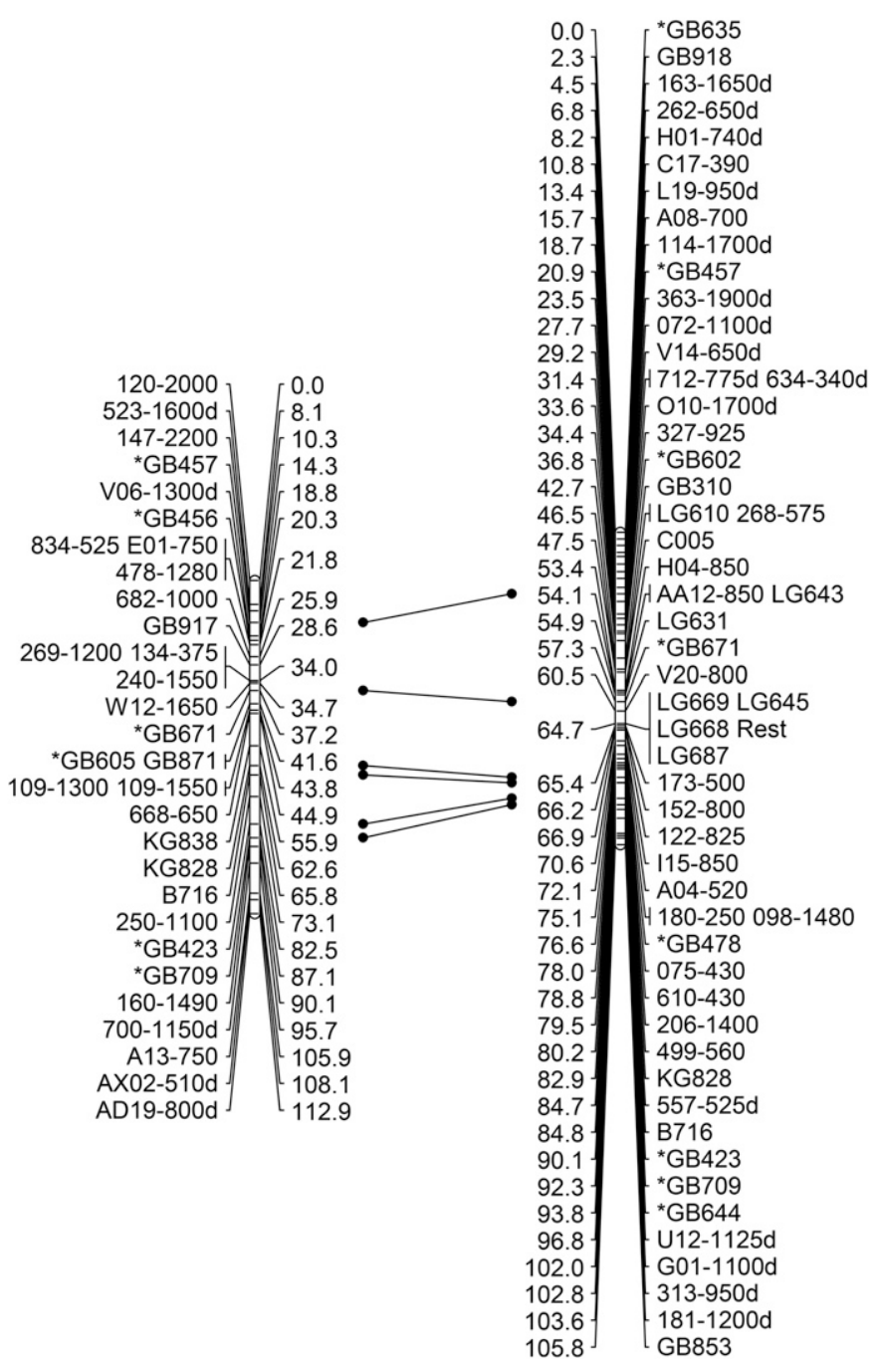

Fig. 2. (Continued)

algorithm (Fig. 1) and allele sizes at 192 loci. The dendrogram confirmed the wide genetic diversity in hazelnut, grouped the accessions according to their geographic origins, and showed the four major groups seen in previous studies: Spanish-Italian, Black Sea, Central European, and English (Bhattarai and Mehlenbacher, 2017; Boccacci et al., 2006; Colburn et al., 2017; Gökirmak et al., 2009; Gürcan et al., 2010). The Central European group includes four cultivars of German origin (Gunslebert, Hall's Giant, Gustav's Zellernuss, and Early Long Zellernuss), as well as 'Bergeri' from Belgium and 'Alli' from Estonia. The Black Sea group includes six accessions from Turkey and one from Republic of Georgia. The English group includes 'Cosford' from Reading, England, 'Rote Zellernuss' from the Netherlands, and 'Buttner's Zellernuss' from Landsberg, Germany. Their adjacent placement in the dendrogram suggests that the latter two might be seedlings of 'Cosford'. The ornamental 'Contorta' originated in England, as did 'Du Chilly', which is grown as 'Kentish Cob' in southeastern England. 'Pellicule Rouge', obtained from France, has leaves and pellicles with anthocyanin, but all other traits and its DNA fingerprint are identical to the English cultivar White Filbert 


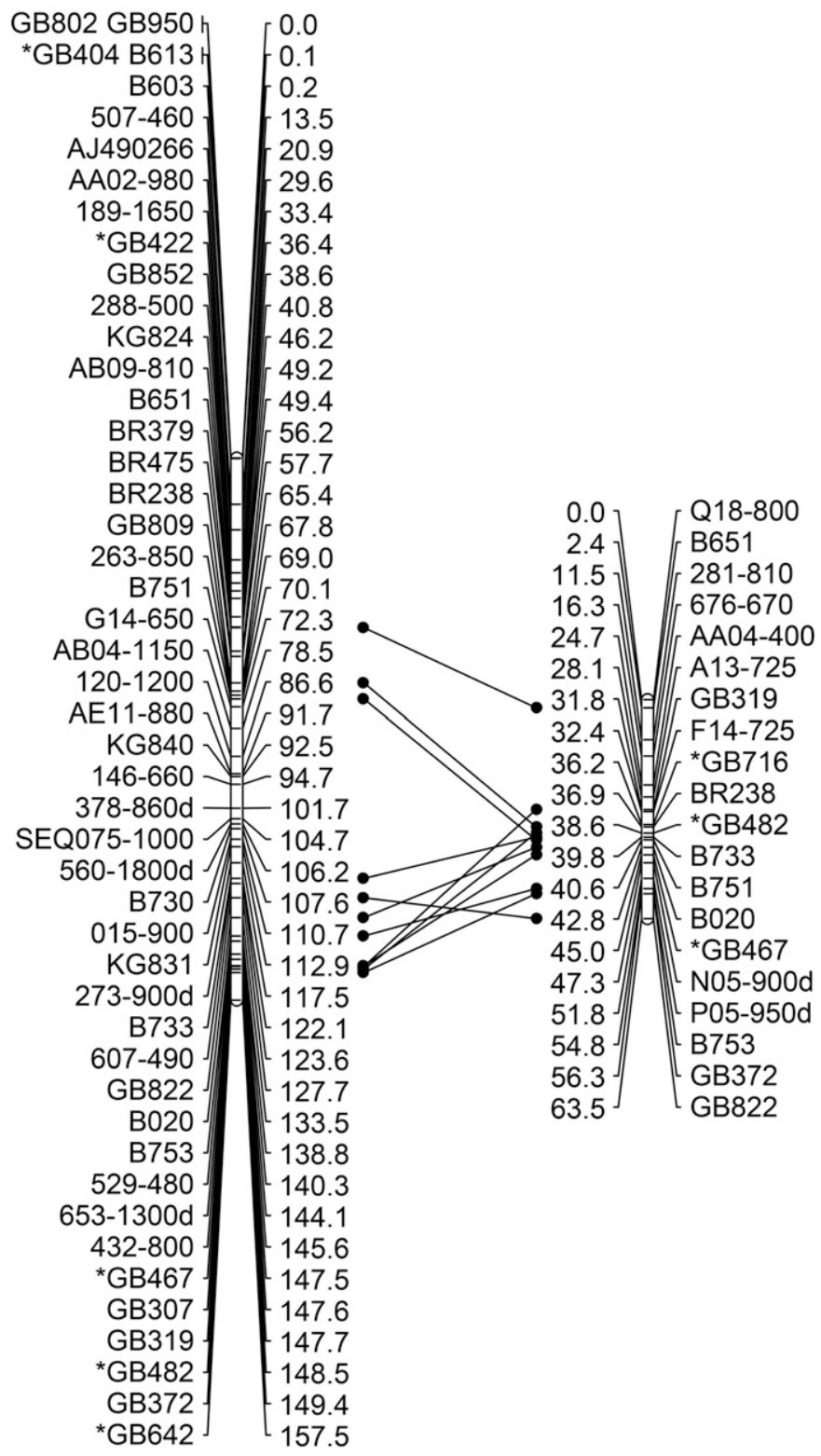

Fig. 2. (Continued)

(Gökirmak et al., 2009). 'Des Anglais' was obtained from Bordeaux, France, but its name indicates an English origin. All of the Spanish and Italian cultivars were included in the large Spanish-Italian group.

\section{Discussion}

The high throughput and low cost of next-generation sequencing allows plant genomes to be sequenced and SSR markers to be developed efficiently as a by-product of genome sequencing. In hazelnut, we identified 9094 'Jefferson' genome sequences that contained tetra-, penta- or hexanucleotide repeats and proceeded in a stepwise manner to develop polymorphic SSR markers from them. Of the 1013 sequences for which aligned sequences were visually inspected, 246 showed variation in number of repeat units but conserved flanking

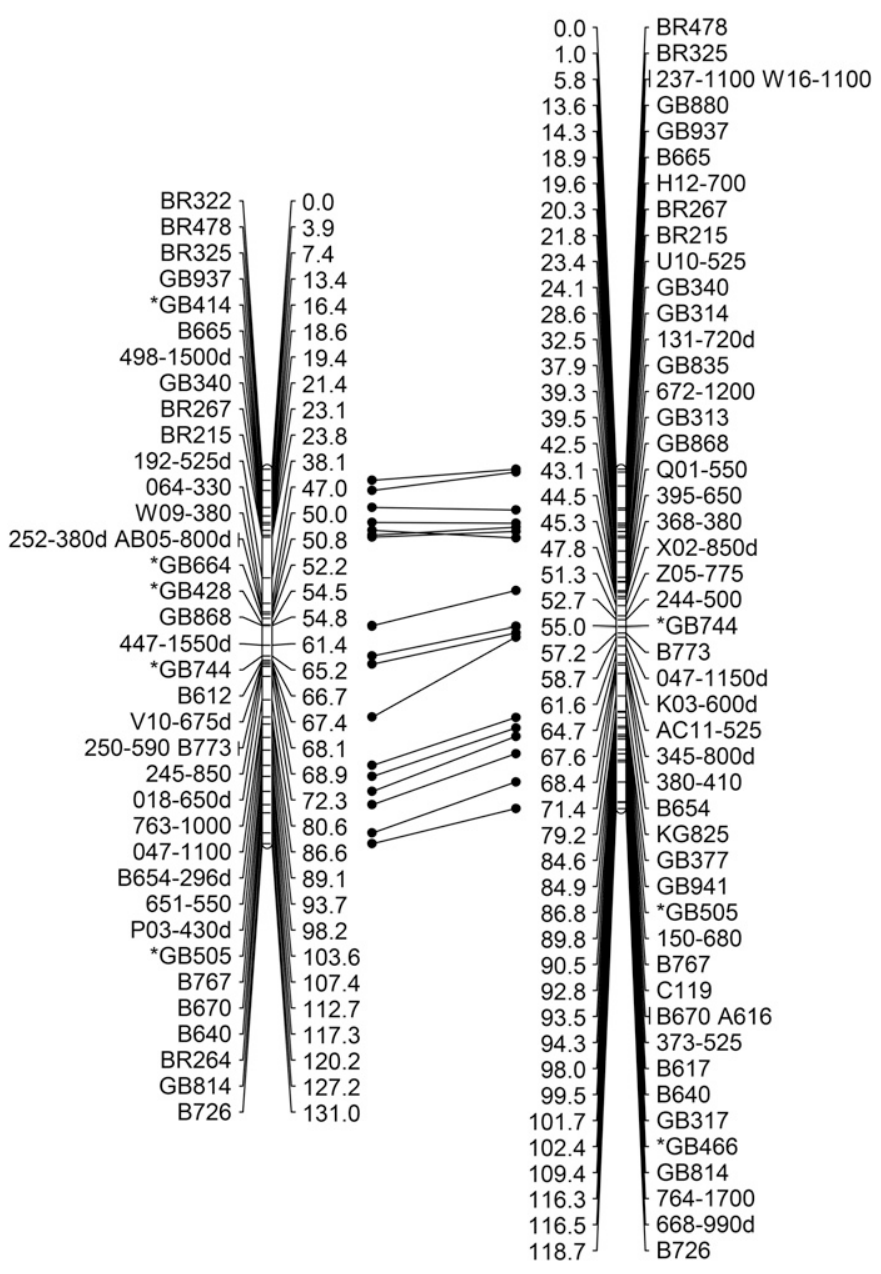

Fig. 2. (Continued)

sequences. After primer design, amplification, allele sizing, and characterization, this number was reduced to the 192 new polymorphic SSR loci described in this paper, of which 169 amplified only one or two bands in all cultivars, as expected in a diploid species. The ratio of single-locus polymorphic SSRs developed to number of primer pairs designed was $68.7 \%$ in this study, compared with $28.5 \%$ for the mostly trinucleotide repeat SSRs developed from transcriptome sequences (Colburn et al., 2017) without in silico evaluation. The comparison illustrates the improved efficiency that results from this evaluation. For the dinucleotide repeat SSRs developed from enriched libraries, the ratio was an intermediate 57\% (Gürcan et al., 2010). Although single nucleotide polymorphism (SNP) markers can be generated in large numbers by procedures including genotypingby-sequencing [GBS (Elshire et al., 2011)] and double digest RADseq (Peterson et al., 2012), SSR markers continue to have many research and breeding applications in plants. In hazelnut, for example, Özturk et al. (2017) studied associations of SSR markers with nut and kernel traits in a Slovenian hazelnut collection, and Marinoni et al. (2018) used SSR and SNP markers to identify QTL in a seedling population from 'Tonda Gentile delle Langhe' $x$ 'Merveille de Bollwiller'.

Most of the tetra-, penta-, and hexa- SSRs identified in this study were composed of only As and Ts (52\%). The very high 
9S

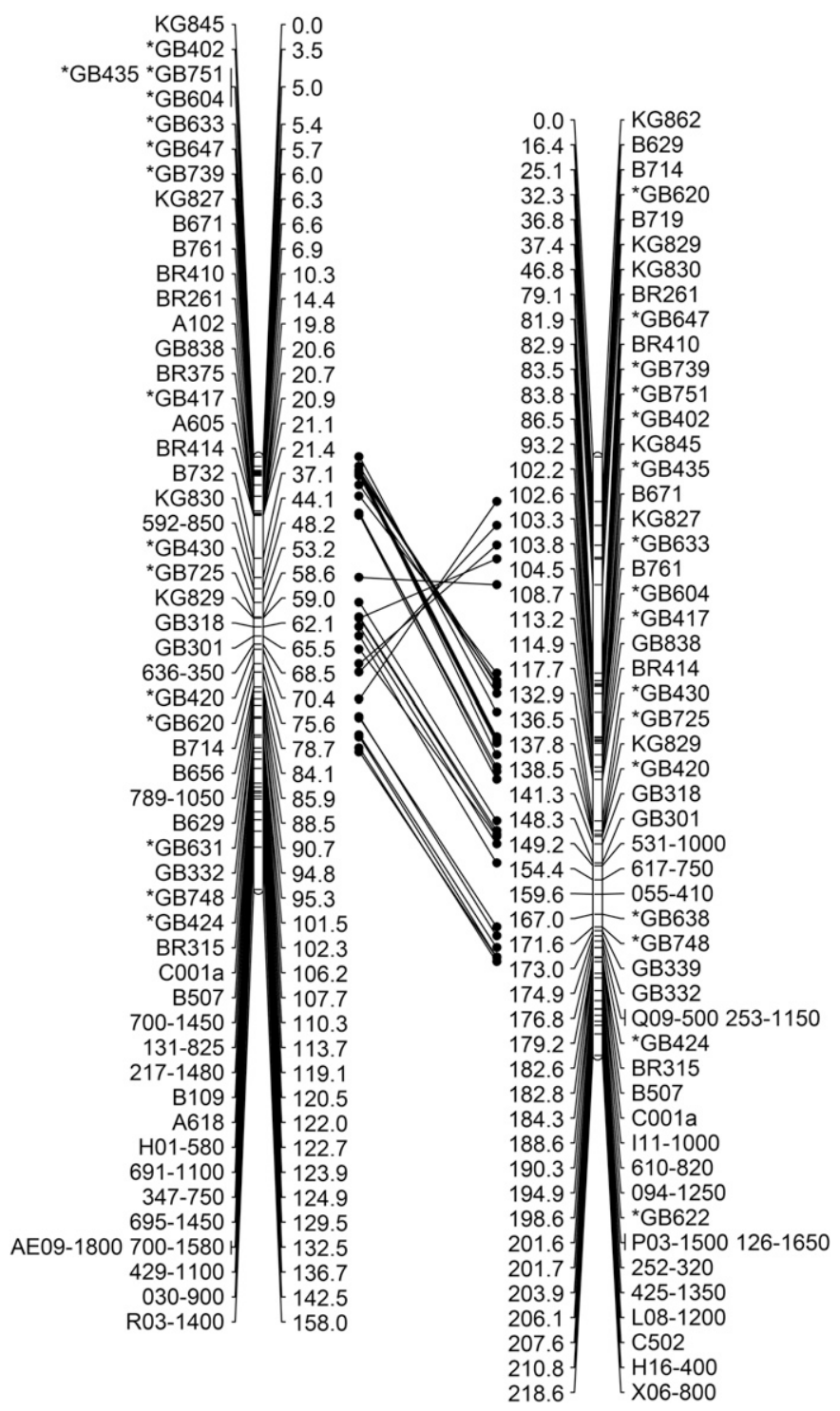

Fig. 2. (Continued)

frequency of A and T bases in SSRs have been observed in many other tree species (Xia et al., 2017). Mononucleotide repeats, although abundant in the hazelnut genome, were not pursued as they tend to be difficult to score. Dinucleotide repeats were not pursued as large numbers had previously been developed (Bassil et al., 2005a, 2005b; Boccacci et al., 2005, 2015; Gürcan et al., 2010; Gürcan and Mehlenbacher, 2010a; Sathuvalli and Mehlenbacher, 2013) and stuttering is a common problem with dinucleotide repeats (Hearne et al., 1992). Colburn et al. (2017) developed 111 SSRs from transcriptome sequences, most of which were trinucleotide repeats, and Bhattarai and Mehlenbacher (2017) developed 150 trirepeat SSRs from the Illumina draft genome sequence for 'Jefferson'. This study adds 192 markers to the 525 previously developed, and further saturates the genetic map. Previous studies (Bassil et al., 2005a, 2013; Boccacci et al., 2005, 2015; Gürcan and Mehlenbacher, 2010b) showed a high rate of transferability to other Corylus species, and lower transferability $(\approx 30 \%)$ to the
$10 S$

10R

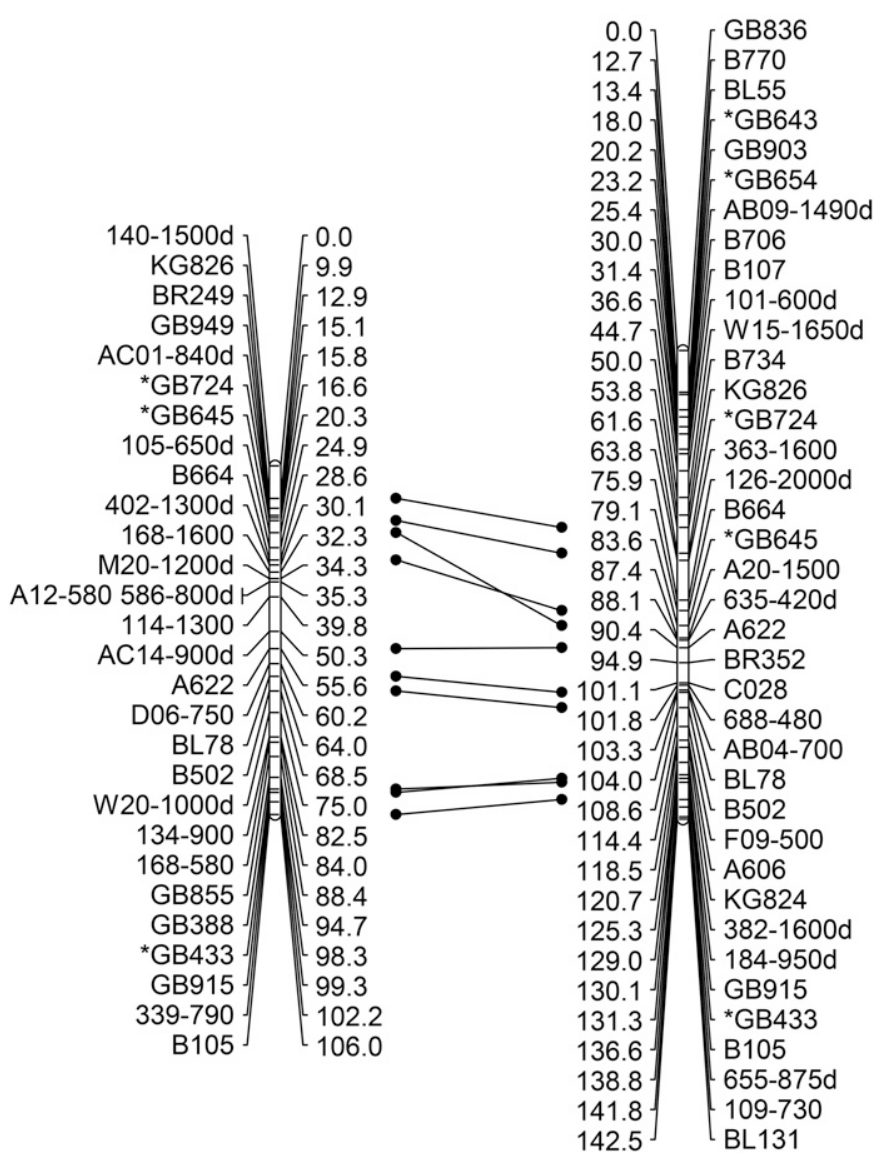

Fig. 2. (Continued)

genera Betula and Alnus, which are also in the family Betulaceae. Thus, the SSR markers developed in this study could have applications beyond C. avellana.

Of the new polymorphic SSRs developed in this study, 23 primer pairs amplified more than two bands in some hazelnut accessions. SSRs of this type were previously reported in hazelnut (Bhattarai and Mehlenbacher, 2017; Gürcan and Mehlenbacher, 2010a) and other plant species (ChavarriagaAguirre et al., 1998; Kim et al., 2014). We attribute this to either nonspecific amplification or genome duplication events, including paralogous sequences.

The count of private or unique alleles (occurring in only one individual) is 201 at 103 SSR loci (Supplemental Table 6). These unique alleles were confirmed by repeating the PCR and allele sizing. Null alleles, which fail to amplify with PCR, are the result of a mutation in either one or both primer binding sites of the genome sequences. The presence of null alleles leads to errors in pedigree and segregation analysis (Dakin and Avise, 2004; Pemberton et al., 1995). The mean frequency of null alleles was low $(\mathrm{r}=0.03)$, although a few loci had high values and 16 (GB405, GB409, GB421, GB454, GB461, GB465, GB505, GB532, GB602, GB624, GB640, GB646, GB649, GB671, GB718, and GB721) had values $>0.20$.

The UPGMA dendrogram, based on binary data of allele sizes at 192 SSRs, showed accessions clustered according to their geographic origin into four main groups: Central European, Black Sea, English, and Spanish-Italian. This grouping is 
$11 \mathrm{~S}$

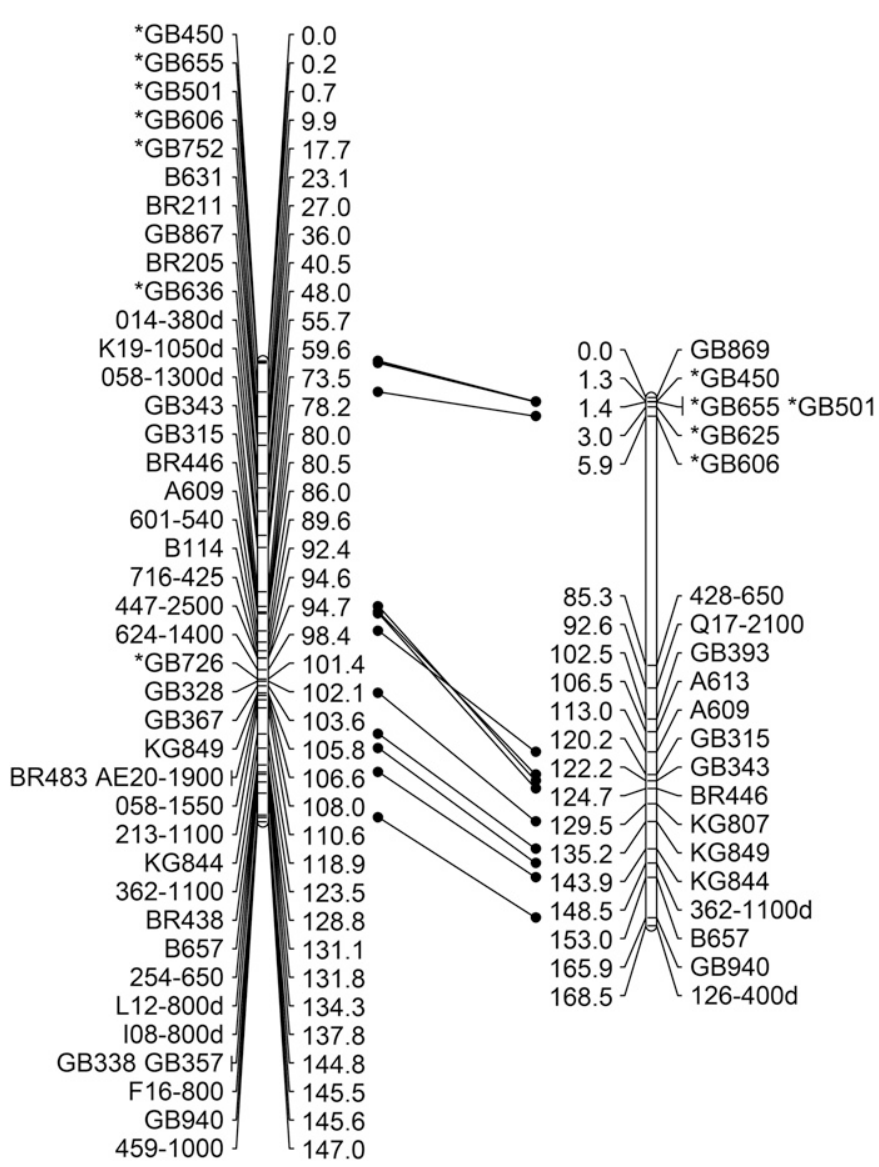

Fig. 2. (Continued)

similar to previous studies (Boccacci et al., 2006; Colburn et al., 2017; Gökirmak et al., 2009; Gürcan et al., 2010). The dendrogram (Fig. 1) shows a high level of diversity in the 50 accessions, including 13 diverse accessions at the top that did not cluster with any of the others (Fig. 1).

Of the 192 new SSR markers, 135 segregated in the mapping population, of which 132 were placed on the map and three with distorted segregation remained unlinked. Segregation ratios at 135 loci (Supplemental Table 4) were examined for goodnessof-fit to expected ratios. Poor fit to Mendelian expectations $(P<$ 0.05 ) was observed at 20 loci, of which 11 showed very poor fit $(P<0.01)$. Several SSRs did not segregate in the reference mapping population. Their map locations may be determined in future research using alternate mapping populations, or by alignment with a mapped genome sequence contig. Linkage groups are presented separately for the female and male parents (Fig. 2). The female parent map consists of 11 distinct linkage groups, while the male parent map initially had 10 distinct groups, with LG2 and LG7 merged into a single large group, as first encountered by Mehlenbacher et al. (2006) and more recently by Beltramo et al. (2016) for a population from 'Tonda Gentile delle Langhe' x 'Merveille de Bollwiller'. Reciprocal translocations are common in hazelnut (Salesses, 1973; Salesses and Bonnet, 1988), and may be responsible for this merger. We separated LG2 and LG7 in the male parent map following the method of Colburn et al. (2017) and present 11 groups. The newly developed markers were assigned to all 11 LGs (Fig. 2), but were not evenly distributed.

Four markers (GB478, GB456, GB605, and GB671) were placed on LG6 $<20 \mathrm{cM}$ from the locus from 'Gasaway' for resistance to eastern filbert blight (EFB) caused by Anisogramma anomala (Mehlenbacher et al., 2006), although none are closer than four SSRs developed from BAC sequences that cosegregate with the allele for resistance (Sathuvalli and Mehlenbacher, 2013). EFB resistance from five other sources maps to the same region (Bhattarai et al., 2017b; Colburn et al., 2015; Sathuvalli et al., 2012). Three other markers (GB467, GB482, and GB642), were assigned to LG7 in the region of the EFB resistance loci from 'Ratoli', 'Yoder \#5', and C. americana 'Rush' (Bhattarai et al., 2017a; Sathuvalli et al., 2011a). Four markers (GB609, GB618, GB669, and GB740) were placed on LG2 near the EFB resistance locus from Georgian selection OSU 759.010 (Sathuvalli et al., 2011b). These new markers will be useful for mapping additional EFB resistance sources and developing breeder-friendly DNA markers in these regions for use in marker-assisted selection. Additionally, GB646 was placed on LG5 near the S-locus that controls pollen-stigma incompatibility (Ives et al., 2014; Mehlenbacher et al., 2006).

The genomic SSRs developed in this study add to those developed previously and will facilitate research in hazelnut genetics, including cultivar fingerprinting, parentage analysis, studies of genetic diversity, mapping of qualitative trait loci and QTL, marker-assisted breeding, and the fine mapping and cloning of genes. Because SSR markers map to the same location in different populations, they allow the alignment or merger of genetic maps from different crosses. In addition, the mapped SSR markers will allow alignment of the linkage map with the genome sequences and the physical map of BAC contigs.

\section{Literature Cited}

Bassil, N.V., R. Botta, and S.A. Mehlenbacher. 2005a. Microsatellite markers in hazelnut: Isolation, characterization, and cross-species amplification. J. Amer. Soc. Hort. Sci. 130:543549.

Bassil, N.V., S.A. Mehlenbacher, and R. Botta. 2005b. Additional microsatellite markers of the european hazelnut. Acta Hort. 686:105110

Bassil, N., P. Boccacci, R. Botta, J. Postman, and S. Mehlenbacher. 2013. Nuclear and chloroplast microsatellite markers to assess genetic diversity and evolution in hazelnut species, hybrids and cultivars. Genet. Resources Crop Evol. 60:543568.

Beltramo, C., N. Valentini, E. Portis, D. Torello Marinoni, P. Boccacci, M.A. Sandoval Prando, and R. Botta. 2016. Genetic mapping and QTL analysis in European hazelnut (Corylus avellana L.). Mol. Breed. 36:27.

Bhattarai, G. and S.A. Mehlenbacher. 2017. In silico development and characterization of tri-nucleotide simple sequence repeat markers in hazelnut (Corylus avellana L.). PLOS One 12:e0178061, doi: 10.1371/journal.pone.0178061.

Bhattarai, G., S.A. Mehlenbacher, and D.C. Smith. 2017a. Eastern filbert blight disease resistance from Corylus americana 'Rush' and selection 'Yoder \#5' maps to linkage group 7. Tree Genet. Genomes 13:45.

Bhattarai, G., S.A. Mehlenbacher, and D.C. Smith. 2017b. Inheritance and mapping of eastern filbert blight resistance from 'Uebov' hazelnut. J. Amer. Soc. Hort. Sci. 142:289-297. 
Boccacci, P., A. Akkak, N.V. Bassil, S.A. Mehlenbacher, and R. Botta 2005. Characterization and evaluation of microsatellite loci in European hazelnut (Corylus avellana L.) and their transferability to other Corylus species. Mol. Ecol. Notes 5:934-937.

Boccacci, P., A. Akkak, and R. Botta. 2006. DNA typing and genetic relations among european hazelnut (Corylus avellana L.) cultivars using microsatellite markers. Genome 49:598-611.

Boccacci, P., C. Beltramo, M.A. Sandoval Prando, A. Lembo, C. Sartor, S.A. Mehlenbacher, R. Botta, and D. Torello Marinoni. 2015. In silico mining, characterization and cross-species transferability of EST-SSR markers for European hazelnut (Corylus avellana L.). Mol. Breed. 35:21.

Botstein, D., R.L. White, M. Skolnick, and R.W. Davis. 1980. Construction of a genetic linkage map in man using restriction fragment length polymorphisms. Amer. J. Hum. Genet. 32:314331 .

Chavarriaga-Aguirre, P.P., M.M. Maya, M.W. Bonierbale, S. Kresovich, M.A. Fregene, J. Tohme, and G. Kochert. 1998. Microsatellites in cassava (Manihot esculenta Crantz): Discovery, inheritance and variability. Theor. Appl. Genet. 97:493-501.

Colburn, B.C., S.A. Mehlenbacher, V.R. Sathuvalli, and D.C. Smith. 2015. Novel sources of eastern filbert blight resistance in hazelnut accessions 'Culpla', 'Crvenje' and OSU 495.072. J. Amer. Soc. Hort. Sci. 139:191-200.

Colburn, B.C., S.A. Mehlenbacher, and V.R. Sathuvalli. 2017. Development and mapping of microsatellite markers from transcriptome sequences of European hazelnut (Corylus avellana L.) and use for germplasm characterization. Mol. Breed. 37:16.

Dakin, E.E. and J.C. Avise. 2004. Microsatellite null alleles in parentage analysis. Heredity 93:504-509.

Ellegren, H. 2004. Microsatellites: Simple sequences with complex evolution. Nat. Rev. Genet. 5:435-445.

Elshire, R.J., J.C. Glaubitz, Q. Sun, J.A. Poland, K. Kawamoto, E.S. Buckler, and S.E. Mitchell. 2011. A robust, simple genotyping-bysequencing (GBS) approach for high diversity species. PLOS One 6(5): e19379, doi: 10.1371/journal.pone.0019379.

Food and Agriculture Organization of the United Nations. 2017. FAOSTAT. Compare data. 1 Aug. 2017. <http://www.fao.org/faostat/ en/\#compare>.

Gökirmak, T., S.A. Mehlenbacher, and N.V. Bassil. 2009. Characterization of European hazelnut (Corylus avellana) cultivars using SSR markers. Genet. Resources Crop Evol. 56:147-172.

Gürcan, K. and S.A. Mehlenbacher. 2010a. Development of microsatellite marker loci for european hazelnut (Corylus avellana L.) from ISSR fragments. Mol. Breed. 26:551-559.

Gürcan, K. and S.A. Mehlenbacher. 2010b. Transferability of microsatellite markers in the Betulaceae. J. Amer. Soc. Hort. Sci. 135:159-173.

Gürcan, K., S.A. Mehlenbacher, R. Botta, and P. Boccacci. 2010. Development, characterization, segregation, and mapping of microsatellite markers for European hazelnut (Corylus avellana L.) from enriched genomic libraries and usefulness in genetic diversity studies. Tree Genet. Genomes 6:513-531.

Hearne, C.M., S. Ghosh, and J.A. Todd. 1992. Microsatellites for linkage analysis of genetic traits. Trends Genet. 8:288-294.

Ives, C., V.R. Sathuvalli, B.C. Colburn, and S.A. Mehlenbacher. 2014. Mapping the incompatibility and style color loci in two hazelnut progenies. HortScience 49:250-253.

Kalinowski, S.T. and M.L. Taper. 2006. Maximum likelihood estimation of the frequency of null alleles at microsatellite loci. Conserv. Genet. 7:991-995.

Kim, N.H., H.I. Choi, K.H. Kim, W. Jang, and T.J. Yang. 2014. Evidence of genome duplication revealed by sequence analysis of multi-loci expressed sequence tag-simple sequence repeat bands in Panax ginseng Meyer. J. Ginseng Res. 38:130-135.

Kumar, S., G. Stecher, and K. Tamura. 2016. MEGA7: Molecular evolutionary genetics analysis Version 7.0 for bigger datasets. Mol. Biol. Evol. 33:1870-1874.
Li, H., J. Ruan, and R. Durbin. 2008. Mapping short DNA sequencing reads and calling variants using mapping quality scores. Genome Res. 18:1851-1858.

Liu, K. and S.V. Muse. 2005. PowerMarker: An integrated analysis environment for genetic marker analysis. Bioinformatics 21:21282129.

Lunde, C.F., S.A. Mehlenbacher, and D.C. Smith. 2000. Survey of hazelnut cultivars for response to eastern filbert blight inoculation. HortScience 35:729-731.

Marinoni, D.T., N. Valentini, E. Portis, A. Acquadro, C. Beltramo, S. A. Mehlenbacher, T.C. Mockler, E.R. Rowley, and R. Botta. 2018. High density SNP mapping and QTL analysis for time of leaf budburst in Corylus avellana L. PLOS One 13(4):e0195408, doi: 10.1371/journal.pone.0195408.

Martins, W.S., D.C.S. Lucas, K.F.S. Neves, and D.J. Bertioli. 2009. WebSat - A Web Software for MicroSatellite marker development. Bioinformation 3:282-283.

Mehlenbacher, S.A., R.N. Brown, E.R. Nouhra, T. Gökirmak, N.V. Bassil, and T.L. Kubisiak. 2006. A genetic linkage map for hazelnut (Corylus avellana L.) based on RAPD and SSR markers. Genome 49:122-133

Milne, I., G. Stephen, M. Bayer, P.J.A. Cock, L. Pritchard, L. Cardle, P.D. Shaw, and D. Marshall. 2013. Using Tablet for visual exploration of second-generation sequencing data. Briefings Bioinformatics 14:193-202.

Nei, M. 1973. Analysis of gene diversity in subdivided populations. Proc. Natl. Acad. Sci. USA 70:3321-3323.

Oregon Hazelnuts. 2018. Oregon hazelnuts. 28 Apr. 2018. <http:// oregonhazelnuts.org/>

Özturk, S.C., S.E. Özturk, I. Celik, F. Stampar, R. Veberic, S. Doganlar, A. Solar, and A. Frary. 2017. Molecular genetic diversity and association mapping of nut and kernel traits in Slovenian hazelnut (Corylus avellana) germplasm. Tree Genet. Genomes 13:16.

Parida, S.K., S.K. Kalia, S. Kaul, V. Dalal, G. Hemaprabha, A. Selvi, A. Pandit, A. Singh, K. Gaikwad, T.R. Sharma, P. Shankar, S. Nagendra, K. Singh, and T. Mohapatra. 2009. Informative genomic microsatellite markers for efficient genotyping applications in sugarcane. Theor. Appl. Genet. 118:327-338.

Pemberton, J.M., J. Slate, D.R. Bancroft, and J.A. Barrett. 1995. Nonamplifying alleles at microsatellite loci: A caution for parentage and population studies. Mol. Ecol. 4:249-252.

Peterson, B.K., J.N. Weber, E.H. Kay, H.S. Fisher, and H.E. Hoekstra. 2012. Double digest RADseq: An inexpensive method for de novo SNP discovery and genotyping in model and non-model species. PLOS One 7(5):e37135, doi: 10.1371/journal. pone. 0037135 .

Rinehart, T.A. 2004. AFLP analysis using GeneMapper ${ }^{\circledR}$ software and an Excel ${ }^{\circledR}$ macro that aligns and converts output to binary. Biotechniques 37:186-188.

Rowley, E.R. 2016. Genetic resource development for European hazelnut (Corylus avellana L.). Oregon State Univ., Corvallis, $\mathrm{PhD}$ Diss. 14 July 2018. <http://ir.library.oregonstate.edu/concern/ graduate_thesis_or_dissertations/gq67jv47b>.

Salesses, G. 1973. Etude cytologique du genre Corylus. Mise en évidence d'une translocation hétérozygote chex quelques variétés de noisetier cultivé (Corylus avellana L.) à fertilité pollinique réduite. Ann. Amelior. Plant. 23:59-66.

Salesses, G. and A. Bonnet. 1988. Etude cytogénétique d'hybrides entre varietés de noisetier (Corylus avellana L.) porteuses d'une translocation à l'état hétérozygote. Cytologia (Tokyo) 53:407-413.

Sathuvalli, V.R., S.A. Mehlenbacher, and D.C. Smith. 2012. Identification and mapping of DNA markers linked to eastern filbert blight resistance from OSU 408.040 hazelnut. HortScience 47:570-573.

Sathuvalli, V.R., H. Chen, S.A. Mehlenbacher, and D.C. Smith. 2011a. DNA markers linked to eastern filbert blight resistance in 'Ratoli' hazelnut (Corylus avellana L.). Tree Genet. Genomes 7: 337-345. 
Sathuvalli, V.R., S.A. Mehlenbacher, and D.C. Smith. 2011b. DNA markers linked to eastern filbert blight resistance from a hazelnut selection from the Republic of Georgia. J. Amer. Soc. Hort. Sci. 136:350-357.

Sathuvalli, V.R. and S.A. Mehlenbacher. 2013. De novo sequencing of hazelnut bacterial artificial chromosomes (BACs) using multiplex Illumina sequencing and targeted marker development for eastern filbert blight resistance. Tree Genet. Genomes 9:1109-1118.

Testolin, R. and G. Cipriani. 2010. Molecular markers for germplasm identification and characterization. Acta Hort. 859:59-72.

Thiel, T., W. Michalek, R.K. Varshney, and A. Graner. 2003. Exploiting EST databases for the development and characterization of gene-derived SSR-markers in barley (Hordeum vulgare L.). Theor. Appl. Genet. 106:411-422.

Untergasser, A., I. Cutcutache, T. Koressaar, J. Ye, B.C. Faircloth, M. Remm, and S.G. Rozen. 2012. Primer3 - New capabilities and interfaces. Nucleic Acids Res. 40(15):e115, doi: 10.1093/nar/ gks596.

Xia, X., L.L. Luan, G. Qin, L.F. Yu, Z.W. Wang, W.C. Dong, Y. Song, Y. Qiao, X.S. Zhang, Y.L. Sang, and L. Yang. 2017. Genome-wide analysis of SSR and ILP markers in trees: Diversity profiling, alternate distribution, and applications in duplication. Sci. Rep. $7: 17902$. 
GB401

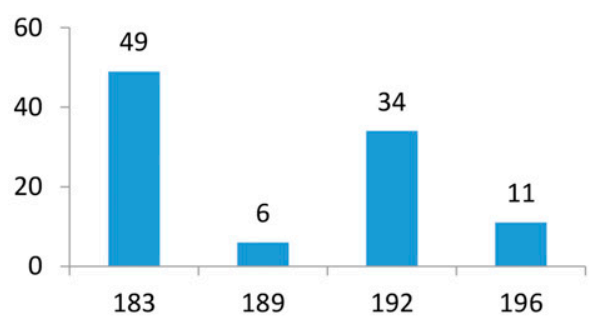

GB403

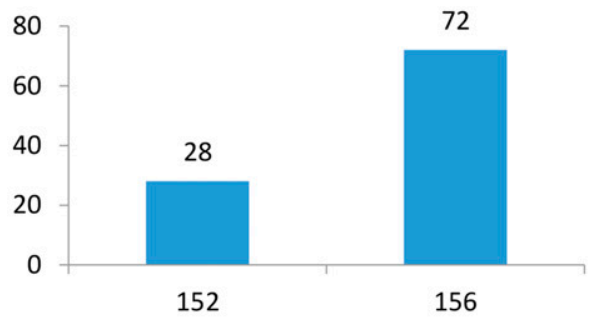

GB405

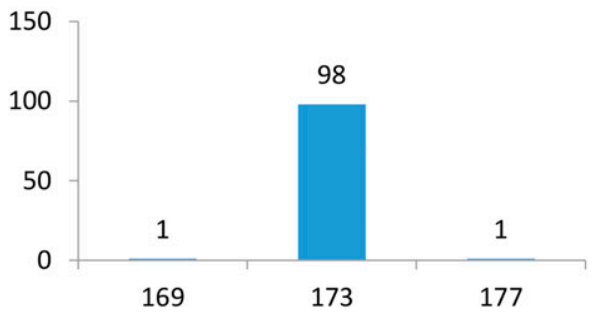

GB408

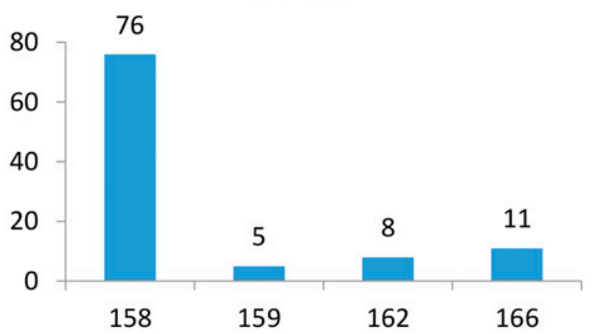

GB402

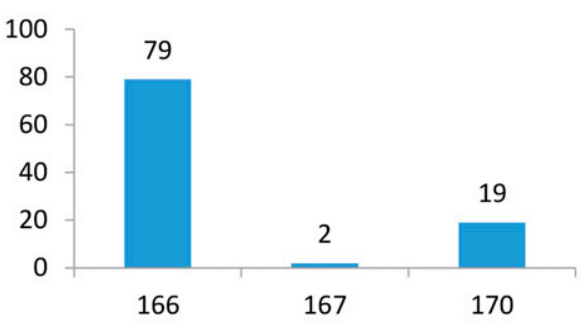

GB404

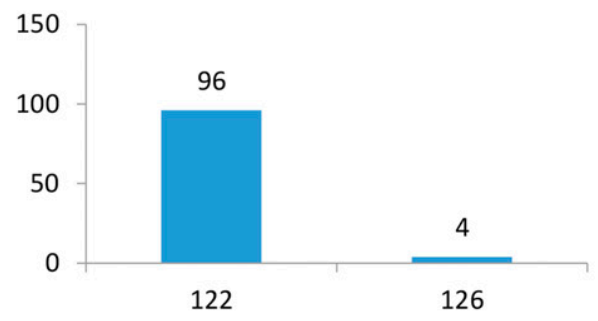

GB407

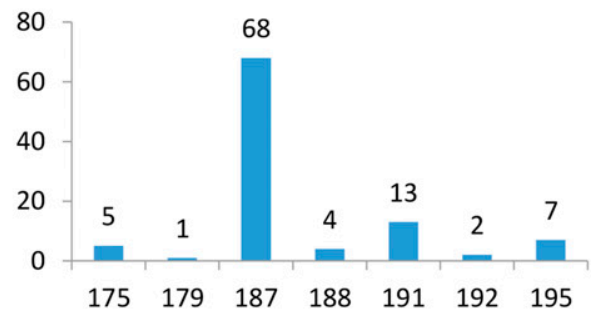

GB409

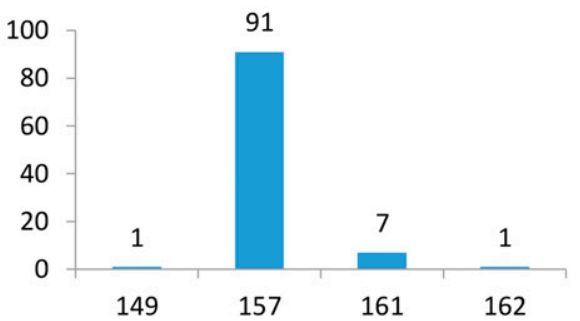

Supplemental Fig. 1. Histograms showing allele frequencies at 194 new simple sequence repeat loci in hazelnut. 
GB410

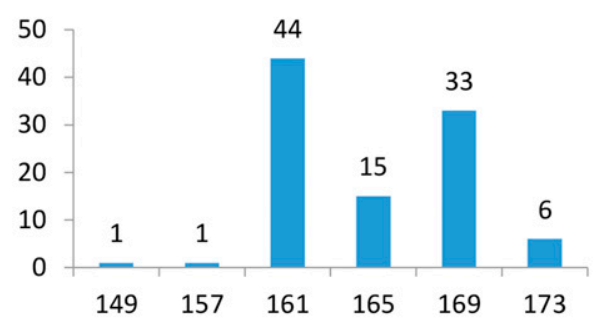

GB414

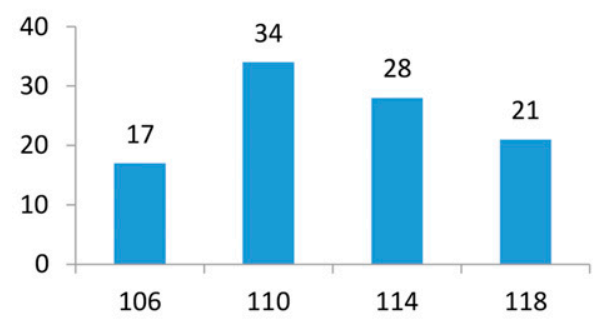

GB417

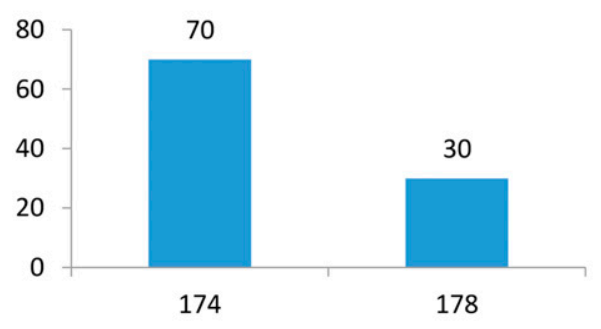

GB420

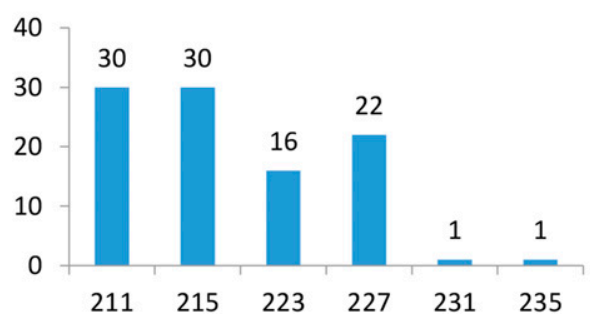

GB413

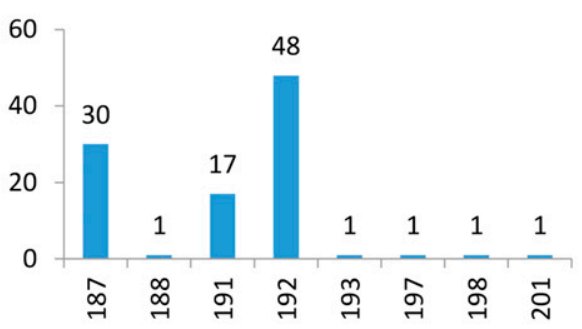

GB416

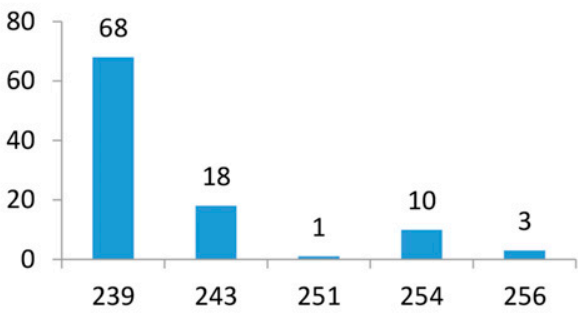

\section{GB418}

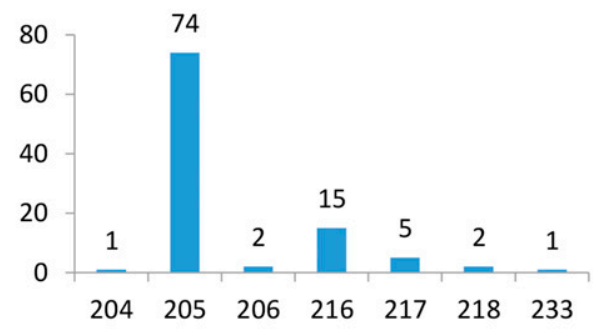

GB421

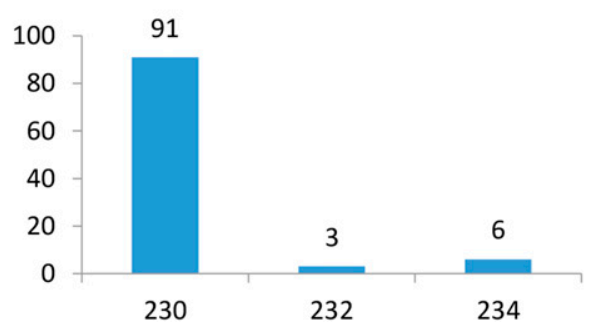

Supplemental Fig. 1. (Continued) 

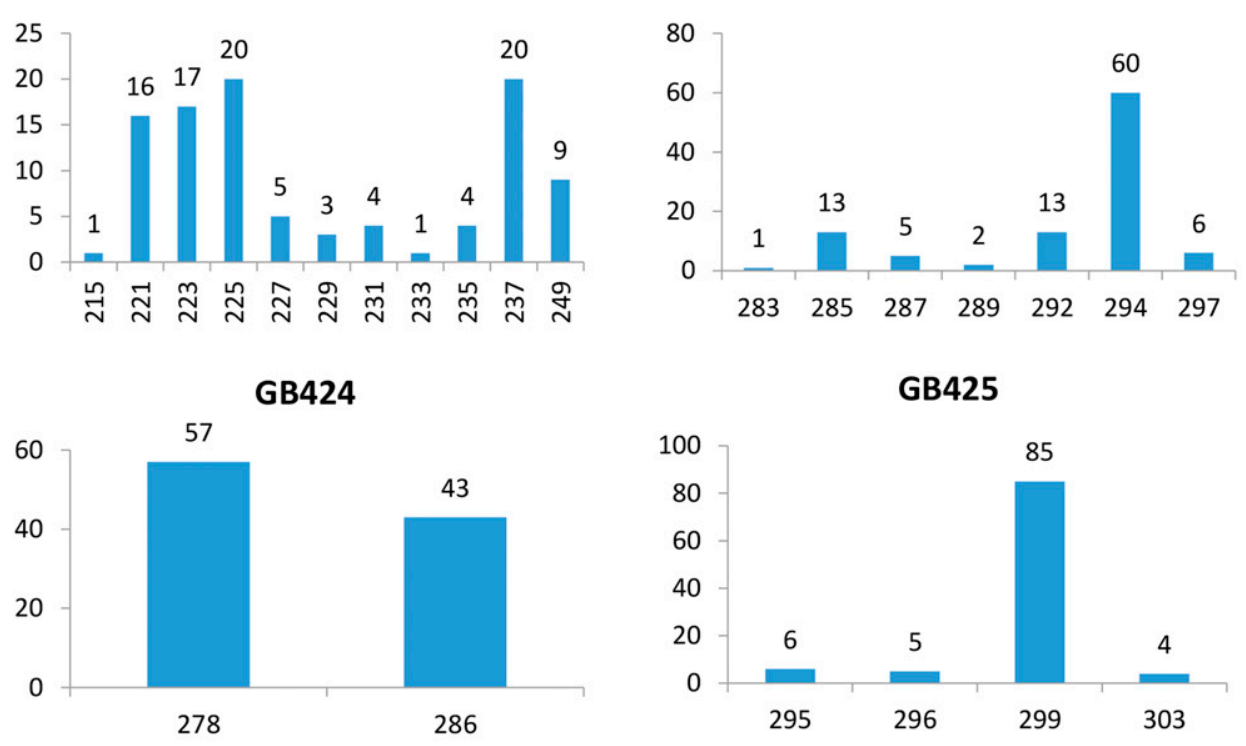

GB425
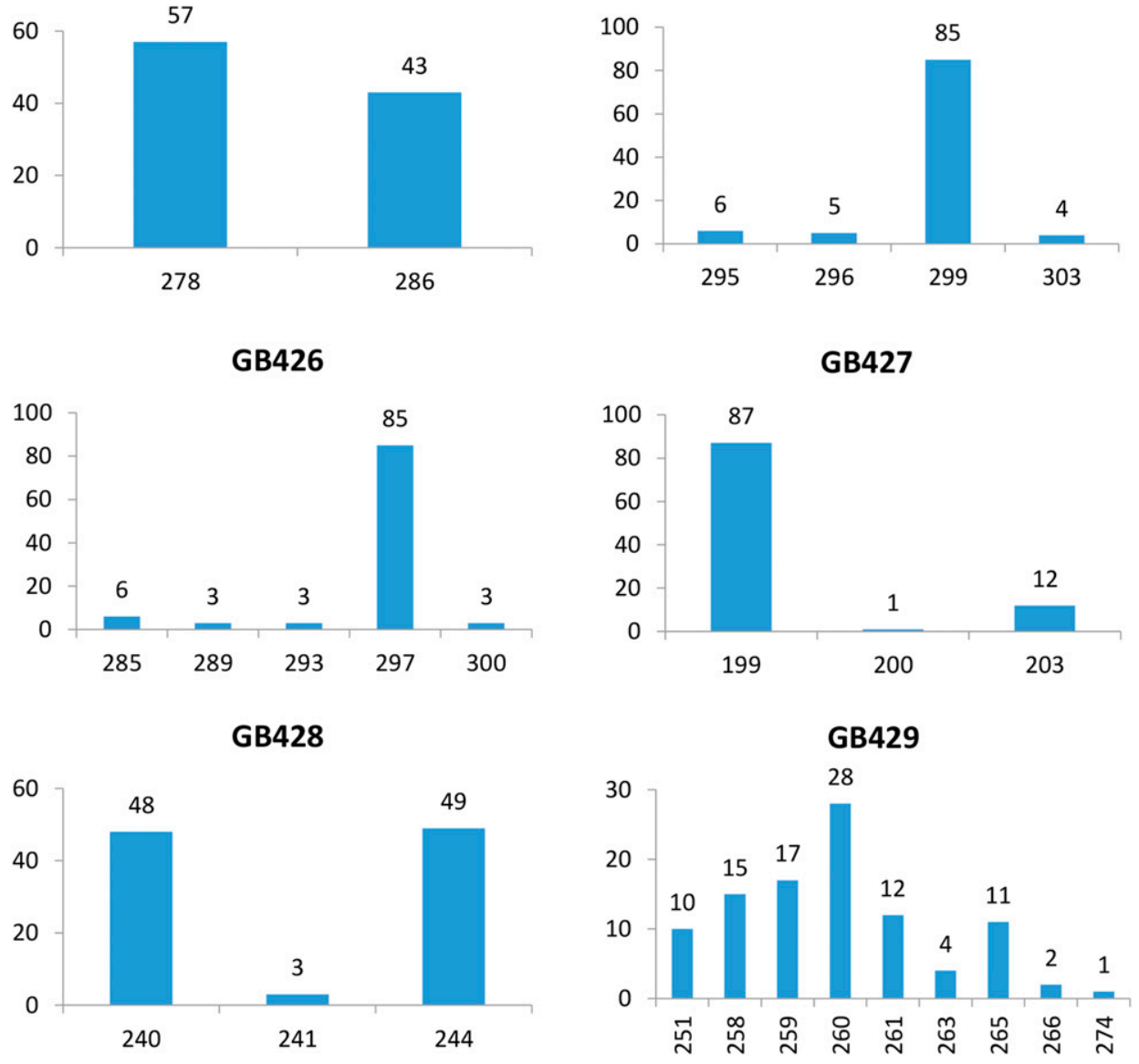

Supplemental Fig. 1. (Continued) 
GB430

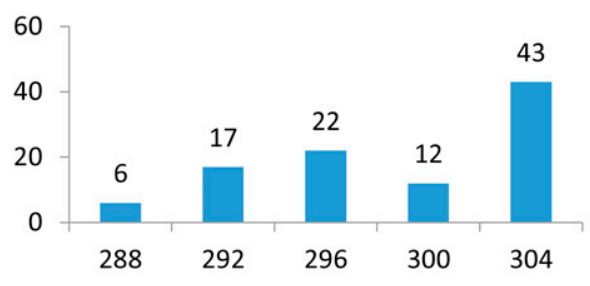

GB432

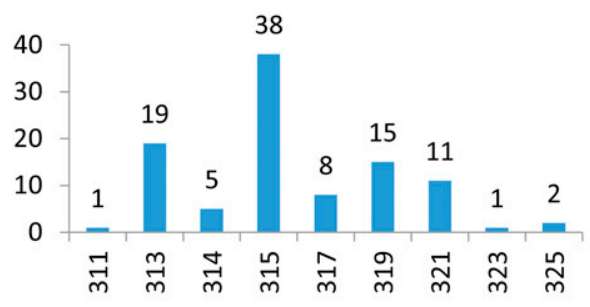

GB434

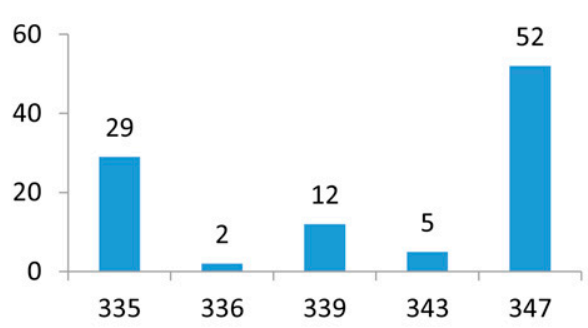

GB436

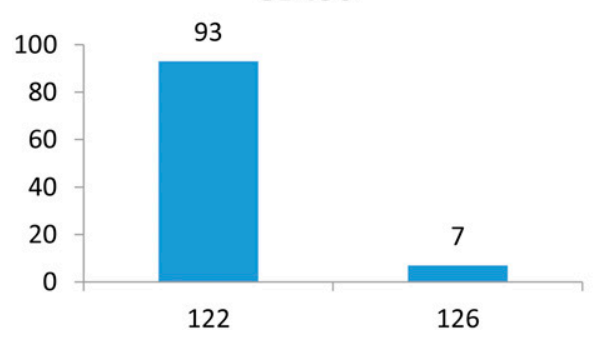

GB431

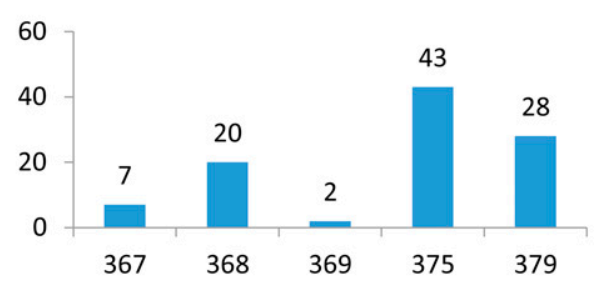

GB433

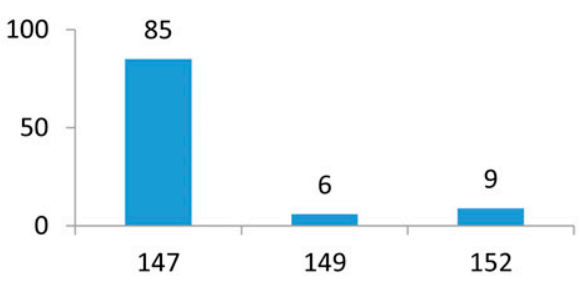

GB435

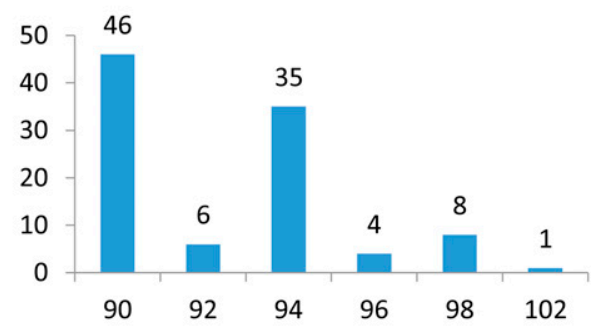

GB437

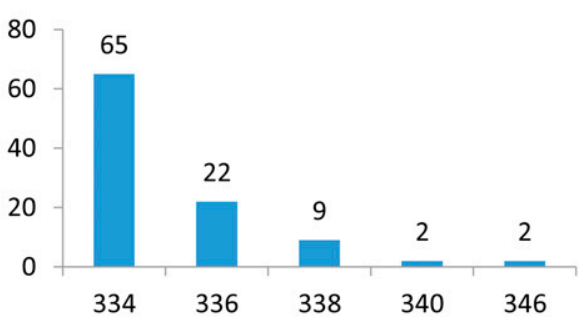

Supplemental Fig. 1. (Continued) 

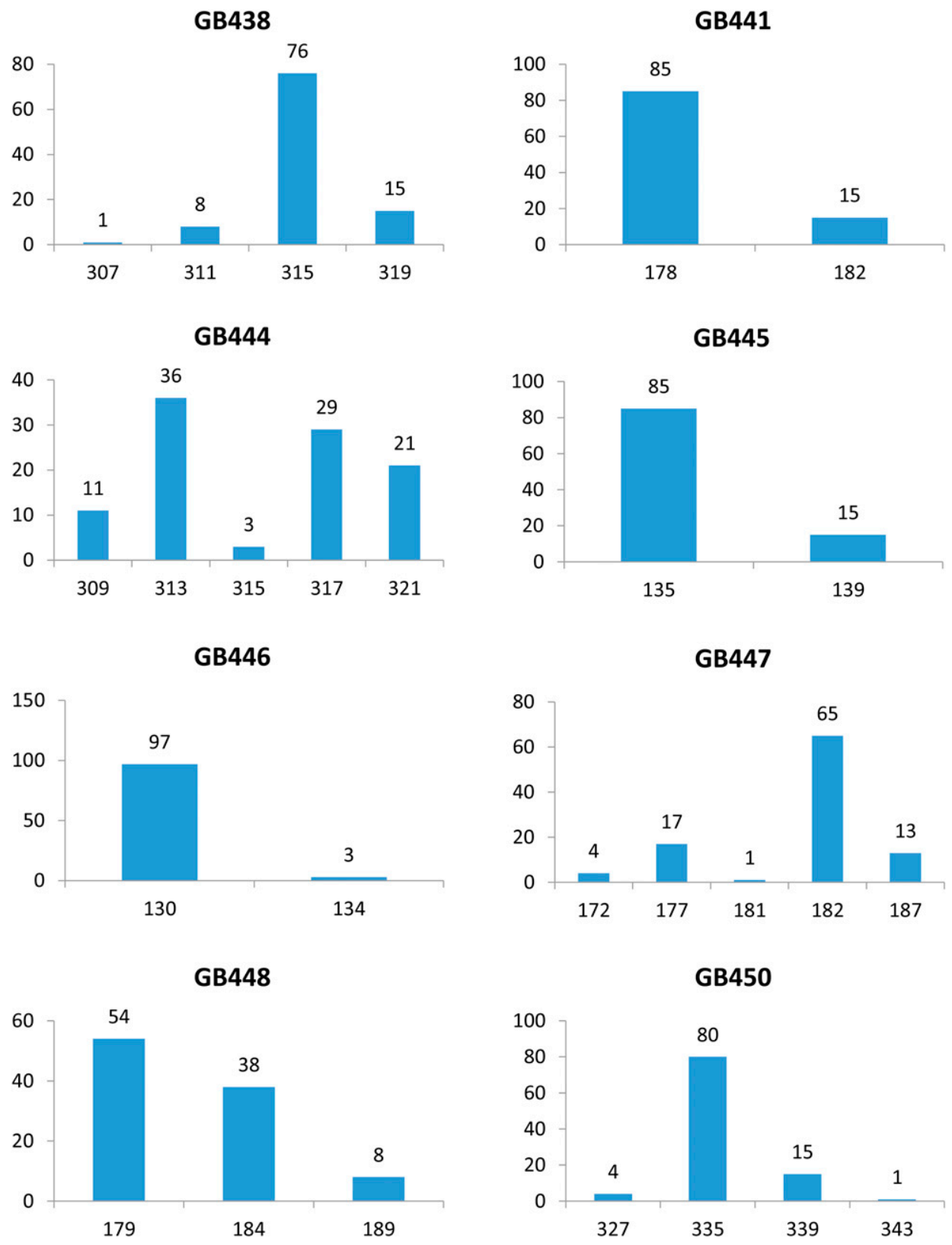

Supplemental Fig. 1. (Continued) 
GB452

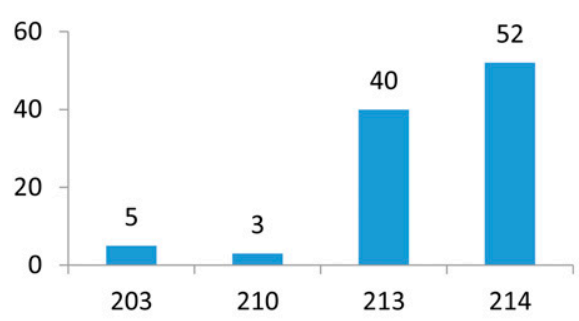

GB456

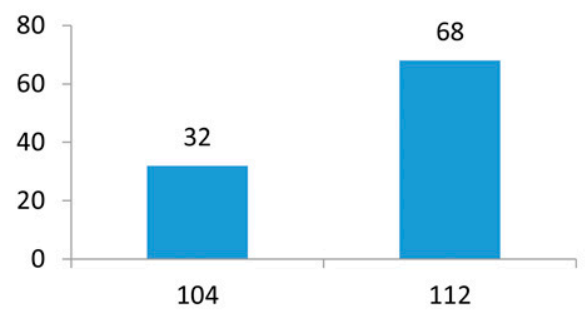

GB458

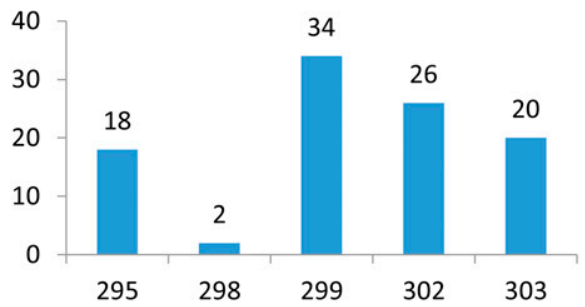

GB462

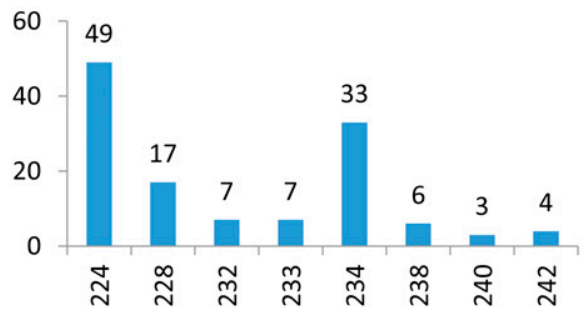

GB454

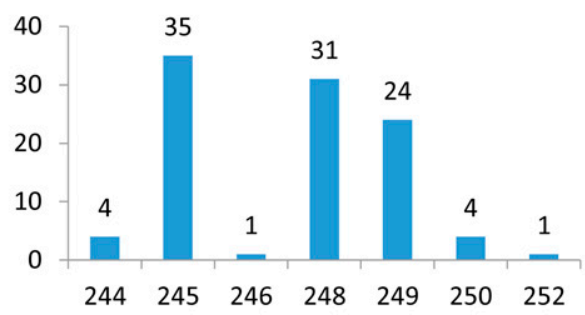

GB457

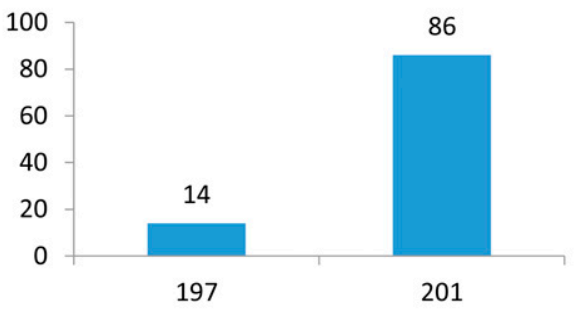

GB461

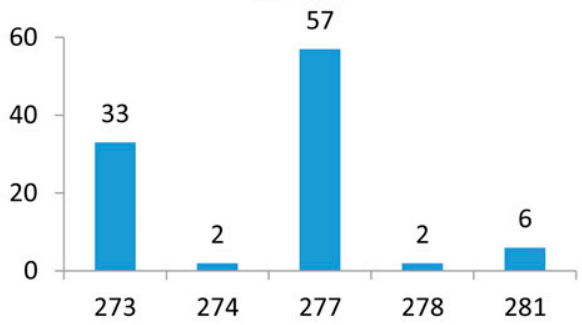

\section{GB463}

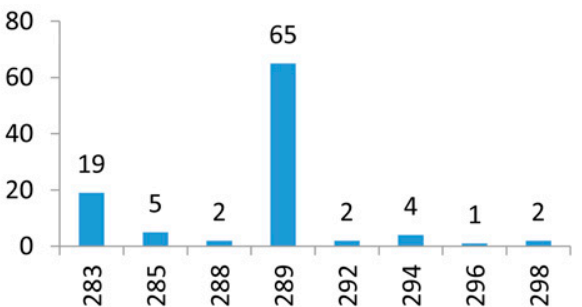

Supplemental Fig. 1. (Continued) 
GB465

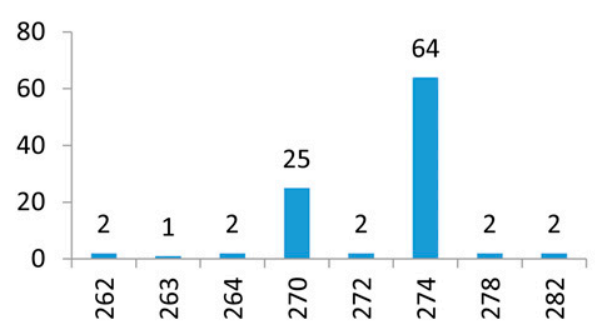

GB467

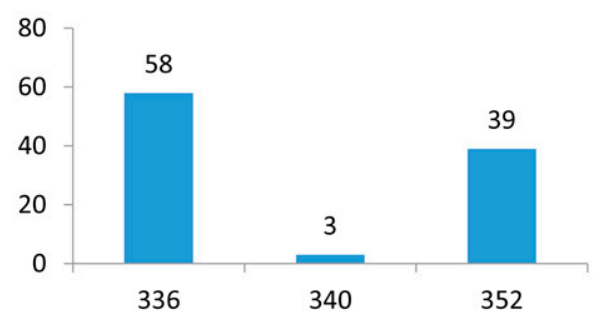

GB469

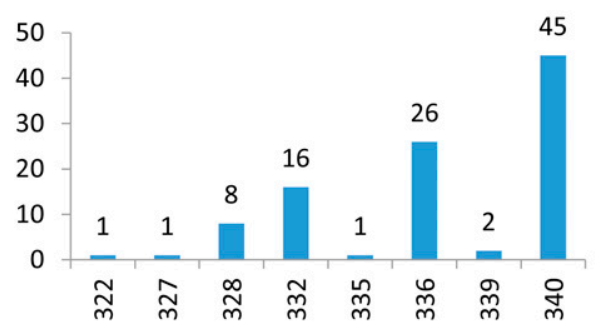

GB473

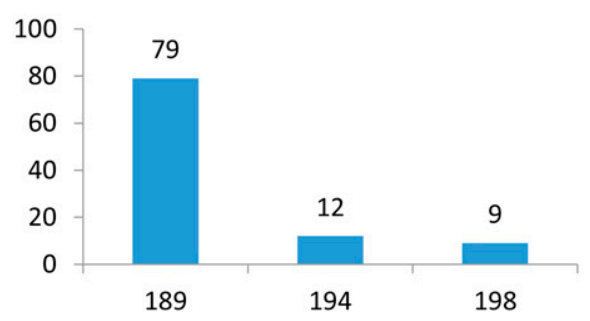

GB466

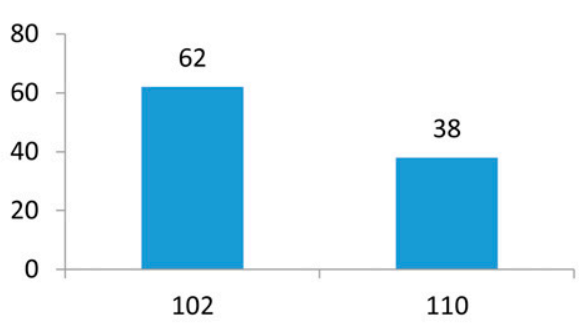

GB468

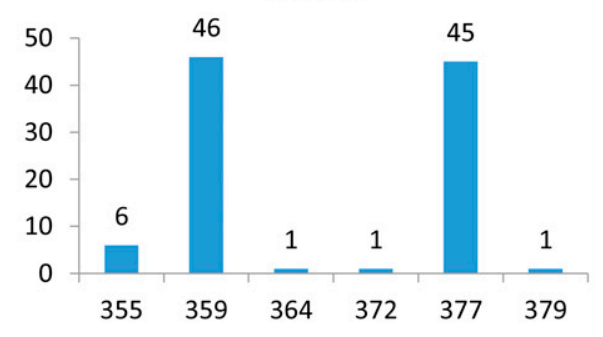

GB470

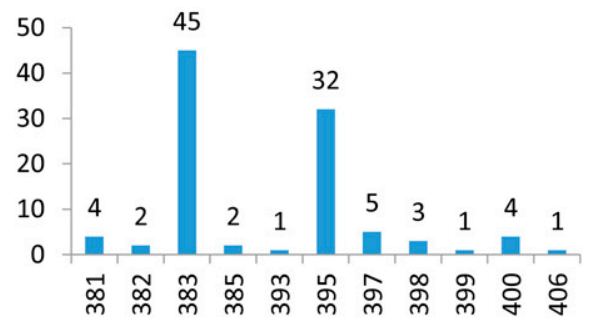

GB475

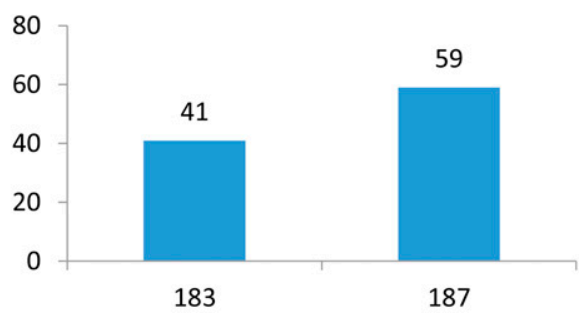

Supplemental Fig. 1. (Continued) 
GB476

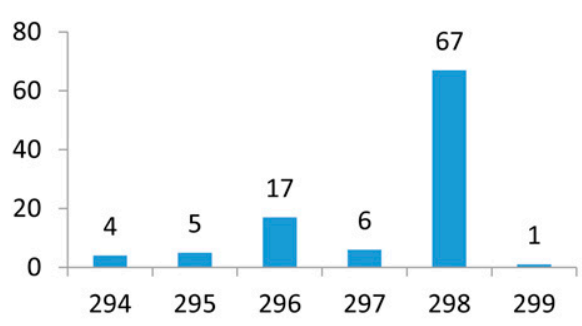

GB478

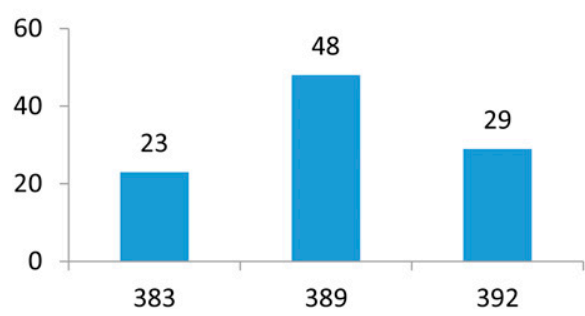

GB482

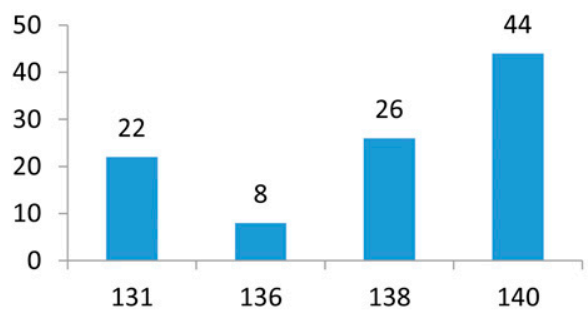

GB501

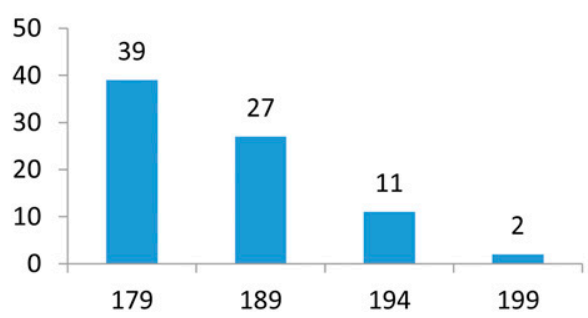

GB477

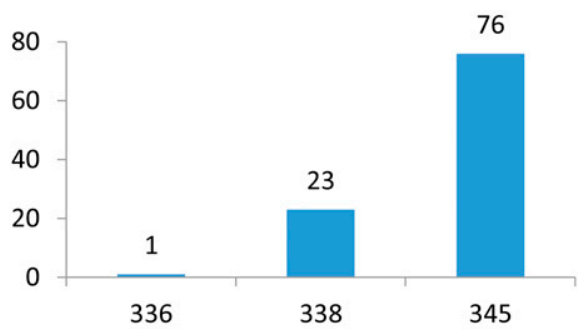

GB480

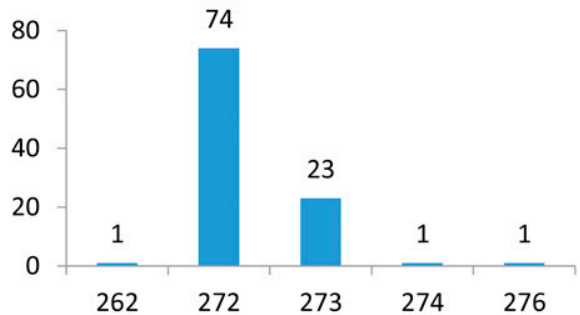

GB483

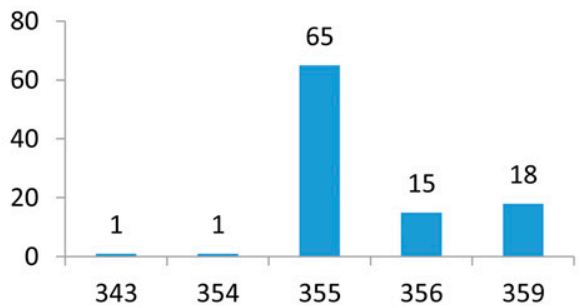

GB504

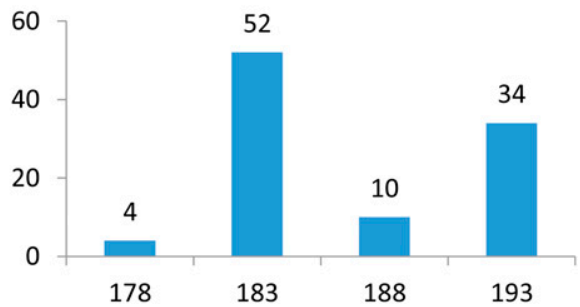

Supplemental Fig. 1. (Continued) 
GB505

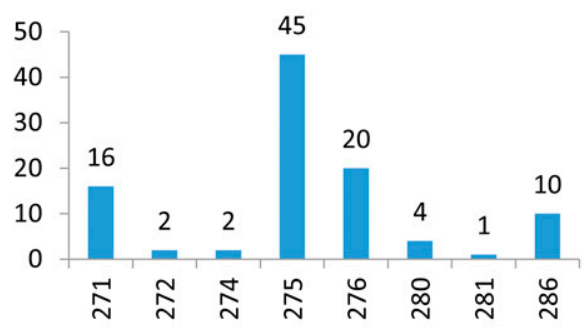

GB527

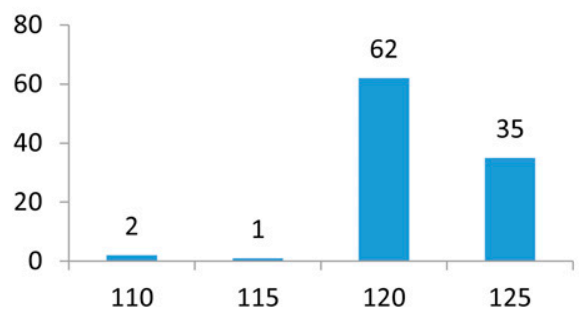

GB533

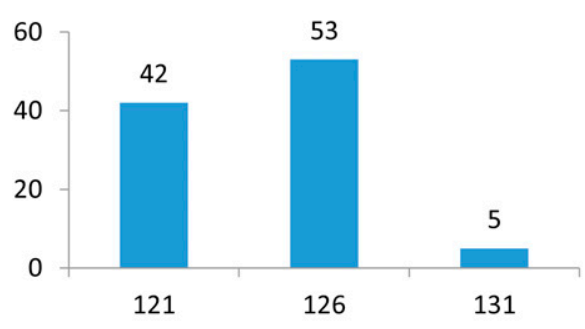

GB537

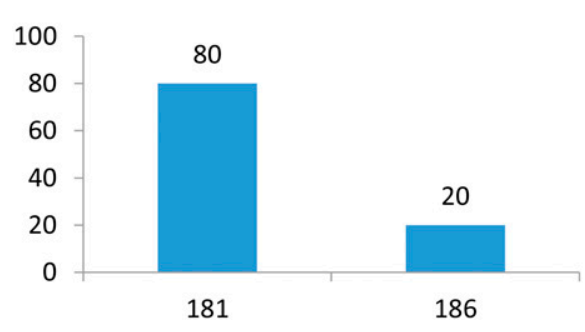

GB526

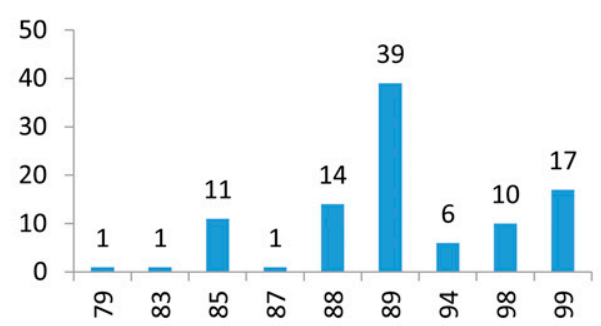

GB532

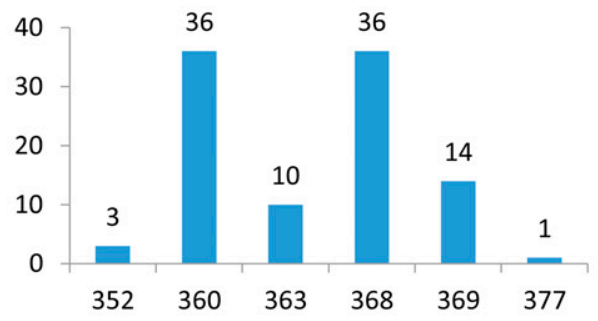

GB535

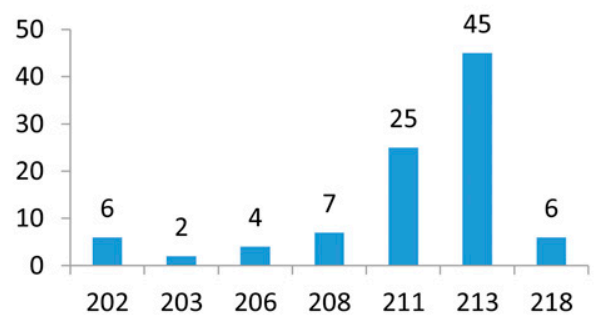

GB544

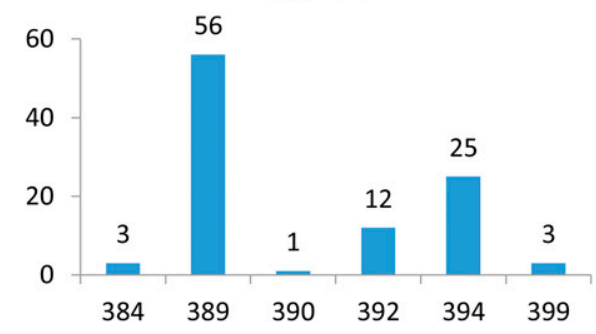

Supplemental Fig. 1. (Continued) 
GB545

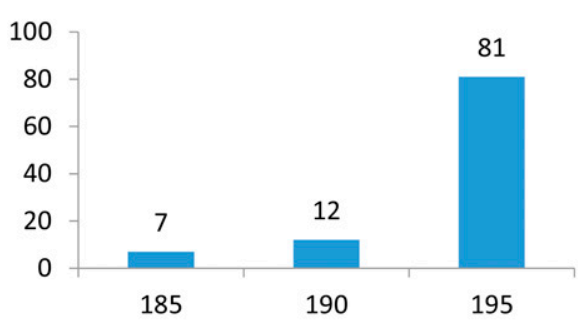

GB551

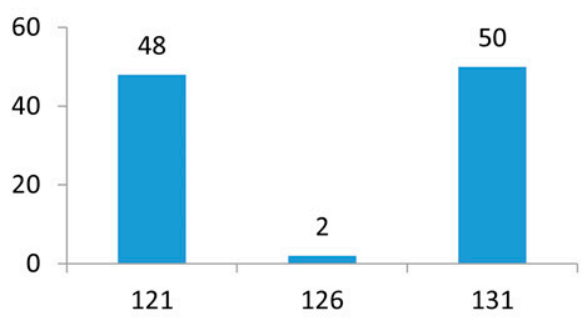

GB563

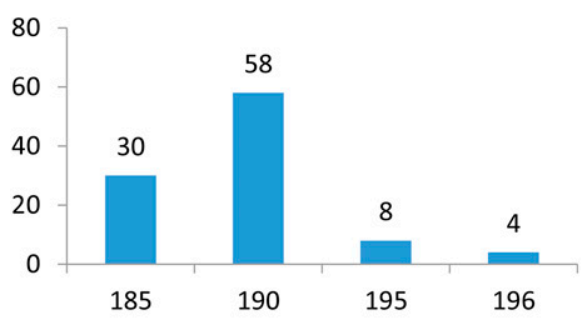

GB568

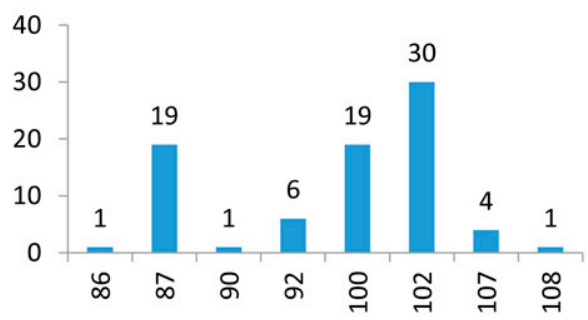

GB548

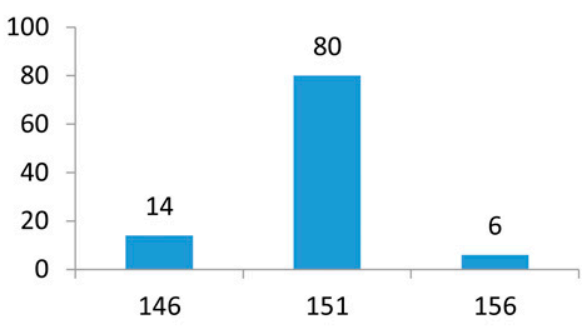

GB560

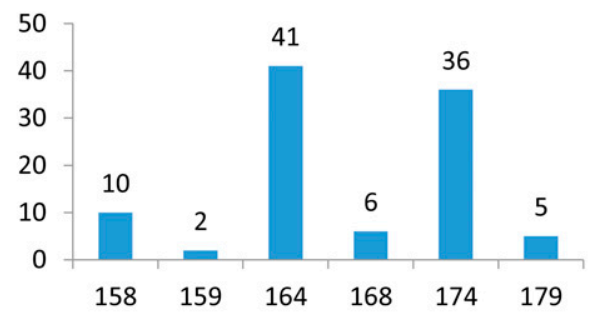

GB565

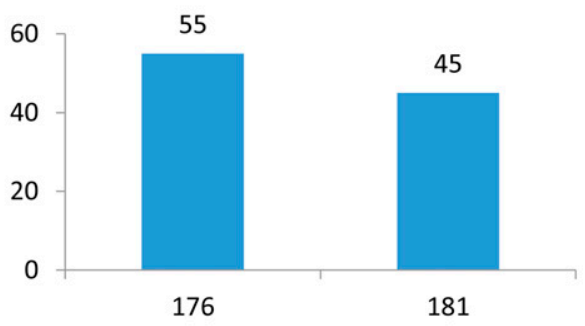

GB577

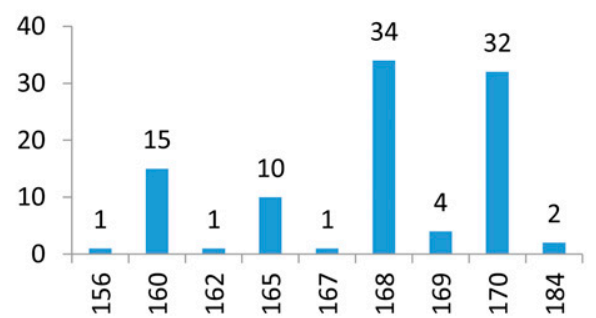

Supplemental Fig. 1. (Continued) 

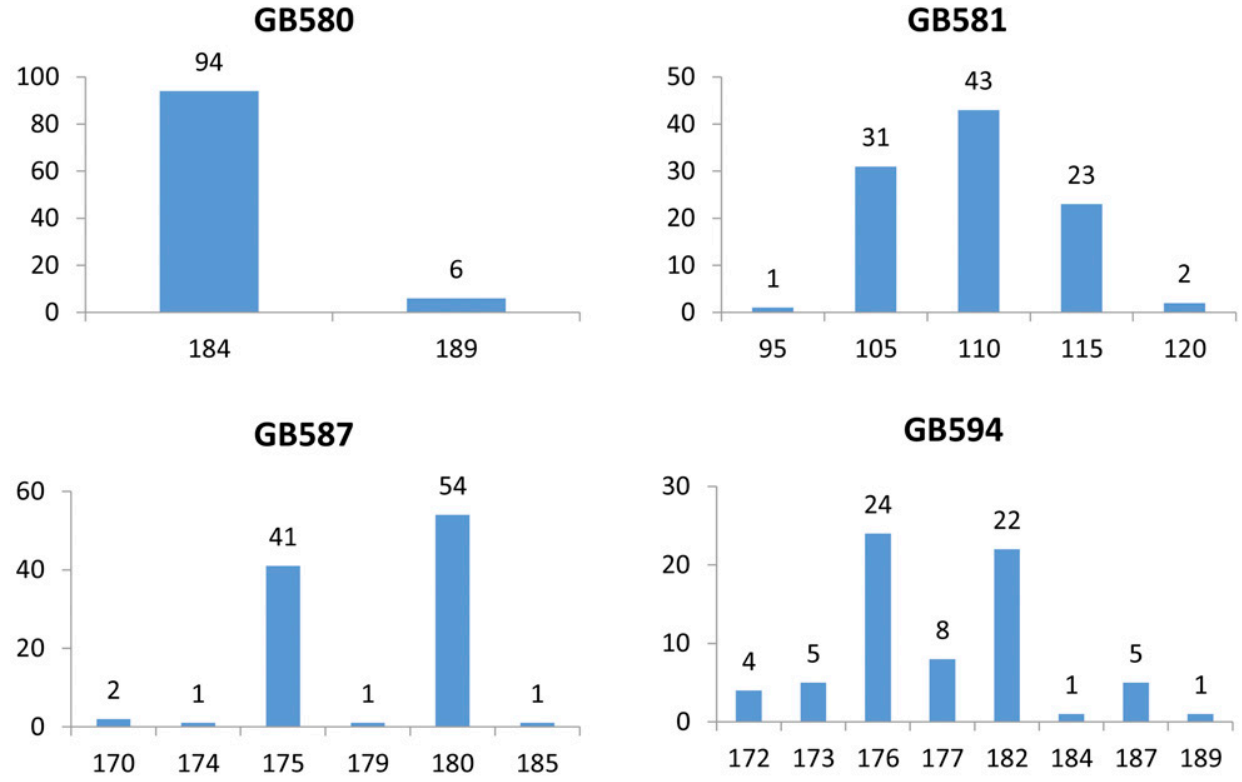

GB601

GB602
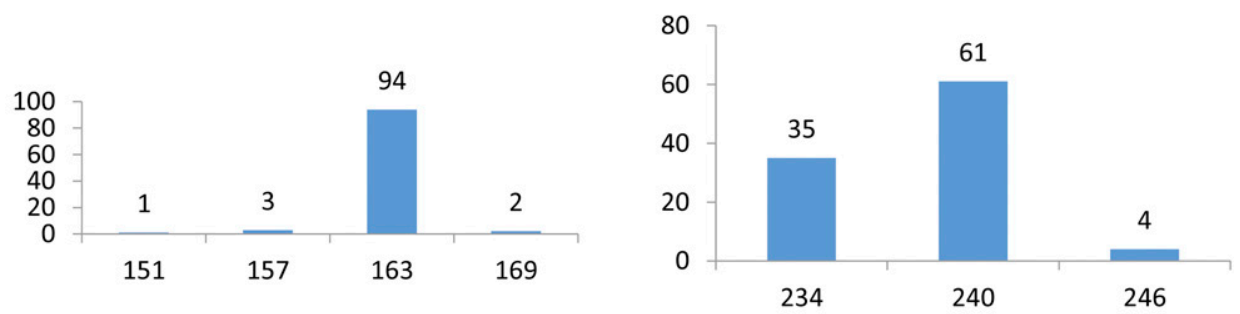

GB603

GB604
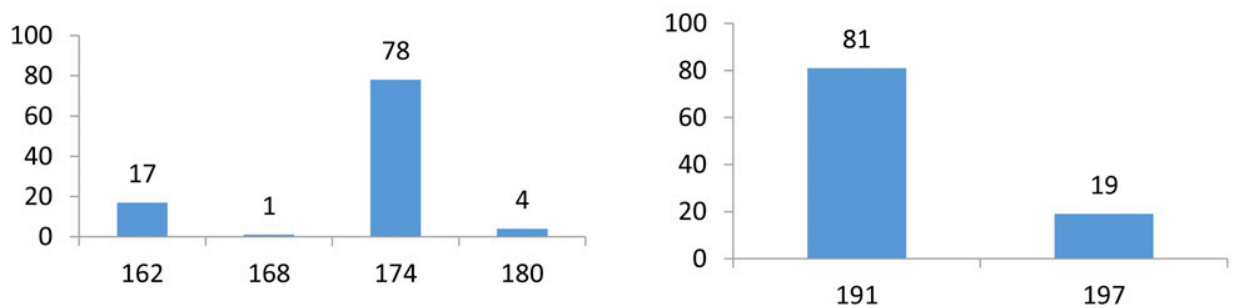

Supplemental Fig. 1. (Continued) 
GB605

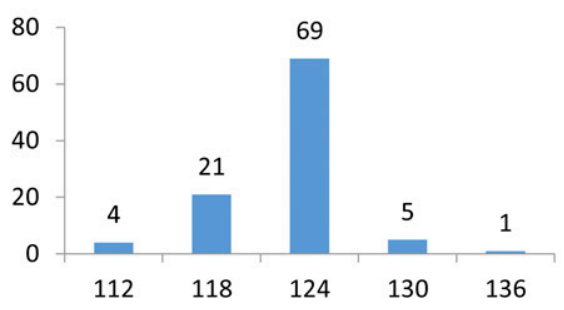

GB609

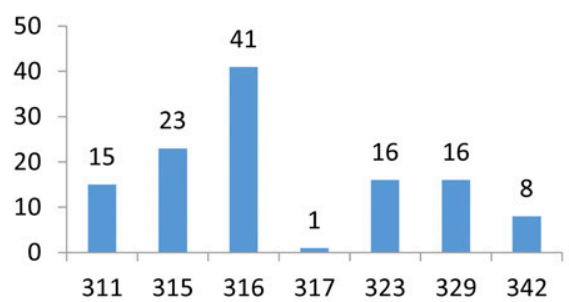

GB613

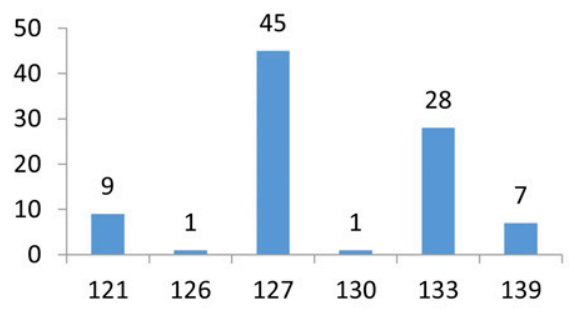

GB615

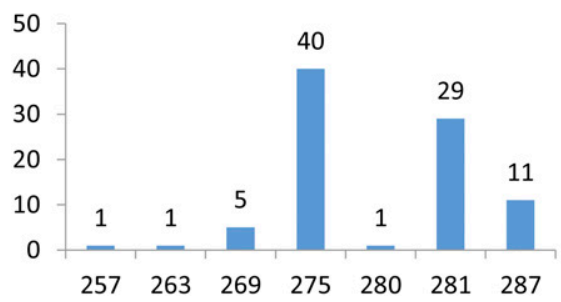

GB606

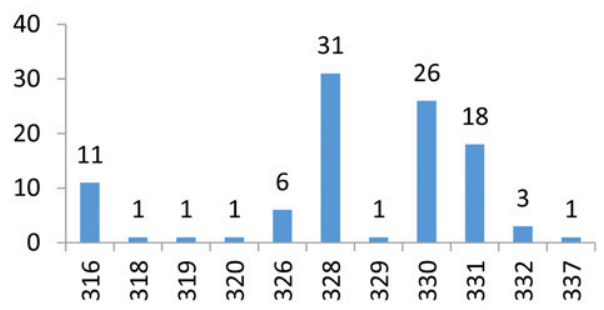

GB610

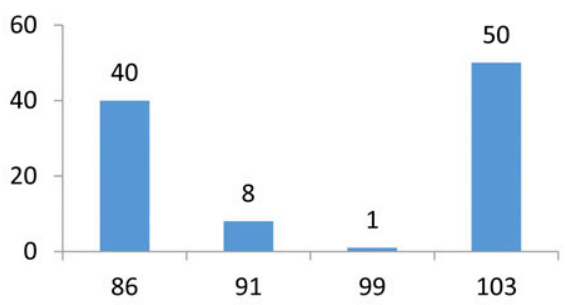

GB614
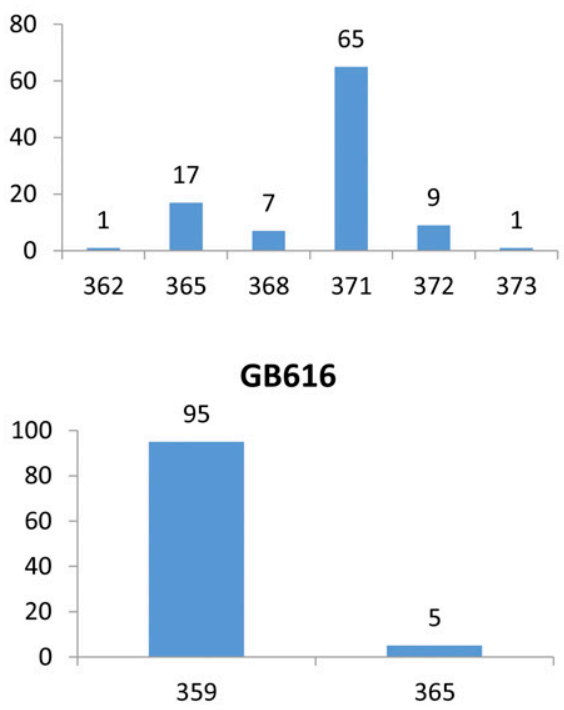

Supplemental Fig. 1. (Continued) 
GB617

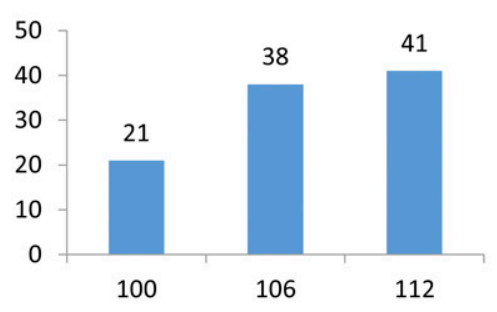

GB619

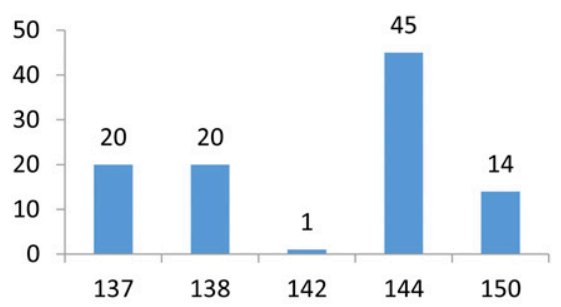

GB621

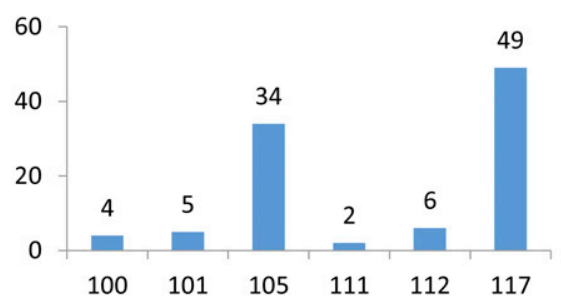

GB623

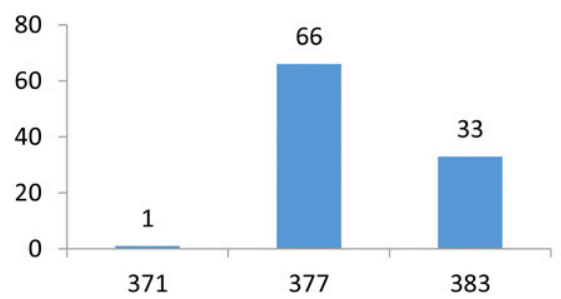

GB618

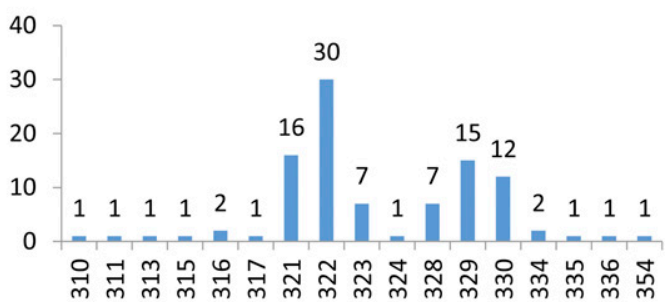

GB620

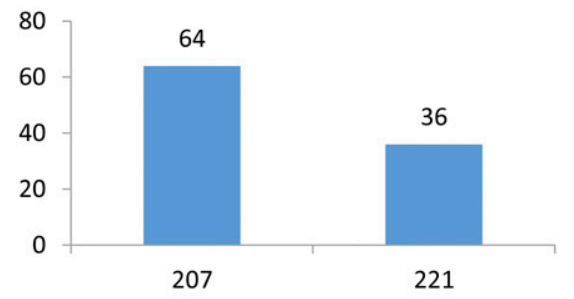

GB622

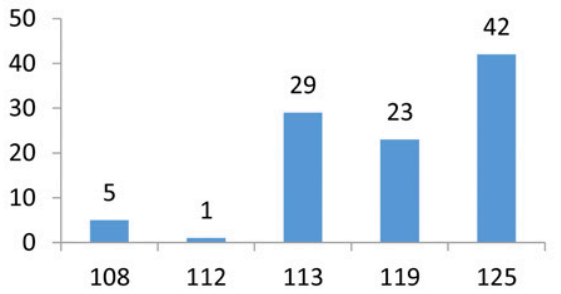

GB624

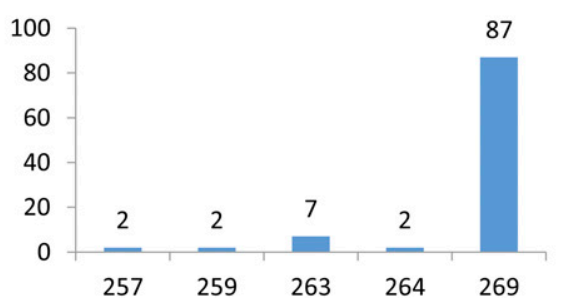

Supplemental Fig. 1. (Continued) 
GB625

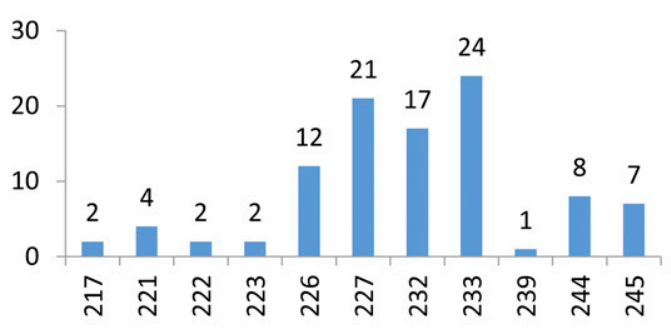

GB627

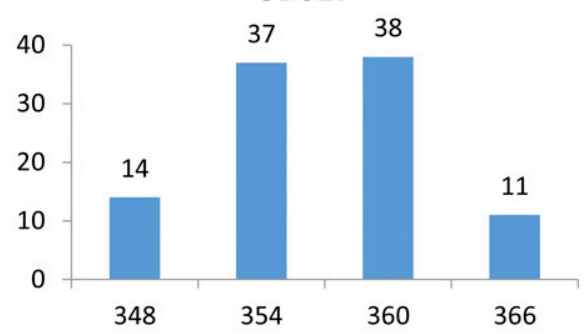

GB631

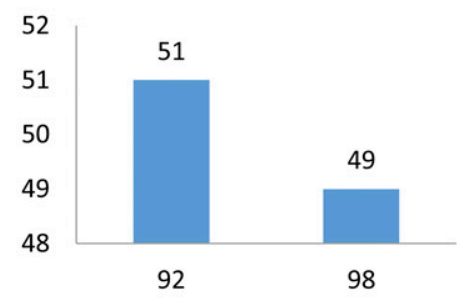

GB634

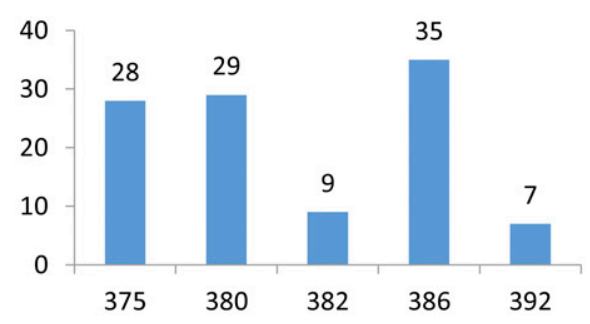

GB626

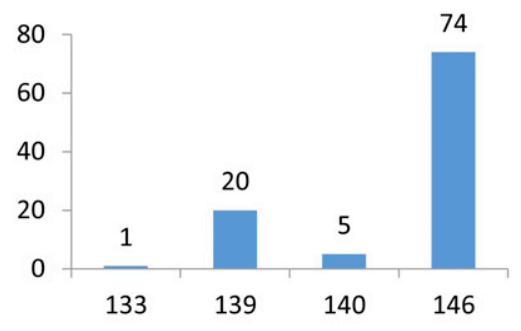

GB628

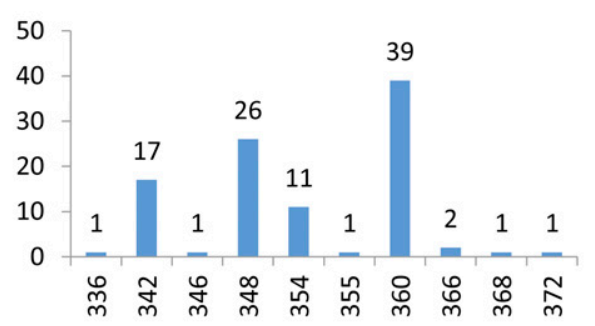

GB633

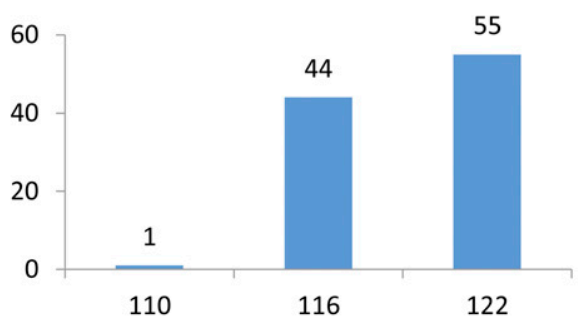

\section{GB635}

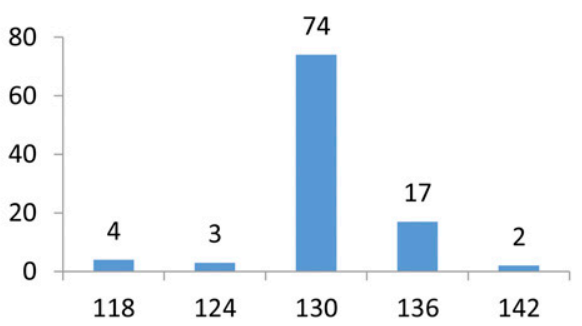

Supplemental Fig. 1. (Continued) 
GB636

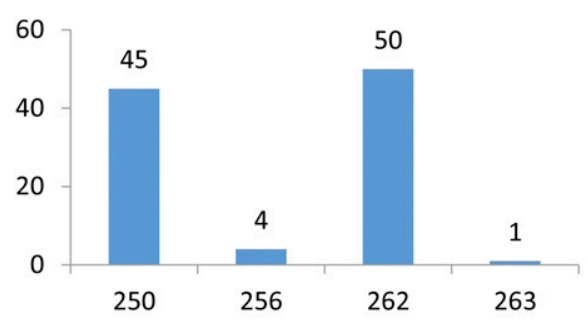

GB639

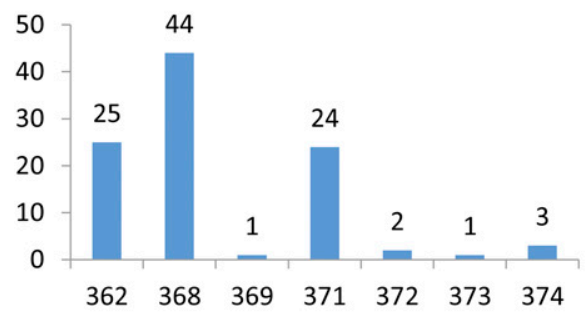

GB641

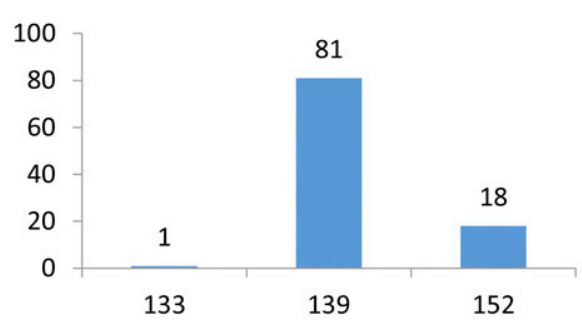

GB643

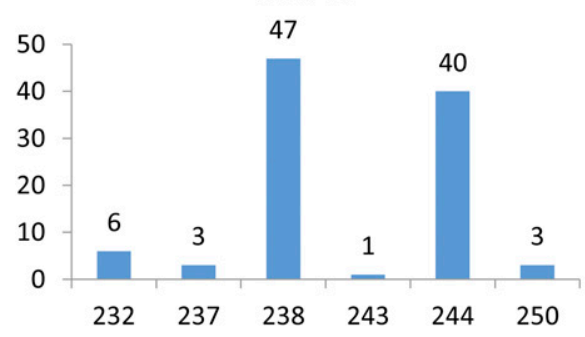

GB638

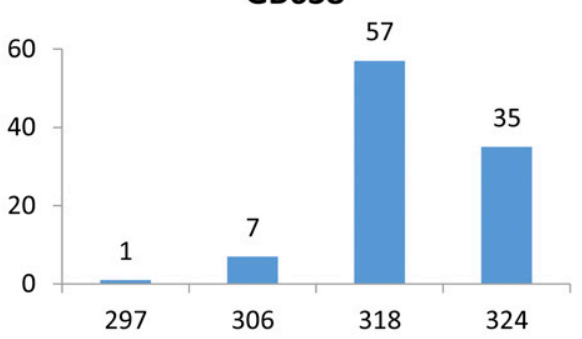

GB640

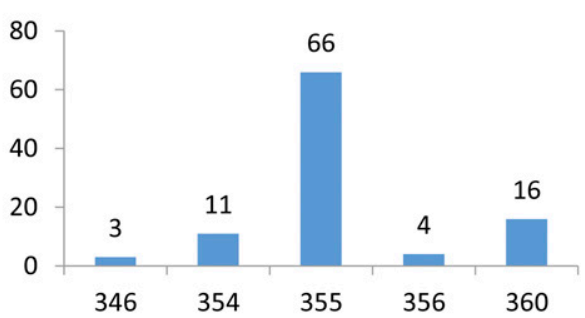

GB642

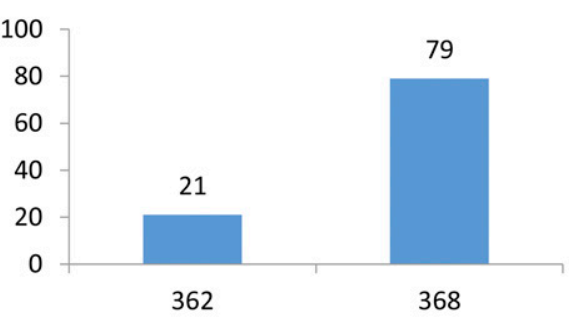

GB644

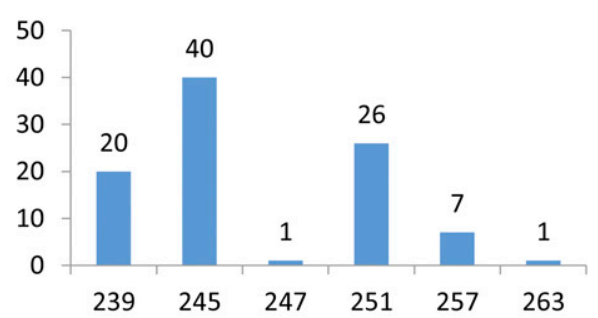

Supplemental Fig. 1. (Continued) 


\section{GB645}

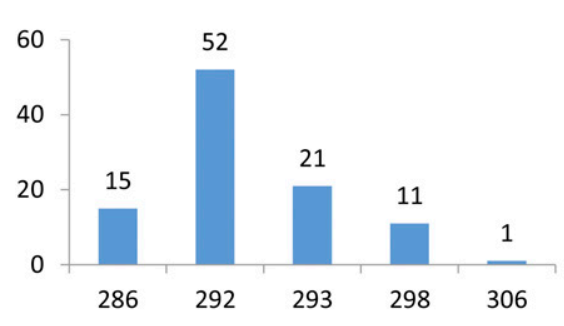

GB647

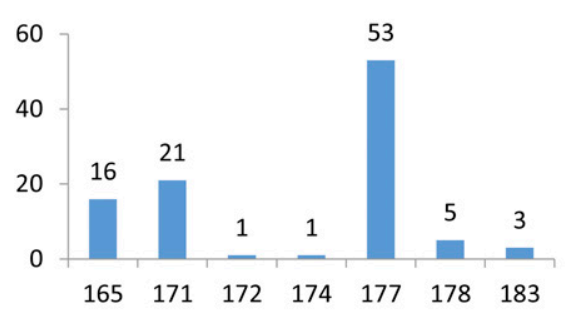

\section{GB649}

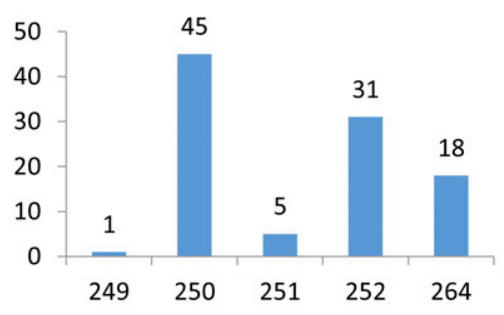

GB652

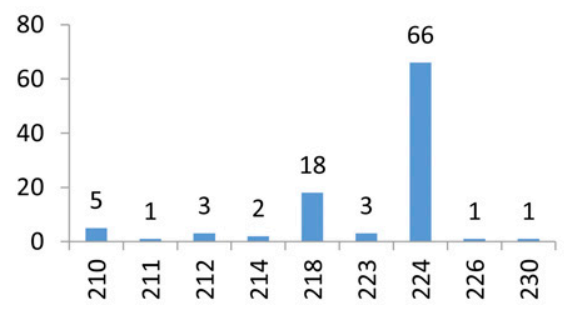

GB646

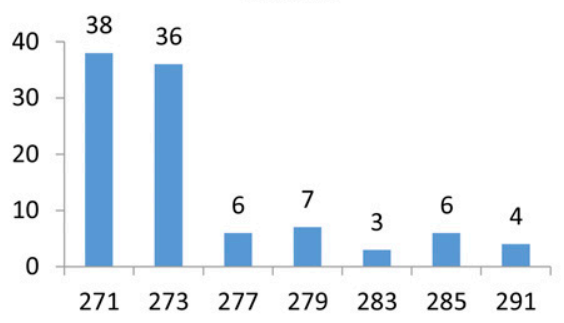

GB648

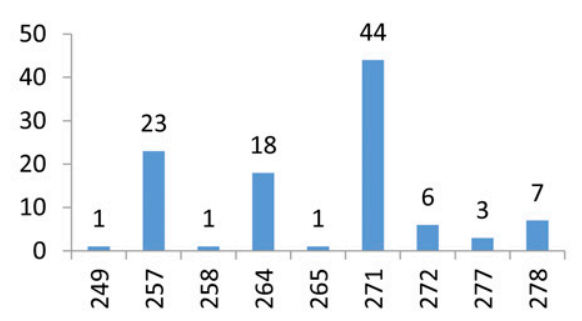

GB650

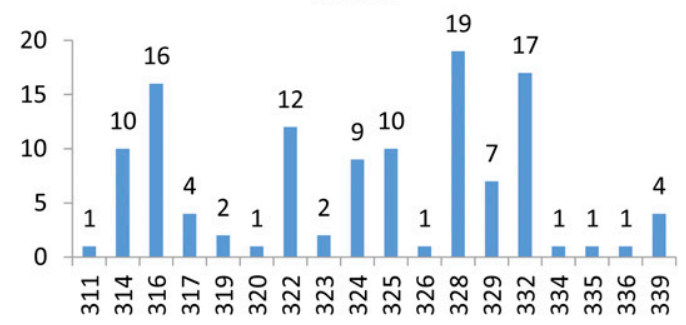

GB653

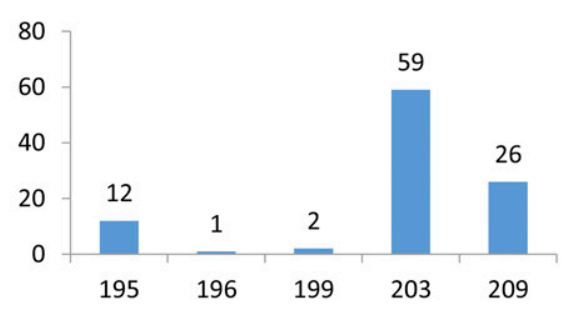

Supplemental Fig. 1. (Continued) 

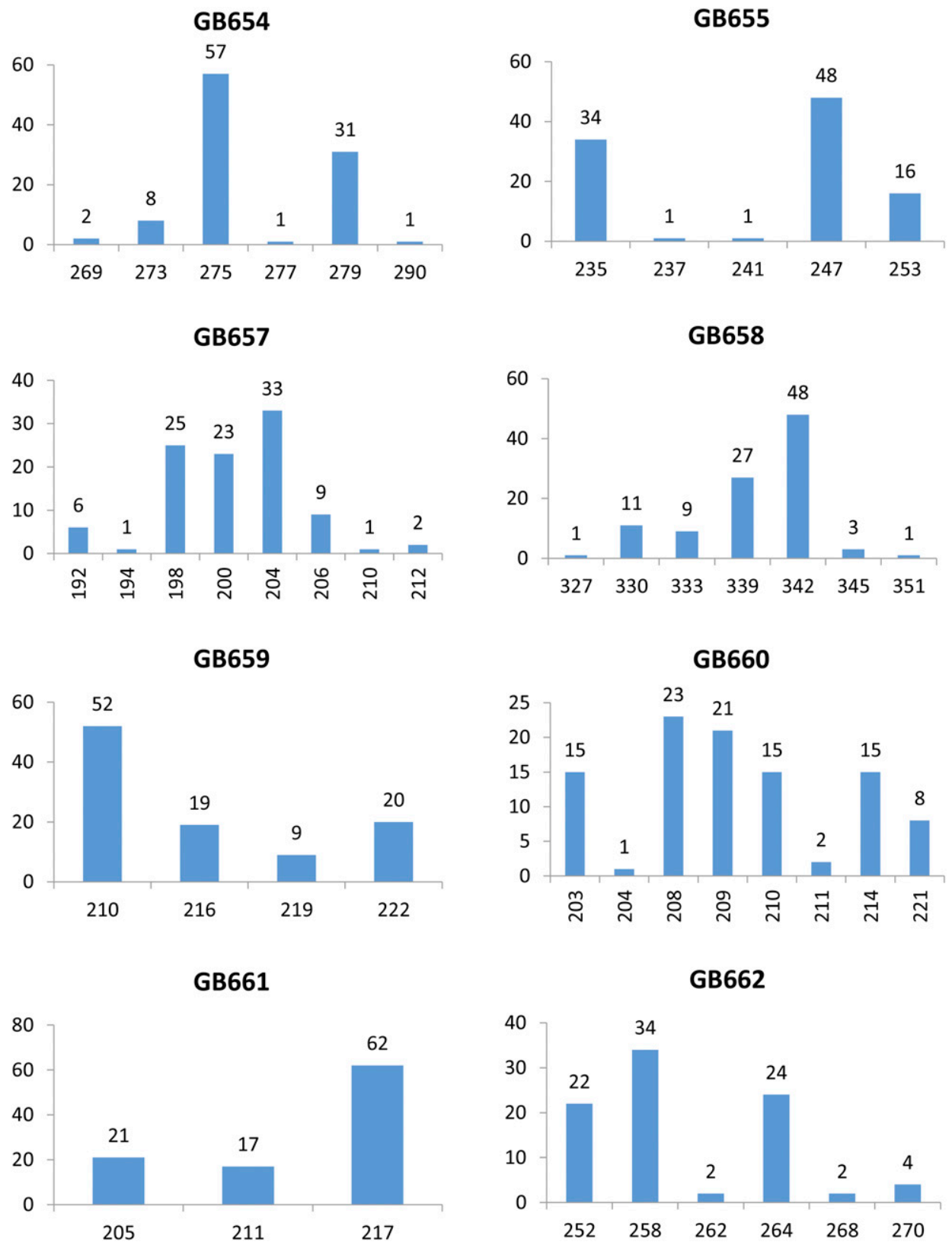

Supplemental Fig. 1. (Continued) 
GB663

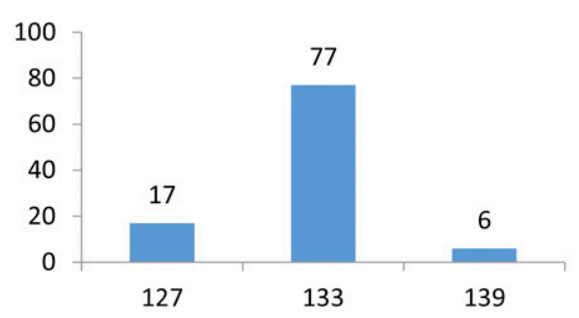

GB665

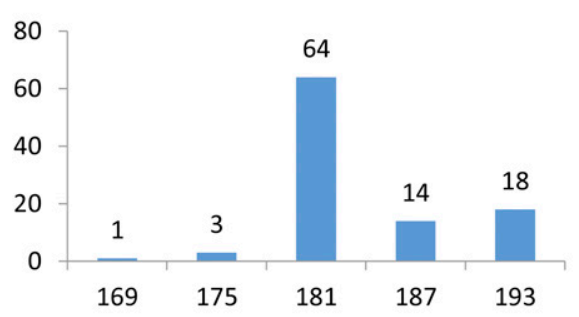

GB668

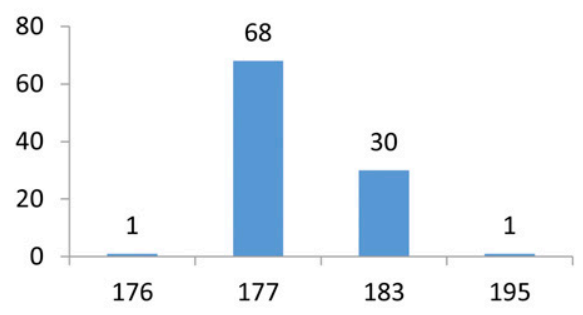

GB670

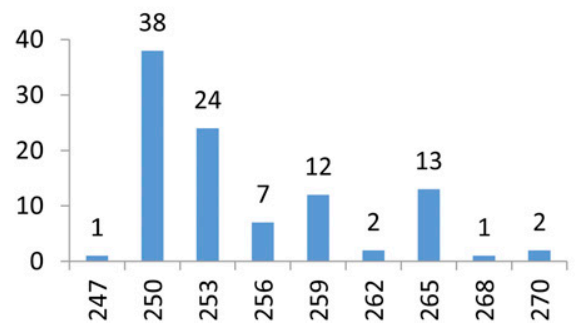

GB664

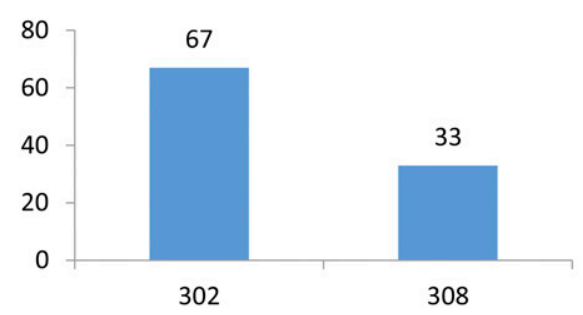

GB666

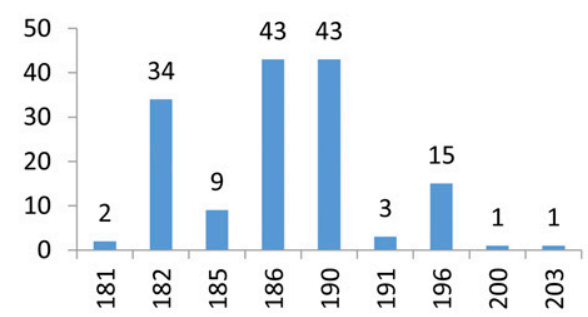

GB669

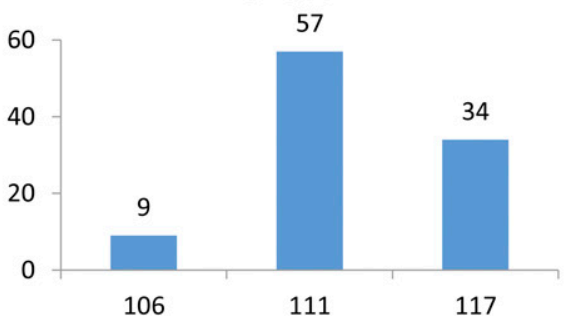

GB671

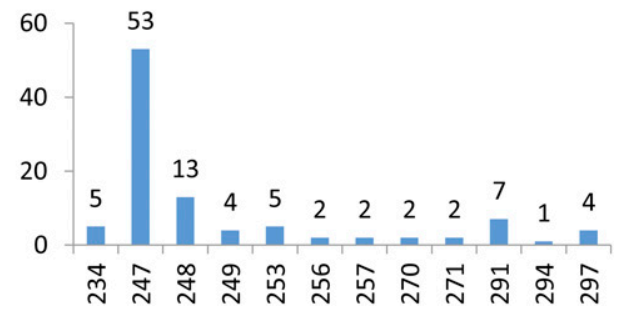

Supplemental Fig. 1. (Continued) 
GB672

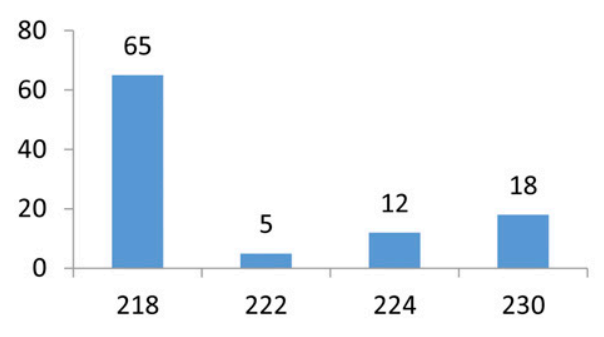

GB674

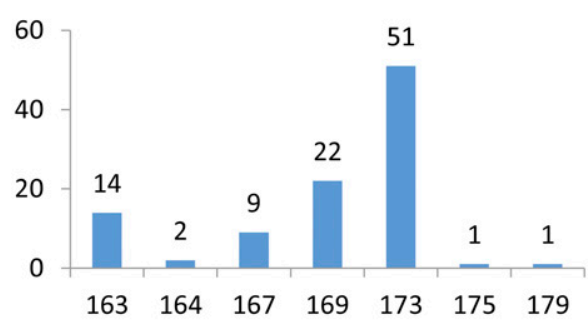

GB676

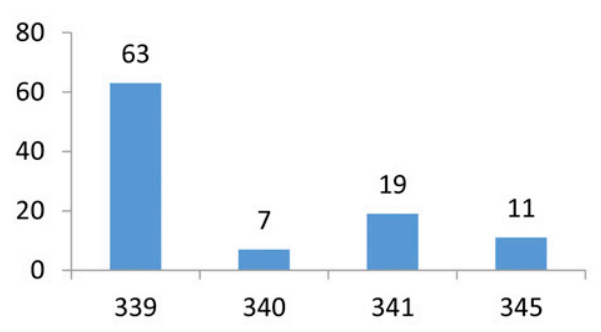

GB702

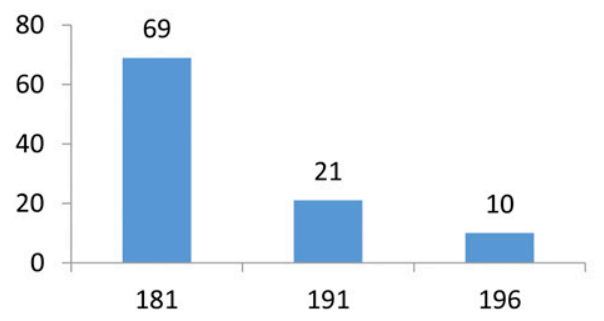

GB673

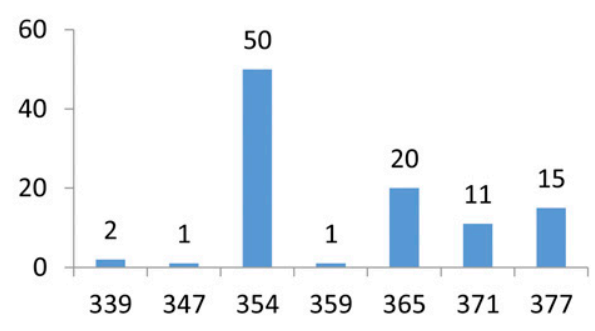

GB675

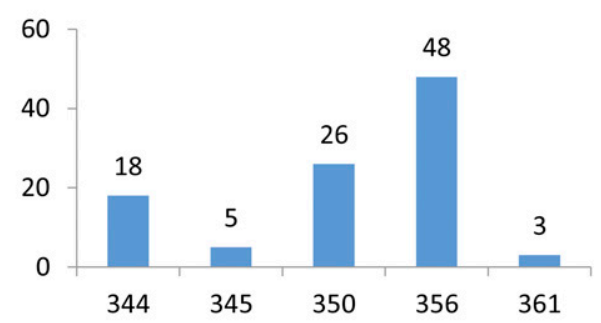

\section{GB678}

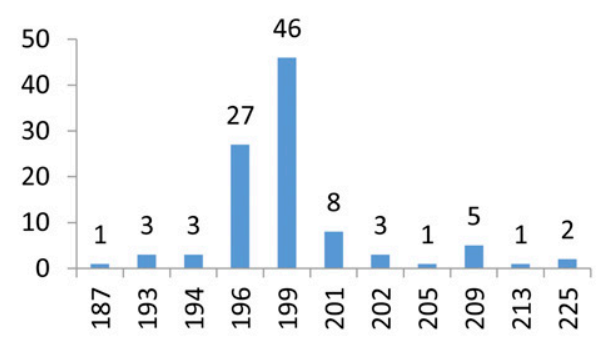

GB704

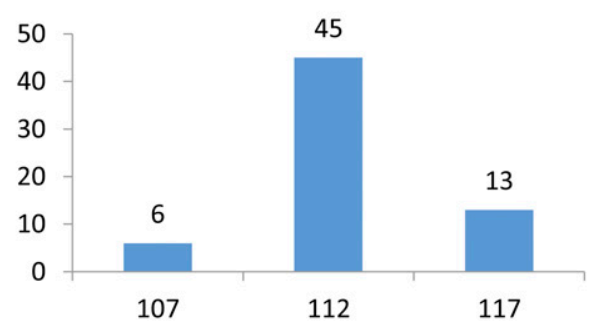

Supplemental Fig. 1. (Continued) 

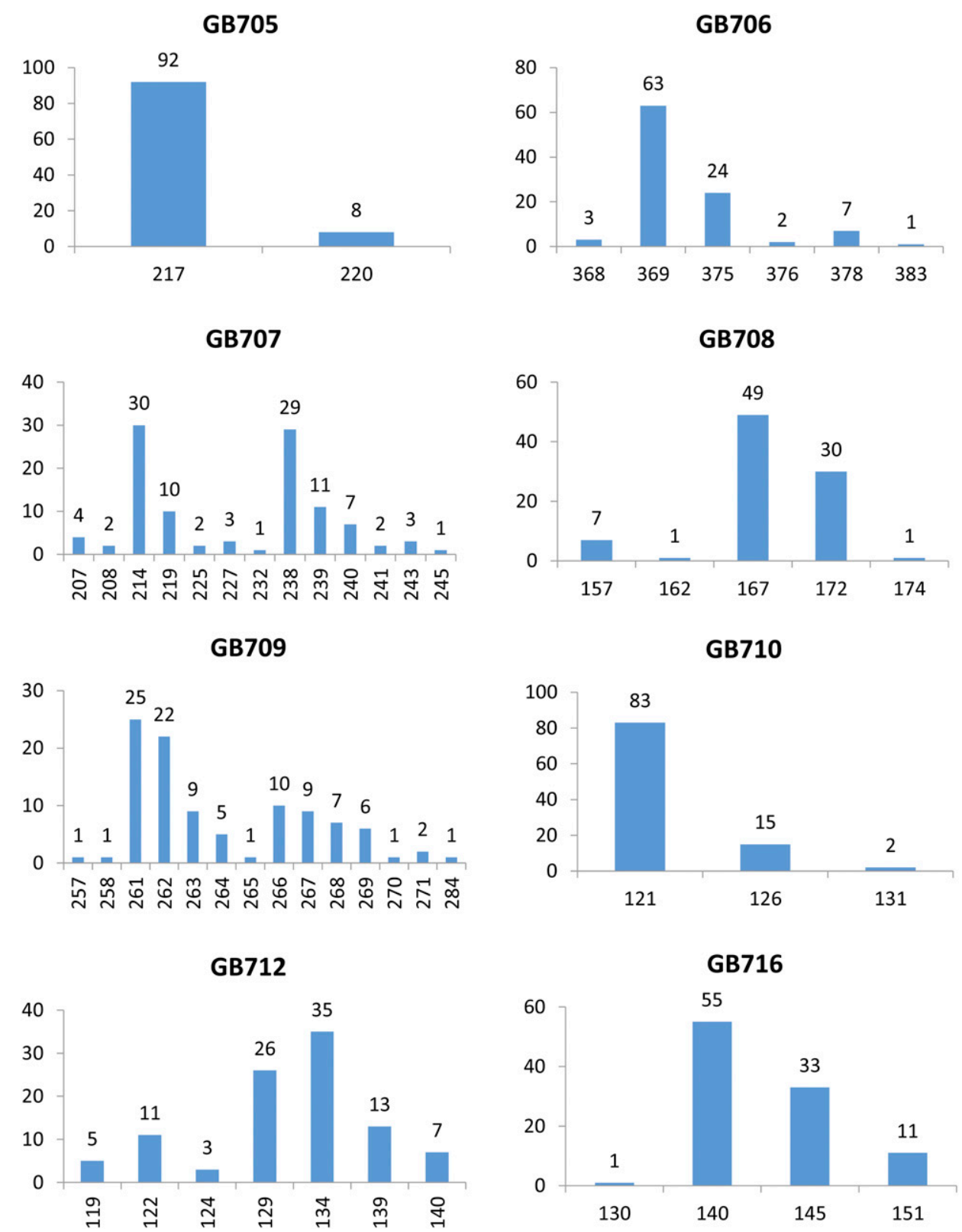

Supplemental Fig. 1. (Continued) 

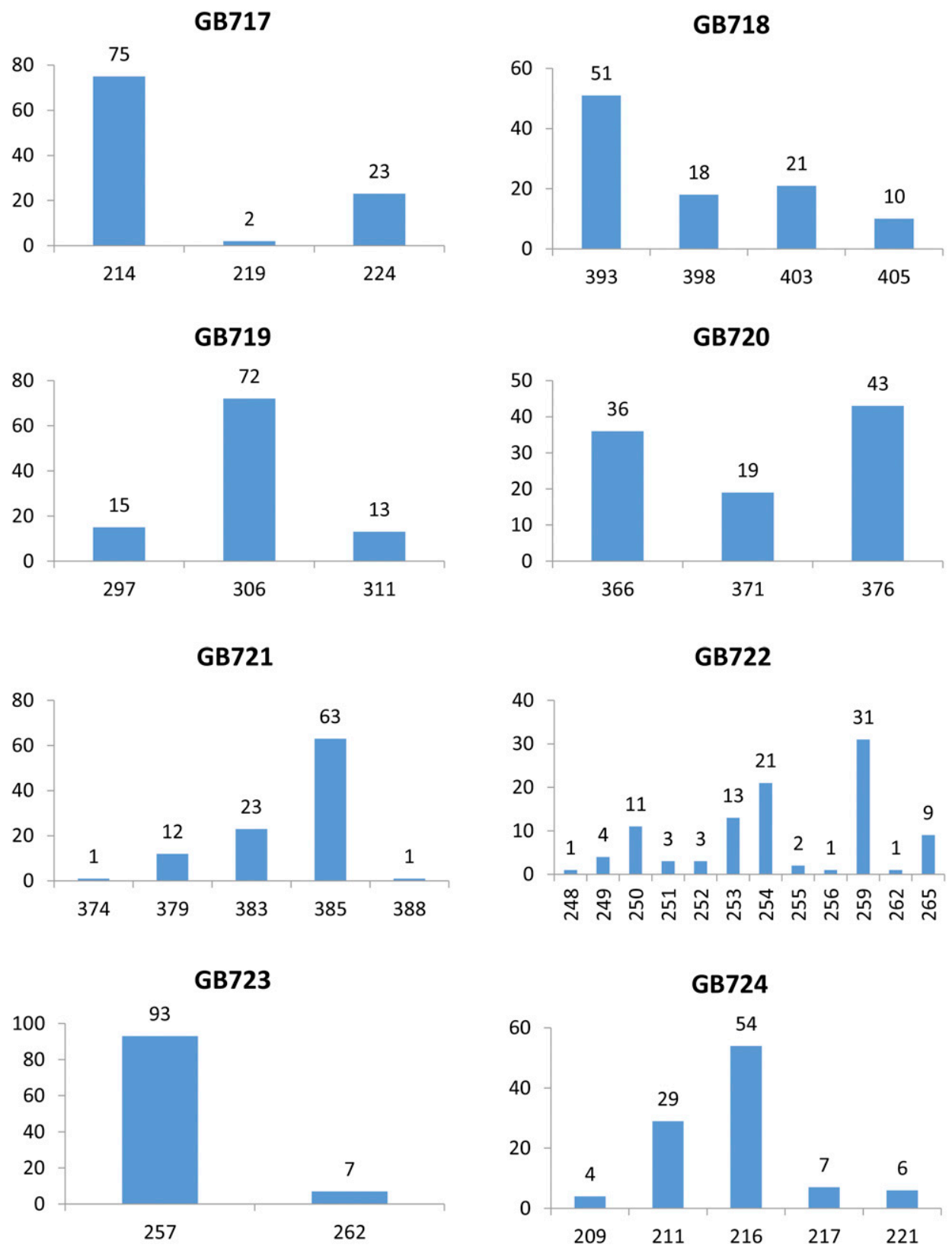

Supplemental Fig. 1. (Continued) 


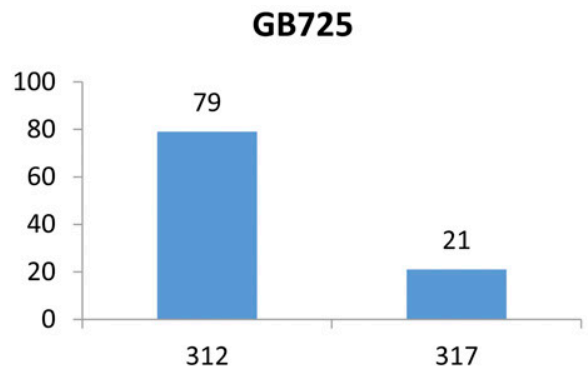

GB726
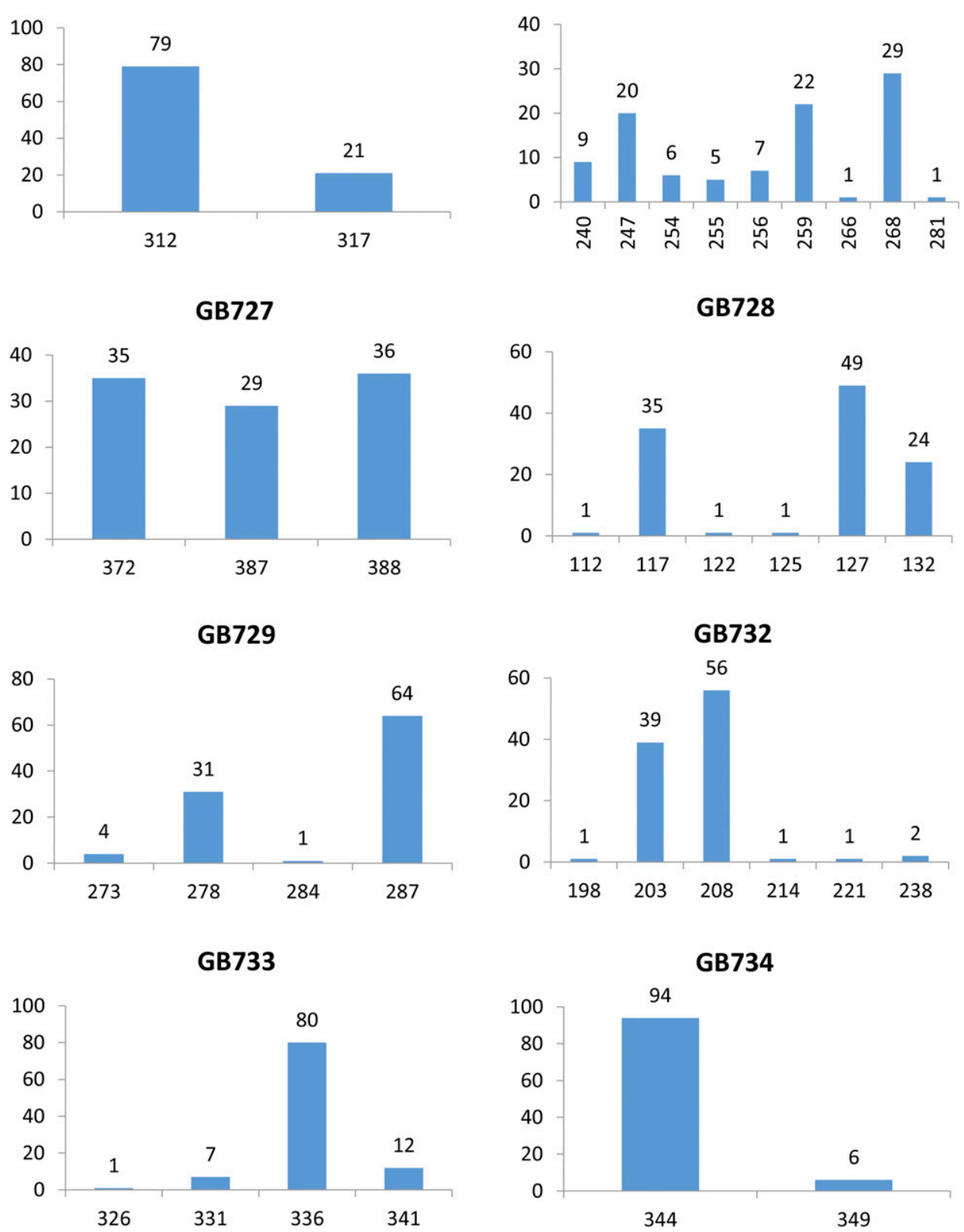

Supplemental Fig. 1. (Continued) 

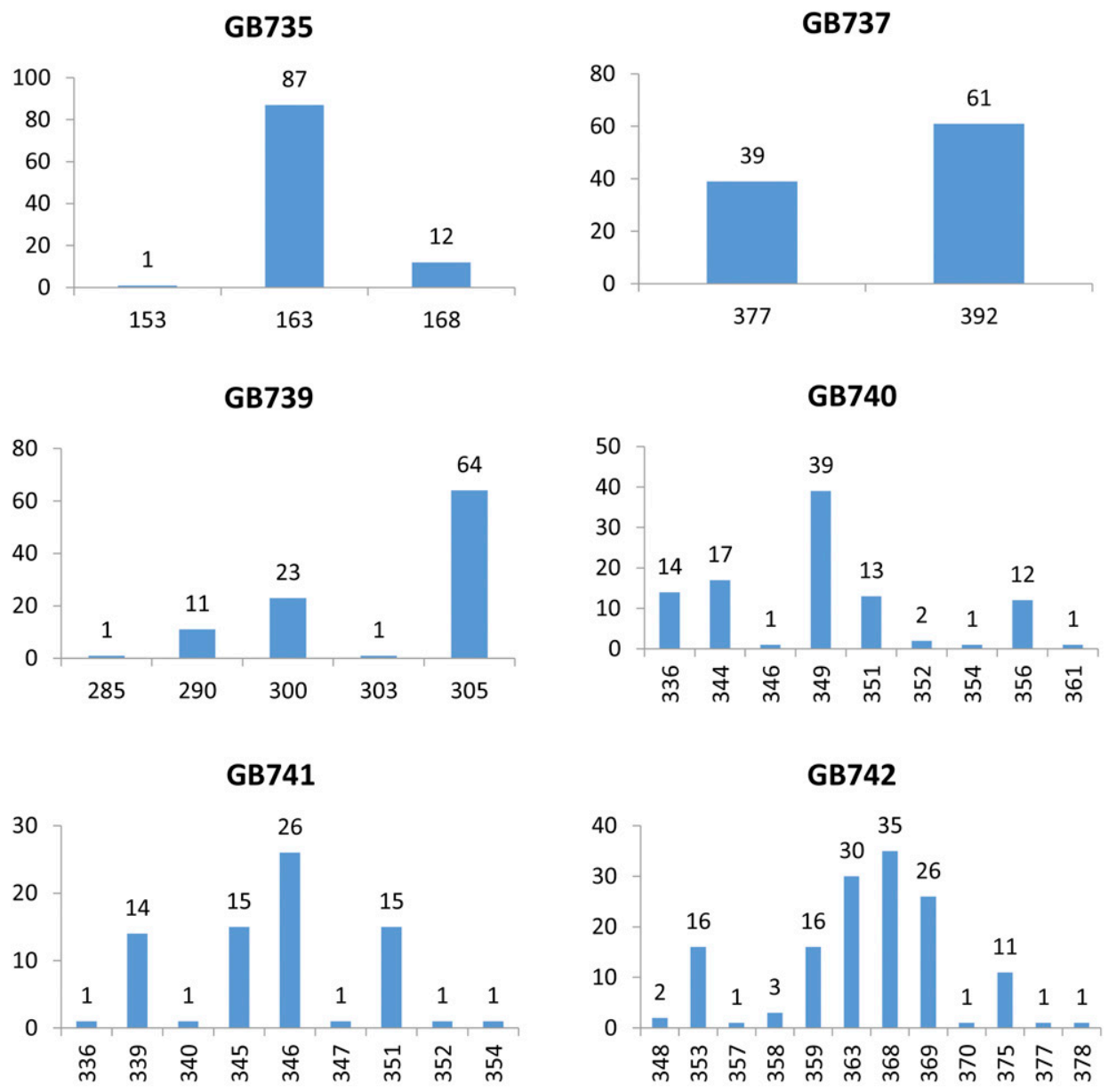

\section{GB743}
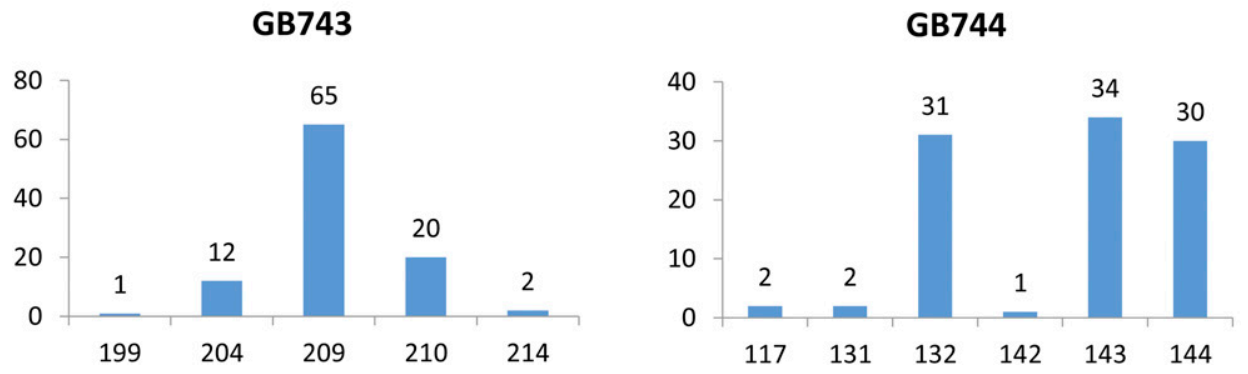

Supplemental Fig. 1. (Continued) 
GB745

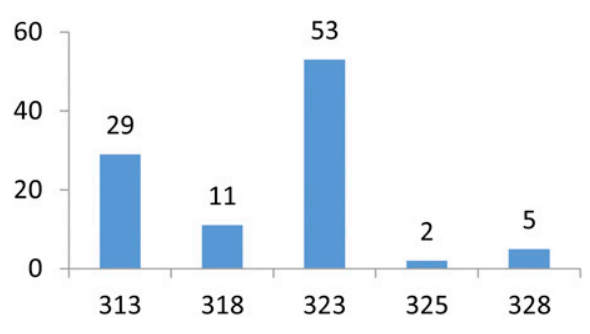

GB747

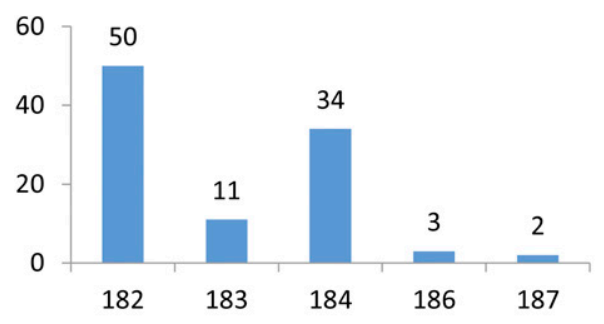

GB749

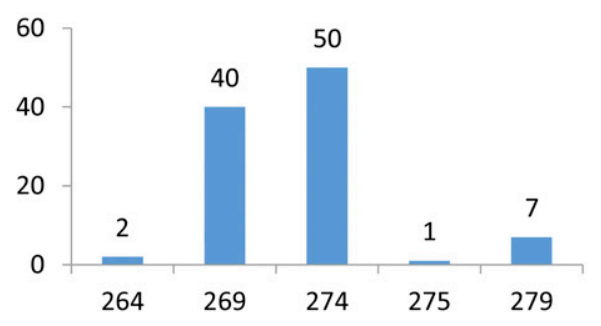

GB751

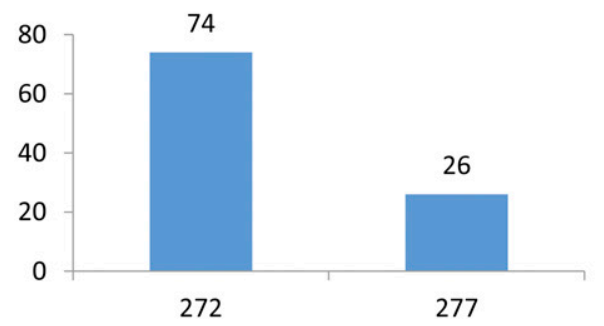

GB746

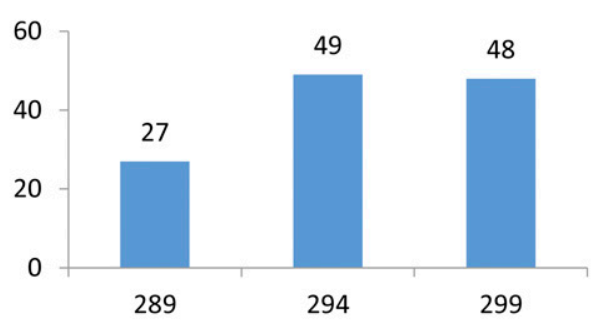

GB748

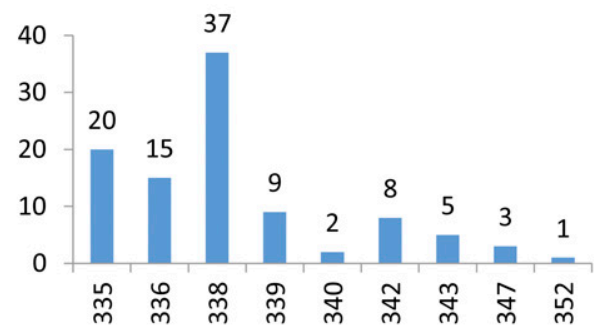

GB750

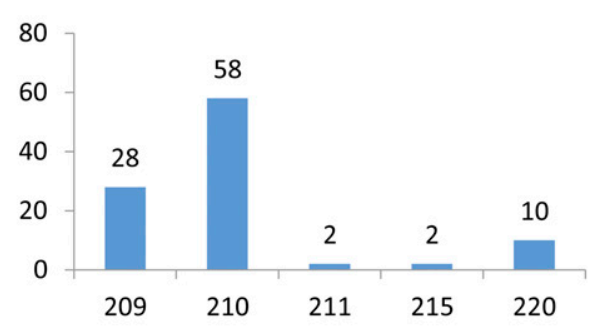

GB752

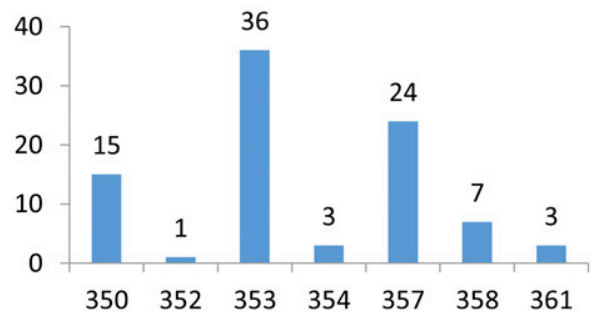

Supplemental Fig. 1. (Continued) 
Supplemental Table 1. Repeat motifs, amplicon size, primer sequences, and annealing temperatures (Tm) of simple sequence repeat markers developed from the 'Jefferson' hazelnut genome sequence.

\begin{tabular}{|c|c|c|c|c|}
\hline Locus & Repeat motif & Size & Primers $\left(5-3^{\prime}\right)$ & $\operatorname{Tm}\left({ }^{\circ} \mathrm{C}\right)$ \\
\hline$\overline{\text { GB401 }}$ & $(\mathrm{AACC})_{4}$ & $183-196$ & $\begin{array}{l}\text { [6FAM] CCTTTTCGCTCATCATATCCA } \\
\text { TTTGTGTGTGGGTGTAGATTCC }\end{array}$ & 60 \\
\hline GB402 & $(\mathrm{ACGC})_{4}(\mathrm{TCCT})_{4}$ & $166-170$ & $\begin{array}{l}\text { [HEX]AGTACGAAAACTGCGTGTCAAA } \\
\text { AACAAACAAAACAAACGCCC }\end{array}$ & 59 \\
\hline GB403 & $(\mathrm{ACGT})_{4}$ & $152-156$ & $\begin{array}{l}\text { [HEX]TAATAAATGGCTCCCGAAGAGA } \\
\text { GGGTTTAGAGAAGCTCCCTCAT }\end{array}$ & 60 \\
\hline GB404 & $(\mathrm{AGCA})_{4}$ & $122-126$ & $\begin{array}{l}\text { [6FAM]AGAGGGCTCGGCTCTACATAA } \\
\text { CTCGATCTCATCCTTGCTTGTT }\end{array}$ & 60 \\
\hline GB405 & $(\mathrm{AGCT})_{4}$ & $173-177$ & $\begin{array}{l}\text { [HEX]GGCCCTATAAATACCTTCTTCTCC } \\
\text { СТСТСТСТСТСТСТСТСТCAAGCC }\end{array}$ & 59 \\
\hline GB407 & $(\mathrm{AGGG})_{5}$ & $175-191$ & $\begin{array}{l}\text { [HEX]CACAGCCTTCTTCCATCTCTTT } \\
\text { TGCTCTCTTTTCTTTCCTCTGC }\end{array}$ & 59 \\
\hline GB408 & $(\mathrm{AGTG})_{5}$ & $158-166$ & $\begin{array}{l}\text { [HEX]AGATCAGCTAGAAGCAATTCGG } \\
\text { TTGGATAACTTGGGGCTGTTT }\end{array}$ & 60 \\
\hline GB409 & $(\mathrm{ATCC})_{4}$ & $157-161$ & $\begin{array}{l}\text { [HEX]TCTCCTCCCCTCTCATCCTT } \\
\text { AACGGCTGAAAAGAATAGCATC }\end{array}$ & 60 \\
\hline GB410 & $(\mathrm{ATCC})_{4} \mathrm{AG}(\mathrm{CCAT})_{4}$ & $157-173$ & $\begin{array}{l}\text { [HEX]CCTCTACTATCTAGGAAGCCCCA } \\
\text { ACTTTGGCCTTTTGGACTTTG }\end{array}$ & 60 \\
\hline GB413 & $(\mathrm{CCAG})_{4}$ & $187-197$ & $\begin{array}{l}\text { [6FAM]CTGCTTCATGTGGAAATGTTGT } \\
\text { ACATAGGGTAGAGCTGTGGAGC }\end{array}$ & 60 \\
\hline GB414 & $(\mathrm{CCAT})_{6}$ & $106-118$ & $\begin{array}{l}\text { [6FAM]CAAGAGAGAGGGATGGTACGTT } \\
\text { AGAGGAAGAGGATTGATGGATG }\end{array}$ & 59 \\
\hline GB416 & $(\mathrm{CCTC})_{5}$ & $239-257$ & $\begin{array}{l}\text { [NED]ACCGTATGCTGATTTGTATGGG } \\
\text { CTGTGTTCCTCTTTTCCTCCAC }\end{array}$ & 60 \\
\hline GB417 & $(\mathrm{CTAG})_{4}$ & $174-178$ & $\begin{array}{l}\text { [6FAM]TACTGTGAAATGTGGTCACTGC } \\
\text { ATGTTGCAGAATTGAAGGAAAA }\end{array}$ & 59 \\
\hline GB418 & $(\mathrm{CTAG})_{5}$ & $205-217$ & $\begin{array}{l}\text { [6FAM]TATTGGAGCCACAGAAGACGTA } \\
\text { GAAGCGCACTGGAGTTTATTTT }\end{array}$ & 59 \\
\hline GB420 & $(\mathrm{CTAG})_{7}$ & $211-227$ & $\begin{array}{l}\text { [NED]CAATAGGTGTAGATGACGTGGC } \\
\text { AACGAGTTTAAGCAACAATCCC }\end{array}$ & 59 \\
\hline GB421 & $(\mathrm{CTGC})_{4}$ & $230-232$ & $\begin{array}{l}\text { [NED]AGAGACCGCCATCATTCTAAAG } \\
\text { ATTAAGATCACAACTGGCTGGG }\end{array}$ & 59 \\
\hline GB422 & $(\mathrm{CTTC})_{4}$ & $221-237$ & $\begin{array}{l}\text { [6FAM]CTCTCTCCTTGGCACTCACAC } \\
\text { CTTTGATGGGTTTTGCTCTTCT }\end{array}$ & 60 \\
\hline GB423 & $(\mathrm{GAGC})_{5}$ & $285-297$ & $\begin{array}{l}\text { [6FAM]GTCAAAGCTGAGGAATGGTTTT } \\
\text { TCGGTTGTCACTTGGTCAATTA }\end{array}$ & 59 \\
\hline GB424 & $(\mathrm{GATA})_{5}$ & $278-286$ & $\begin{array}{l}\text { [6FAM]ATCACCTCACATGACACACCTC } \\
\text { GCTGAAGAGCCATAAACAGACC }\end{array}$ & 59 \\
\hline GB425 & $(\mathrm{GATG})_{4}$ & $295-299$ & $\begin{array}{l}\text { [6FAM]CTTAGGTTTACGTGGCTGTTCC } \\
\text { TCCGAGGTGTGATGTTAAGAAA }\end{array}$ & 60 \\
\hline GB426 & $(\mathrm{GCCT})_{6}$ & $285-300$ & $\begin{array}{l}\text { [6FAM]AAACTGGAAGAGAAAGTGCGAG } \\
\text { GAACTGACCTGGCTTGAGTCTT }\end{array}$ & 60 \\
\hline GB427 & $(\mathrm{GCTA})_{4}$ & 199-203 & $\begin{array}{l}\text { [6FAM]TTCTTCTTCTTCTTCAAACGCC } \\
\text { TAAAAGCGTGGCAGTAAATCCT }\end{array}$ & 60 \\
\hline GB428 & $(\mathrm{GCTA})_{5}$ & $240-244$ & $\begin{array}{l}\text { [NED]TGATCTGTGTAAGGGAAAGAAGC } \\
\text { TAATGGACCCAAAGAAACCAAC }\end{array}$ & 59 \\
\hline GB429 & $(\mathrm{GCTA})_{6}$ & $241-265$ & $\begin{array}{l}\text { [NED]TCCTTCCTCCAAACATCTTGA } \\
\text { TCTAATCCATCCACAATGGTTC }\end{array}$ & 59 \\
\hline GB430 & $(\text { GGAT })_{4}$ & $292-304$ & $\begin{array}{l}\text { [6FAM]CTGAGCAAGCCAATAAAGCAT } \\
\text { ATCCGGTTCTTCCACAATACAT }\end{array}$ & 59 \\
\hline GB431 & $(\mathrm{GGCA})_{4}$ & $368-379$ & $\begin{array}{l}\text { [6FAM]TCATAGCAAAGGGAATCATCAC } \\
\text { GTTTATTGTGGTGTGGGTTCTG }\end{array}$ & 59 \\
\hline GB432 & $(\text { GGGA })_{5}$ & $312-321$ & $\begin{array}{l}\text { [HEX]AAACAAGGGAAATCGTGCC } \\
\text { AGGATGAGCTGTGAAAGAAAGG }\end{array}$ & 59 \\
\hline GB433 & $(\mathrm{GGTT})_{5}$ & $147-152$ & $\begin{array}{l}\text { [6FAM]GTCAAACCGTGGTAAAGGAAAA } \\
\text { AGAAACCCGAACCTAACCTAGC }\end{array}$ & 60 \\
\hline
\end{tabular}


Supplemental Table 1. Continued.

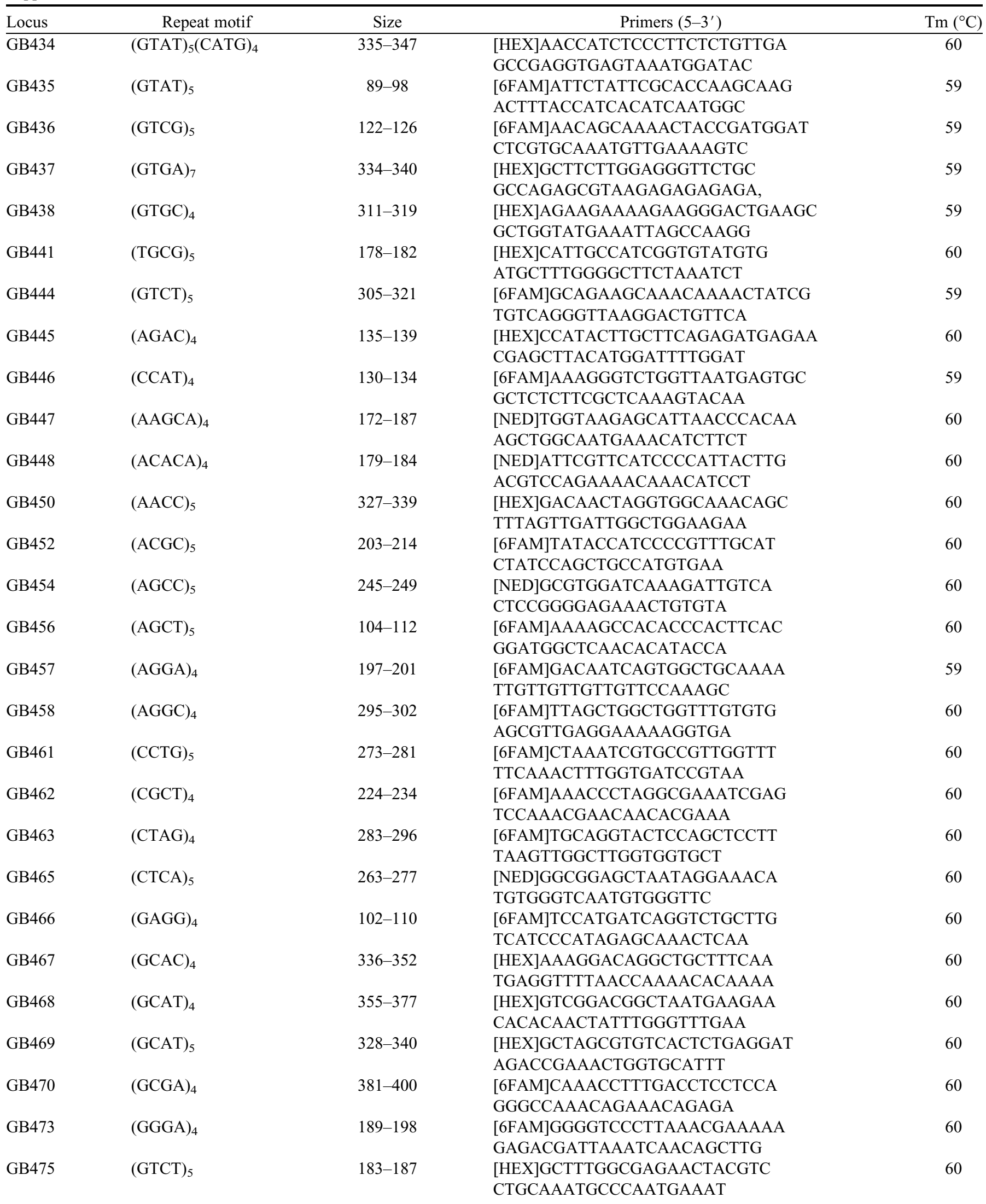


Supplemental Table 1. Continued.

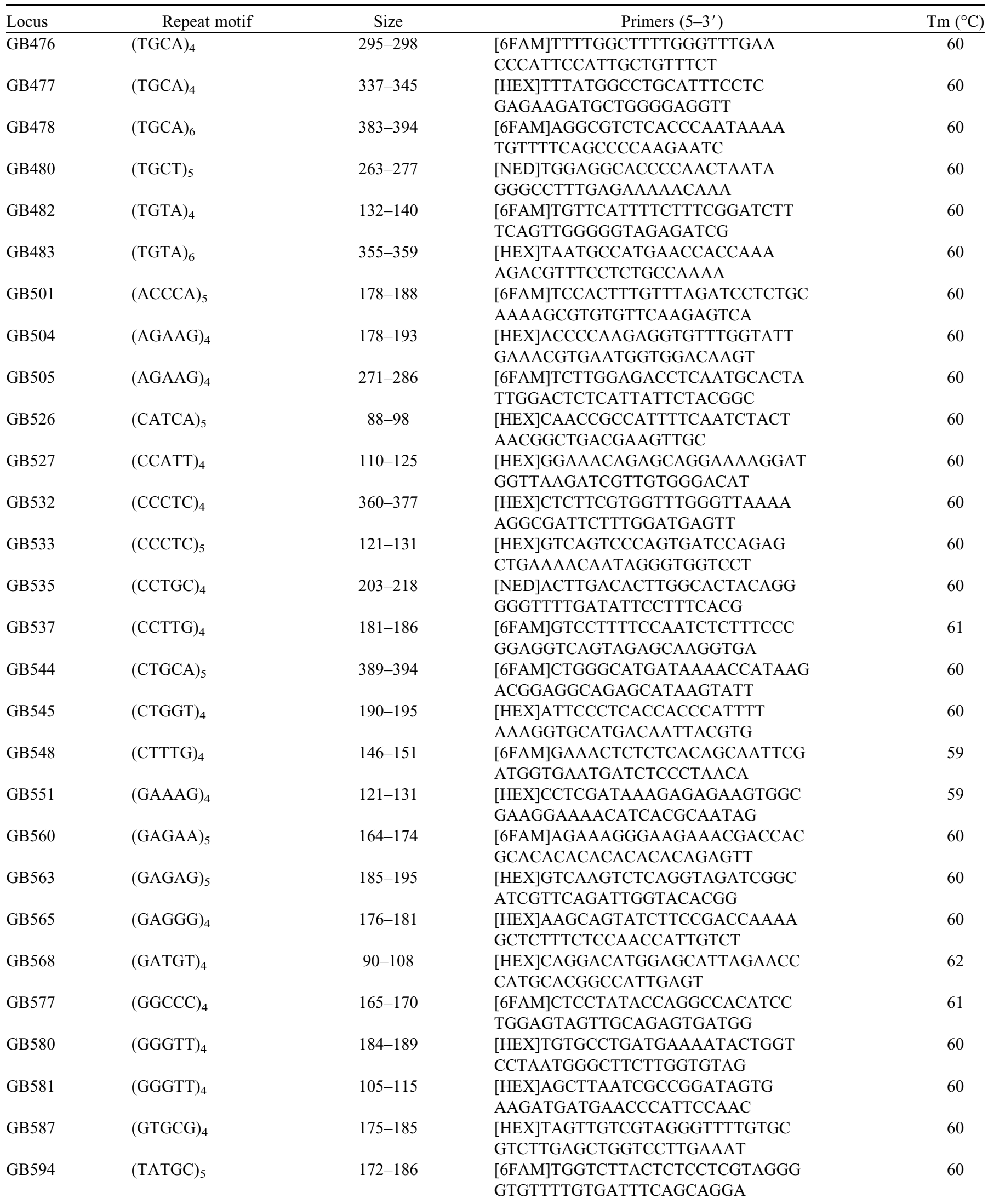


Supplemental Table 1. Continued.

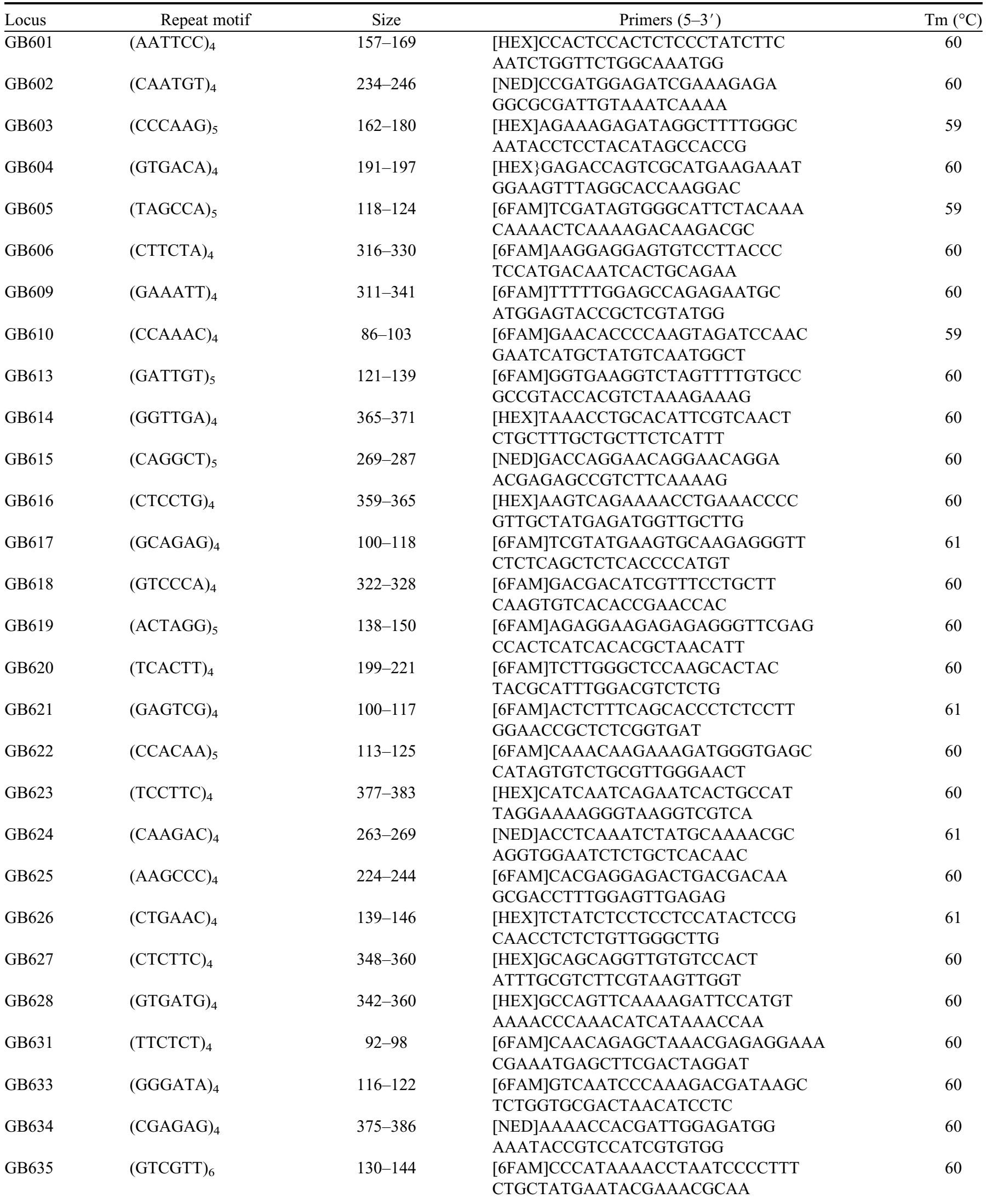


Supplemental Table 1. Continued.

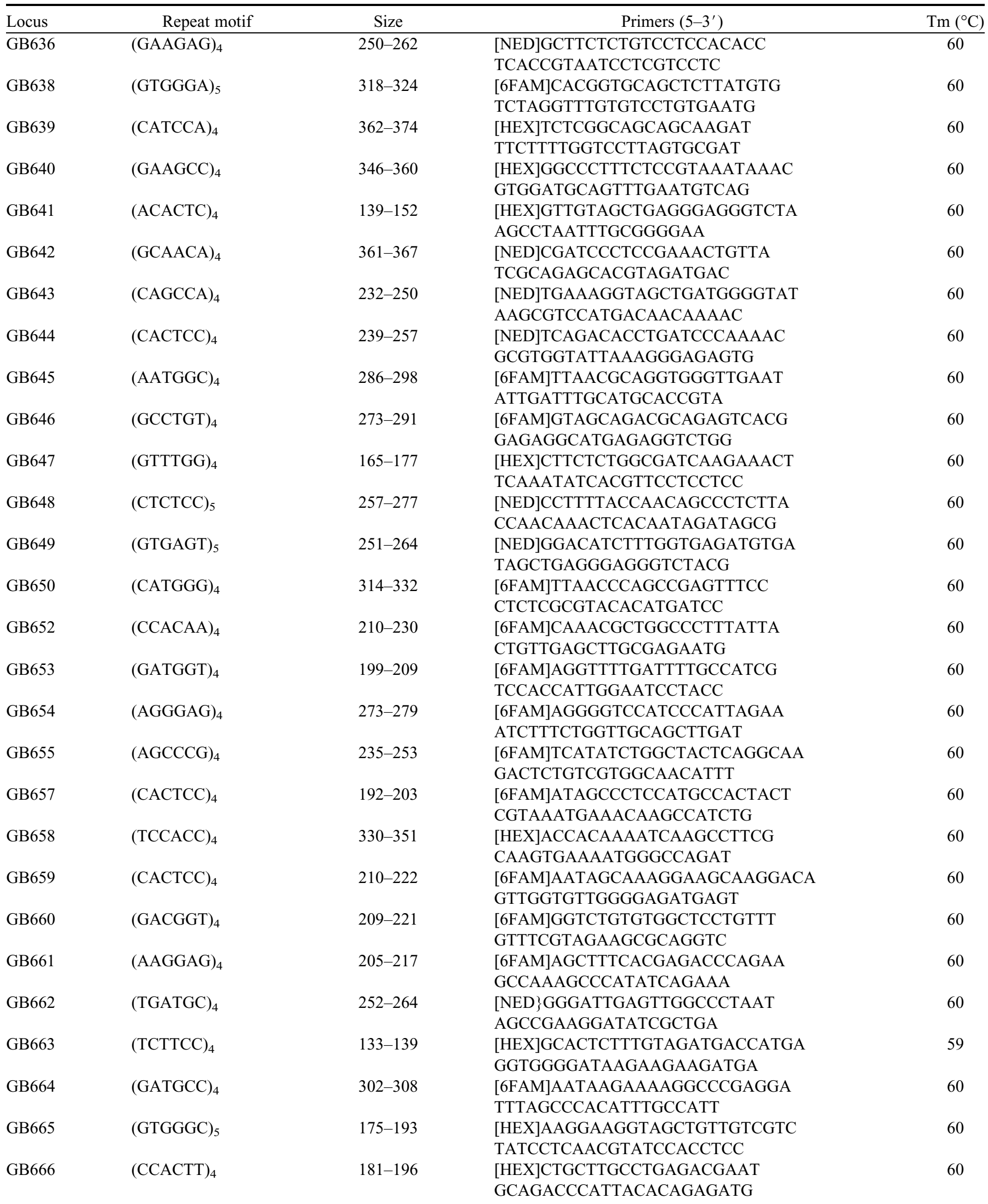


Supplemental Table 1. Continued.

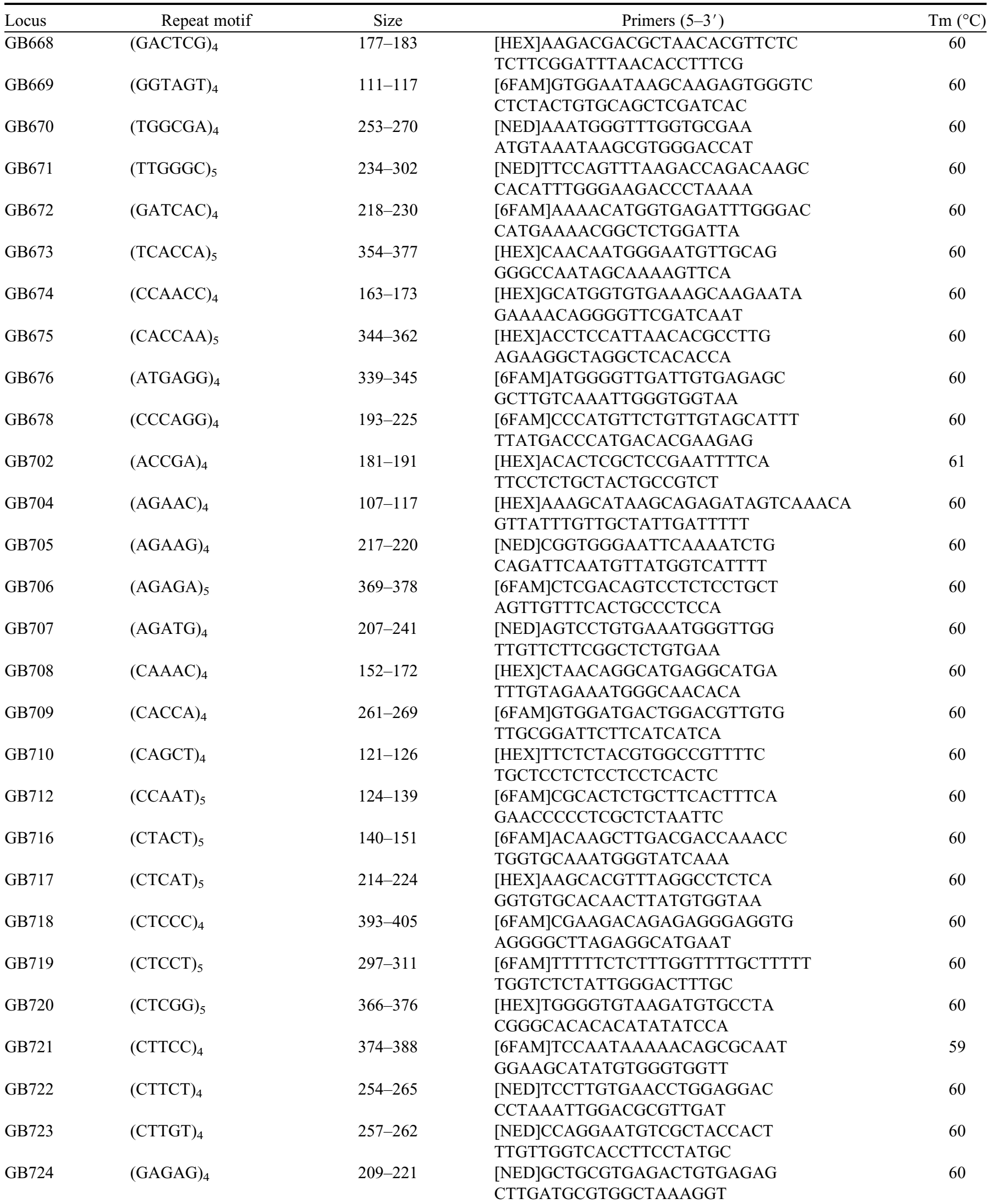


Supplemental Table 1. Continued.

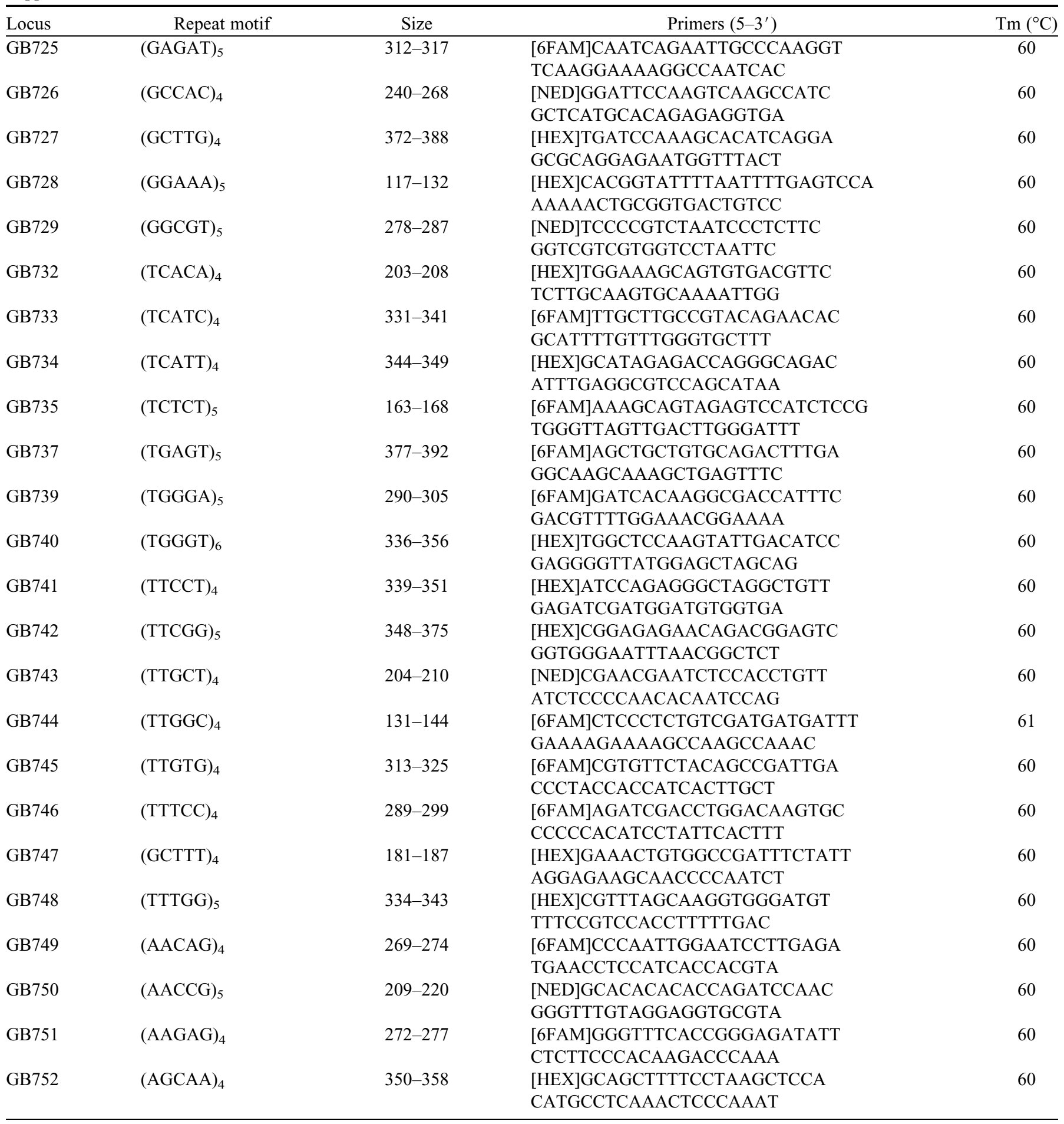


Supplemental Table 2. Repeat motifs at SSR in the 'Jefferson' hazelnut genome by type and number of repeats.

\begin{tabular}{|c|c|c|c|c|c|c|c|c|c|c|c|c|c|}
\hline \multirow[b]{2}{*}{ Repeat motif } & \multicolumn{12}{|c|}{ Number of repeats } & \multirow[b]{2}{*}{ Percentage } \\
\hline & 4 & 5 & 6 & 7 & 8 & 9 & 10 & 11 & 12 & 13 & 14 & Total & \\
\hline \multicolumn{14}{|l|}{ Dinucleotide } \\
\hline $\mathrm{AC} / \mathrm{GT}$ & - & - & 1,271 & 712 & 521 & 350 & 204 & 143 & 129 & 82 & 8 & 3,420 & 10.28 \\
\hline $\mathrm{AG} / \mathrm{CT}$ & - & - & 3,860 & 2,798 & 2,310 & 2,048 & 1,743 & 1,818 & 1,642 & 206 & 6 & 16,431 & 49.38 \\
\hline $\mathrm{AT} / \mathrm{AT}$ & - & - & 5,971 & 3,559 & 2,131 & 1,054 & 393 & 148 & 61 & 60 & 5 & 13,382 & 40.22 \\
\hline $\mathrm{CG} / \mathrm{CG}$ & - & - & 29 & 10 & & 1 & & & & & & 40 & 0.12 \\
\hline Sum & & & 11,131 & 7,079 & 4,962 & 3,453 & 2,340 & 2,109 & 1,832 & 348 & 19 & 33,273 & 100.00 \\
\hline \multicolumn{14}{|l|}{ Trinucleotide } \\
\hline AAC/GTT & - & 326 & 117 & 45 & 27 & 5 & 2 & & & & & 522 & 5.99 \\
\hline AAG/CTT & - & 1,220 & 625 & 325 & 228 & 74 & & & & & & 2,472 & 28.39 \\
\hline AAT/ATT & - & 1,957 & 975 & 479 & 260 & 85 & & & & & & 3,756 & 43.13 \\
\hline $\mathrm{ACC} / \mathrm{GGT}$ & - & 204 & 78 & 46 & 13 & 3 & 4 & & & & & 348 & 4.00 \\
\hline ACG/CGT & - & 52 & 16 & 5 & 3 & & & & & & & 76 & 0.87 \\
\hline ACT/AGT & - & 66 & 21 & 11 & 1 & 2 & 3 & & & & & 104 & 1.19 \\
\hline $\mathrm{AGC} / \mathrm{CTG}$ & - & 147 & 70 & 23 & 12 & 4 & & 1 & & & & 257 & 2.95 \\
\hline $\mathrm{AGG} / \mathrm{CCT}$ & - & 229 & 98 & 52 & 27 & 5 & 5 & 1 & & & & 417 & 4.79 \\
\hline ATC/ATG & - & 403 & 178 & 93 & 45 & 13 & & & & & & 732 & 8.41 \\
\hline CCG/CGG & - & 21 & 3 & & & & & & & & & 24 & 0.28 \\
\hline Sum & & 4,625 & 2,181 & 1,079 & 616 & 191 & 14 & 2 & 0 & 0 & 0 & 8,708 & 100.00 \\
\hline \multicolumn{14}{|l|}{ Tetranucleotide } \\
\hline AAAC/GTTT & 378 & 91 & 23 & 2 & & & & & & & & 494 & 7.72 \\
\hline AAAG/CTTT & 658 & 227 & 68 & 13 & & & & & & & & 966 & 15.09 \\
\hline AAAT/ATTT & 2,846 & 619 & 51 & 4 & & & & & & & & 3,520 & 54.97 \\
\hline AACC/GGTT & 39 & 10 & 4 & & & & & & & & & 53 & 0.83 \\
\hline AACG/CGTT & 2 & & & & & & & & & & & 2 & 0.03 \\
\hline AACT/AGTT & 14 & 5 & & 1 & 1 & & & & & & & 21 & 0.33 \\
\hline AAGC/CTTG & 28 & 2 & & & & & & & & & & 30 & 0.47 \\
\hline AAGG/CCTT & 27 & 8 & 2 & 1 & & & & & & & & 38 & 0.59 \\
\hline AAGT/ACTT & & 1 & & & & & & & & & & 1 & 0.02 \\
\hline AATC/ATTG & 43 & 12 & 5 & & 1 & & & & & & & 61 & 0.95 \\
\hline AATG/ATTC & 29 & 7 & 2 & & & & & & & & & 38 & 0.59 \\
\hline AATT/AATT & 322 & 97 & 14 & 2 & & & & & & & & 435 & 6.79 \\
\hline ACAG/CTGT & 24 & 11 & 1 & & 1 & & & & & & & 37 & 0.58 \\
\hline ACAT/ATGT & 126 & 36 & 24 & 5 & & & & & & & & 191 & 2.98 \\
\hline ACCC/GGGT & 14 & 1 & & & & & & & & & & 15 & 0.23 \\
\hline $\mathrm{ACCG} / \mathrm{CGGT}$ & 4 & 1 & & & & & & & & & & 5 & 0.08 \\
\hline ACCT/AGGT & 8 & 1 & & & & & & & & & & 9 & 0.14 \\
\hline ACGC/CGTG & 12 & 2 & & & & & & & & & & 14 & 0.22 \\
\hline ACGT/ACGT & 12 & 2 & & & & & & & & & & 14 & 0.22 \\
\hline ACTC/AGTG & 36 & 8 & 1 & 2 & 1 & & & & & & & 48 & 0.75 \\
\hline ACTG/AGTC & 3 & 1 & & & & & & & & & & 4 & 0.06 \\
\hline AGAT/ATCT & 36 & 20 & 6 & 2 & & & & & & & & 64 & 1.00 \\
\hline AGCC/CTGG & 9 & 2 & & & & & & & & & & 11 & 0.17 \\
\hline $\mathrm{AGCG} / \mathrm{CGCT}$ & 15 & 1 & 1 & & & & & & & & & 17 & 0.27 \\
\hline AGCT/AGCT & 79 & 13 & 2 & 1 & & & & & & & & 95 & 1.48 \\
\hline AGGC/CCTG & 8 & 1 & 1 & & & & & & & & & 10 & 0.16 \\
\hline AGGG/CCCT & 55 & 15 & 2 & 1 & & & & & & & & 73 & 1.14 \\
\hline ATCC/ATGG & 35 & 11 & 6 & & & & & & & & & 52 & 0.81 \\
\hline ATCG/ATCG & 4 & 1 & & & & & & & & & & 5 & 0.08 \\
\hline ATGC/ATGC & 66 & 8 & 1 & & & & & & & & & 75 & 1.17 \\
\hline CCCG/CGGG & 1 & & & & & & & & & & & 1 & 0.02 \\
\hline CCGG/CCGG & 4 & & & & & & & & & & & 4 & 0.06 \\
\hline Sum & 4,941 & 1,219 & 220 & 41 & 12 & 9 & 10 & 11 & 12 & 13 & 14 & 6,403 & 100.00 \\
\hline \multicolumn{14}{|l|}{ Pentanucleotide } \\
\hline AAAAC/GTTTT & 155 & 36 & 1 & & & & & & & & & 192 & 10.91 \\
\hline AAAAG/CTTTT & 363 & 88 & 1 & & & & & & & & & 452 & 25.68 \\
\hline
\end{tabular}

Continued next page 
Supplemental Table 2. Continued.

\begin{tabular}{|c|c|c|c|c|c|c|c|c|c|c|c|c|c|}
\hline \multirow[b]{2}{*}{ Repeat motif } & \multicolumn{12}{|c|}{ Number of repeats } & \multirow[b]{2}{*}{ Percentage } \\
\hline & 4 & 5 & 6 & 7 & 8 & 9 & 10 & 11 & 12 & 13 & 14 & Total & \\
\hline \multicolumn{14}{|c|}{ Pentanucleotide (cont'd) } \\
\hline AAAAT/ATTTT & 574 & 64 & & & & & & & & & & 638 & 36.25 \\
\hline AAACG/CGTTT & 2 & 1 & & & & & & & & & & 3 & 0.17 \\
\hline AAACT/AGTTT & 3 & 2 & & & & & & & & & & 5 & 0.28 \\
\hline AAAGT/ACTTT & 1 & & 1 & & & & & & & & & 2 & 0.11 \\
\hline AAATC/ATTTG & 25 & 1 & & & & & & & & & & 26 & 1.48 \\
\hline AAATG/ATTTC & 7 & & & & & & & & & & & 7 & 0.40 \\
\hline AAATT/AATTT & 37 & 5 & & & & & & & & & & 42 & 2.39 \\
\hline AACAC/GTGTT & 10 & 1 & & & & & & & & & & 11 & 0.63 \\
\hline AACAG/CTGTT & 4 & & & & & & & & & & & 4 & 0.23 \\
\hline AACCT/AGGTT & 1 & 2 & & & & & & & & & & 3 & 0.17 \\
\hline AACGC/CGTTG & 1 & & & & & & & & & & & 1 & 0.06 \\
\hline AACTC/AGTTG & 16 & 2 & & & & & & & & & & 18 & 1.02 \\
\hline AACTG/AGTTC & 1 & & & & & & & & & & & 1 & 0.06 \\
\hline AACTT/AAGTT & 1 & 1 & & & & & & & & & & 2 & 0.11 \\
\hline AAGAC/CTTGT & 3 & & 1 & & & & & & & & & 4 & 0.23 \\
\hline AAGAG/CTCTT & 30 & 9 & 2 & & & & & & & & & 41 & 2.33 \\
\hline AAGAT/ATCTT & 6 & 1 & & & & & & & & & & 7 & 0.40 \\
\hline AAGCC/CTTGG & 5 & & & & & & & & & & & 5 & 0.28 \\
\hline AAGCT/AGCTT & 3 & & & & & & & & & & & 3 & 0.17 \\
\hline AAGGC/CCTTG & 2 & 1 & & & & & & & & & & 3 & 0.17 \\
\hline AAGGG/CCCTT & 8 & 4 & & & & & & & & & & 12 & 0.68 \\
\hline AATCG/ATTCG & 3 & & & & & & & & & & & 3 & 0.17 \\
\hline AATCT/AGATT & 11 & 1 & 1 & & & & & & & & & 13 & 0.74 \\
\hline AATGC/ATTGC & 3 & & & & & & & & & & & 3 & 0.17 \\
\hline AATGG/ATTCC & 2 & & & & & & & & & & & 2 & 0.11 \\
\hline AATGT/ACATT & 1 & & & & & & & & & & & 1 & 0.06 \\
\hline AATTC/AATTG & 7 & 1 & & & & & & & & & & 8 & 0.45 \\
\hline ACACC/GGTGT & 3 & 1 & & & & & & & & & & 4 & 0.23 \\
\hline ACACG/CGTGT & 2 & & & & & & & & & & & 2 & 0.11 \\
\hline ACACT/AGTGT & 2 & & & & & & & & & & & 2 & 0.11 \\
\hline ACATC/ATGTG & 6 & 1 & & & & & & & & & & 7 & 0.40 \\
\hline ACATG/ATGTC & 8 & & & & & & & & & & & 8 & 0.45 \\
\hline ACCAG/CTGGT & 2 & & & & & & & & & & & 2 & 0.11 \\
\hline ACCAT/ATGGT & 1 & & 1 & & & & & & & & & 2 & 0.11 \\
\hline ACCCC/GGGGT & 6 & 3 & & & & & & & & & & 9 & 0.51 \\
\hline ACCCG/CGGGT & 4 & & & & & & & & & & & 4 & 0.23 \\
\hline ACCCT/AGGGT & 1 & & & & & & & & & & & 1 & 0.06 \\
\hline ACCGC/CGGTG & 2 & & & & & & & & & & & 2 & 0.11 \\
\hline ACCTG/AGGTC & 1 & & & & & & & & & & & 1 & 0.06 \\
\hline ACGAT/ATCGT & 1 & & & & & & & & & & & 1 & 0.06 \\
\hline ACGCC/CGTGG & 1 & 1 & & & & & & & & & & 2 & 0.11 \\
\hline ACTAG/AGTCT & 1 & & & & & & & & & & & 1 & 0.06 \\
\hline
\end{tabular}


Supplemental Table 2. Continued.

\begin{tabular}{|c|c|c|c|c|c|c|c|c|c|c|c|c|c|}
\hline \multirow[b]{2}{*}{ Repeat motif } & \multicolumn{12}{|c|}{ Number of repeats } & \multirow[b]{2}{*}{ Percentage } \\
\hline & 4 & 5 & 6 & 7 & 8 & 9 & 10 & 11 & 12 & 13 & 14 & Total & \\
\hline \multicolumn{14}{|c|}{ Pentanucleotide (cont'd) } \\
\hline ACTCC/AGTGG & 1 & & & & & & & & & & & 1 & 0.06 \\
\hline ACTCT/AGAGT & 2 & 2 & & & & & & & & & & 4 & 0.23 \\
\hline ACTGC/AGTGC & 1 & 1 & & & & & & & & & & 2 & 0.11 \\
\hline AGATC/ATCTG & 1 & & & & & & & & & & & 1 & 0.06 \\
\hline AGATG/ATCTC & 11 & 4 & 1 & & & & & & & & & 16 & 0.91 \\
\hline AGCAT/ATGCT & 3 & 1 & & & & & & & & & & 4 & 0.23 \\
\hline AGCCC/CTGGG & 4 & & & & & & & & & & & 4 & 0.23 \\
\hline AGCCG/CGGCT & 5 & 1 & & & & & & & & & & 6 & 0.34 \\
\hline AGCTC/AGCTG & 3 & & & & & & & & & & & 3 & 0.17 \\
\hline AGGGG/CCCCT & 6 & 1 & & & & & & & & & & 7 & 0.40 \\
\hline ATATC/ATATG & 9 & 1 & & & & & & & & & & 10 & 0.57 \\
\hline ATCCC/ATGGG & 4 & 2 & 1 & & & & & & & & & 7 & 0.40 \\
\hline ATGCC/ATGGC & 3 & 2 & & & & & & & & & & 5 & 0.28 \\
\hline CCCCG/CGGGG & 1 & & & & & & & & & & & 1 & 0.06 \\
\hline CCCGG/CCGGG & 1 & & & & & & & & & & & 1 & 0.06 \\
\hline Sum & 1,481 & 266 & 13 & 0 & 0 & 0 & 0 & 0 & 0 & 0 & 0 & 1,760 & 100.00 \\
\hline \multicolumn{14}{|l|}{ Hexanucleotide } \\
\hline AAAAAC/GTTTTT & 72 & 1 & & & & & & & & & & 73 & 7.84 \\
\hline AAAAAG/CTTTTT & 168 & 2 & & & & & & & & & & 170 & 18.26 \\
\hline AAAAAT/ATTTTT & 112 & 5 & & & & & & & & & & 117 & 12.57 \\
\hline AAAACC/GGTTTT & 8 & & & & & & & & & & & 8 & 0.86 \\
\hline AAAATT/AATTTT & 7 & & & & & & & & & & & 7 & 0.75 \\
\hline AAACAC/GTGTTT & 5 & 2 & & & & & & & & & & 7 & 0.75 \\
\hline AAACAG/CTGTTT & 3 & 1 & & & & & & & & & & 4 & 0.43 \\
\hline AAACAT/ATGTTT & 4 & 2 & & & & & & & & & & 6 & 0.64 \\
\hline AAACCC/GGGTTT & 4 & 1 & & & & & & & & & & 5 & 0.54 \\
\hline AAACTT/AAGTTT & 1 & & & & & & & & & & & 1 & 0.11 \\
\hline AAAGAC/CTTTGT & & 1 & & & & & & & & & & 1 & 0.11 \\
\hline AAAGAG/CTCTTT & 23 & & & & & & & & & & & 23 & 2.47 \\
\hline AAAGAT/ATCTTT & 2 & & & & & & & & & & & 2 & 0.21 \\
\hline AAAGCC/CTTTGG & 2 & & & & & & & & & & & 2 & 0.21 \\
\hline AAAGGG/CCCTTT & 2 & 1 & & & & & & & & & & 3 & 0.32 \\
\hline AAAGTG/ACTTTC & 3 & 1 & & & & & & & & & & 4 & 0.43 \\
\hline AAAGTT/AACTTT & 2 & & & & & & & & & & & 2 & 0.21 \\
\hline AAATAC/ATTTGT & 2 & & & & & & & & & & & 2 & 0.21 \\
\hline AAATAG/ATTTCT & 1 & & & & & & & & & & & 1 & 0.11 \\
\hline AAATAT/ATATTT & 1 & & & & & & & & & & & 1 & 0.11 \\
\hline AAATCC/ATTTGG & 4 & & & & & & & & & & & 4 & 0.43 \\
\hline AAATGC/ATTTGC & 1 & & & & & & & & & & & 1 & 0.11 \\
\hline AAATGG/ATTTCC & 1 & & & & & & & & & & & 1 & 0.11 \\
\hline AAATTC/AATTTG & 10 & 1 & & & & & & & & & & 11 & 1.18 \\
\hline AAATTG/AATTTC & 3 & & & & & & & & & & & 3 & 0.32 \\
\hline
\end{tabular}


Supplemental Table 2. Continued.

\begin{tabular}{|c|c|c|c|c|c|c|c|c|c|c|c|c|c|}
\hline \multirow[b]{2}{*}{ Repeat motif } & \multicolumn{12}{|c|}{ Number of repeats } & \multirow[b]{2}{*}{ Percentage } \\
\hline & 4 & 5 & 6 & 7 & 8 & 9 & 10 & 11 & 12 & 13 & 14 & Total & \\
\hline \multicolumn{14}{|l|}{ Hexanucleotide (cont'd) } \\
\hline AACAAG/CTTGTT & 7 & 1 & & & & & & & & & & 8 & 0.86 \\
\hline AACACC/GGTGTT & 4 & 2 & & & & & & & & & & 6 & 0.64 \\
\hline AACACG/CGTGTT & 1 & & & & & & & & & & & 1 & 0.11 \\
\hline AACATC/ATGTTG & 4 & & & & & & & & & & & 4 & 0.43 \\
\hline AACATG/ATGTTC & 9 & 1 & & & & & & & & & & 10 & 1.07 \\
\hline AACCAC/GGTTGT & 2 & 2 & & & & & & & & & & 4 & 0.43 \\
\hline AACCAG/CTGGTT & 1 & & & & & & & & & & & 1 & 0.11 \\
\hline AACCAT/ATGGTT & 1 & & & & & & & & & & & 1 & 0.11 \\
\hline AACCCC/GGGGTT & 1 & & & & & & & & & & & 1 & 0.11 \\
\hline AACCTC/AGGTTG & 4 & & & & & & & & & & & 4 & 0.43 \\
\hline AACCTG/AGGTTC & 1 & & & & & & & & & & & 1 & 0.11 \\
\hline AACGAC/CGTTGT & & & 1 & & & & & & & & & 1 & 0.11 \\
\hline AACGCC/CGTTGG & 1 & & & & & & & & & & & 1 & 0.11 \\
\hline AACGGC/CCGTTG & & 1 & & & & & & & & & & 1 & 0.11 \\
\hline AACTCC/AGTTGG & 2 & 2 & & & & & & & & & & 4 & 0.43 \\
\hline AACTCG/AGTTCG & 1 & & & & & & & & & & & 1 & 0.11 \\
\hline AACTCT/AGAGTT & 1 & & & & & & & & & & & 1 & 0.11 \\
\hline AACTTC/AAGTTG & 2 & & & & & & & & & & & 2 & 0.21 \\
\hline AACTTG/AAGTTC & 1 & & & & & & & & & & & 1 & 0.11 \\
\hline AAGAAT/ATTCTT & 1 & & & & & & & & & & & 1 & 0.11 \\
\hline AAGACC/CTTGGT & 2 & & & & & & & & & & & 2 & 0.21 \\
\hline AAGCCC/CTTGGG & 4 & 2 & & & & & & & & & & 6 & 0.64 \\
\hline AAGCCG/CGGCTT & 2 & & & & & & & & & & & 2 & 0.21 \\
\hline AAGCGG/CCGCTT & & & 1 & & & & & & & & & 1 & 0.11 \\
\hline AAGCTC/AGCTTG & 1 & 1 & & & & & & & & & & 2 & 0.21 \\
\hline AAGGAG/CCTTCT & 10 & & 1 & & & & & & & & & 11 & 1.18 \\
\hline AAGGAT/ATCCTT & & 2 & & & & & & & & & & 2 & 0.21 \\
\hline AAGGGC/CCCTTG & 1 & & & & & & & & & & & 1 & 0.11 \\
\hline AAGGGG/CCCCTT & 1 & & & & & & & & & & & 1 & 0.11 \\
\hline AAGGTG/ACCTTC & 1 & 1 & & & & & & & & & & 2 & 0.21 \\
\hline AAGTAG/ACTTCT & 2 & 1 & & & & & & & & & & 3 & 0.32 \\
\hline AAGTGC/ACTTGC & & 1 & & & & & & & & & & 1 & 0.11 \\
\hline AAGTGG/ACTTCC & 1 & & & & & & & & & & & 1 & 0.11 \\
\hline AATAGC/ATTGCT & 1 & & & & & & & & & & & 1 & 0.11 \\
\hline AATAGG/ATTCCT & 1 & & & & & & & & & & & 1 & 0.11 \\
\hline AATAGT/ACTATT & 3 & & & & & & & & & & & 3 & 0.32 \\
\hline AATATG/ATATTC & 1 & & & & & & & & & & & 1 & 0.11 \\
\hline AATCAC/ATTGTG & 3 & 1 & & & & & & & & & & 4 & 0.43 \\
\hline AATCAG/ATTCTG & 1 & & & & & & & & & & & 1 & 0.11 \\
\hline AATCAT/ATGATT & 5 & 1 & & & & & & & & & & 6 & 0.64 \\
\hline AATCCC/ATTGGG & 1 & & & & & & & & & & & 1 & 0.11 \\
\hline AATCCG/ATTCGG & 1 & & & & & & & & & & & 1 & 0.11 \\
\hline
\end{tabular}


Supplemental Table 2. Continued.

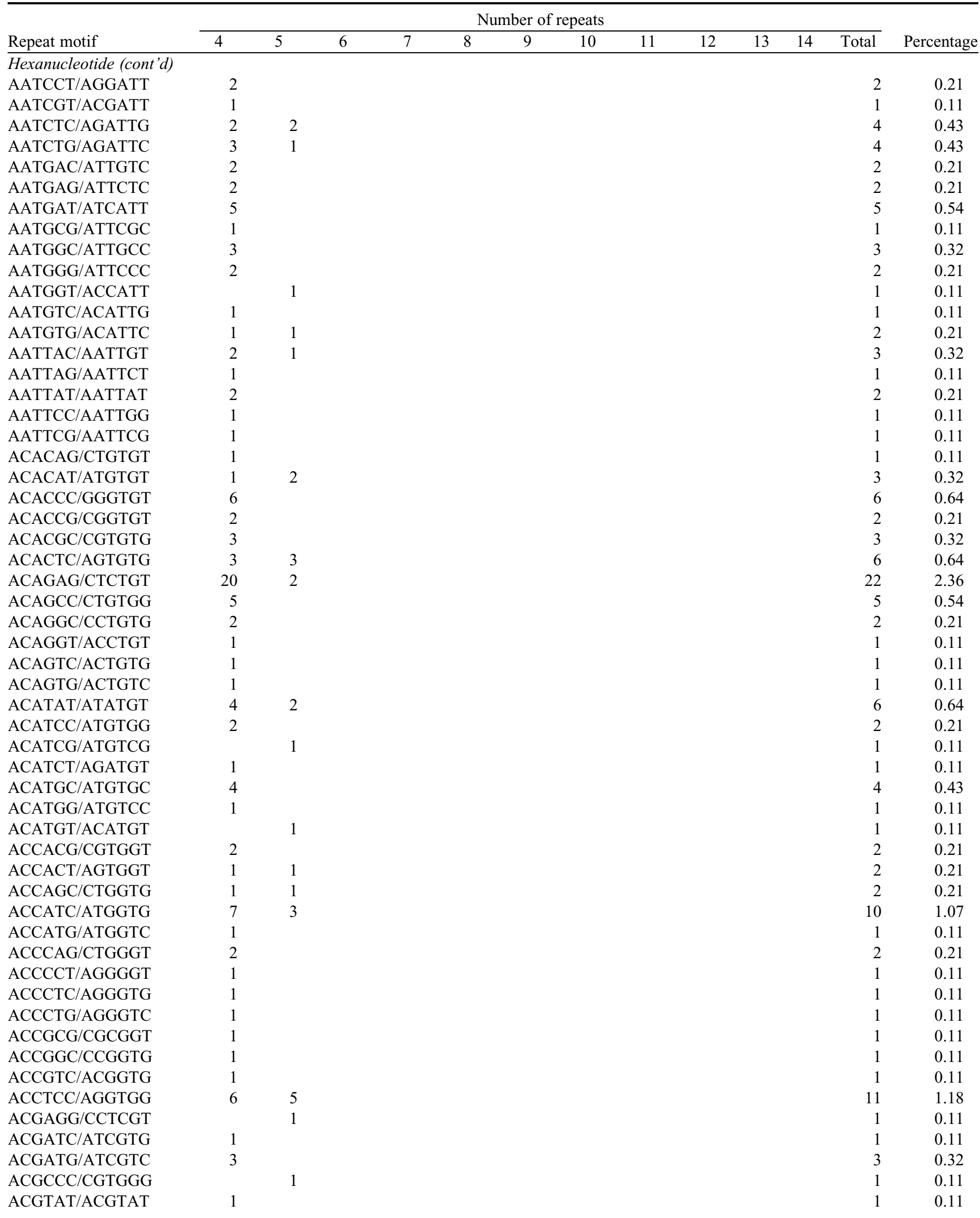


Supplemental Table 2. Continued.

\begin{tabular}{|c|c|c|c|c|c|c|c|c|c|c|c|c|c|}
\hline \multirow[b]{2}{*}{ Repeat motif } & \multicolumn{12}{|c|}{ Number of repeats } & \multirow[b]{2}{*}{ Percentage } \\
\hline & 4 & 5 & 6 & 7 & 8 & 9 & 10 & 11 & 12 & 13 & 14 & Total & \\
\hline \multicolumn{14}{|l|}{ Hexanucleotide (cont'd) } \\
\hline ACGTCC/ACGTGG & 1 & & & & & & & & & & & 1 & 0.11 \\
\hline ACTATC/AGTGAT & 2 & & & & & & & & & & & 2 & 0.21 \\
\hline ACTATG/AGTCAT & 1 & & & & & & & & & & & 1 & 0.11 \\
\hline ACTCCG/AGTCGG & 1 & 1 & & & & & & & & & & 2 & 0.21 \\
\hline ACTCCT/AGGAGT & 2 & & & & & & & & & & & 2 & 0.21 \\
\hline ACTCGG/AGTCCG & 1 & & & & & & & & & & & 1 & 0.11 \\
\hline АСТCTC/AGAGTG & 7 & 2 & & & & & & & & & & 9 & 0.97 \\
\hline ACTGCC/AGTGGC & 2 & & & & & & & & & & & 2 & 0.21 \\
\hline ACTGCG/AGTCGC & 1 & & & & & & & & & & & 1 & 0.11 \\
\hline AGAGCG/CGCTCT & 2 & & & & & & & & & & & 2 & 0.21 \\
\hline AGAGGC/CCTCTG & 2 & & & & & & & & & & & 2 & 0.21 \\
\hline AGAGGG/CCCTCT & 21 & 3 & & & & & & & & & & 24 & 2.58 \\
\hline AGATAT/ATATCT & 4 & & & & & & & & & & & 4 & 0.43 \\
\hline AGATCT/AGATCT & 3 & & & & & & & & & & & 3 & 0.32 \\
\hline AGATGG/ATCTCC & 3 & 1 & & & & & & & & & & 4 & 0.43 \\
\hline AGCAGG/CCTGCT & 2 & & & & & & & & & & & 2 & 0.21 \\
\hline AGCATC/ATGCTG & 2 & & & & & & & & & & & 2 & 0.21 \\
\hline AGCATG/ATGCTC & 2 & & & & & & & & & & & 2 & 0.21 \\
\hline AGCCAT/ATGGCT & 1 & 1 & & & & & & & & & & 2 & 0.21 \\
\hline AGCCCC/CTGGGG & 2 & & & & & & & & & & & 2 & 0.21 \\
\hline AGGCAT/ATGCCT & & 1 & & & & & & & & & & 1 & 0.11 \\
\hline AGGCCC/CCTGGG & 1 & & & & & & & & & & & 1 & 0.11 \\
\hline AGGGAT/ATCCCT & 2 & 1 & 1 & & & & & & & & & 4 & 0.43 \\
\hline AGGGCC/CCCTGG & 1 & & & & & & & & & & & 1 & 0.11 \\
\hline AGGGGG/CCCCCT & 2 & & & & & & & & & & & 2 & 0.21 \\
\hline ATATGC/ATATGC & 2 & & & & & & & & & & & 2 & 0.21 \\
\hline ATCATG/ATCATG & 1 & & & & & & & & & & & 1 & 0.11 \\
\hline ATCCCC/ATGGGG & 1 & & & & & & & & & & & 1 & 0.11 \\
\hline ATCGCC/ATGGCG & 2 & 1 & & & & & & & & & & 3 & 0.32 \\
\hline ATCGGC/ATGCCG & 1 & & & & & & & & & & & 1 & 0.11 \\
\hline ATGCCC/ATGGGC & 1 & & & & & & & & & & & 1 & 0.11 \\
\hline Sum & 853 & 133 & 50 & 49 & 56 & 63 & 70 & 77 & 84 & 91 & 98 & 931 & 100.00 \\
\hline
\end{tabular}


Supplemental Table 3. Alleles at 169 simple sequence repeat marker loci in 50 hazelnut accessions. All cultivars showed one or two alleles at each AU7 locus.




Supplemental Table 3. Continued.

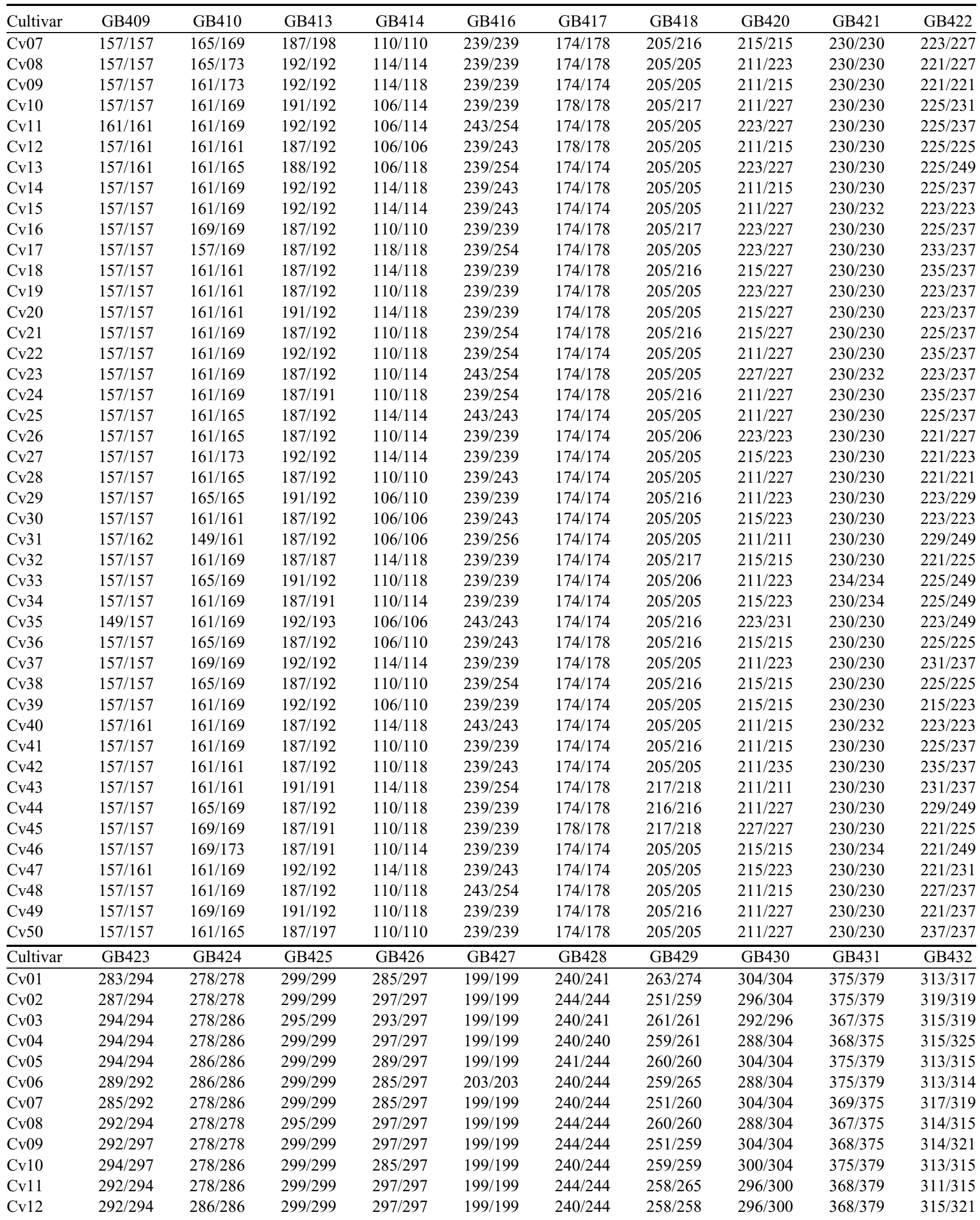


Supplemental Table 3. Continued.

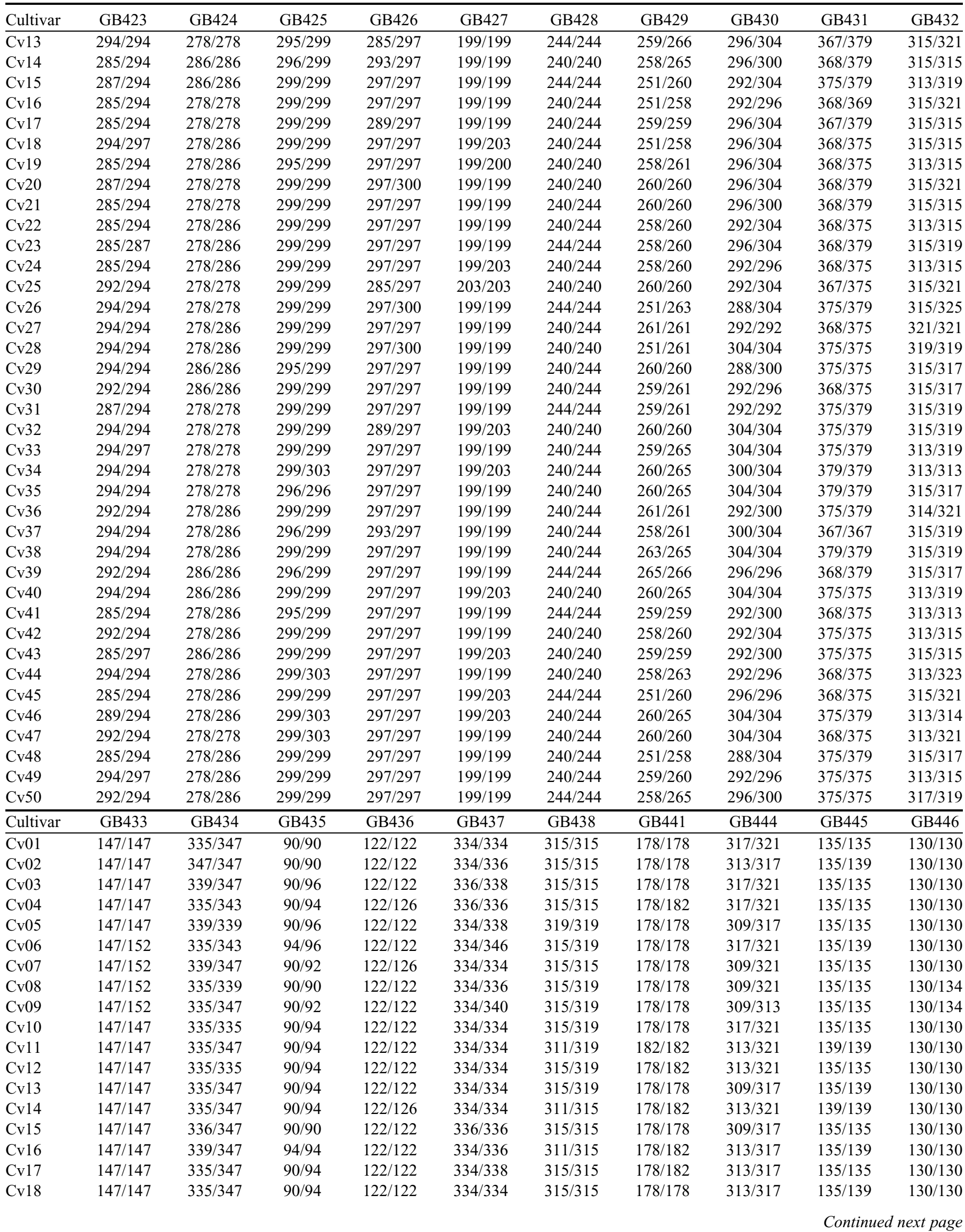


Supplemental Table 3. Continued.

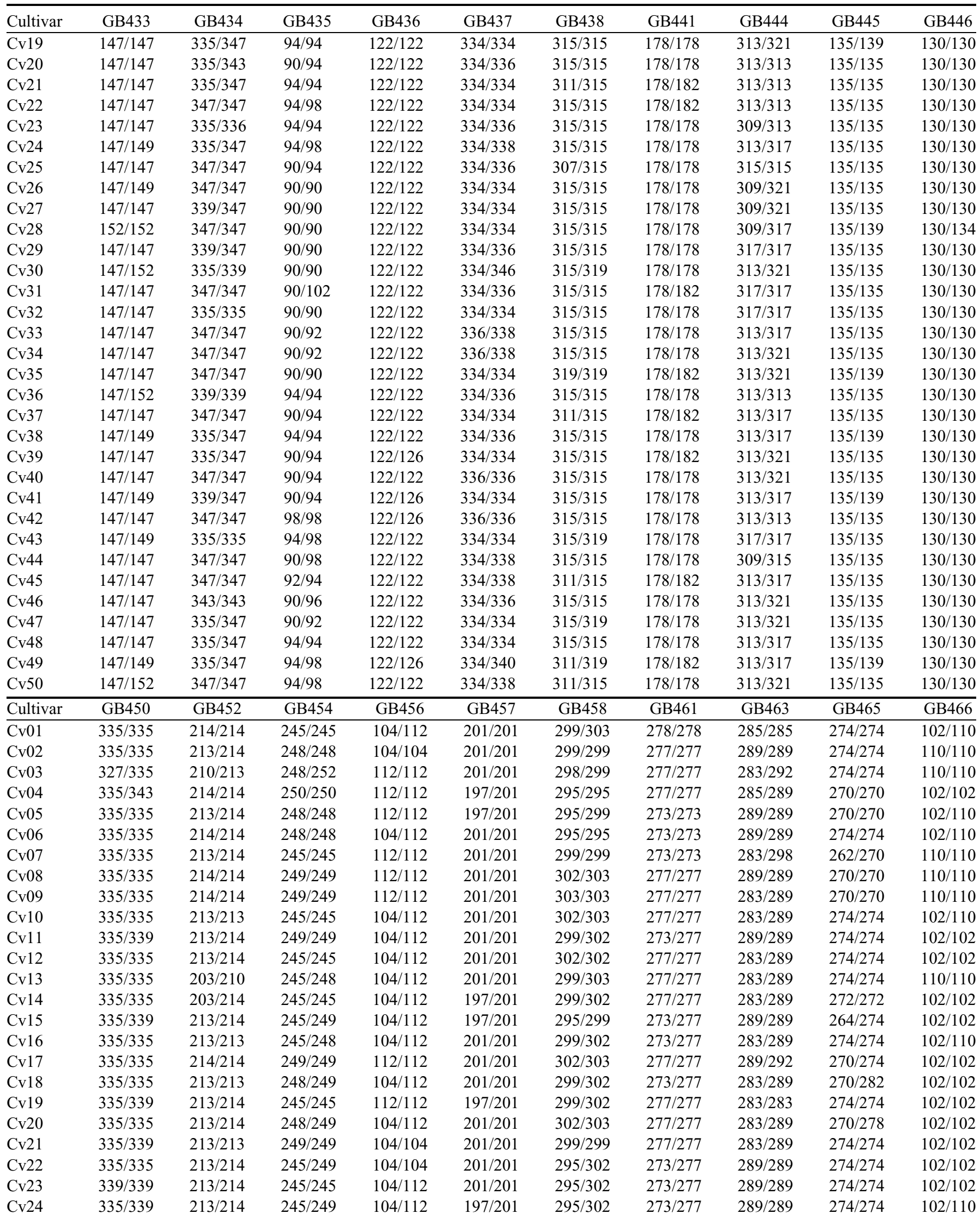


Supplemental Table 3. Continued.

\begin{tabular}{|c|c|c|c|c|c|c|c|c|c|c|}
\hline Cultivar & GB450 & GB452 & GB454 & GB456 & GB457 & GB458 & GB461 & GB463 & GB465 & GB466 \\
\hline Cv25 & $335 / 339$ & $213 / 213$ & $248 / 248$ & $112 / 112$ & $197 / 197$ & $303 / 303$ & $273 / 277$ & $289 / 289$ & $274 / 274$ & $102 / 110$ \\
\hline Cv26 & $335 / 335$ & $213 / 214$ & $248 / 248$ & $112 / 112$ & $201 / 201$ & $299 / 299$ & $281 / 281$ & $289 / 289$ & $263 / 274$ & $102 / 102$ \\
\hline Cv27 & $327 / 335$ & $213 / 214$ & $249 / 249$ & $112 / 112$ & $201 / 201$ & $302 / 303$ & $273 / 273$ & $283 / 289$ & $270 / 270$ & $110 / 110$ \\
\hline Cv29 & $335 / 335$ & $213 / 213$ & $248 / 248$ & $112 / 112$ & $201 / 201$ & $299 / 303$ & $274 / 274$ & $289 / 289$ & $270 / 270$ & $102 / 110$ \\
\hline Cv30 & $335 / 335$ & $213 / 214$ & $245 / 248$ & $104 / 112$ & $201 / 201$ & $302 / 303$ & $277 / 281$ & $283 / 289$ & $274 / 274$ & $102 / 102$ \\
\hline Cv33 & $335 / 335$ & $214 / 214$ & $248 / 248$ & $104 / 112$ & $201 / 201$ & $295 / 299$ & $277 / 277$ & $289 / 289$ & $274 / 274$ & $110 / 110$ \\
\hline Cv34 & $335 / 335$ & $214 / 214$ & $248 / 248$ & $104 / 112$ & $201 / 201$ & $295 / 299$ & $281 / 281$ & $289 / 294$ & $274 / 274$ & $110 / 110$ \\
\hline Cv35 & $327 / 335$ & $214 / 214$ & $245 / 246$ & $104 / 104$ & $201 / 201$ & $299 / 302$ & $277 / 277$ & $285 / 289$ & $274 / 274$ & $102 / 102$ \\
\hline Cv36 & $335 / 335$ & $214 / 214$ & $245 / 245$ & $104 / 112$ & $201 / 201$ & $298 / 303$ & $273 / 277$ & $283 / 289$ & $274 / 274$ & $102 / 110$ \\
\hline Cv37 & $335 / 335$ & $203 / 214$ & $245 / 245$ & $112 / 112$ & $197 / 201$ & $299 / 302$ & $277 / 277$ & $283 / 294$ & $274 / 274$ & $102 / 102$ \\
\hline Cv38 & $335 / 335$ & $213 / 214$ & $245 / 248$ & $112 / 112$ & $197 / 201$ & $299 / 299$ & $273 / 273$ & $289 / 294$ & $270 / 278$ & $102 / 110$ \\
\hline Cv42 & $335 / 335$ & $213 / 214$ & $244 / 249$ & $104 / 104$ & $201 / 201$ & $299 / 302$ & $277 / 277$ & $289 / 289$ & $274 / 274$ & $102 / 102$ \\
\hline Cv43 & $335 / 339$ & $213 / 214$ & $245 / 249$ & $104 / 112$ & $201 / 201$ & $295 / 302$ & $277 / 277$ & $289 / 289$ & $274 / 274$ & $102 / 110$ \\
\hline $\mathrm{Cv} 44$ & $335 / 339$ & $213 / 214$ & $244 / 249$ & $112 / 112$ & $201 / 201$ & $295 / 302$ & $273 / 277$ & $289 / 289$ & $270 / 274$ & $102 / 110$ \\
\hline $\mathrm{Cv} 45$ & $335 / 335$ & $213 / 214$ & $245 / 245$ & $104 / 112$ & $201 / 201$ & $299 / 302$ & $277 / 281$ & $289 / 289$ & $274 / 274$ & $102 / 102$ \\
\hline $\mathrm{Cv} 46$ & $335 / 335$ & $214 / 214$ & $248 / 248$ & $104 / 112$ & $201 / 201$ & $295 / 299$ & $273 / 273$ & $289 / 289$ & $274 / 274$ & $110 / 110$ \\
\hline Cv47 & $335 / 339$ & $214 / 214$ & $245 / 249$ & $112 / 112$ & $201 / 201$ & $302 / 303$ & $273 / 273$ & $289 / 289$ & $270 / 270$ & $110 / 110$ \\
\hline $\mathrm{Cv} 48$ & $335 / 335$ & $213 / 214$ & $244 / 249$ & $112 / 112$ & $197 / 201$ & $299 / 299$ & $277 / 277$ & $289 / 289$ & $270 / 274$ & $102 / 102$ \\
\hline Cv49 & $335 / 339$ & $213 / 214$ & $245 / 249$ & $104 / 112$ & $197 / 201$ & $295 / 303$ & $273 / 277$ & $283 / 283$ & $274 / 274$ & $102 / 102$ \\
\hline Cv50 & $335 / 339$ & $203 / 214$ & $244 / 245$ & $112 / 112$ & $197 / 201$ & $299 / 302$ & $273 / 273$ & $289 / 289$ & $274 / 274$ & $102 / 110$ \\
\hline Cultivar & GB467 & GB468 & GB469 & GB470 & GB473 & GB475 & GB476 & GB477 & GB478 & GB480 \\
\hline$\overline{\mathrm{Cv} 01}$ & $336 / 336$ & $359 / 377$ & $328 / 336$ & $383 / 400$ & $189 / 189$ & $183 / 183$ & $298 / 298$ & $345 / 345$ & $389 / 389$ & $272 / 273$ \\
\hline Cv10 & $352 / 352$ & $359 / 377$ & $340 / 340$ & $395 / 395$ & $189 / 189$ & $187 / 187$ & $298 / 298$ & $345 / 345$ & $383 / 389$ & $272 / 272$ \\
\hline Cv11 & $336 / 352$ & $359 / 377$ & $336 / 340$ & $395 / 395$ & $189 / 189$ & $183 / 187$ & $296 / 298$ & $345 / 345$ & $389 / 389$ & $272 / 272$ \\
\hline Cv12 & $336 / 352$ & $359 / 359$ & $332 / 340$ & $395 / 395$ & $189 / 189$ & $187 / 187$ & $296 / 298$ & $345 / 345$ & $383 / 389$ & $272 / 273$ \\
\hline Cv13 & $336 / 352$ & $359 / 379$ & $340 / 340$ & $395 / 395$ & $189 / 198$ & $187 / 187$ & $296 / 298$ & $345 / 345$ & $389 / 389$ & $262 / 273$ \\
\hline Cv14 & $352 / 352$ & $359 / 359$ & $328 / 340$ & $395 / 395$ & $189 / 189$ & $183 / 187$ & $296 / 298$ & $345 / 345$ & $389 / 389$ & $272 / 273$ \\
\hline Cv15 & $336 / 336$ & $355 / 359$ & $336 / 340$ & $383 / 383$ & $189 / 194$ & $183 / 187$ & $298 / 298$ & $345 / 345$ & $392 / 392$ & $272 / 273$ \\
\hline Cv16 & $336 / 352$ & $359 / 377$ & $332 / 336$ & $383 / 395$ & $189 / 189$ & $183 / 183$ & $296 / 298$ & $345 / 345$ & $383 / 389$ & $272 / 272$ \\
\hline Cv17 & $336 / 352$ & $359 / 377$ & $340 / 340$ & $383 / 383$ & $189 / 189$ & $183 / 187$ & $296 / 296$ & $338 / 345$ & $389 / 392$ & $272 / 272$ \\
\hline Cv18 & $336 / 352$ & $359 / 377$ & $332 / 340$ & $383 / 395$ & $189 / 194$ & $187 / 187$ & $296 / 298$ & $338 / 345$ & $383 / 389$ & $273 / 273$ \\
\hline Cv19 & $336 / 352$ & $359 / 359$ & $332 / 340$ & $395 / 395$ & $189 / 189$ & $183 / 187$ & $296 / 298$ & $345 / 345$ & $383 / 389$ & $272 / 273$ \\
\hline Cv20 & $336 / 352$ & $359 / 377$ & $336 / 340$ & $397 / 397$ & $189 / 189$ & $187 / 187$ & $296 / 298$ & $338 / 345$ & $383 / 383$ & $272 / 273$ \\
\hline Cv21 & $352 / 352$ & $359 / 377$ & $332 / 336$ & $383 / 395$ & $189 / 189$ & $183 / 183$ & $295 / 298$ & $345 / 345$ & $389 / 389$ & $272 / 272$ \\
\hline $\mathrm{Cv} 22$ & $336 / 352$ & $359 / 359$ & $336 / 340$ & $383 / 383$ & $189 / 198$ & $183 / 183$ & $298 / 298$ & $345 / 345$ & $389 / 389$ & $273 / 273$ \\
\hline Cv23 & $336 / 352$ & $359 / 359$ & $332 / 340$ & $383 / 395$ & $189 / 189$ & $187 / 187$ & $296 / 298$ & $345 / 345$ & $389 / 392$ & $272 / 272$ \\
\hline Cv24 & $336 / 352$ & $359 / 359$ & $332 / 340$ & $383 / 395$ & $189 / 189$ & $183 / 183$ & $294 / 298$ & $345 / 345$ & $389 / 392$ & $272 / 272$ \\
\hline Cv25 & $336 / 336$ & $364 / 377$ & $340 / 340$ & $383 / 383$ & $189 / 198$ & $187 / 187$ & $297 / 297$ & $338 / 345$ & $392 / 392$ & $272 / 272$ \\
\hline Cv26 & $336 / 336$ & $359 / 377$ & $328 / 336$ & $383 / 383$ & $189 / 194$ & $183 / 187$ & $298 / 298$ & $338 / 345$ & $392 / 392$ & $272 / 272$ \\
\hline Cv27 & $336 / 352$ & $377 / 377$ & $336 / 340$ & $383 / 383$ & $189 / 194$ & $187 / 187$ & $295 / 297$ & $338 / 345$ & $383 / 389$ & $272 / 273$ \\
\hline Cv28 & $336 / 352$ & $359 / 377$ & $332 / 336$ & $383 / 383$ & $189 / 189$ & $187 / 187$ & $298 / 298$ & $338 / 345$ & $383 / 392$ & $272 / 272$ \\
\hline Cv29 & $336 / 352$ & $377 / 377$ & $340 / 340$ & $383 / 395$ & $189 / 194$ & $187 / 187$ & $298 / 298$ & $338 / 345$ & $383 / 383$ & $272 / 272$ \\
\hline Cv30 & $336 / 352$ & $359 / 377$ & $332 / 336$ & $383 / 395$ & $189 / 194$ & $187 / 187$ & $298 / 298$ & $345 / 345$ & $389 / 392$ & $272 / 273$ \\
\hline
\end{tabular}

Continued next page 
Supplemental Table 3. Continued.

\begin{tabular}{|c|c|c|c|c|c|c|c|c|c|c|}
\hline Cultivar & GB467 & GB468 & GB469 & GB470 & GB473 & GB475 & GB476 & GB477 & GB478 & GB480 \\
\hline$\overline{\mathrm{Cv} 31}$ & $336 / 336$ & $377 / 377$ & $328 / 328$ & $385 / 385$ & $189 / 189$ & $183 / 183$ & $298 / 298$ & $338 / 345$ & $389 / 389$ & $272 / 272$ \\
\hline Cv32 & $336 / 336$ & $359 / 359$ & $336 / 340$ & $395 / 400$ & $189 / 194$ & $187 / 187$ & $298 / 298$ & $338 / 345$ & $392 / 392$ & $272 / 272$ \\
\hline Cv33 & $336 / 352$ & $359 / 377$ & $336 / 339$ & $383 / 398$ & $189 / 189$ & $183 / 187$ & $298 / 298$ & $345 / 345$ & $392 / 392$ & $272 / 273$ \\
\hline Cv35 & $336 / 340$ & $359 / 359$ & $336 / 340$ & $395 / 406$ & $189 / 189$ & $183 / 187$ & $296 / 298$ & $345 / 345$ & $389 / 389$ & $272 / 274$ \\
\hline Cv36 & $352 / 352$ & $377 / 377$ & $332 / 336$ & $383 / 395$ & $189 / 189$ & $187 / 187$ & $297 / 299$ & $338 / 345$ & $392 / 392$ & $272 / 272$ \\
\hline Cv37 & $336 / 336$ & $359 / 359$ & $328 / 340$ & $383 / 395$ & $189 / 189$ & $183 / 187$ & $296 / 298$ & $345 / 345$ & $389 / 392$ & $272 / 272$ \\
\hline Cv39 & $336 / 336$ & $355 / 359$ & $328 / 340$ & $398 / 398$ & $189 / 189$ & $183 / 183$ & $298 / 298$ & $345 / 345$ & $389 / 389$ & $272 / 272$ \\
\hline $\mathrm{Cv} 40$ & $336 / 352$ & $355 / 359$ & $340 / 340$ & $395 / 395$ & $189 / 198$ & $183 / 187$ & $295 / 298$ & $338 / 345$ & $383 / 392$ & $272 / 272$ \\
\hline Cv41 & $352 / 352$ & $377 / 377$ & $332 / 336$ & $395 / 395$ & $189 / 189$ & $183 / 183$ & $294 / 298$ & $345 / 345$ & $383 / 389$ & $273 / 273$ \\
\hline Cv42 & $336 / 352$ & $359 / 359$ & $340 / 340$ & $383 / 383$ & $189 / 189$ & $187 / 187$ & $298 / 298$ & $336 / 345$ & $389 / 392$ & $272 / 272$ \\
\hline Cv43 & $352 / 352$ & $359 / 359$ & $340 / 340$ & $383 / 395$ & $189 / 189$ & $183 / 187$ & $294 / 298$ & $345 / 345$ & $389 / 389$ & $272 / 273$ \\
\hline Cv44 & $336 / 336$ & $377 / 377$ & $339 / 340$ & $393 / 400$ & $189 / 189$ & $183 / 187$ & $298 / 298$ & $338 / 345$ & $383 / 383$ & $272 / 272$ \\
\hline Cv49 & $336 / 352$ & $359 / 359$ & $336 / 340$ & $383 / 383$ & $189 / 194$ & $183 / 183$ & $295 / 297$ & $345 / 345$ & $389 / 389$ & $272 / 273$ \\
\hline Cv50 & $336 / 352$ & $355 / 377$ & $332 / 340$ & $395 / 397$ & $189 / 198$ & $183 / 187$ & $298 / 298$ & $338 / 345$ & $389 / 392$ & $272 / 276$ \\
\hline Cultivar & GB482 & GB483 & GB504 & GB505 & GB526 & GB527 & GB532 & GB533 & GB537 & GB544 \\
\hline$\overline{\mathrm{Cv} 01}$ & $131 / 136$ & $355 / 355$ & $183 / 183$ & $275 / 275$ & $79 / 89$ & $120 / 120$ & $360 / 360$ & $121 / 126$ & $181 / 181$ & $389 / 392$ \\
\hline Cv02 & $138 / 140$ & $356 / 356$ & $183 / 183$ & $272 / 281$ & $85 / 89$ & $120 / 125$ & $360 / 360$ & $121 / 126$ & $181 / 181$ & $392 / 394$ \\
\hline Cv03 & $131 / 138$ & $343 / 355$ & $193 / 193$ & $271 / 271$ & $89 / 94$ & $120 / 125$ & $360 / 369$ & $121 / 126$ & $181 / 186$ & $389 / 392$ \\
\hline Cv04 & $131 / 138$ & $355 / 355$ & $183 / 188$ & $275 / 275$ & $85 / 89$ & $120 / 120$ & $360 / 360$ & $121 / 121$ & $181 / 181$ & $389 / 389$ \\
\hline Cv05 & $138 / 138$ & $355 / 356$ & $193 / 193$ & $275 / 275$ & $83 / 88$ & $120 / 125$ & $360 / 369$ & $121 / 121$ & $181 / 186$ & $389 / 389$ \\
\hline Cv06 & $138 / 138$ & $355 / 355$ & $183 / 188$ & $275 / 275$ & $85 / 89$ & $125 / 125$ & $360 / 360$ & $121 / 131$ & $181 / 186$ & $389 / 389$ \\
\hline Cv07 & $131 / 140$ & $355 / 355$ & $193 / 193$ & $271 / 271$ & $85 / 88$ & $120 / 125$ & $360 / 360$ & $121 / 126$ & $181 / 186$ & $389 / 389$ \\
\hline Cv16 & $138 / 140$ & $355 / 356$ & $183 / 193$ & $275 / 280$ & $88 / 98$ & $120 / 120$ & $369 / 369$ & $126 / 126$ & $181 / 181$ & $394 / 394$ \\
\hline Cv17 & $136 / 140$ & $355 / 355$ & $183 / 183$ & $275 / 275$ & $94 / 99$ & $120 / 120$ & $368 / 368$ & $126 / 131$ & $181 / 181$ & $389 / 394$ \\
\hline Cv18 & $136 / 140$ & $355 / 356$ & $183 / 183$ & $271 / 276$ & $89 / 99$ & $120 / 125$ & $360 / 360$ & $126 / 126$ & $181 / 181$ & $389 / 394$ \\
\hline Cv19 & $138 / 140$ & $355 / 355$ & $183 / 183$ & $275 / 275$ & $89 / 99$ & $120 / 125$ & $369 / 369$ & $126 / 131$ & $181 / 181$ & $389 / 394$ \\
\hline $\mathrm{Cv} 20$ & $140 / 140$ & $355 / 355$ & $183 / 193$ & $275 / 275$ & $89 / 94$ & $120 / 120$ & $360 / 360$ & $126 / 126$ & $181 / 181$ & $389 / 394$ \\
\hline Cv21 & $138 / 140$ & $356 / 359$ & $188 / 193$ & $275 / 275$ & $89 / 99$ & $120 / 120$ & $363 / 369$ & $126 / 126$ & $181 / 181$ & $389 / 394$ \\
\hline Cv22 & $138 / 140$ & $355 / 356$ & $183 / 193$ & $275 / 275$ & $85 / 89$ & $120 / 120$ & $363 / 369$ & $121 / 126$ & $181 / 181$ & $389 / 392$ \\
\hline Cv23 & $138 / 140$ & $355 / 356$ & $183 / 193$ & $271 / 276$ & $89 / 99$ & $120 / 120$ & $368 / 368$ & $121 / 126$ & $181 / 186$ & $384 / 389$ \\
\hline Cv24 & $131 / 140$ & $355 / 356$ & $183 / 193$ & $276 / 276$ & $89 / 89$ & $120 / 125$ & $363 / 368$ & $121 / 126$ & $181 / 181$ & $389 / 394$ \\
\hline Cv25 & $140 / 140$ & $355 / 359$ & $178 / 178$ & $275 / 275$ & $85 / 89$ & $125 / 125$ & $360 / 369$ & $121 / 126$ & $181 / 186$ & $389 / 389$ \\
\hline Cv26 & $131 / 140$ & $355 / 355$ & $183 / 193$ & $271 / 280$ & $89 / 99$ & $120 / 120$ & $360 / 360$ & $121 / 126$ & $181 / 181$ & $389 / 392$ \\
\hline $\mathrm{Cv} 27$ & $131 / 140$ & $355 / 355$ & $183 / 193$ & $275 / 275$ & $89 / 89$ & $125 / 125$ & $368 / 368$ & $121 / 126$ & $181 / 181$ & $389 / 394$ \\
\hline Cv28 & $140 / 140$ & $355 / 355$ & $188 / 188$ & $271 / 276$ & $85 / 89$ & $115 / 125$ & $360 / 369$ & $121 / 121$ & $181 / 186$ & $389 / 389$ \\
\hline Cv29 & $138 / 138$ & $355 / 355$ & $183 / 193$ & $275 / 280$ & $89 / 89$ & $120 / 120$ & $360 / 360$ & $126 / 126$ & $181 / 181$ & $389 / 389$ \\
\hline Cv30 & $131 / 140$ & $359 / 359$ & $183 / 183$ & $275 / 275$ & $85 / 89$ & $120 / 125$ & $352 / 360$ & $121 / 126$ & $181 / 181$ & $389 / 389$ \\
\hline Cv31 & $138 / 140$ & $355 / 355$ & $183 / 183$ & $272 / 276$ & $85 / 89$ & $120 / 120$ & $360 / 368$ & $121 / 126$ & $181 / 181$ & $389 / 394$ \\
\hline Cv32 & $138 / 138$ & $354 / 359$ & $183 / 193$ & $274 / 276$ & $99 / 99$ & $125 / 125$ & $363 / 369$ & $121 / 121$ & $181 / 186$ & $389 / 389$ \\
\hline Cv33 & $138 / 140$ & $355 / 359$ & $188 / 193$ & $275 / 275$ & $85 / 89$ & $120 / 125$ & $360 / 369$ & $121 / 126$ & $181 / 181$ & $389 / 389$ \\
\hline Cv34 & $138 / 138$ & $355 / 359$ & $193 / 193$ & $275 / 275$ & $89 / 99$ & $125 / 125$ & $352 / 360$ & $121 / 131$ & $181 / 186$ & $389 / 389$ \\
\hline Cv35 & $131 / 140$ & $355 / 356$ & $183 / 183$ & $286 / 286$ & $89 / 99$ & $120 / 120$ & $368 / 368$ & $121 / 126$ & $181 / 186$ & $389 / 394$ \\
\hline Cv36 & $140 / 140$ & $355 / 355$ & $193 / 193$ & $271 / 271$ & $85 / 89$ & $120 / 125$ & $368 / 368$ & $121 / 126$ & $181 / 181$ & $389 / 394$ \\
\hline
\end{tabular}


Supplemental Table 3. Continued.

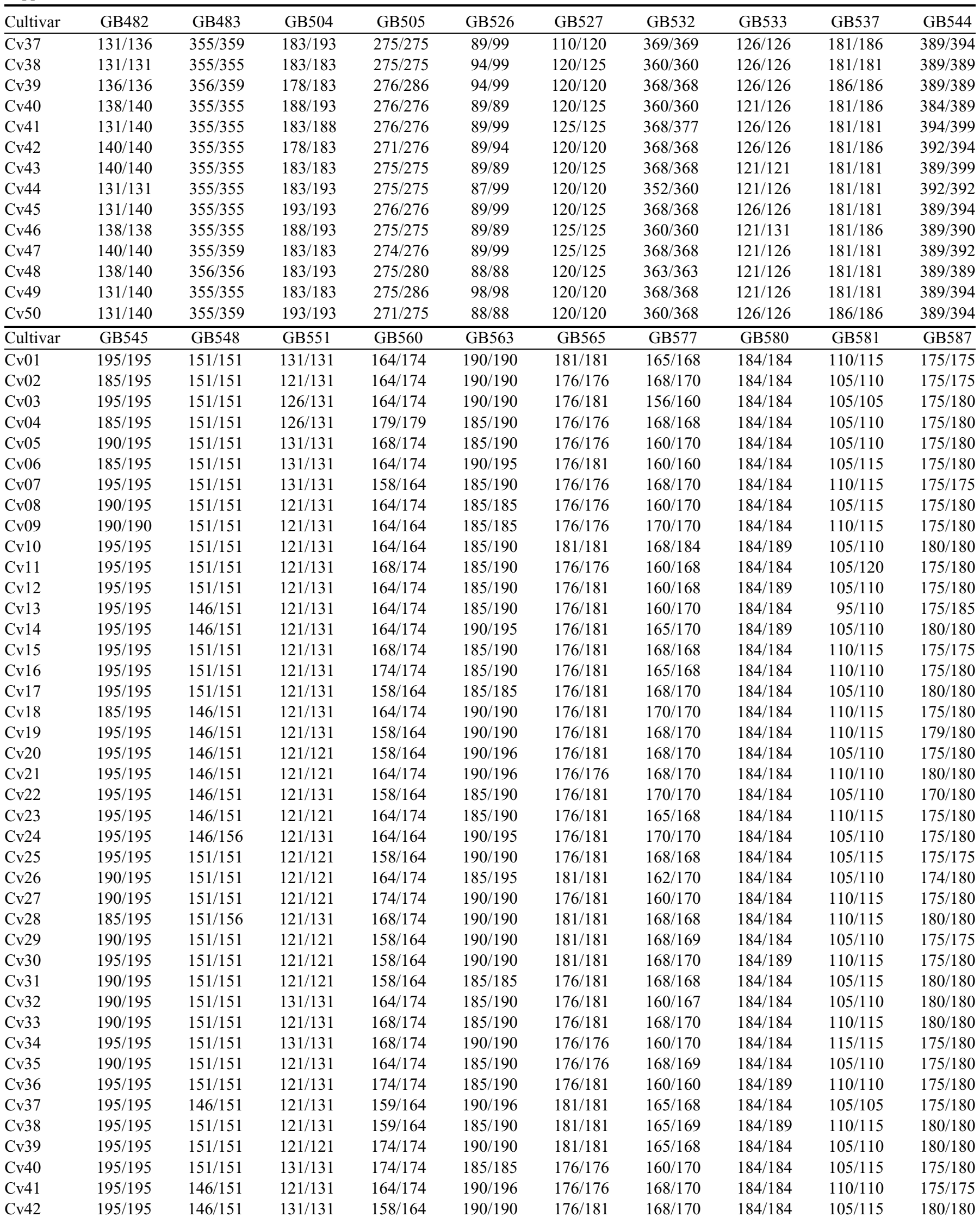


Supplemental Table 3. Continued.

\begin{tabular}{|c|c|c|c|c|c|c|c|c|c|c|}
\hline Cultivar & GB545 & GB548 & GB551 & GB560 & GB563 & GB565 & GB577 & GB580 & GB581 & GB587 \\
\hline$\overline{\mathrm{Cv} 43}$ & $195 / 195$ & $151 / 156$ & $121 / 131$ & $164 / 164$ & $185 / 195$ & $176 / 181$ & $170 / 184$ & $184 / 184$ & $105 / 110$ & $\overline{180 / 180}$ \\
\hline $\mathrm{Cv} 44$ & $195 / 195$ & $151 / 156$ & $121 / 131$ & $179 / 179$ & $190 / 195$ & $176 / 181$ & $165 / 170$ & $184 / 184$ & $105 / 110$ & $170 / 175$ \\
\hline $\mathrm{Cv} 45$ & $195 / 195$ & $151 / 156$ & $121 / 121$ & $174 / 179$ & $190 / 190$ & $176 / 181$ & $165 / 170$ & $184 / 184$ & $105 / 110$ & $175 / 180$ \\
\hline $\mathrm{Cv} 47$ & $190 / 195$ & $151 / 151$ & $121 / 131$ & $164 / 164$ & $185 / 190$ & $176 / 181$ & $168 / 170$ & $184 / 184$ & $110 / 110$ & $175 / 180$ \\
\hline Cv48 & $185 / 195$ & $146 / 151$ & $121 / 131$ & $174 / 174$ & $190 / 195$ & $176 / 176$ & $168 / 170$ & $184 / 184$ & $110 / 120$ & $180 / 180$ \\
\hline Cv49 & $195 / 195$ & $151 / 156$ & $131 / 131$ & $164 / 174$ & $185 / 195$ & $176 / 176$ & $168 / 169$ & $184 / 184$ & $105 / 105$ & $175 / 180$ \\
\hline Cultivar & GB601 & GB602 & GB603 & GB604 & GB605 & GB606 & GB614 & GB616 & GB617 & $\overline{\text { GB618 }}$ \\
\hline$\overline{\mathrm{Cv} 01}$ & $163 / 163$ & $234 / 240$ & $174 / 174$ & $191 / 191$ & $124 / 124$ & $330 / 331$ & $371 / 372$ & $359 / 359$ & $100 / 106$ & $322 / 322$ \\
\hline Cv02 & $163 / 163$ & $234 / 240$ & $162 / 174$ & $191 / 191$ & $118 / 124$ & $316 / 319$ & $371 / 371$ & $359 / 359$ & $100 / 106$ & $322 / 328$ \\
\hline $\mathrm{Cv} 03$ & $163 / 169$ & $234 / 234$ & $174 / 174$ & $191 / 191$ & $124 / 136$ & $318 / 330$ & $371 / 371$ & $359 / 359$ & $106 / 106$ & $313 / 322$ \\
\hline $\mathrm{Cv} 04$ & $163 / 163$ & $240 / 240$ & $174 / 174$ & $191 / 191$ & $118 / 124$ & $328 / 331$ & $371 / 371$ & $359 / 359$ & $106 / 106$ & $323 / 329$ \\
\hline Cv05 & $163 / 163$ & $234 / 240$ & $174 / 174$ & $191 / 191$ & $124 / 130$ & $316 / 331$ & $368 / 371$ & $359 / 359$ & $100 / 100$ & $322 / 322$ \\
\hline Cv09 & $163 / 163$ & $240 / 240$ & $174 / 174$ & $191 / 191$ & $118 / 124$ & $316 / 328$ & $371 / 371$ & $359 / 359$ & $100 / 112$ & $323 / 329$ \\
\hline Cv10 & $163 / 163$ & $234 / 240$ & $162 / 174$ & $191 / 197$ & $124 / 124$ & $328 / 328$ & $371 / 371$ & $359 / 359$ & $106 / 112$ & $316 / 329$ \\
\hline Cv11 & $163 / 163$ & $234 / 240$ & $162 / 174$ & $191 / 197$ & $124 / 124$ & $330 / 330$ & $365 / 365$ & $359 / 359$ & $106 / 112$ & $321 / 329$ \\
\hline Cv12 & $163 / 163$ & $234 / 240$ & $162 / 174$ & $191 / 197$ & $118 / 124$ & $328 / 330$ & $365 / 371$ & $359 / 359$ & $112 / 112$ & $316 / 323$ \\
\hline Cv13 & $163 / 169$ & $234 / 240$ & $162 / 174$ & $191 / 191$ & $124 / 124$ & $330 / 330$ & $368 / 371$ & $359 / 365$ & $106 / 106$ & $322 / 329$ \\
\hline Cv14 & $163 / 163$ & $240 / 240$ & $162 / 174$ & $191 / 197$ & $118 / 124$ & $330 / 330$ & $365 / 368$ & $359 / 365$ & $112 / 112$ & $321 / 329$ \\
\hline Cv15 & $163 / 163$ & $240 / 240$ & $174 / 180$ & $191 / 191$ & $124 / 124$ & $330 / 331$ & $371 / 372$ & $359 / 359$ & $100 / 106$ & $322 / 322$ \\
\hline Cv16 & $163 / 163$ & $240 / 240$ & $174 / 174$ & $191 / 197$ & $118 / 124$ & $328 / 331$ & $371 / 371$ & $359 / 359$ & $100 / 112$ & $322 / 322$ \\
\hline Cv17 & $157 / 163$ & $234 / 240$ & $174 / 174$ & $191 / 191$ & $124 / 124$ & $328 / 328$ & $365 / 371$ & $359 / 359$ & $106 / 112$ & $322 / 330$ \\
\hline Cv18 & $151 / 163$ & $234 / 234$ & $174 / 174$ & $191 / 197$ & $124 / 124$ & $316 / 328$ & $371 / 371$ & $359 / 359$ & $100 / 112$ & $321 / 329$ \\
\hline Cv19 & $157 / 163$ & $234 / 234$ & $174 / 174$ & $191 / 197$ & $118 / 124$ & $326 / 326$ & $371 / 372$ & $359 / 359$ & $106 / 106$ & $321 / 329$ \\
\hline Cv20 & $163 / 163$ & $234 / 234$ & $174 / 174$ & $191 / 197$ & $124 / 124$ & $328 / 330$ & $371 / 372$ & $359 / 359$ & $100 / 112$ & $322 / 329$ \\
\hline Cv28 & $157 / 163$ & $234 / 240$ & $162 / 174$ & $191 / 191$ & $124 / 124$ & $331 / 332$ & $371 / 371$ & $359 / 359$ & $106 / 106$ & $323 / 330$ \\
\hline Cv29 & $163 / 163$ & $240 / 240$ & $174 / 174$ & $191 / 191$ & $112 / 124$ & $328 / 331$ & $365 / 371$ & $359 / 359$ & $106 / 106$ & $322 / 329$ \\
\hline Cv30 & $163 / 163$ & $240 / 240$ & $162 / 174$ & $191 / 191$ & $118 / 124$ & $328 / 337$ & $368 / 371$ & $359 / 359$ & $106 / 112$ & $315 / 334$ \\
\hline Cv31 & $163 / 163$ & $234 / 240$ & $162 / 174$ & $191 / 191$ & $124 / 130$ & $328 / 331$ & $371 / 371$ & $359 / 359$ & $106 / 106$ & $311 / 323$ \\
\hline Cv32 & $163 / 163$ & $234 / 240$ & $174 / 174$ & $191 / 191$ & $124 / 124$ & $316 / 316$ & $371 / 371$ & $359 / 359$ & $106 / 112$ & $322 / 330$ \\
\hline Cv33 & $163 / 163$ & $234 / 240$ & $174 / 174$ & $191 / 191$ & $124 / 124$ & $328 / 328$ & $365 / 371$ & $359 / 359$ & $100 / 106$ & $322 / 354$ \\
\hline Cv34 & $163 / 163$ & $234 / 240$ & $174 / 174$ & $191 / 191$ & $118 / 124$ & $316 / 328$ & $371 / 371$ & $359 / 359$ & $106 / 106$ & $322 / 328$ \\
\hline Cv35 & $163 / 163$ & $234 / 240$ & $174 / 180$ & $191 / 191$ & $118 / 124$ & $330 / 330$ & $365 / 365$ & $359 / 359$ & $106 / 112$ & $321 / 335$ \\
\hline Cv36 & $163 / 163$ & $234 / 240$ & $162 / 174$ & $191 / 197$ & $112 / 124$ & $320 / 328$ & $365 / 371$ & $359 / 359$ & $100 / 100$ & $322 / 330$ \\
\hline Cv37 & $163 / 163$ & $234 / 240$ & $162 / 162$ & $191 / 197$ & $124 / 124$ & $330 / 331$ & $365 / 368$ & $359 / 365$ & $112 / 112$ & $322 / 322$ \\
\hline Cv38 & $163 / 163$ & $240 / 240$ & $174 / 174$ & $191 / 191$ & $124 / 124$ & $330 / 331$ & $371 / 371$ & $359 / 359$ & $100 / 112$ & $324 / 330$ \\
\hline Cv39 & $163 / 163$ & $234 / 234$ & $162 / 174$ & $191 / 191$ & $124 / 130$ & $330 / 331$ & $365 / 368$ & $359 / 365$ & $106 / 106$ & $317 / 329$ \\
\hline Cv40 & $163 / 163$ & $234 / 240$ & $174 / 174$ & $191 / 197$ & $124 / 124$ & $316 / 331$ & $365 / 371$ & $359 / 359$ & $106 / 106$ & $322 / 322$ \\
\hline Cv41 & $163 / 163$ & $240 / 240$ & $174 / 174$ & $191 / 191$ & $124 / 124$ & $328 / 328$ & $371 / 371$ & $359 / 359$ & $106 / 112$ & $321 / 336$ \\
\hline Cv42 & $163 / 163$ & $240 / 240$ & $174 / 174$ & $191 / 191$ & $124 / 124$ & $328 / 328$ & $365 / 371$ & $359 / 359$ & $112 / 112$ & $321 / 321$ \\
\hline Cv43 & $163 / 163$ & $240 / 240$ & $174 / 174$ & $191 / 197$ & $118 / 124$ & $328 / 328$ & $371 / 371$ & $359 / 359$ & $112 / 112$ & $322 / 330$ \\
\hline Cv44 & $163 / 163$ & $234 / 234$ & $162 / 174$ & $191 / 191$ & $124 / 124$ & $328 / 328$ & $371 / 372$ & $359 / 359$ & $106 / 112$ & $321 / 329$ \\
\hline $\mathrm{Cv} 45$ & $163 / 163$ & $240 / 240$ & $174 / 174$ & $197 / 197$ & $118 / 124$ & $328 / 330$ & $371 / 372$ & $359 / 359$ & $112 / 112$ & $321 / 321$ \\
\hline Cv46 & $163 / 163$ & $240 / 246$ & $174 / 174$ & $191 / 191$ & $118 / 130$ & $316 / 328$ & $362 / 373$ & $359 / 359$ & $106 / 112$ & $330 / 330$ \\
\hline Cv47 & $163 / 163$ & $240 / 240$ & $174 / 174$ & $191 / 191$ & $112 / 118$ & $328 / 330$ & $365 / 371$ & $359 / 359$ & $100 / 112$ & $329 / 329$ \\
\hline
\end{tabular}


Supplemental Table 3. Continued.

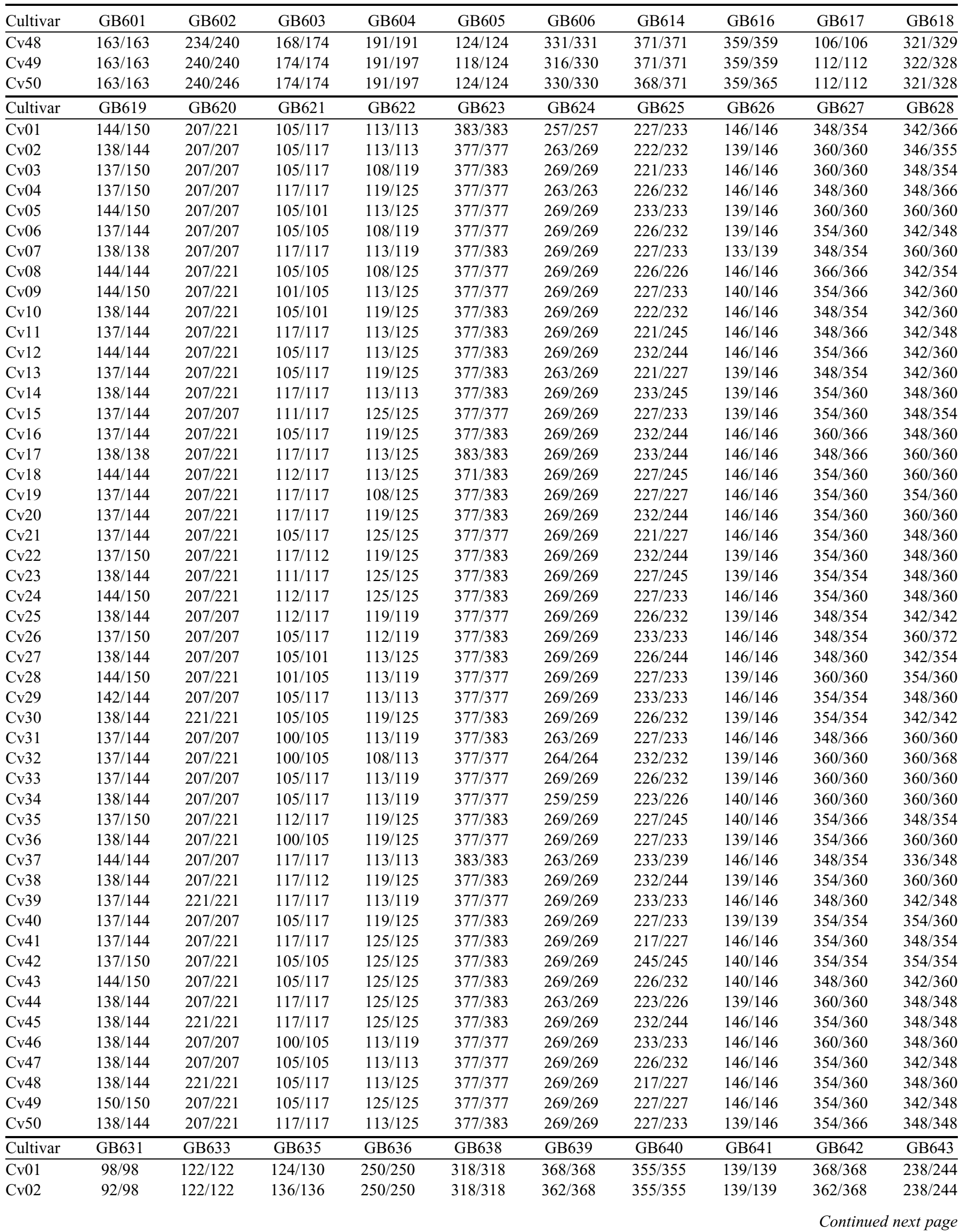


Supplemental Table 3. Continued.

\begin{tabular}{|c|c|c|c|c|c|c|c|c|c|c|}
\hline Cultivar & GB631 & GB633 & GB635 & GB636 & GB638 & GB639 & GB640 & GB641 & GB642 & GB643 \\
\hline$\overline{\mathrm{Cv03}}$ & $92 / 98$ & $116 / 122$ & $130 / 136$ & $262 / 262$ & $306 / 318$ & $368 / 368$ & $355 / 355$ & $139 / 139$ & $368 / 368$ & $238 / 238$ \\
\hline $\mathrm{Cv04}$ & $92 / 98$ & $122 / 122$ & $124 / 130$ & $250 / 262$ & $306 / 318$ & $368 / 374$ & $355 / 355$ & $139 / 139$ & $362 / 368$ & $238 / 244$ \\
\hline Cv05 & $92 / 98$ & $122 / 122$ & $130 / 136$ & $262 / 262$ & $318 / 318$ & $368 / 368$ & $355 / 355$ & $139 / 139$ & $362 / 362$ & $238 / 238$ \\
\hline $\mathrm{Cv07}$ & $92 / 98$ & $116 / 122$ & $136 / 142$ & $250 / 262$ & $306 / 318$ & $368 / 368$ & $354 / 354$ & $139 / 139$ & $368 / 368$ & $238 / 238$ \\
\hline Cv08 & $92 / 98$ & $116 / 122$ & $130 / 130$ & $250 / 250$ & $306 / 318$ & $362 / 371$ & $355 / 355$ & $139 / 139$ & $368 / 368$ & $238 / 244$ \\
\hline Cv11 & $98 / 98$ & $116 / 116$ & $130 / 130$ & $262 / 263$ & $318 / 324$ & $369 / 371$ & $360 / 360$ & $139 / 152$ & $368 / 368$ & $238 / 244$ \\
\hline Cv12 & $92 / 98$ & $116 / 122$ & $130 / 130$ & $250 / 262$ & $318 / 318$ & $362 / 371$ & $360 / 360$ & $139 / 139$ & $368 / 368$ & $238 / 244$ \\
\hline Cv13 & $98 / 98$ & $116 / 122$ & $130 / 136$ & $250 / 262$ & $318 / 318$ & $368 / 371$ & $356 / 360$ & $139 / 152$ & $368 / 368$ & $238 / 244$ \\
\hline Cv14 & $92 / 98$ & $116 / 122$ & $130 / 130$ & $262 / 262$ & $318 / 324$ & $371 / 372$ & $360 / 360$ & $139 / 152$ & $368 / 368$ & $238 / 238$ \\
\hline Cv15 & $92 / 98$ & $116 / 122$ & $130 / 136$ & $262 / 262$ & $324 / 324$ & $368 / 368$ & $354 / 354$ & $139 / 139$ & $362 / 368$ & $232 / 244$ \\
\hline Cv16 & $98 / 98$ & $116 / 116$ & $118 / 130$ & $250 / 262$ & $318 / 324$ & $368 / 371$ & $355 / 355$ & $139 / 152$ & $368 / 368$ & $232 / 238$ \\
\hline Cv20 & $98 / 98$ & $116 / 122$ & $130 / 130$ & $250 / 250$ & $306 / 324$ & $368 / 371$ & $354 / 360$ & $139 / 152$ & $368 / 368$ & $232 / 238$ \\
\hline Cv21 & $92 / 98$ & $116 / 122$ & $130 / 130$ & $262 / 262$ & $318 / 324$ & $368 / 371$ & $355 / 355$ & $139 / 152$ & $362 / 368$ & $238 / 238$ \\
\hline $\mathrm{Cv} 22$ & $92 / 98$ & $122 / 122$ & $130 / 136$ & $250 / 262$ & $324 / 324$ & $368 / 371$ & $355 / 355$ & $139 / 139$ & $368 / 368$ & $238 / 244$ \\
\hline Cv23 & $92 / 98$ & $116 / 122$ & $130 / 136$ & $250 / 262$ & $324 / 324$ & $368 / 371$ & $354 / 354$ & $139 / 152$ & $368 / 368$ & $232 / 238$ \\
\hline Cv24 & $92 / 98$ & $116 / 122$ & $130 / 130$ & $250 / 262$ & $324 / 324$ & $368 / 371$ & $355 / 355$ & $139 / 152$ & $368 / 368$ & $238 / 244$ \\
\hline Cv25 & $92 / 98$ & $116 / 122$ & $130 / 130$ & $250 / 262$ & $318 / 324$ & $362 / 362$ & $355 / 355$ & $139 / 139$ & $368 / 368$ & $244 / 244$ \\
\hline Cv26 & $98 / 98$ & $122 / 122$ & $130 / 136$ & $250 / 256$ & $318 / 318$ & $362 / 368$ & $355 / 355$ & $139 / 139$ & $362 / 368$ & $237 / 244$ \\
\hline Cv27 & $92 / 98$ & $116 / 116$ & $130 / 130$ & $250 / 262$ & $318 / 318$ & $362 / 371$ & $355 / 355$ & $139 / 139$ & $362 / 368$ & $238 / 238$ \\
\hline Cv28 & $92 / 98$ & $116 / 122$ & $130 / 130$ & $256 / 262$ & $318 / 324$ & $368 / 368$ & $355 / 355$ & $139 / 139$ & $368 / 368$ & $232 / 238$ \\
\hline Cv29 & $92 / 92$ & $116 / 116$ & $130 / 130$ & $262 / 262$ & $318 / 324$ & $368 / 368$ & $355 / 355$ & $139 / 139$ & $368 / 368$ & $238 / 250$ \\
\hline Cv30 & $92 / 98$ & $122 / 122$ & $130 / 130$ & $250 / 262$ & $318 / 318$ & $362 / 371$ & $355 / 355$ & $139 / 139$ & $362 / 368$ & $238 / 243$ \\
\hline Cv31 & $92 / 98$ & $110 / 122$ & $130 / 130$ & $256 / 256$ & $297 / 306$ & $362 / 368$ & $355 / 355$ & $139 / 139$ & $362 / 368$ & $244 / 250$ \\
\hline Cv39 & $92 / 92$ & $116 / 122$ & $130 / 136$ & $250 / 262$ & $324 / 324$ & $371 / 373$ & $346 / 346$ & $139 / 139$ & $368 / 368$ & $238 / 238$ \\
\hline Cv40 & $92 / 98$ & $116 / 122$ & $124 / 130$ & $250 / 262$ & $318 / 324$ & $362 / 371$ & $354 / 354$ & $139 / 139$ & $362 / 368$ & $238 / 244$ \\
\hline Cv41 & $92 / 98$ & $122 / 122$ & $130 / 130$ & $250 / 262$ & $318 / 324$ & $368 / 371$ & $355 / 355$ & $139 / 152$ & $362 / 368$ & $238 / 244$ \\
\hline $\mathrm{Cv} 42$ & $92 / 98$ & $122 / 122$ & $130 / 130$ & $250 / 262$ & $324 / 324$ & $362 / 368$ & $360 / 360$ & $139 / 152$ & $368 / 368$ & $244 / 244$ \\
\hline Cv43 & $92 / 92$ & $116 / 122$ & $130 / 130$ & $250 / 262$ & $318 / 324$ & $362 / 368$ & $360 / 360$ & $139 / 152$ & $368 / 368$ & $244 / 244$ \\
\hline Cv44 & $92 / 98$ & $116 / 122$ & $118 / 130$ & $250 / 262$ & $324 / 324$ & $362 / 371$ & $355 / 355$ & $139 / 152$ & $362 / 362$ & $238 / 244$ \\
\hline Cv45 & $92 / 98$ & $116 / 116$ & $118 / 130$ & $250 / 250$ & $324 / 324$ & $368 / 371$ & $355 / 355$ & $139 / 152$ & $368 / 368$ & $237 / 237$ \\
\hline Cv46 & $92 / 98$ & $122 / 122$ & $130 / 136$ & $250 / 250$ & $318 / 318$ & $362 / 368$ & $355 / 355$ & $139 / 139$ & $368 / 368$ & $238 / 244$ \\
\hline Cv47 & $92 / 98$ & $116 / 122$ & $130 / 130$ & $250 / 262$ & $318 / 318$ & $371 / 374$ & $355 / 355$ & $139 / 139$ & $368 / 368$ & $238 / 244$ \\
\hline Cv48 & $92 / 92$ & $116 / 122$ & $118 / 130$ & $262 / 262$ & $318 / 318$ & $362 / 368$ & $355 / 355$ & $139 / 139$ & $368 / 368$ & $244 / 244$ \\
\hline Cv49 & $92 / 98$ & $116 / 122$ & $130 / 130$ & $250 / 262$ & $324 / 324$ & $368 / 368$ & $355 / 355$ & $139 / 139$ & $362 / 368$ & $244 / 244$ \\
\hline Cv50 & $98 / 98$ & $116 / 122$ & $130 / 142$ & $250 / 262$ & $318 / 324$ & $368 / 368$ & $346 / 354$ & $139 / 152$ & $368 / 368$ & $238 / 244$ \\
\hline Cultivar & GB645 & GB646 & GB647 & GB649 & GB652 & GB653 & GB654 & GB655 & GB657 & GB658 \\
\hline$\overline{\mathrm{Cv} 01}$ & $298 / 298$ & $279 / 285$ & $171 / 177$ & $250 / 250$ & $224 / 224$ & $195 / 203$ & $269 / 279$ & $237 / 247$ & $200 / 206$ & $333 / 351$ \\
\hline $\mathrm{Cv02}$ & $292 / 292$ & $273 / 273$ & $165 / 183$ & $250 / 250$ & $224 / 224$ & $203 / 209$ & $279 / 279$ & $235 / 235$ & $200 / 200$ & $339 / 342$ \\
\hline Cv03 & $292 / 306$ & $271 / 271$ & $165 / 177$ & $251 / 252$ & $211 / 224$ & $195 / 203$ & $275 / 279$ & $241 / 247$ & $200 / 206$ & $342 / 342$ \\
\hline $\mathrm{Cv} 04$ & $292 / 292$ & $273 / 273$ & $165 / 177$ & $250 / 250$ & $218 / 224$ & $195 / 203$ & $275 / 290$ & $235 / 235$ & $192 / 200$ & $342 / 345$ \\
\hline Cv05 & $292 / 292$ & $271 / 271$ & $177 / 177$ & $250 / 250$ & $214 / 214$ & $203 / 209$ & $277 / 279$ & $235 / 247$ & $198 / 204$ & $339 / 342$ \\
\hline Cv06 & $286 / 298$ & $271 / 271$ & $177 / 177$ & $250 / 250$ & $218 / 224$ & $203 / 209$ & $273 / 275$ & $235 / 247$ & $192 / 200$ & $342 / 342$ \\
\hline Cv07 & $286 / 292$ & $271 / 271$ & $177 / 177$ & $250 / 250$ & $218 / 224$ & $203 / 209$ & $273 / 279$ & $247 / 247$ & $200 / 206$ & $339 / 342$ \\
\hline Cv08 & $292 / 293$ & $271 / 277$ & $177 / 177$ & $252 / 252$ & $224 / 224$ & $203 / 209$ & $275 / 279$ & $247 / 247$ & $192 / 200$ & $330 / 342$ \\
\hline
\end{tabular}


Supplemental Table 3. Continued.

\begin{tabular}{|c|c|c|c|c|c|c|c|c|c|c|}
\hline Cultivar & GB645 & GB646 & GB647 & GB649 & GB652 & GB653 & GB654 & GB655 & GB657 & GB658 \\
\hline$\overline{\text { Cv09 }}$ & $292 / 293$ & $273 / 279$ & $177 / 177$ & $250 / 250$ & $218 / 226$ & $203 / 209$ & $275 / 279$ & $247 / 253$ & $198 / 204$ & $339 / 342$ \\
\hline Cv10 & $286 / 292$ & $271 / 277$ & $171 / 177$ & $250 / 250$ & $218 / 223$ & $195 / 203$ & $275 / 275$ & $253 / 253$ & $198 / 204$ & $330 / 339$ \\
\hline Cv11 & $286 / 293$ & $273 / 273$ & $177 / 177$ & $252 / 264$ & $210 / 224$ & $203 / 203$ & $275 / 275$ & $235 / 247$ & $200 / 200$ & $330 / 339$ \\
\hline Cv13 & $292 / 292$ & $271 / 271$ & $177 / 177$ & $252 / 264$ & $224 / 224$ & $203 / 209$ & $279 / 279$ & $247 / 247$ & $194 / 200$ & $342 / 342$ \\
\hline Cv14 & $286 / 292$ & $271 / 291$ & $171 / 178$ & $252 / 264$ & $210 / 224$ & $195 / 203$ & $275 / 275$ & $235 / 247$ & $200 / 206$ & $330 / 342$ \\
\hline Cv17 & $292 / 298$ & $273 / 273$ & $165 / 177$ & $252 / 264$ & $224 / 224$ & $195 / 203$ & $269 / 275$ & $247 / 253$ & $198 / 204$ & $330 / 339$ \\
\hline Cv18 & $292 / 298$ & $273 / 285$ & $165 / 171$ & $252 / 264$ & $218 / 224$ & $203 / 209$ & $275 / 275$ & $247 / 253$ & $198 / 204$ & $339 / 342$ \\
\hline Cv19 & $292 / 293$ & $271 / 271$ & $165 / 171$ & $252 / 264$ & $218 / 224$ & $203 / 209$ & $275 / 279$ & $235 / 235$ & $204 / 204$ & $333 / 342$ \\
\hline Cv20 & $292 / 293$ & $271 / 271$ & $171 / 177$ & $252 / 264$ & $224 / 230$ & $203 / 209$ & $275 / 275$ & $247 / 253$ & $198 / 204$ & $342 / 342$ \\
\hline Cv21 & $292 / 293$ & $273 / 273$ & $165 / 171$ & $252 / 264$ & $224 / 224$ & $203 / 209$ & $275 / 275$ & $235 / 235$ & $198 / 204$ & $339 / 342$ \\
\hline Cv22 & $292 / 293$ & $271 / 271$ & $165 / 177$ & $250 / 250$ & $223 / 223$ & $203 / 209$ & $275 / 279$ & $247 / 253$ & $200 / 200$ & $330 / 345$ \\
\hline Cv27 & $292 / 292$ & $273 / 279$ & $177 / 177$ & $252 / 252$ & $224 / 224$ & $203 / 209$ & $275 / 275$ & $235 / 247$ & $200 / 206$ & $339 / 342$ \\
\hline Cv28 & $292 / 292$ & $271 / 271$ & $165 / 177$ & $252 / 252$ & $218 / 224$ & $195 / 203$ & $275 / 279$ & $235 / 247$ & $198 / 204$ & $339 / 342$ \\
\hline Cv29 & $292 / 293$ & $273 / 273$ & $174 / 177$ & $250 / 250$ & $218 / 224$ & $195 / 203$ & $273 / 279$ & $235 / 247$ & $200 / 206$ & $339 / 342$ \\
\hline Cv30 & $292 / 293$ & $273 / 279$ & $177 / 178$ & $252 / 252$ & $224 / 224$ & $203 / 209$ & $275 / 279$ & $247 / 253$ & $198 / 198$ & $342 / 342$ \\
\hline Cv31 & $292 / 292$ & $273 / 273$ & $165 / 171$ & $250 / 250$ & $218 / 224$ & $195 / 203$ & $275 / 279$ & $247 / 247$ & $200 / 212$ & $339 / 342$ \\
\hline Cv32 & $286 / 292$ & $273 / 291$ & $177 / 177$ & $250 / 250$ & $210 / 224$ & $203 / 203$ & $275 / 275$ & $235 / 247$ & $204 / 204$ & $339 / 345$ \\
\hline Cv33 & $292 / 292$ & $273 / 279$ & $165 / 177$ & $250 / 250$ & $224 / 224$ & $203 / 209$ & $273 / 279$ & $235 / 247$ & $204 / 204$ & $339 / 342$ \\
\hline Cv34 & $286 / 292$ & $273 / 273$ & $165 / 177$ & $250 / 250$ & $224 / 224$ & $203 / 203$ & $273 / 275$ & $247 / 247$ & $198 / 204$ & $339 / 342$ \\
\hline Cv35 & $293 / 298$ & $271 / 277$ & $177 / 178$ & $250 / 250$ & $210 / 224$ & $196 / 203$ & $275 / 275$ & $235 / 247$ & $198 / 198$ & $327 / 330$ \\
\hline Cv36 & $286 / 292$ & $273 / 273$ & $171 / 171$ & $250 / 250$ & $224 / 224$ & $203 / 209$ & $275 / 275$ & $235 / 247$ & $204 / 204$ & $333 / 342$ \\
\hline Cv37 & $286 / 292$ & $273 / 291$ & $171 / 177$ & $251 / 264$ & $212 / 224$ & $203 / 203$ & $275 / 275$ & $235 / 247$ & $198 / 204$ & $330 / 342$ \\
\hline Cv45 & $292 / 293$ & $271 / 271$ & $171 / 183$ & $252 / 264$ & $218 / 224$ & $195 / 203$ & $275 / 279$ & $235 / 253$ & $200 / 200$ & $333 / 342$ \\
\hline Cv46 & $286 / 292$ & $271 / 271$ & $177 / 177$ & $252 / 252$ & $218 / 224$ & $203 / 203$ & $273 / 273$ & $235 / 247$ & $198 / 204$ & $339 / 342$ \\
\hline Cv47 & $292 / 293$ & $273 / 279$ & $177 / 177$ & $250 / 250$ & $224 / 224$ & $203 / 203$ & $275 / 275$ & $235 / 253$ & $192 / 198$ & $330 / 339$ \\
\hline $\mathrm{Cv} 48$ & $286 / 298$ & $273 / 273$ & $165 / 165$ & $252 / 252$ & $218 / 224$ & $195 / 203$ & $275 / 275$ & $253 / 253$ & $204 / 210$ & $342 / 342$ \\
\hline Cv49 & $292 / 298$ & $273 / 291$ & $171 / 177$ & $251 / 252$ & $224 / 224$ & $199 / 209$ & $279 / 279$ & $235 / 247$ & $198 / 198$ & $339 / 342$ \\
\hline Cv50 & $292 / 293$ & $285 / 285$ & $171 / 177$ & $252 / 264$ & $224 / 224$ & $199 / 203$ & $273 / 279$ & $235 / 247$ & $198 / 204$ & $339 / 342$ \\
\hline Cultivar & GB659 & GB660 & GB661 & GB663 & GB664 & GB665 & GB668 & GB669 & GB670 & $\overline{\text { GB671 }}$ \\
\hline$\overline{\mathrm{Cv} 01}$ & $210 / 210$ & $208 / 210$ & $217 / 217$ & $133 / 139$ & $302 / 302$ & $181 / 193$ & $177 / 183$ & $111 / 117$ & $247 / 253$ & $253 / 257$ \\
\hline $\mathrm{Cv02}$ & $210 / 216$ & $208 / 209$ & $217 / 217$ & $133 / 139$ & $302 / 302$ & $181 / 181$ & $177 / 183$ & $111 / 117$ & $265 / 265$ & $248 / 253$ \\
\hline $\mathrm{Cv03}$ & $210 / 210$ & $208 / 208$ & $205 / 211$ & $127 / 133$ & $302 / 302$ & $181 / 187$ & $177 / 183$ & $111 / 111$ & $250 / 256$ & $247 / 247$ \\
\hline Cv04 & $210 / 216$ & $210 / 210$ & $217 / 217$ & $127 / 133$ & $302 / 308$ & $175 / 181$ & $177 / 177$ & $111 / 117$ & $265 / 265$ & $291 / 291$ \\
\hline Cv05 & $210 / 222$ & $203 / 211$ & $205 / 217$ & $133 / 133$ & $302 / 308$ & $181 / 181$ & $177 / 183$ & $106 / 111$ & $250 / 256$ & $249 / 249$ \\
\hline Cv06 & $210 / 210$ & $208 / 208$ & $205 / 205$ & $127 / 133$ & $302 / 302$ & $181 / 193$ & $177 / 183$ & $111 / 117$ & $250 / 250$ & $247 / 248$ \\
\hline $\mathrm{Cv07}$ & $210 / 216$ & $203 / 208$ & $217 / 217$ & $127 / 133$ & $302 / 302$ & $181 / 187$ & $177 / 183$ & $111 / 117$ & $250 / 268$ & $247 / 247$ \\
\hline Cv08 & $210 / 210$ & $203 / 208$ & $211 / 217$ & $127 / 133$ & $302 / 308$ & $181 / 193$ & $177 / 177$ & $111 / 117$ & $250 / 250$ & $247 / 247$ \\
\hline Cv09 & $210 / 210$ & $203 / 210$ & $211 / 217$ & $127 / 133$ & $308 / 308$ & $181 / 193$ & $177 / 177$ & $111 / 117$ & $253 / 253$ & $247 / 247$ \\
\hline Cv10 & $210 / 219$ & $203 / 209$ & $205 / 217$ & $127 / 133$ & $302 / 308$ & $181 / 193$ & $177 / 177$ & $111 / 117$ & $250 / 250$ & $247 / 247$ \\
\hline Cv11 & $210 / 219$ & $210 / 214$ & $217 / 217$ & $133 / 133$ & $302 / 308$ & $181 / 193$ & $177 / 183$ & $106 / 111$ & $253 / 259$ & $247 / 247$ \\
\hline Cv12 & $216 / 219$ & $208 / 208$ & $217 / 217$ & $127 / 133$ & $302 / 302$ & $181 / 193$ & $177 / 183$ & $111 / 117$ & $250 / 250$ & $247 / 247$ \\
\hline Cv13 & $210 / 216$ & $203 / 209$ & $211 / 217$ & $133 / 133$ & $302 / 302$ & $187 / 193$ & $183 / 183$ & $106 / 111$ & $250 / 250$ & $247 / 247$ \\
\hline Cv14 & $210 / 219$ & $210 / 214$ & $217 / 217$ & $133 / 133$ & $302 / 302$ & $181 / 181$ & $177 / 183$ & $111 / 111$ & $250 / 256$ & $234 / 247$ \\
\hline
\end{tabular}


Supplemental Table 3. Continued.

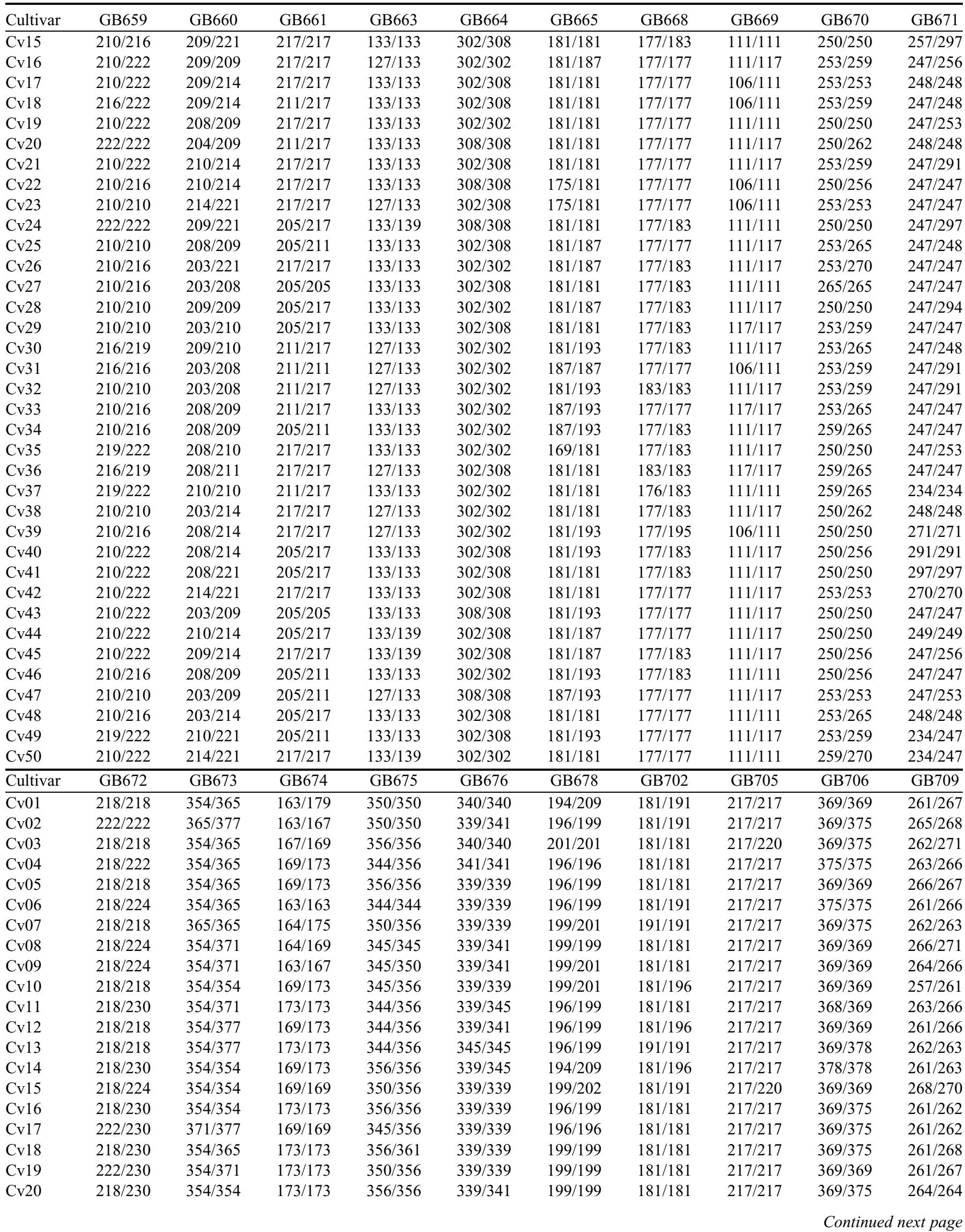


Supplemental Table 3. Continued.

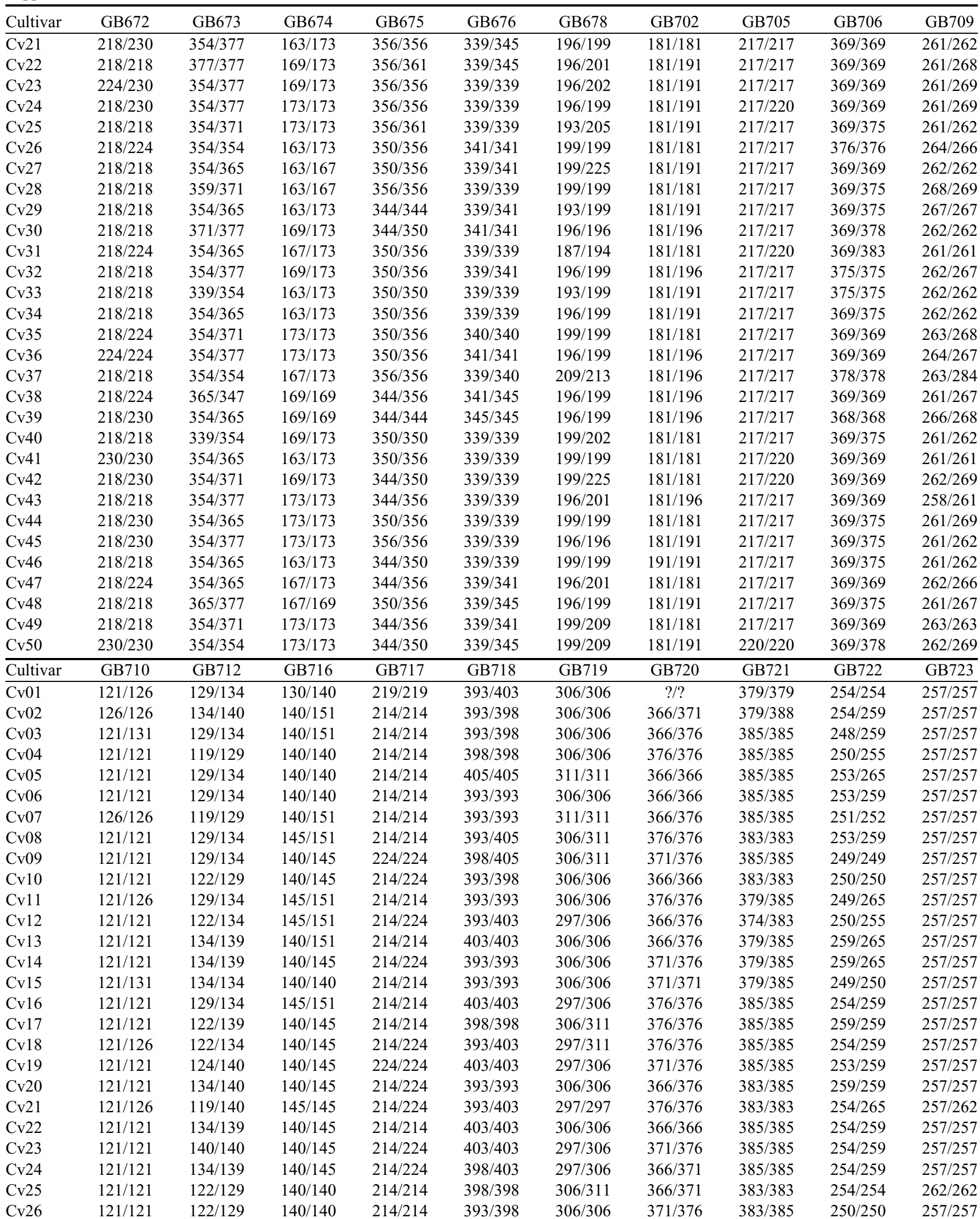

Continued next page 
Supplemental Table 3. Continued.

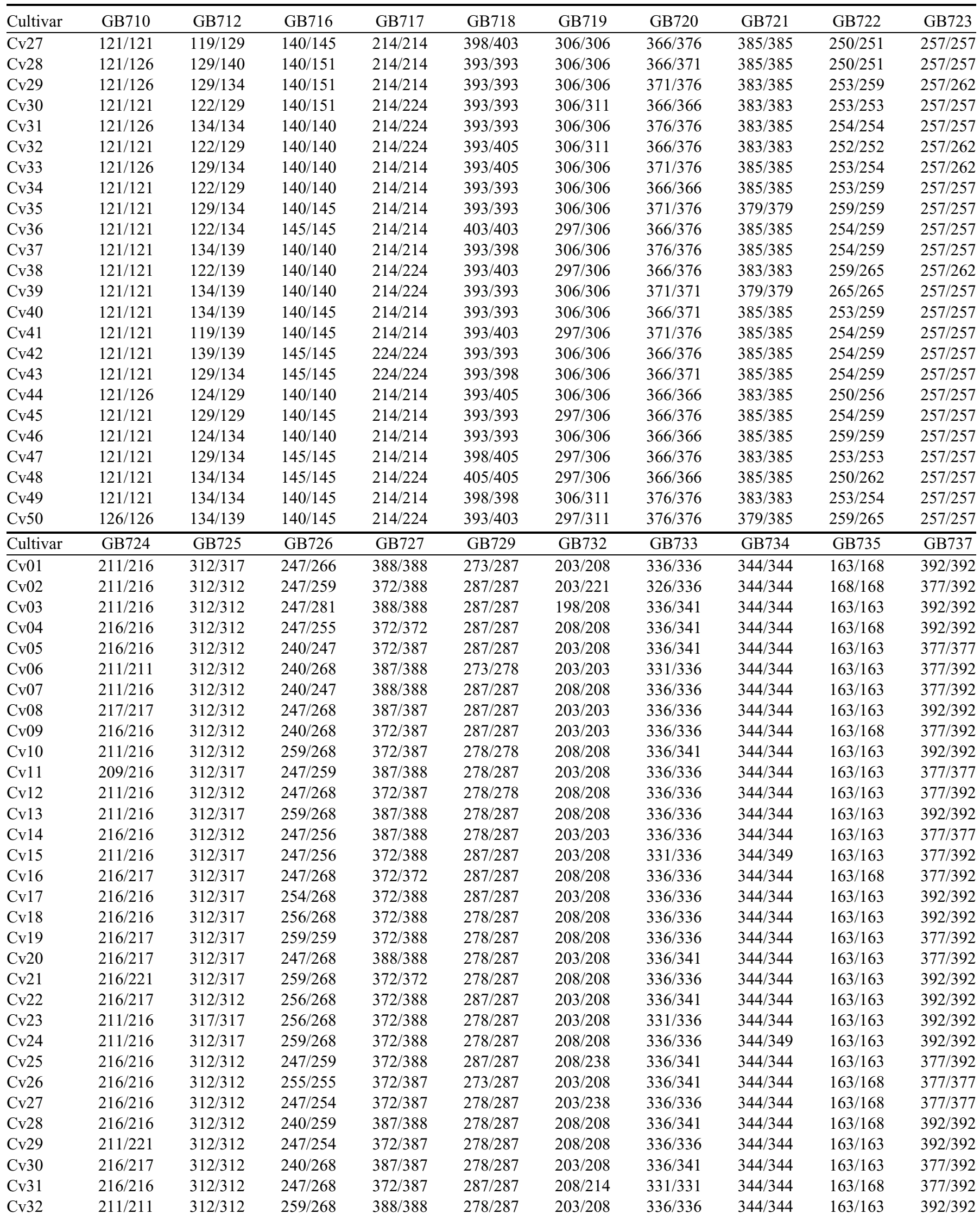


Supplemental Table 3. Continued.

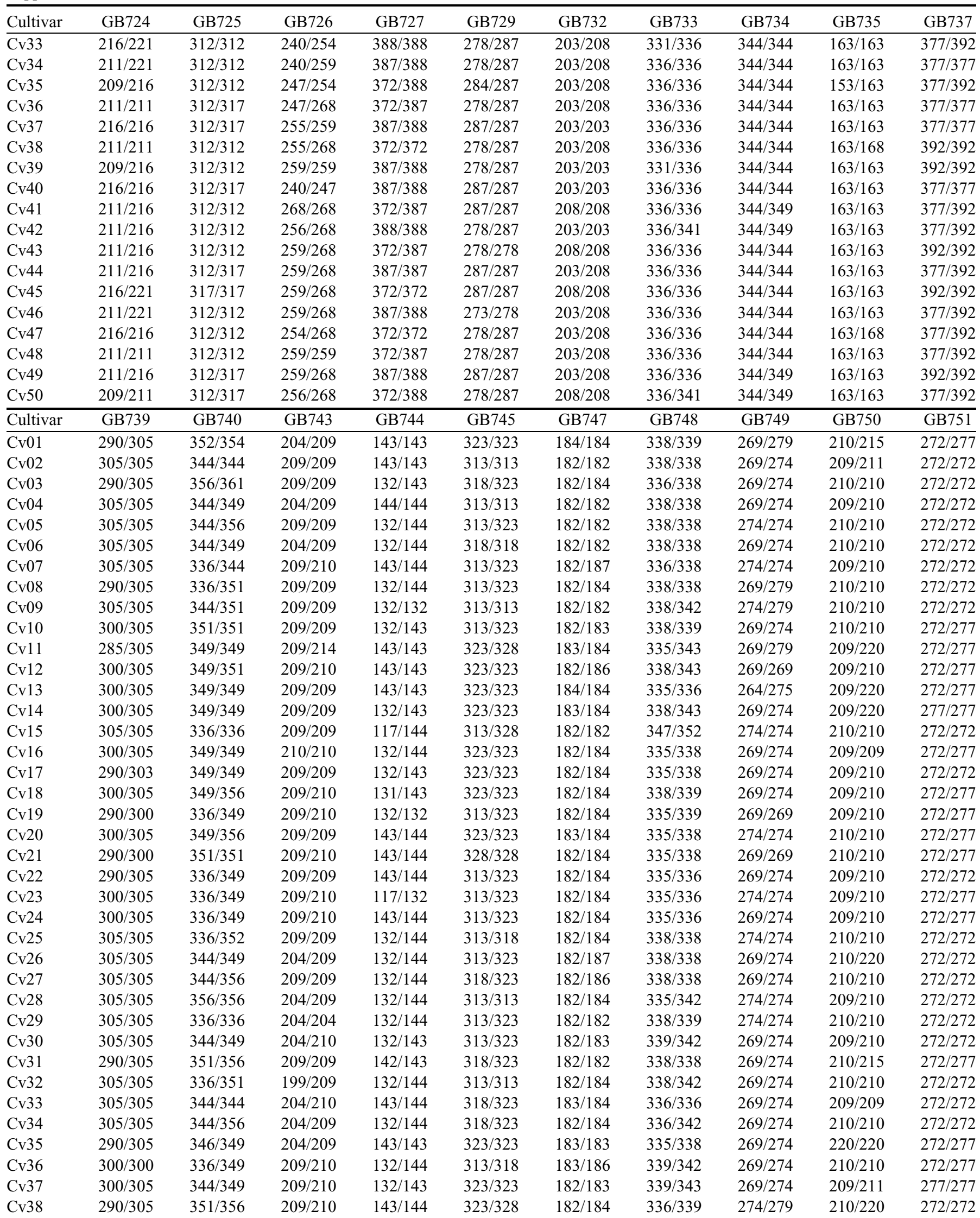

Continued next page 
Supplemental Table 3. Continued.

\begin{tabular}{|c|c|c|c|c|c|c|c|c|c|c|}
\hline Cultivar & GB739 & GB740 & GB743 & GB744 & GB745 & GB747 & GB748 & GB749 & GB750 & GB751 \\
\hline Cv39 & $300 / 305$ & $349 / 349$ & $209 / 214$ & $132 / 143$ & $323 / 323$ & $182 / 184$ & $338 / 338$ & $264 / 269$ & $220 / 220$ & $277 / 277$ \\
\hline $\mathrm{Cv} 40$ & $300 / 305$ & $344 / 349$ & $209 / 209$ & $132 / 143$ & $318 / 323$ & $182 / 184$ & $335 / 342$ & $269 / 274$ & $210 / 210$ & $272 / 277$ \\
\hline Cv41 & $300 / 305$ & $349 / 349$ & $209 / 210$ & $144 / 144$ & $323 / 323$ & $182 / 184$ & $335 / 336$ & $269 / 279$ & $209 / 210$ & $272 / 272$ \\
\hline Cv43 & $300 / 305$ & $349 / 351$ & $209 / 209$ & $132 / 143$ & $313 / 323$ & $182 / 184$ & $335 / 338$ & $269 / 274$ & $209 / 210$ & $272 / 277$ \\
\hline $\mathrm{Cv} 44$ & $300 / 305$ & $344 / 349$ & $209 / 209$ & $143 / 144$ & $323 / 323$ & $182 / 184$ & $335 / 336$ & $274 / 274$ & $209 / 210$ & $272 / 272$ \\
\hline Cv45 & $300 / 305$ & $349 / 349$ & $209 / 210$ & $132 / 144$ & $323 / 323$ & $182 / 184$ & $335 / 336$ & $269 / 269$ & $209 / 210$ & $272 / 277$ \\
\hline Cv47 & $305 / 305$ & $351 / 356$ & $209 / 210$ & $132 / 132$ & $313 / 318$ & $182 / 182$ & $338 / 342$ & $274 / 279$ & $210 / 210$ & $272 / 272$ \\
\hline $\mathrm{Cv} 48$ & $290 / 305$ & $349 / 349$ & $209 / 210$ & $143 / 144$ & $313 / 323$ & $182 / 184$ & $340 / 347$ & $269 / 274$ & $209 / 209$ & $272 / 272$ \\
\hline Cv49 & $300 / 305$ & $336 / 351$ & $209 / 209$ & $143 / 144$ & $313 / 313$ & $183 / 184$ & $335 / 336$ & $274 / 274$ & $210 / 210$ & $272 / 277$ \\
\hline Cv50 & $300 / 305$ & $349 / 349$ & $209 / 210$ & $131 / 144$ & $325 / 325$ & $182 / 184$ & $335 / 343$ & $269 / 269$ & $209 / 220$ & $272 / 277$ \\
\hline
\end{tabular}


Supplemental Table 4. Alleles at 23 simple sequence repeat marker loci in 50 hazelnut accessions. Some cultivars showed more than two alleles.

\begin{tabular}{|c|c|c|c|c|c|}
\hline Cultivar name & Cultivar & GB462 & GB501 & GB535 & GB568 \\
\hline OSU 495.049 & Cv01 & $224 / 232$ & $179 / 179$ & $211 / 213$ & $100 / 100$ \\
\hline Albania 55 & $\mathrm{Cv} 02$ & $228 / 233$ & $179 / 179$ & $211 / 213$ & $102 / 102$ \\
\hline Fusco Rubra & $\mathrm{Cv} 03$ & $224 / 228 / 232$ & $189 / 189$ & $211 / 213$ & $102 / 102$ \\
\hline Pendula & $\mathrm{Cv} 05$ & $224 / 232$ & $189 / 199$ & $211 / 213$ & $102 / 102$ \\
\hline Hall's Giant & $\mathrm{Cv06}$ & $224 / 233 / 240$ & $189 / 189$ & $218 / 218$ & $102 / 102$ \\
\hline Gasaway & $\mathrm{Cv} 07$ & $224 / 233 / 240$ & $189 / 194$ & $202 / 213$ & $92 / 102$ \\
\hline Cosford & Cv09 & $224 / 224$ & $179 / 189$ & $211 / 213$ & $102 / 102$ \\
\hline DuChilly & Cv10 & $224 / 233$ & $179 / 194$ & $211 / 213$ & $100 / 102$ \\
\hline Palaz & Cv11 & $224 / 233$ & $179 / 179$ & $206 / 208 / 211 / 213$ & $87 / 100 / 107$ \\
\hline Pellicule Rouge & Cv12 & $224 / 232$ & $179 / 194$ & $211 / 213$ & $87 / 100$ \\
\hline Imperiale de Trebizonde & Cv13 & $224 / 228 / 232$ & $179 / 194$ & $202 / 211 / 213$ & $87 / 102$ \\
\hline Tombul Ghiaghli & Cv14 & $224 / 233$ & $179 / 194$ & $208 / 213$ & $87 / 100$ \\
\hline Römische Nuss & Cv19 & $224 / 234$ & $179 / 194$ & $211 / 213$ & $87 / 102 / 107$ \\
\hline Casina & Cv20 & $224 / 234$ & $179 / 179$ & $211 / 213$ & $102 / 102$ \\
\hline Ratoli & Cv21 & $224 / 234$ & $179 / 189$ & $206 / 208$ & $87 / 102$ \\
\hline Mortarella & $\mathrm{Cv} 22$ & $224 / 234$ & $179 / 189 / 194$ & $211 / 213$ & $87 / 102 / 107$ \\
\hline Tonda di Giffoni & Cv23 & $224 / 234$ & $179 / 179$ & $213 / 213$ & $87 / 100$ \\
\hline Barcelona & $\mathrm{Cv} 24$ & $224 / 238 / 234$ & $179 / 179$ & $213 / 213$ & $87 / 100$ \\
\hline Cutleaf & Cv25 & $224 / 234$ & $189 / 189$ & $211 / 213$ & $100 / 100$ \\
\hline OSU 681.078 & Cv26 & $224 / 234 / 238$ & $189 / 189$ & $211 / 213$ & $87 / 100$ \\
\hline Barcelloner Zellernuss & $\mathrm{Cv} 27$ & $224 / 234$ & $179 / 179$ & $211 / 213$ & $100 / 100$ \\
\hline Aurea & Cv28 & $224 / 228 / 242$ & $179 / 179$ & $211 / 213 / 218$ & $102 / 102$ \\
\hline OSU 408.040 & Cv29 & $224 / 234$ & $179 / 189$ & $211 / 213$ & $102 / 102$ \\
\hline OSU 556.027 & Cv37 & $224 / 234$ & $179 / 179$ & $211 / 213$ & $92 / 92$ \\
\hline B-3 & Cv38 & $224 / 234 / 238$ & $179 / 179$ & $203 / 206 / 208$ & $102 / 102$ \\
\hline OSU 54.039 & Cv39 & $224 / 228 / 234$ & $179 / 189$ & $206 / 208$ & $92 / 92$ \\
\hline Gunslebert & $\mathrm{Cv} 40$ & $224 / 228 / 234$ & $179 / 189$ & $213 / 218$ & $86 / 100$ \\
\hline Sant Jaume & Cv41 & $224 / 228 / 234 / 238$ & $179 / 189$ & $213 / 213$ & $87 / 100$ \\
\hline Iannusa Racinante & $\mathrm{Cv} 42$ & $224 / 228 / 234$ & $179 / 179$ & $213 / 213$ & $87 / 100$ \\
\hline Gem & $\mathrm{Cv} 43$ & $224 / 234 / 238$ & $179 / 179$ & $213 / 213$ & $87 / 100$ \\
\hline Artellet & $\mathrm{Cv} 44$ & $224 / 228 / 234$ & $179 / 189$ & $202 / 213$ & $102 / 102$ \\
\hline Simon & Cv45 & $224 / 234$ & $179 / 189$ & $211 / 213$ & $87 / 100 / 107$ \\
\hline Gustav's Zellernuss & $\mathrm{Cv} 46$ & $228 / 234 / 224$ & $189 / 189$ & $213 / 218$ & $102 / 102$ \\
\hline Buttner's Zellernuss & $\mathrm{Cv} 47$ & $224 / 228 / 234$ & $179 / 179$ & $213 / 213$ & $87 / 100$ \\
\hline Tapparona di SCC & $\mathrm{Cv} 48$ & $224 / 228 / 234$ & $179 / 199$ & $208 / 213$ & $92 / 102$ \\
\hline OSU 252.146 & Cv49 & $224 / 234 / 238$ & $179 / 189$ & $213 / 213$ & $100 / 102$ \\
\hline OSU 414.062 & Cv50 & $224 / 228 / 234 / 242$ & $179 / 189$ & $208 / 213$ & $102 / 108$ \\
\hline Cultivar & GB594 & GB609 & GB610 & GB613 & GB615 \\
\hline$\overline{\mathrm{Cv} 01}$ & $176 / 176$ & $315 / 316$ & $86 / 103$ & $127 / 127$ & $281 / 281$ \\
\hline Cv02 & $177 / 177$ & $316 / 316$ & $86 / 103$ & $127 / 133$ & $257 / 263 / 281 / 287$ \\
\hline Cv03 & $182 / 182$ & $316 / 317$ & $86 / 103$ & $121 / 126$ & $287 / 287$ \\
\hline Cv04 & $182 / 182$ & $316 / 316$ & $86 / 91 / 103$ & $127 / 133$ & $281 / 281$ \\
\hline Cv05 & $182 / 182$ & $316 / 316$ & $86 / 103$ & $127 / 133$ & $281 / 281$ \\
\hline
\end{tabular}


Supplemental Table 4. Continued.

\begin{tabular}{|c|c|c|c|c|c|}
\hline Cultivar & GB594 & GB609 & GB610 & GB613 & GB615 \\
\hline$\overline{\mathrm{Cv} 06}$ & $177 / 177$ & $315 / 315$ & $86 / 103$ & $127 / 133$ & $275 / 281$ \\
\hline Cv07 & $182 / 182$ & $315 / 316$ & $86 / 91 / 103$ & $127 / 127$ & $275 / 275$ \\
\hline Cv08 & $172 / 182 / 187$ & $316 / 323 / 329 / 311 / 342$ & $86 / 103$ & $127 / 133$ & $275 / 275$ \\
\hline Cv10 & $176 / 176$ & $315 / 329 / 323 / 311$ & $86 / 103$ & $127 / 127$ & $281 / 287$ \\
\hline Cv11 & $176 / 176$ & $316 / 316$ & $86 / 103$ & $127 / 127$ & $275 / 275$ \\
\hline Cv14 & $172 / 182$ & $316 / 323 / 329 / 311$ & $103 / 103$ & $127 / 127$ & $269 / 275 / 281$ \\
\hline Cv15 & $182 / 182$ & $316 / 316$ & $86 / 103$ & $133 / 139$ & $275 / 281 / 287$ \\
\hline Cv16 & $182 / 182$ & $315 / 316$ & $86 / 103$ & $133 / 133$ & $275 / 281$ \\
\hline Cv17 & $176 / 176$ & $315 / 316$ & $86 / 103$ & $127 / 130$ & $281 / 287 / 275$ \\
\hline Cv18 & $176 / 176$ & $315 / 316$ & $86 / 103$ & $127 / 133$ & $275 / 281$ \\
\hline Cv19 & $176 / 176$ & $315 / 316$ & $86 / 103$ & $127 / 133$ & $275 / 275$ \\
\hline Cv23 & $176 / 182$ & $316 / 316$ & $103 / 103$ & $127 / 133$ & $275 / 275$ \\
\hline Cv24 & $177 / 177$ & $316 / 316$ & $86 / 91 / 103$ & $133 / 139$ & $275 / 275$ \\
\hline Cv25 & $177 / 182$ & $316 / 323 / 329$ & $86 / 103$ & $127 / 133$ & $275 / 281$ \\
\hline Cv26 & $177 / 182$ & $315 / 316$ & $86 / 103$ & $127 / 133$ & $281 / 281$ \\
\hline Cv27 & $182 / 187$ & $315 / 316$ & $86 / 103$ & $127 / 133$ & $275 / 275$ \\
\hline Cv28 & $176 / 176$ & $315 / 316$ & $86 / 103$ & $127 / 133$ & $275 / 281$ \\
\hline Cv29 & $172 / 176 / 182 / 187$ & $316 / 316$ & $86 / 103$ & $127 / 127$ & $275 / 275$ \\
\hline Cv30 & $173 / 184$ & $323 / 329 / 311 / 342$ & $103 / 103$ & $121 / 127$ & $275 / 275$ \\
\hline Cv31 & $177 / 177$ & $315 / 316$ & $86 / 103$ & $121 / 127$ & $275 / 281$ \\
\hline Cv32 & $172 / 176$ & $316 / 323 / 329 / 311 / 342$ & $86 / 103$ & $127 / 133$ & $275 / 275$ \\
\hline Cv33 & $173 / 187$ & $316 / 323 / 329 / 311 / 342$ & $86 / 103$ & $121 / 127$ & $275 / 281$ \\
\hline Cv34 & $177 / 177$ & $315 / 323 / 329 / 311 / 342$ & $103 /$ & $127 / 133$ & $275 / 281 / 287$ \\
\hline $\mathrm{Cv} 42$ & $176 / 176$ & $316 / 316$ & $86 / 91 / 103$ & $127 / 133 / 139$ & $281 / 287 / 275$ \\
\hline Cv43 & $176 / 176$ & $315 / 316$ & $103 / 103$ & $127 / 133 / 139$ & $275 / 275$ \\
\hline $\mathrm{Cv} 44$ & $176 / 182$ & $315 / 316$ & $103 / 103$ & $127 / 133 / 139$ & $275 / 281 / 287$ \\
\hline $\mathrm{Cv} 45$ & $182 / 182$ & $315 / 316$ & $86 / 103$ & $127 / 133$ & $281 / 281$ \\
\hline $\mathrm{Cv} 46$ & $173 / 173$ & $315 / 315$ & $86 / 103$ & $127 / 133$ & $275 / 275$ \\
\hline $\mathrm{Cv} 47$ & $182 / 187$ & $315 / 323 / 329 / 311 / 342$ & $86 / 103$ & $127 / 133$ & $281 / 287$ \\
\hline $\mathrm{Cv} 48$ & $176 / 176$ & $316 / 316$ & $91 / 103$ & $121 / 127$ & $269 / 275$ \\
\hline $\mathrm{Cv} 49$ & $176 / 176$ & $316 / 316$ & $86 / 103$ & $127 / 139$ & $275 / 287 / 281$ \\
\hline Cv50 & $182 / 182$ & $315 / 329 / 323 / 311$ & $86 / 91 / 103$ & $127 / 127$ & $269 / 275 / 280$ \\
\hline Cultivar & GB634 & GB644 & GB648 & GB650 & GB662 \\
\hline $\mathrm{Cv01}$ & $380 / 380$ & $251 / 257$ & $257 / 271 / 264$ & $324 / 332$ & $258 / 264$ \\
\hline $\mathrm{Cv} 02$ & $380 / 386$ & $239 / 239$ & $271 / 271$ & $322 / 322$ & $264 / 270$ \\
\hline $\mathrm{Cv} 03$ & $380 / 380$ & $245 / 251$ & $265 / 271$ & $316 / 324$ & $258 / 264$ \\
\hline $\mathrm{Cv} 04$ & $380 / 386$ & $239 / 245$ & $257 / 271 / 264$ & $322 / 329$ & $258 / 258$ \\
\hline Cv05 & $386 / 386$ & $239 / 245$ & $257 / 257$ & $316 / 328$ & $258 / 264$ \\
\hline $\mathrm{Cv} 06$ & $380 / 386$ & $251 / 251$ & $257 / 271 / 277$ & $322 / 329$ & $252 / 258$ \\
\hline $\mathrm{Cv} 07$ & $380 / 380$ & $239 / 245 / 251 / 257$ & $271 / 271$ & $316 / 328$ & $258 / 258$ \\
\hline $\mathrm{Cv} 08$ & $380 / 386$ & $251 / 251$ & $257 / 271 / 264$ & $325 / 328$ & $252 / 258$ \\
\hline Cv09 & $386 / 386$ & $239 / 251$ & $257 / 271 / 264$ & $314 / 328$ & $252 / 264$ \\
\hline Cv10 & $375 / 386$ & $245 / 245$ & $271 / 271$ & $324 / 332$ & $258 / 264$ \\
\hline Cv11 & $375 / 382 / 386 / 392$ & $245 / 251$ & $257 / 271 / 264$ & $328 / 328$ & $258 / 258$ \\
\hline
\end{tabular}


Supplemental Table 4. Continued.

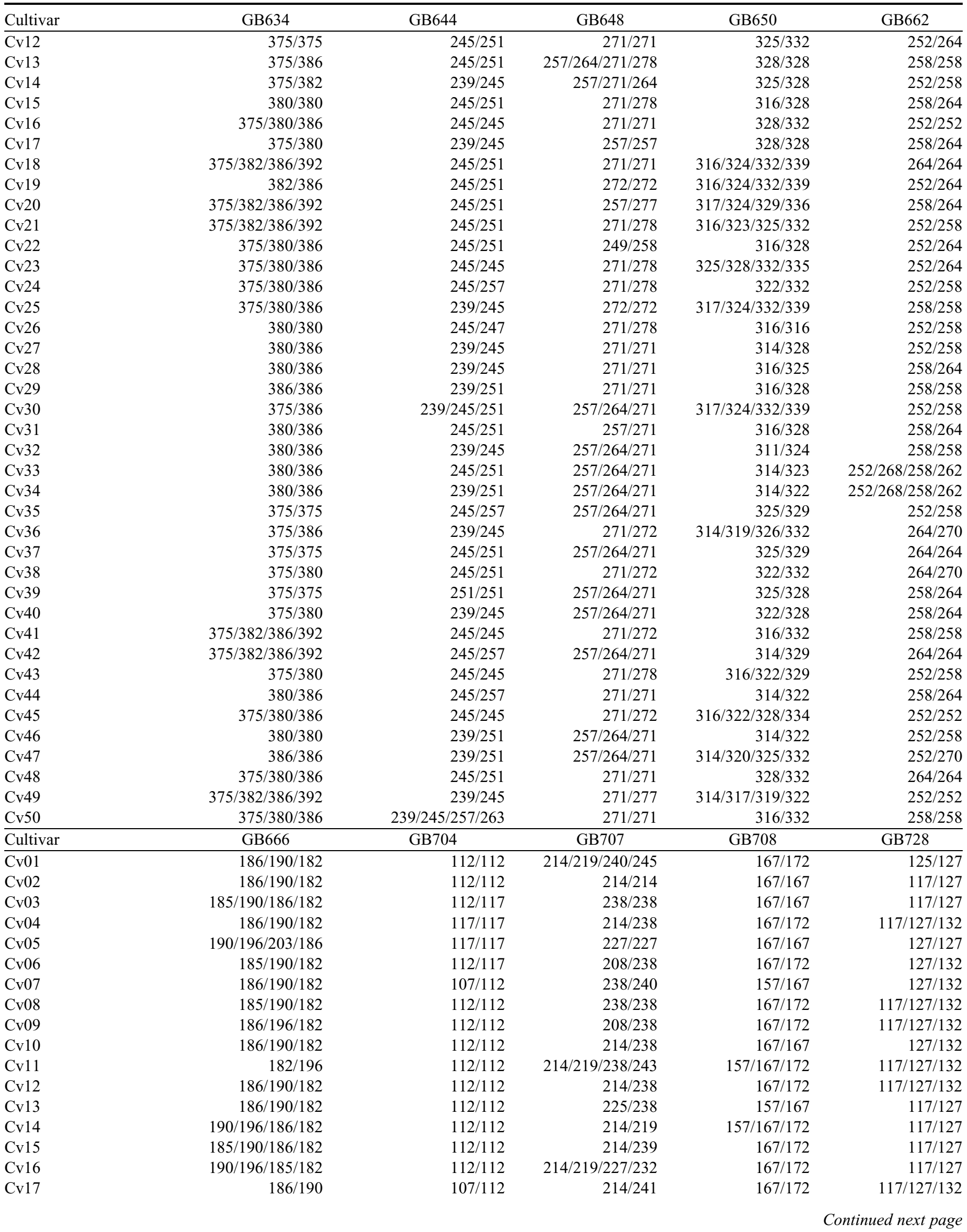


Supplemental Table 4. Continued.

\begin{tabular}{|c|c|c|c|c|c|}
\hline Cultivar & GB666 & GB704 & GB707 & GB708 & GB728 \\
\hline$\overline{C v 18}$ & $186 / 190$ & $112 / 112$ & $214 / 238$ & $167 / 172$ & $127 / 132$ \\
\hline Cv19 & $186 / 190$ & $112 / 112$ & $214 / 214$ & $167 / 172$ & $127 / 132$ \\
\hline Cv20 & $186 / 190$ & $112 / 117$ & $214 / 227$ & $167 / 167$ & $117 / 127 / 132$ \\
\hline Cv22 & $190 / 196 / 186 / 182$ & $112 / 112$ & $214 / 219 / 238 / 243$ & $167 / 172$ & $127 / 132$ \\
\hline Cv23 & $186 / 190 / 185$ & $112 / 112$ & $214 / 239$ & $167 / 172$ & $117 / 127$ \\
\hline Cv26 & $186 / 190$ & $112 / 112$ & $214 / 238$ & $167 / 172$ & $127 / 127$ \\
\hline $\mathrm{Cv} 27$ & $186 / 190 / 182$ & $112 / 117$ & $240 / 241$ & $167 / 167$ & $117 / 127$ \\
\hline Cv28 & $186 / 190$ & $112 / 112$ & $214 / 238$ & $167 / 167$ & $127 / 127$ \\
\hline Cv29 & $186 / 190 / 182$ & $117 / 117$ & $239 / 240$ & $167 / 167$ & $127 / 132$ \\
\hline Cv30 & $186 / 190 / 182$ & $112 / 112$ & $238 / 238$ & $167 / 172$ & $117 / 127$ \\
\hline Cv31 & $190 / 200 / 186 / 182$ & $112 / 112$ & $238 / 240$ & $167 / 172$ & $122 / 127$ \\
\hline Cv35 & $182 / 182$ & $107 / 107$ & $214 / 219$ & $167 / 172$ & $117 / 127$ \\
\hline Cv36 & $186 / 190 / 196 / 182$ & $112 / 112$ & $214 / 238$ & $167 / 174$ & $117 / 127$ \\
\hline Cv37 & $186 / 196 / 182$ & $112 / 112$ & $207 / 214 / 219$ & $157 / 167$ & $117 / 127$ \\
\hline Cv38 & $186 / 190$ & $112 / 112$ & $214 / 239$ & $167 / 167$ & $117 / 132$ \\
\hline Cv39 & $186 / 190 / 182$ & $112 / 112$ & $238 / 239$ & $167 / 172$ & $112 / 117 / 127$ \\
\hline $\mathrm{Cv} 40$ & $186 / 190 / 182$ & $112 / 117$ & $238 / 239$ & $167 / 167$ & $117 / 127$ \\
\hline Cv41 & $185 / 190 / 186$ & $112 / 112$ & $207 / 238$ & $167 / 172$ & $117 / 127 / 132$ \\
\hline $\mathrm{Cv} 42$ & $190 / 196 / 186 / 185$ & $107 / 112$ & $214 / 240$ & $167 / 167$ & $117 / 127$ \\
\hline Cv43 & $186 / 190 / 182$ & $112 / 112$ & $214 / 238$ & $167 / 172$ & $127 / 132$ \\
\hline $\mathrm{Cv} 44$ & $186 / 196 / 190 / 182$ & $112 / 112$ & $207 / 238$ & $167 / 172$ & $117 / 127 / 132$ \\
\hline Cv45 & $186 / 196 / 182$ & $112 / 112$ & $214 / 219$ & $167 / 172$ & $117 / 127$ \\
\hline Cv46 & $186 / 190 / 182$ & $112 / 117$ & $207 / 239$ & $167 / 172$ & $117 / 127 / 132$ \\
\hline Cv03 & $346 / 354$ & $348 / 368 / 375$ & \multicolumn{2}{|c|}{$294 / 299$} & $353 / 357$ \\
\hline Cv04 & $346 / 346$ & $368 / 368$ & \multicolumn{2}{|c|}{$294 / 299$} & $353 / 357$ \\
\hline Cv05 & $346 / 346$ & $359 / 369$ & \multicolumn{2}{|c|}{$299 / 299$} & $357 / 358$ \\
\hline Cv06 & $339 / 346$ & $363 / 375 / 368$ & \multicolumn{2}{|c|}{$294 / 299 / 289$} & $358 / 358$ \\
\hline Cv07 & $339 / 351$ & $359 / 369 / 368$ & \multicolumn{2}{|c|}{$294 / 299 / 289$} & $353 / 353$ \\
\hline Cv08 & $339 / 351$ & $353 / 375 / 368$ & \multicolumn{2}{|c|}{$289 / 294$} & $357 / 358$ \\
\hline Cv09 & $339 / 351$ & $353 / 363 / 369 / 368$ & \multicolumn{2}{|c|}{$294 / 299 / 289$} & $353 / 357$ \\
\hline Cv10 & $339 / 351$ & $363 / 369$ & \multicolumn{2}{|c|}{$294 / 299 / 289$} & $353 / 353$ \\
\hline Cv11 & $345 / 351$ & $363 / 368$ & \multicolumn{2}{|c|}{$294 / 299 / 289$} & $350 / 354$ \\
\hline Cv12 & $346 / 351$ & $363 / 368$ & \multicolumn{2}{|c|}{$289 / 294 / 299$} & $350 / 353$ \\
\hline Cv13 & $345 / 345$ & $359 / 368$ & \multicolumn{2}{|c|}{$294 / 299$} & $353 / 357$ \\
\hline Cv14 & $339 / 345 / 351$ & $359 / 368 / 369$ & \multicolumn{2}{|c|}{$294 / 299$} & $350 / 357$ \\
\hline Cv15 & $346 / 351$ & $359 / 369 / 368$ & \multicolumn{2}{|c|}{$294 / 299$} & $350 / 353 / 358 / 361$ \\
\hline Cv16 & $345 / 345$ & $363 / 375 / 368$ & \multicolumn{2}{|c|}{$294 / 299 / 289$} & $350 / 353$ \\
\hline Cv17 & $345 / 345$ & $359 / 363 / 369$ & $289 /$ & & $350 / 353$ \\
\hline Cv18 & $346 / 346$ & $363 / 369$ & $289 /$ & & $350 / 353$ \\
\hline Cv19 & $345 / 345$ & $353 / 359 / 369 / 368$ & & & $353 / 357 / 358$ \\
\hline Cv20 & $346 / 346$ & $363 / 369$ & $294 /$ & & $350 / 357$ \\
\hline Cv21 & $345 / 345$ & $359 / 368$ & $289 /$ & & $353 / 353$ \\
\hline Cv22 & $346 / 346$ & $363 / 369 / 368$ & $294 /$ & & $350 / 353$ \\
\hline Cv23 & $345 / 352$ & $359 / 363 / 369 / 368$ & $289 /$ & & $350 / 357 / 361$ \\
\hline
\end{tabular}


Supplemental Table 4. Continued.

\begin{tabular}{|c|c|c|c|c|}
\hline Cultivar & GB741 & GB742 & GB746 & GB752 \\
\hline Cv24 & $346 / 346$ & $359 / 363 / 368$ & $294 / 299 / 289$ & $353 / 353$ \\
\hline Cv25 & $346 / 346$ & $353 / 375 / 368$ & $294 / 299$ & $353 / 357$ \\
\hline Cv26 & $339 / 346$ & $353 / 375 / 368$ & $294 / 299$ & $353 / 357$ \\
\hline Cv28 & $339 / 339$ & $358 / 368 / 375$ & $294 / 299$ & $353 / 357$ \\
\hline Cv29 & $339 / 346$ & $363 / 368$ & $294 / 299$ & $353 / 357$ \\
\hline $\mathrm{Cv} 32$ & $346 / 351$ & $353 / 363 / 375$ & $294 / 299$ & $353 / 357$ \\
\hline Cv33 & $346 / 346$ & $353 / 378$ & $294 / 299$ & $353 / 358$ \\
\hline Cv34 & $346 / 351$ & $353 / 368 / 377$ & $294 / 299$ & $353 / 353$ \\
\hline Cv35 & $345 / 351$ & $353 / 358 / 363 / 368$ & $294 / 299 / 289$ & $350 / 354$ \\
\hline Cv36 & $339 / 346$ & $348 / 353 / 368 / 363$ & $294 / 299$ & $358 / 358$ \\
\hline Cv37 & $345 / 345$ & $359 / 369$ & $294 / 299$ & $357 / 357$ \\
\hline Cv42 & $346 / 346$ & $363 / 369$ & $294 / 299 / 289$ & $350 / 350$ \\
\hline Cv43 & $340 / 347$ & $359 / 363 / 369 / 368$ & $294 / 299 / 289$ & $353 / 353$ \\
\hline $\mathrm{Cv} 44$ & $336 / 336$ & $359 / 363 / 369$ & $294 / 299$ & $352 / 352$ \\
\hline Cv45 & $345 / 345$ & $363 / 375 / 368 / 369$ & $294 / 299 / 289$ & $350 / 353$ \\
\hline Cv46 & $339 / 346$ & $363 / 375 / 368$ & $294 / 299 / 289$ & $353 / 357$ \\
\hline Cv47 & $346 / 351$ & $363 / 369 / 368$ & $289 / 294$ & $353 / 353$ \\
\hline Cv48 & $339 / 346$ & $353 / 359 / 363$ & $294 / 299$ & $353 / 357$ \\
\hline Cv49 & $345 / 351$ & $353 / 363 / 368 / 369$ & $294 / 299 / 289$ & $353 / 357$ \\
\hline Cv50 & $351 / 351$ & $363 / 368 / 369$ & $294 / 299 / 289$ & $353 / 353$ \\
\hline
\end{tabular}


Supplemental Table 5. Segregation at new simple sequence repeat markers and linkage group assignments in the hazelnut mapping population (OSU 252.146 x OSU 414.062).

\begin{tabular}{|c|c|c|c|c|c|c|}
\hline Locus & Alleles (Female $\times$ Male) & Expected ratio & Observed ratio & $\chi^{2}$ & $P$ & Linkage group and alleles \\
\hline GB401 & $183 / 196 \times 183 / 196$ & $1: 2: 1$ & $28: 78: 32$ & 2.58 & 0.28 & 196 on $5 \mathrm{~S}, 183$ on $5 \mathrm{R}$ \\
\hline GB402 & $166 / 170 \times 166 / 170$ & $1: 2: 1$ & $36: 72: 30$ & 0.78 & 0.68 & 166 on $9 \mathrm{~S}, 170$ on $9 \mathrm{R}$ \\
\hline GB404 & $122 / 126 \times 122 / 126$ & $1: 2: 1$ & $30: 59: 49$ & 8.13 & 0.02 & 126 on $7 \mathrm{~S}, 122$ on $2 \mathrm{R}$ (falls out at $\mathrm{LOD}=4$ ) \\
\hline GB410 & $169 / 169 \times 161 / 165$ & $1: 1$ & $63: 71$ & 0.48 & 0.49 & 165 on $4 \mathrm{R}$ \\
\hline GB413 & $191 / 192 \times 187 / 197$ & $1: 1: 1: 1$ & $36: 25: 35: 39$ & 3.28 & 0.35 & 191 on $1 \mathrm{~S}, 187$ on $1 \mathrm{R}$ \\
\hline GB414 & $110 / 118 \times 110 / 110$ & $1: 1$ & $74: 63$ & 0.88 & 0.35 & $118 \mathrm{~d}$ on $8 \mathrm{~S}$ \\
\hline GB418 & $205 / 216 \times 205 / 205$ & $1: 1$ & $55: 77$ & 3.67 & 0.06 & 216 on $1 \mathrm{~S}$ \\
\hline GB420 & $211 / 227 \times 211 / 227$ & $1: 2: 1$ & $34: 76: 28$ & 1.94 & 0.38 & 211 on $9 \mathrm{~S}, 211$ on $9 \mathrm{R}$ \\
\hline GB422 & $221 / 237 \times 237 / 237$ & $1: 1$ & $80: 53$ & 5.48 & 0.02 & 221 on $7 \mathrm{~S}$ \\
\hline GB423 & $294 / 297 \times 292 / 294$ & $1: 1: 1: 1$ & $33: 31: 42: 29$ & 2.93 & 0.40 & 297 on $6 \mathrm{~S}, 292$ on $6 \mathrm{R}$ \\
\hline GB424 & $278 / 286 \times 278 / 286$ & $1: 2: 1$ & $32: 78: 28$ & 2.58 & 0.28 & 286 on $9 \mathrm{~S}, 286$ on $9 \mathrm{R}$ \\
\hline GB428 & $240 / 244 \times 244 / 244$ & $1: 1$ & $71: 67$ & 0.12 & 0.73 & $240 \mathrm{~d}$ on $8 \mathrm{~S}$ \\
\hline GB435 & $94 / 98 \times 94 / 98$ & $1: 2: 1$ & $27: 70: 41$ & 2.87 & 0.24 & 98 on $9 \mathrm{~S}, 94$ on $9 \mathrm{R}$ \\
\hline GB436 & $122 / 126 \times 122 / 122$ & $1: 1$ & $72: 64$ & 0.47 & 0.49 & $126 \mathrm{~d}$ on $4 \mathrm{~S}$ \\
\hline GB437 & $334 / 340 \times 334 / 338$ & $1: 1: 1: 1$ & $37: 35: 28: 32$ & 1.39 & 0.71 & 340 on $4 \mathrm{~S}, 338 \mathrm{~d}$ on $4 \mathrm{R}$ \\
\hline GB438 & $311 / 319 \times 311 / 315$ & $1: 1: 1: 1$ & $33: 39: 26: 30$ & 2.81 & 0.42 & 319 on $4 \mathrm{~S}, 315$ on $4 \mathrm{R}$ \\
\hline GB441 & $178 / 182 \times 178 / 178$ & $1: 1$ & $68: 69$ & 0.01 & 0.93 & $182 \mathrm{~d}$ on $4 \mathrm{~S}$ \\
\hline GB444 & $313 / 317 \times 313 / 321$ & $1: 1: 1: 1$ & $48: 31: 31: 25$ & 8.73 & 0.03 & 317 on $1 \mathrm{~S}$ \\
\hline GB447 & $182 / 187 \times 182 / 187$ & $1: 2: 1$ & $35: 65: 38$ & 0.59 & 0.74 & 187 on $1 \mathrm{~S}, 182$ on $1 \mathrm{R}$ \\
\hline GB450 & $335 / 339 \times 335 / 339$ & $1: 2: 1$ & $41: 77: 20$ & 8.25 & 0.02 & 339 on $11 \mathrm{~S}, 339$ on $11 \mathrm{R}$ \\
\hline GB456 & $104 / 112 \times 112 / 112$ & $1: 1$ & $66: 70$ & 0.12 & 0.73 & 104 on $6 \mathrm{~S}$ \\
\hline GB457 & $197 / 201 \times 197 / 201$ & $1: 2: 1$ & $36: 71: 31$ & 0.48 & 0.79 & 201 on $6 \mathrm{~S}, 201$ on $6 \mathrm{R}$ \\
\hline GB458 & $295 / 303 \times 299 / 302$ & $1: 1: 1: 1$ & $35: 28: 34: 39$ & 1.82 & 0.61 & 295 on $2 \mathrm{~S}, 299$ on $2 \mathrm{R}$ \\
\hline GB473 & $189 / 194 \times 189 / 198$ & $1: 1: 1: 1$ & $35: 36: 22: 31$ & 3.94 & 0.27 & $194 d$ on $1 \mathrm{~S}, 198 \mathrm{~d}$ on $1 \mathrm{R}$ \\
\hline GB475 & $183 / 183 \times 183 / 187$ & $1: 1$ & $84: 53$ & 7.01 & 0.01 & 187 on $4 \mathrm{R}$ (gap at end) \\
\hline GB477 & $345 / 345 \times 338 / 345$ & $1: 1$ & $61: 77$ & 1.86 & 0.17 & $338 \mathrm{~d}$ on $3 \mathrm{R}$ \\
\hline GB478 & $389 / 389 \times 389 / 392$ & $1: 1$ & $61: 76$ & 1.64 & 0.20 & 392 on $6 \mathrm{R}$ \\
\hline GB482 & $132 / 140 \times 132 / 140$ & $1: 2: 1$ & $40: 63: 35$ & 1.41 & 0.50 & 132 on $7 \mathrm{~S}, 132$ on $7 \mathrm{R}$ \\
\hline GB483 & $355 / 355 \times 355 / 359$ & $1: 1$ & $24: 22$ & 0.09 & 0.77 & 359 on $2 \mathrm{R}$ \\
\hline GB501 & $178 / 188 \times 178 / 188$ & $1: 2: 1$ & $20: 76: 42$ & 8.43 & 0.01 & 179 on $11 \mathrm{~S}, 179$ on $11 \mathrm{R}$ \\
\hline GB505 & $275 / 286 \times 271 / 275$ & $1: 1: 1: 1$ & $28: 35: 36: 34$ & 1.17 & 0.76 & $286 \mathrm{~d}$ on $8 \mathrm{~S}, 271 \mathrm{~d}$ on $8 \mathrm{R}$ \\
\hline GB532 & $368 / 368 \times 360 / 368$ & $1: 1$ & $75: 62$ & 1.23 & 0.27 & $360 \mathrm{~d}$ on $3 \mathrm{R}$ \\
\hline GB533 & $121 / 126 \times 126 / 126$ & $1: 1$ & $62: 76$ & 1.42 & 0.23 & 121 on $1 \mathrm{~S}$ \\
\hline GB535 & $213 / 213 \times 208 / 213$ & $1: 1$ & $69: 67$ & 0.03 & 0.86 & 208 on $2 R$ \\
\hline GB544 & $389 / 394 \times 389 / 394$ & $1: 2: 1$ & $28: 80: 30$ & 3.57 & 0.17 & 394 on $5 \mathrm{~S}, 389$ on $5 \mathrm{R}$ \\
\hline GB548 & $151 / 156 \times 146 / 151$ & $1: 1: 1: 1$ & $36: 33: 40: 27$ & 2.65 & 0.45 & 156 on $1 \mathrm{~S}, 146$ on $1 \mathrm{R}$ \\
\hline GB563 & $185 / 195 \times 190 / 190$ & $1: 1$ & $79: 59$ & 2.90 & 0.09 & 195 on $1 \mathrm{~S}$ \\
\hline GB565 & $176 / 176 \times 176 / 181$ & $1: 1$ & $75: 61$ & 1.44 & 0.23 & 181 on $2 \mathrm{R}$ \\
\hline GB568 & $100 / 102 \times 102 / 108$ & $1: 1: 1: 1$ & $31: 94: 9: 0$ & 160.87 & 0.00 & 100d on 7S (large gap on map) \\
\hline GB581 & $105 / 105 \times 110 / 115$ & $1: 1$ & $75: 61$ & 1.44 & 0.23 & 110 on $1 \mathrm{R}$ \\
\hline GB587 & $175 / 180 \times 175 / 180$ & $1: 2: 1$ & $33: 67: 38$ & 0.48 & 0.79 & 175 on $4 \mathrm{~S}, 175$ on $4 \mathrm{R}$ \\
\hline GB602 & $240 / 240 \times 240 / 246$ & $1: 1$ & $64: 72$ & 0.47 & 0.49 & 246 on $6 \mathrm{R}$ \\
\hline GB604 & $191 / 197 \times 191 / 197$ & $1: 2: 1$ & $39: 70: 29$ & 1.48 & 0.48 & 191 on $9 \mathrm{~S}, 197$ on $9 \mathrm{R}$ \\
\hline GB605 & $118 / 124 \times 124 / 124$ & $1: 1$ & $67: 70$ & 0.07 & 0.80 & 118 on $6 \mathrm{~S}$ \\
\hline
\end{tabular}


Supplemental Table 5. Continued.

\begin{tabular}{|c|c|c|c|c|c|c|}
\hline Locus & Alleles $($ Female $\times$ Male $)$ & Expected ratio & Observed ratio & $\chi^{2}$ & $P$ & Linkage group and alleles \\
\hline$\overline{\text { GB606 }}$ & $316 / 330 \times 330 / 330$ & $1: 1$ & $73: 48$ & 5.17 & 0.02 & $316 \mathrm{~d}$ on $11 \mathrm{~S}$ \\
\hline GB609 & $316 / 316 \times 315 / 329$ & $1: 1$ & $71: 66$ & 0.18 & 0.67 & 329 on $2 \mathrm{R}$ \\
\hline GB613 & $139 / 139 \times 127 / 139$ & $1: 1$ & $69: 69$ & 0.00 & 1.00 & $127 \mathrm{~d}$ on $1 \mathrm{R}$ (poor fit) \\
\hline GB616 & $359 / 359 \times 359 / 365$ & $1: 1$ & $70: 65$ & 0.19 & 0.67 & 365 on $1 \mathrm{R}$ \\
\hline GB618 & $322 / 328 \times 321 / 328$ & $1: 1: 1: 1$ & $36: 37: 27: 31$ & 1.98 & 0.58 & $321 d$ on $2 R$ \\
\hline GB619 & $150 / 150 \times 138 / 144$ & $1: 1$ & $62: 75$ & 1.23 & 0.27 & 144 on $1 \mathrm{R}$ \\
\hline GB621 & $105 / 117 \times 117 / 117$ & $1: 1$ & $76: 61$ & 1.64 & 0.20 & 105 on $4 \mathrm{~S}$ \\
\hline GB622 & $125 / 125 \times 113 / 125$ & $1: 1$ & $65: 72$ & 0.36 & 0.55 & 113 on $9 \mathrm{R}$ \\
\hline GB623 & $377 / 377 \times 377 / 383$ & $1: 1$ & $24: 22$ & 0.09 & 0.77 & $383 d$ on $2 R$ \\
\hline GB625 & $226 / 226 \times 226 / 232$ & $1: 1$ & $90: 47$ & 13.50 & 0.00 & $232 \mathrm{~d}$ on $11 \mathrm{R}$ \\
\hline GB626 & $146 / 146 \times 139 / 146$ & $1: 1$ & $66: 60$ & 0.29 & 0.59 & 139 on $4 \mathrm{R}$ \\
\hline GB627 & $354 / 360 \times 354 / 366$ & $1: 1: 1: 1$ & $37: 35: 37: 27$ & 2.00 & 0.57 & 360 on $1 \mathrm{~S}, 366$ on $1 \mathrm{R}$ \\
\hline GB635 & $130 / 130 \times 130 / 144$ & $1: 1$ & $63: 72$ & 0.60 & 0.44 & 144 on $6 \mathrm{R}$ \\
\hline GB636 & $250 / 261 \times 250 / 261$ & $1: 2: 1$ & $16: 53: 69$ & 48.13 & 0.00 & 261 on $11 \mathrm{~S}, 250$ on $11 \mathrm{R}$ (poor fit) \\
\hline GB638 & $324 / 324 \times 318 / 324$ & $1: 1$ & $68: 69$ & 0.01 & 0.93 & 318 on $9 \mathrm{R}$ \\
\hline GB640 & $355 / 355 \times 346 / 354$ & $1: 1$ & $67: 70$ & 0.07 & 0.80 & $346 \mathrm{~d}$ on $4 \mathrm{R}$ \\
\hline GB641 & $139 / 139 \times 139 / 152$ & $1: 1$ & $71: 66$ & 0.18 & 0.67 & $152 \mathrm{~d}$ on $2 \mathrm{R}$ \\
\hline GB642 & $361 / 367 \times 367 / 367$ & $1: 1$ & $57: 77$ & 2.99 & 0.08 & 361 on $7 \mathrm{~S}$ \\
\hline GB643 & $244 / 244 \times 238 / 244$ & $1: 1$ & $72: 64$ & 0.47 & 0.49 & $238 \mathrm{~d}$ on $10 \mathrm{R}$ \\
\hline GB644 & $239 / 245 \times 245 / 257$ & $1: 1: 1: 1$ & $36: 37: 28: 32$ & 1.53 & 0.68 & 239 on $6 \mathrm{~S}$ (poor fit), $257 \mathrm{~d}$ on $6 \mathrm{R}$ \\
\hline GB645 & $292 / 298 \times 292 / 293$ & $1: 1: 1: 1$ & $20: 23: 50: 43$ & 19.24 & 0.00 & 298 on $10 \mathrm{~S}, 293$ on $10 \mathrm{R}$ \\
\hline GB646 & $273 / 291 \times 285 / 285$ & $1: 1$ & $67: 68$ & 0.01 & 0.93 & 273 on $5 \mathrm{~S}$ \\
\hline GB647 & $171 / 177 \times 171 / 177$ & $1: 2: 1$ & $27: 71: 40$ & 2.57 & 0.28 & 177 on $9 S, 171$ on $9 \mathrm{R}$ \\
\hline GB660 & $210 / 221 \times 214 / 221$ & $1: 1: 1: 1$ & $41: 39: 21: 23$ & 10.58 & 0.01 & $210 d$ on $5 S, 214$ on $5 R$ \\
\hline GB661 & $205 / 211 \times 217 / 217$ & $1: 1$ & $70: 68$ & 0.03 & 0.86 & 205 on $1 \mathrm{~S}$ \\
\hline GB663 & $133 / 133 \times 133 / 139$ & $1: 1$ & $67: 70$ & 0.07 & 0.80 & $139 \mathrm{~d}$ on $4 \mathrm{R}$ \\
\hline GB664 & $302 / 308 \times 302 / 302$ & $1: 1$ & $67: 70$ & 0.07 & 0.80 & 308 on $8 \mathrm{~S}$ \\
\hline GB665 & $181 / 193 \times 181 / 181$ & $1: 1$ & $64: 74$ & 0.72 & 0.39 & 193 on $4 \mathrm{~S}$ \\
\hline GB666 & $181 / 196 \times 190 / 196$ & $1: 1: 1: 1$ & $17: 30: 46: 35$ & 13.56 & 0.00 & 181 on $4 \mathrm{~S}$ (poor fit), 190 on $4 \mathrm{R}$ \\
\hline GB669 & $111 / 117 \times 111 / 111$ & $1: 1$ & $70: 67$ & 0.07 & 0.80 & $117 \mathrm{~d}$ on $2 \mathrm{~S}$ \\
\hline GB670 & $253 / 259 \times 259 / 270$ & $1: 1: 1: 1$ & $28: 30: 33: 42$ & 3.45 & 0.33 & 253 on $4 \mathrm{~S}, 270$ on $4 \mathrm{R}$ \\
\hline GB671 & $234 / 247 \times 234 / 247$ & $1: 2: 1$ & $34: 75: 29$ & 1.41 & 0.50 & 247 on $6 \mathrm{~S}, 247$ on $6 \mathrm{R}$ \\
\hline GB673 & $354 / 371 \times 354 / 354$ & $1: 1$ & $65: 73$ & 0.46 & 0.50 & 371 on $5 \mathrm{~S}$ \\
\hline GB675 & $344 / 356 \times 344 / 350$ & $1: 1: 1: 1$ & $30: 30: 29: 42$ & 3.50 & 0.32 & $356 \mathrm{~d}$ on $4 \mathrm{~S}, 350$ on $4 \mathrm{R}$ \\
\hline GB676 & $339 / 341 \times 339 / 345$ & $1: 1: 1: 1$ & $36: 25: 36: 34$ & 2.53 & 0.47 & $341 \mathrm{~d}$ on $2 \mathrm{~S}, 345$ on $2 \mathrm{R}$ \\
\hline GB678 & $199 / 209 \times 199 / 209$ & $1: 2: 1$ & $32: 67: 39$ & 0.83 & 0.66 & 199 on $5 \mathrm{~S}, 199$ on $5 \mathrm{R}$ \\
\hline GB702 & $181 / 181 \times 181 / 191$ & $1: 1$ & $71: 66$ & 0.18 & 0.67 & 191 on $2 \mathrm{R}$ \\
\hline GB706 & $369 / 369 \times 369 / 378$ & $1: 1$ & $72: 61$ & 0.91 & 0.34 & 378 on $1 \mathrm{R}$ \\
\hline GB707 & $219 / 238 \times 238 / 239$ & $1: 1: 1: 1$ & $46: 26: 33: 31$ & 6.41 & 0.09 & $219 \mathrm{~d}$ on $4 \mathrm{~S}$ \\
\hline GB709 & $263 / 263 \times 262 / 269$ & $1: 1$ & $58: 77$ & 2.67 & 0.10 & $269 \mathrm{~d}$ on $6 \mathrm{R}$ \\
\hline GB712 & $134 / 134 \times 134 / 139$ & $1: 1$ & $74: 62$ & 1.06 & 0.30 & $139 d$ on $1 \mathrm{R}$ \\
\hline GB716 & $140 / 145 \times 140 / 145$ & $1: 2: 1$ & $41: 63: 34$ & 1.75 & 0.42 & 140 on $2 \mathrm{R}, 145$ on $2 \mathrm{~S}$ (poor fit) \\
\hline GB717 & $214 / 214 \times 214 / 224$ & $1: 1$ & $64: 73$ & 0.59 & 0.44 & $224 \mathrm{~d}$ on $4 \mathrm{R}$ \\
\hline GB718 & $398 / 398 \times 393 / 403$ & $1: 1$ & $68: 70$ & 0.03 & 0.86 & $393 d$ on $1 R$ \\
\hline
\end{tabular}

Continued next page 
Supplemental Table 5. Continued.

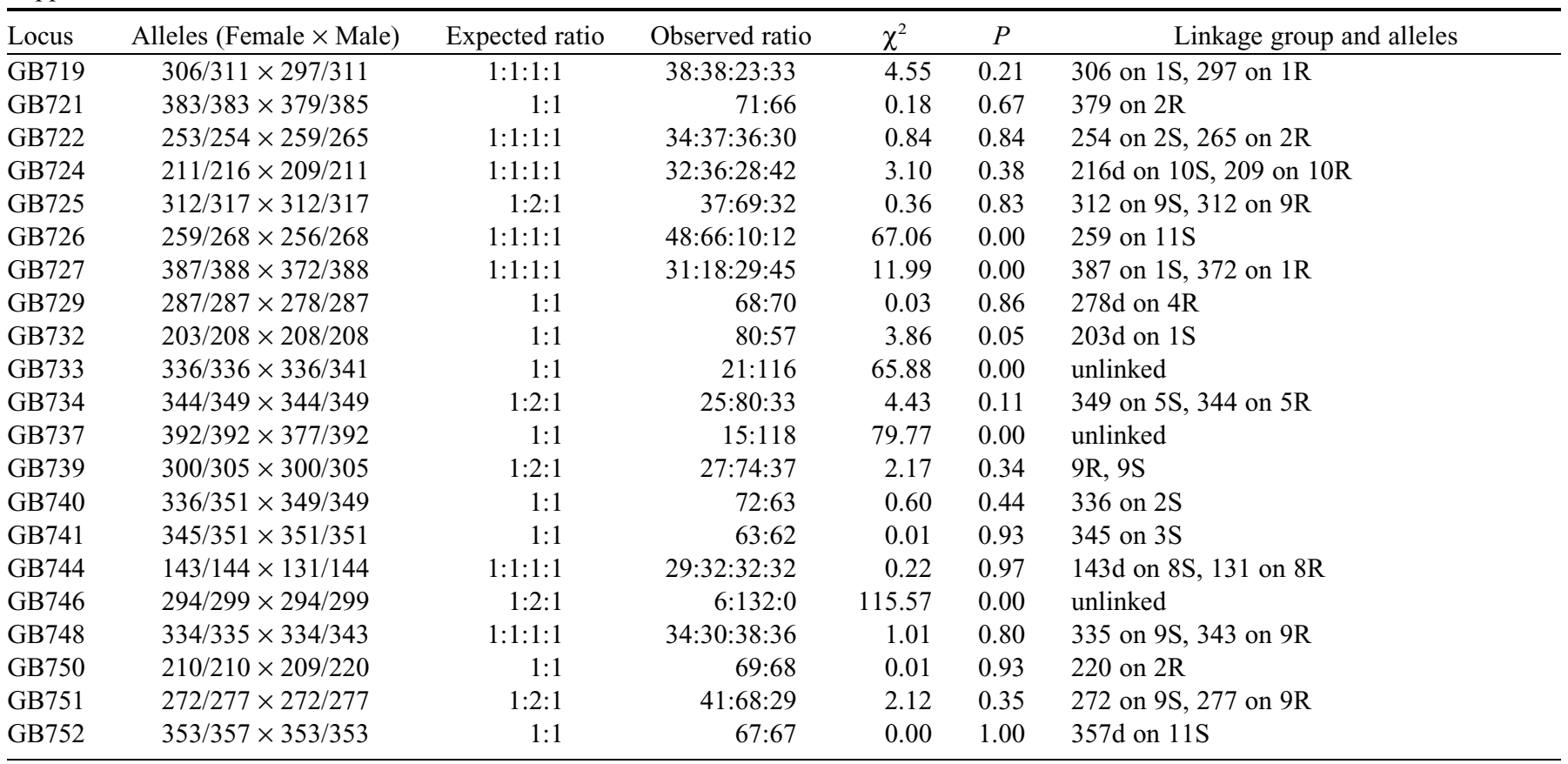


Supplemental Table 6. Private (unique) alleles at SSR loci in 50 hazelnut accessions. At 103 loci, a total of 201 unique alleles were observed.

\begin{tabular}{|c|c|c|c|}
\hline No. & Locus & Allele & Accessions \\
\hline \multirow[t]{2}{*}{1} & GB405 & 169 & Fusco Rubra \\
\hline & & 177 & OSU 495.049 \\
\hline 2 & GB407 & 179 & OSU 681.078 \\
\hline \multirow[t]{2}{*}{3} & GB409 & 149 & OSU 759.010 \\
\hline & & 162 & OSU 26.072 \\
\hline \multirow[t]{2}{*}{4} & GB410 & 149 & OSU 26.072 \\
\hline & & 157 & Tonda G. d. Langhe \\
\hline \multirow[t]{5}{*}{5} & GB413 & 188 & Imperiale de Trebizonde \\
\hline & & 193 & OSU 759.010 \\
\hline & & 197 & OSU 414.062 \\
\hline & & 198 & Gasaway \\
\hline & & 201 & Fusco Rubra \\
\hline 6 & GB416 & 251 & Fusco Rubra \\
\hline \multirow[t]{2}{*}{7} & GB418 & 204 & OSU 495.049 \\
\hline & & 233 & Fusco Rubra \\
\hline \multirow[t]{2}{*}{8} & GB420 & 231 & OSU 759.010 \\
\hline & & 235 & Iannusa Racinante \\
\hline \multirow[t]{2}{*}{9} & GB422 & 215 & OSU 54.039 \\
\hline & & 233 & Tonda G. d. Langhe \\
\hline 10 & GB423 & 283 & OSU 495.049 \\
\hline 11 & GB427 & 200 & Römische Nuss \\
\hline 12 & GB429 & 274 & OSU 495.049 \\
\hline \multirow[t]{2}{*}{13} & GB432 & 311 & Palaz \\
\hline & & 323 & Artellet \\
\hline 14 & GB435 & 102 & OSU 26.072 \\
\hline 15 & GB438 & 307 & Cutleaf \\
\hline 16 & GB447 & 181 & Albania 55 \\
\hline 17 & GB450 & 343 & Ala Kieri (COR187) \\
\hline \multirow[t]{2}{*}{18} & GB454 & 246 & OSU 759.010 \\
\hline & & 252 & Fusco Rubra \\
\hline 19 & GB463 & 296 & OSU 54.039 \\
\hline 20 & GB465 & 263 & OSU 681.078 \\
\hline \multirow[t]{3}{*}{21} & GB468 & 364 & Cutleaf \\
\hline & & 372 & Rode Zeller \\
\hline & & 379 & Imperiale de Trebizonde \\
\hline \multirow[t]{3}{*}{22} & GB469 & 322 & Pendula \\
\hline & & 327 & Fusco Rubra \\
\hline & & 335 & Buttner's Zellernuss \\
\hline \multirow[t]{3}{*}{23} & GB470 & 393 & Artellet \\
\hline & & 399 & B-3 \\
\hline & & 406 & OSU 759.010 \\
\hline 24 & GB476 & 299 & Contorta \\
\hline 25 & GB477 & 336 & Iannusa Racinante \\
\hline \multirow[t]{3}{*}{26} & GB480 & 262 & Imperiale de Trebizonde \\
\hline & & 274 & OSU 759.010 \\
\hline & & 276 & OSU 414.062 \\
\hline \multirow[t]{2}{*}{27} & GB483 & 343 & Fusco Rubra \\
\hline & & 354 & Bergeri \\
\hline 28 & GB505 & 281 & Albania 55 \\
\hline \multirow[t]{3}{*}{29} & GB526 & 79 & OSU 495.049 \\
\hline & & 83 & Pendula \\
\hline & & 87 & Artellet \\
\hline 30 & GB527 & 115 & Aurea \\
\hline 31 & GB532 & 377 & Sant Jaume \\
\hline 32 & GB544 & 390 & Gustav's Zellernuss \\
\hline 33 & GB568 & 86 & Gunslebert \\
\hline
\end{tabular}

Supplemental Table 6. Continued.

\begin{tabular}{llrl}
\hline No. & Locus & Allele & \multicolumn{1}{c}{ Accessions } \\
\hline & & 90 & Tonda G. d. Langhe \\
34 & & 108 & OSU 414.062 \\
& GB577 & 156 & Fusco Rubra \\
& & 162 & OSU 681.078 \\
35 & 167 & Bergeri \\
36 & GB581 & 95 & Imperiale de Trebizonde \\
& GB587 & 174 & OSU 681.078 \\
& & 179 & Römische Nuss \\
& & 185 & Imperiale de Trebizonde
\end{tabular}

$37 \quad$ GB594 $\quad 184$

$38 \quad$ GB601 $\quad 151$

$39 \quad$ GB603 $\quad 168$

$40 \quad$ GB605 136

$41 \quad$ GB606 318

318
319

320

329

337

$42 \quad$ GB609 $\quad 317$

$43 \quad$ GB610 99

$44 \quad$ GB613 126

GB614 $\quad 362$

373

$46 \quad$ GB615 257

263

280

47

GB618 $\quad 310$

311

313

315

317

324

335

336

354

$48 \quad$ GB619 142

$49 \quad$ GB622 112

$50 \quad$ GB623 371

$51 \quad$ GB625

GB626

239

133

336

346

355

368

372

$54 \quad$ GB633 $\quad 110$

$55 \quad$ GB636 263

$56 \quad$ GB638 297

$\begin{array}{lll}57 & \text { GB639 }\end{array}$

$58 \quad$ GB641 373

$\begin{array}{lll}58 & \text { GB641 } & 133 \\ 59 & \text { GB643 } & 243\end{array}$

$\begin{array}{lll}60 & \text { GB644 }\end{array}$

$\begin{array}{lll}61 & \text { GB645 } & 306\end{array}$
Des Anglais

Ratoli

Tonda Romana

Tapparona di SCC

Fusco Rubra

Fusco Rubra

Albania 55

Contorta

Hall's Giant

Des Anglais

Fusco Rubra

Gunslebert

Fusco Rubra

Tonda G. d. Langhe

Gustav's Zellernuss

Gustav's Zellernuss

Albania 55

Albania 55

OSU 414.062

Tonda di Giffoni

OSU 26.072

Fusco Rubra

Des Anglais

OSU 54.039

B-3

OSU 759.010

Sant Jaume

Alli

OSU 408.040

OSU 681.078

Tonda Romana

OSU 556.027

Gasaway

OSU 556.027

Albania 55

Albania 55

Bergeri

OSU 681.078

OSU 26.072

Palaz

OSU 26.072

Palaz

OSU 54.039

DuChilly

Des Anglais

OSU 681.078

OSU 414.062

Fusco Rubra 
Supplemental Table 6. Continued.

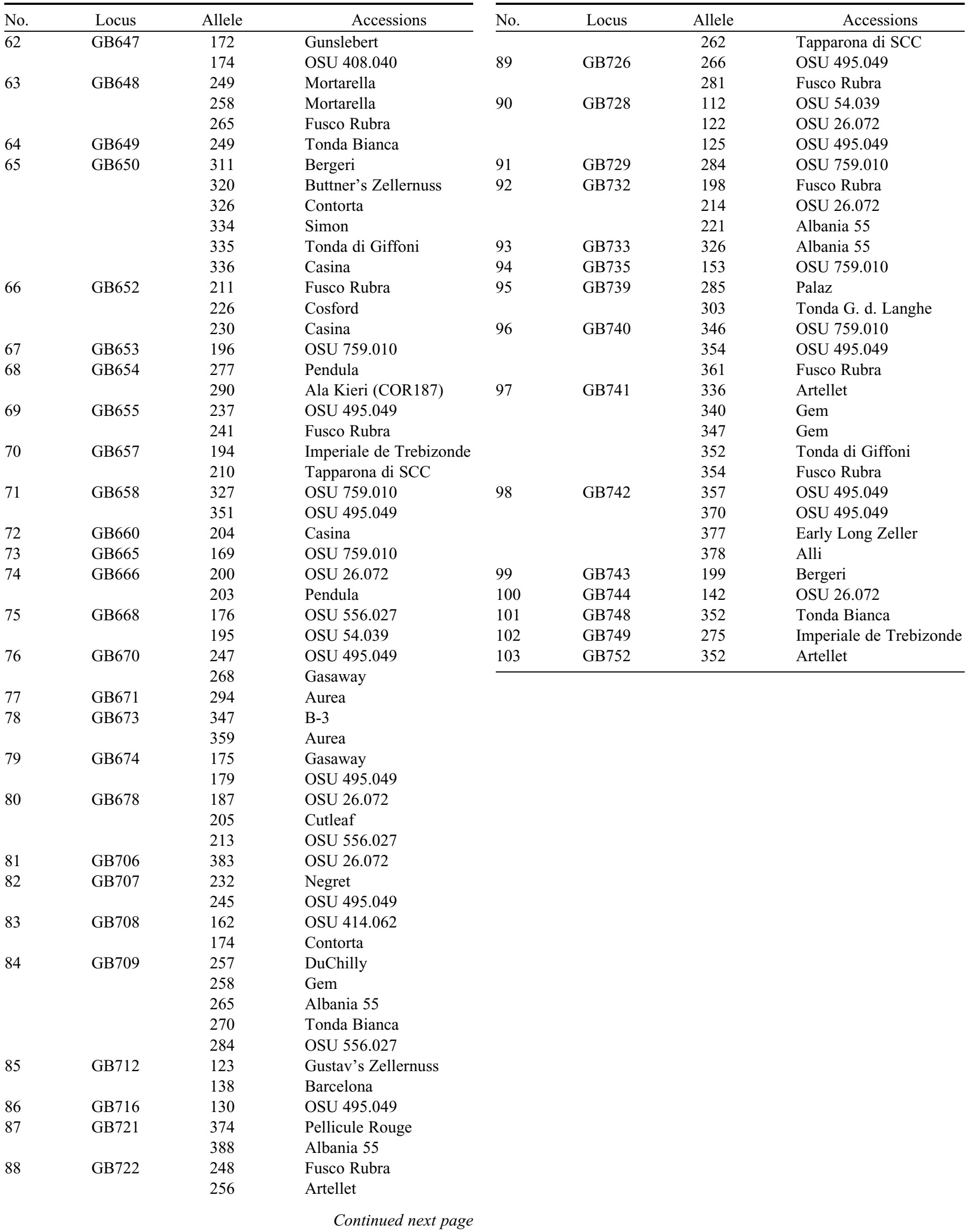

Supplemental Table 6. Continued. 